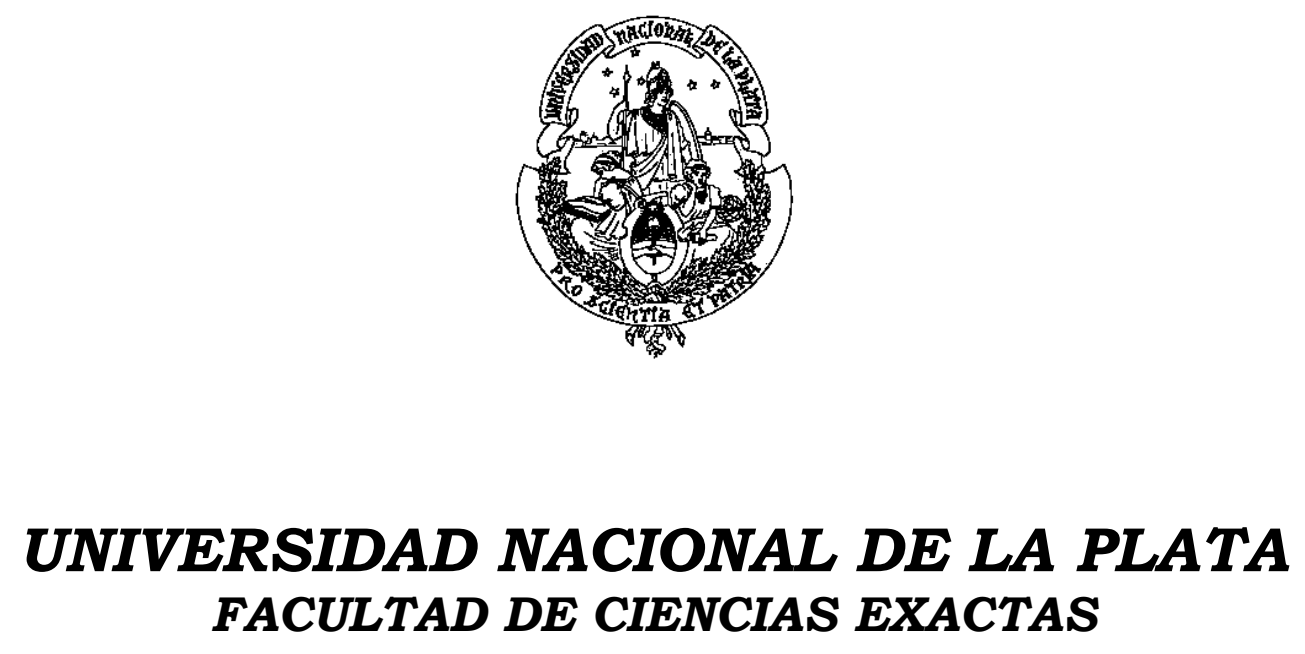

FACULTAD DE CIENCIAS EXACTAS

\begin{abstract}
Trabajo de Tesis de
Maestría en Tecnología e Higiene de los Alimentos
\end{abstract}

\title{
Aplicación de métodos químicos para la remoción de microcistinas en agua destinada al consumo.
}

Jorge Oswaldo Aranda Mosquera

Director: Dra. Leda Giannuzzi

Co-director: Dr. Darío Andrinolo 


\section{Agradecimientos}

A mi directora la doctora Leda Giannuzzi por darme la oportunidad de realizar esta tesis, la paciencia para enseñarme, por abrirme las puertas del laboratorio de toxicología y darme la confianza para ejecutar todos los objetivos propuestos.

A mi Co-director el doctor Darío Andrinolo por su aporte fundamental en el tema y el comentario justo para aterrizar y plasmar las ideas que me rondaron.

A todos mis compañeros de trabajo que me hicieron sentir integrado a un grupo, por su colaboración en cada uno de los momentos que tuve que vivir para lograr este trabajo y acompañarme en todos los momentos de manera incondicional (Dani, Lore, Meli, Ivan y Eze).

Al programa ambiental de extensión universitaria PAEU por facilitarme su espacio para desarrollar algunas de las técnicas y a cada uno de sus integrantes (Leo, Marita, Santi).

A la facultad de ciencias exactas de la UNLP y al centro de investigación y desarrollo en criotecnología de alimentos CIDCA por facilitarme los equipos y materiales para desarrollar esta tesis.

A todos los miembros y docentes de la Maestría en Tecnología e Higiene de los alimentos por sus conocimientos y aportes en mi formación.

A Martita y Marcelo por su cariño incondicional, sus palabras de aliento y su presencia constante.

A todos los nuevos amigos que este viaje me permitió conocer y me ofrecieron su amistad sin condiciones Abe, la Pato, Julián, Omin, Susana y Guille.

A mi familia en especial a Janeth, Odis, Francisco, Jenny, Pacho, Santiago, María por su acompañamiento durante todos estos años, sus consejos y aportes a pesar de la distancia.

A mi suegra Inesita por estar siempre y apoyarnos en todo momento y ser tan especial en el cuidado de su nieto.

A mis cuñados Miguel y Juanma por estar presentes a nuestro lado en la distancia. 
A mi padre a quien debo el lugar en el que estoy gracias a su labor de Padre y Madre y quien me enseñó las bases para enfrentar con paciencia y decoro los altibajos de la vida. Mil gracias viejo por tu apoyo inmenso para ayudarme a cumplir mis sueños.

A mis Hijos Manuela y Camilo por ser ese motor que me impulsa a ser cada vez mejor, a alcanzar mis sueños, a predicar con el ejemplo y quienes me enseñaron el amor puro.

A mi esposa Luisa por ser mi compañera de viaje, el apoyo inclaudicable, el abrazo de amor preciso y el enojo justo, que no me dejó bajar los brazos y me centró en los buenos momentos y en los que no tanto, sin ti esto no habría sido posible gracias amor. 


\section{ÍNDICE}

\section{INTRODUCCION}

1. Cianobacterias 1

1.1. Generalidades 1

1.2. Presencia de las Cianobacterias en agua $\mathbf{5}$

1.3. Eutrofización $\mathbf{5}$

1.4. Florecimientos 7

1.5. Toxinas 8

1.5.1. Hepatotoxinas 9

1.5.2. Microcistinas $\quad \mathbf{1 1}$

1.6. Tratamientos de remoción 15

$\begin{array}{lll}\text { 1.6.1. Cloro } & 17\end{array}$

$\begin{array}{lll}\text { 1.6.2. Hidroperóxidos } & \mathbf{1 8}\end{array}$

1.6.3. Otros peróxidos $\quad 19$

1.6.4. Otros procesos $\quad \mathbf{2 1}$

OBJETIVOS

2. Objetivo General 22

2.1. Objetivos específicos $\quad \mathbf{2 2}$

\section{MATERIALES Y MÉTODOS}

3.1. Productos químicos oxidantes utilizados 23

3.1.1. Solución comercial de hipoclorito de sodio 23

3.1.2. Ácido Peracético 23

3.2. Cepas de cultivo utilizadas 23

3.2.1. Cepa de Microcystis aeruginosa 23

3.2.2. Cepa de E. coli 25

3.3. Parámetros de evaluación en cultivo de Microcystis aeruginosa $\mathbf{2 5}$

3.3.1. Turbidez (método 2130 A-B APHA, 1998) 26

3.3.2. Determinación de proteínas totales por método $\mathbf{2 6}$ Bradford

3.3.3. Determinación de Clorofila-a (Método espectrofotométrico 10200-H, APHA, 1992)

3.3.4. Recuento Celular

3.3.5. Viabilidad celular (Siembra en placa) 28

3.4. Proceso de extracción y purificación de MC-LR 29

3.5. Determinación de toxinas mediante Cromatografía liquida de alta performance (HPLC)

3.6. Determinación de MC-LR por ensayo de inhibición de Proteinfosfatasa (PP1)

3.7. EFECTO DE OXIDANTES QUIMICOS SOBRE CULTIVO DE Microcystis aeruginosa Y MC-LR

3.7.1. Ensayos de remoción de MC-LR empleando cloro 
3.7.2. Variación del pH sobre la efectividad del cloro y la degradación de MC-LR

3.8. Efecto del ácido peracético sobre un cultivo de Microcystis aeruginosa

33

3.9. Efecto del ácido peracético sobre la degradación de Microcistina-LR en solución acuosa

3.9.1. Efecto del pH sobre la degradación de MC-LR en solución acuosa utilizando una solución comercial de ácido peracético

3.9.2. Neutralización del ácido peracético para la determinación de MC por ensayo de inhibición de Protein-fosfatasa 1 (PP1).

3.10. Efecto del ácido Peracético sobre la viabilidad de E. coli

3.10.1. Efectividad del peracètico sobre $E$. coli en solución salina isotónica $0.9 \%$

33

34

34

34

35

\section{RESULTADOS Y DISCUSIÓN}

4.1.1. Ensayos de remoción de MC-LR empleando cloro 37

4.1.2. Cinética de la degradación de cloro 37

4.1.3. CINETICA DE CLORO EN PRESENCIA DE MC-LR A TRES DIFERENTES PH: 6, 7 Y 8.

38

4.1.3.1. Degradación de cloro con distintos niveles iniciales de MC-LR a $\mathrm{pH} 6$

4.1.3.2. Degradación de cloro con distintos niveles iniciales de MC-LR a $\mathrm{pH} 7$

38

39

4.1.3.3. Degradación de cloro a distintos niveles iniciales de MC-LR a $\mathrm{pH} 8$

41

4.1.4. Efecto de la concentración de ácido sin disociar (UAC) sobre la constante de degradación de cloro $\left(\mathrm{K}_{0}\right)$

4.2. Cinéticas de remoción de MC-LR y cloro

43

4.2.1. Degradación de MC-LR a pH 6

4.2.2. Degradación de MC-LR a pH 7

48

4.2.3. Degradación de MC-LR a pH 8

50

4.2.4. Vinculación de los parámetros cinéticos de degradación de MCLR con la concentración de inicial de cloro

4.2.5. Determinación del orden de la reacción para cloro y MC-LR

52

4.3. Determinación del parámetro de concentración por tiempo (C.t)

55

4.4. Efecto de una solución comercial de Ácido Peracético sobre un cultivo de Microcystis aeruginosa productora de Microcistina [DLeu 1] MC-LR

4.4.1. Efecto de una solución de ácido peracético sobre la turbidez (densidad óptica) expresado como absorbancia

59

64

64

4.4.2. Efecto de una solución de APA sobre las proteínas totales 
expresadas en $\mu \mathrm{g} . \mu \mathrm{L}^{-1}$

4.4.3. Efecto del APA sobre la clorofila-a expresada en $\mu \mathrm{g} \cdot \mathrm{L}^{-1}$

4.4.4. Efecto de una solución de ácido peracético sobre el recuento celular expresado en $\mathrm{N}^{\circ}$ de células por $\mathrm{mL}^{-1}$

4.4.5. Efecto de una solución de APA sobre la viabilidad celular utilizando método de siembra en placa

4.4.6. Efecto de una solución de ácido peracético sobre la degradación de MC-LR en cultivo de Microcystis aeruginosa determinado por Cromatografía liquida de alta performance (HPLC)

4.5. Efecto de una solución comercial de Ácido Peracético sobre la MCLR en solución acuosa

82

4.5.1. Efecto del pH sobre la degradación de MC-LR en solución acuosa tratada con una solución de APA

4.5.2. Comparación del efecto del cloro y el ácido peracético sobre la degradación de MC-LR a una misma concentración inicial de

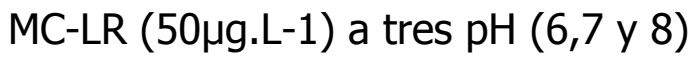

84

4.6. Efecto de una solución comercial de Ácido Peracético sobre la viabilidad de un cultivo de $E$. Coli

87

4.6.1. Evaluación de diferentes dosis y tiempos de contacto de una solución comercial de ácido peracético sobre la viabilidad de $E$. coli en solución salina isotónica $0.9 \%$ y determinación de la concentración inhibitoria mínima (CIM)

5. CONCLUSIONES

6. BIBLIOGRAFÍA

7. ANEXOS 
RESUMEN 


\section{RESUMEN}

El objetivo de esta tesis de maestría fue evaluar y desarrollar metodologías de eliminación de Microcistina-LR (MC-LR) mediante el uso de métodos químicos como el cloro y el ácido peracético. Se ensayaron diferentes técnicas de detección y cuantificación de MC. La técnica de HPLC presento un límite de detección en el orden de los $\mathrm{mg}^{-\mathrm{L}^{-1}}$ y requiriendo pasos previos de preconcentración de las muestras a efectos de ser detectados con dichos límites. Un método con alta sensibilidad fue el de inhibición de la Protein fosfatasa 1 (PP1) con el cual fue posible detectar MC en el orden de los $\mu \mathrm{g} \cdot \mathrm{L}^{-1}$ sin pasos previos de pre-concentración y fue usado para la detección y cuantificación de MC en los ensayos de remoción con los oxidantes ensayados.

El efecto del cloro sobre la cinética de remoción de MC-LR se evaluó exponiendo soluciones acuosas con concentraciones de 10,20 y $50 \mu \mathrm{g} \cdot \mathrm{L}^{-1}$ de MC-LR (extraída de un cultivo de Microcystis aeruginosa cepa CAAT2005) a diversas concentraciones de cloro $1,0,2,0$ y $5,0 \mathrm{mg}^{-\mathrm{L}^{-1}}$ y a tres $\mathrm{pH}: 6,7$ y 8 . La concentración de $\mathrm{MC}$ remanente se determinó mediante ensayo de inhibición de fosfatasa.

El modelo exponencial decreciente fue la manera más apropiada para representar los resultados obtenidos para la degradación de MC-LR mediante el uso de Cloro. El parámetro de ajuste seleccionado fue el tiempo de vida medio, el cual representa el tiempo al cual se reduce a la mitad la concentración inicial de MC. Se calculó el valor de la concentración de ácido sin disociar (ácido hipocloroso) (UAC) a efectos de evaluar su dependencia con la $K_{0}$ (constante de degradación de cloro). Otros parámetros cinéticos evaluados en este trabajo fueron: la velocidad de la reacción, la constante de velocidad, la constante de la reacción y el orden de las reacciones. Se pudo deducir que la reacción fue de segundo orden para el total de la reacción y de primer orden para cada uno de los reactivos (MC-LR y cloro). A su vez se determinó el C.t, el cual representa la concentración de cloro durante el tiempo de contacto necesario para lograr una determinada degradación de MC-LR.

Los resultados de degradación de cloro y MC-LR permitieron inferir que el ácido hipocloroso resultó se la especie oxidante más importante en este modelo de remoción de toxina. La remoción de MC-LR, fue mayor a pH 6. Los valores más bajos de C.t para la degradación de 50, 90 y 95\% de MC-LR se logran a pH 6 .

La aplicación de la solución de ácido peracético entre $1-15 \mathrm{mg} \cdot \mathrm{L}^{-1}$ altero los parámetros del cultivo, disminuyo la turbidez (densidad óptica) por la acción oxidante sobre los pigmentos en especial la clorofila-a. Al observar los recuentos al microscopio se evidencio cambios en la morfología celular 
(birrefringencia) al interior de las células, disminución de la clorofila-a por el efecto oxidante del APA, y desnaturalización de las proteínas totales. Sin embargo en este rango de concentración de APA no se evidenció eficacia en la remoción de MC-LR evaluadas mediante la técnica de HPLC en cultivo de Microcystis aeruginosa.

En los ensayos de remoción de MC con APA en comparación con cloro en soluciones acuosas, el tiempo de degradación media $\left(\mathrm{t}_{1 / 2}\right)$ mostró que a pH 6 las tres concentraciones de cloro y la de ácido peracético se comportan de manera diferente aun siendo este un $\mathrm{pH}$ donde se encuentra la mayor concentración de ácido sin disociar de cloro y donde el APA mostró $t_{1 / 2}$ menores. Comparando el tiempo de vida media del APA y el cloro a los diferentes pH propuestos, se observó que el APA es menos dependiente a las variaciones del $\mathrm{pH}$ con respecto al cloro. Sin embargo si se compara el efecto del oxidante al final de cada tratamiento, el cloro permite obtener concentraciones finales de MC-LR menores que las alcanzadas por el APA.

Para completar el estudio del uso y efecto del APA en un proceso de potabilización de agua, es necesario comprobar su efecto bactericida sobre un indicador de contaminación fecal como la E.coli.

Se observó que si se aumenta la concentración de APA la viabilidad de $E$. coli disminuye, lo que evidencia la acción bactericida del APA. Si se compara dicha acción con un oxidante convencional en el tratamiento de agua como el cloro, podemos dilucidar que el APA es apto para ser usado en un sistema de potabilización de agua. A una dosis de APA de $1 \mathrm{mg} \mathrm{L}^{-1}$ se observa inhibición en los recuentos de $E$. coli a partir de 20 minutos de tiempo de contacto. Con este dato se logró concluir entonces que la concentración inhibitoria mínima (CIM) para $E$. coli en solución salina fisiológica $0.9 \%$ fue de $1 \mathrm{mg}^{-L^{-1}}$. Si se comparan los resultados de APA con los de cloro a una misma concentración inicial de los dos oxidantes $\left(1 \mathrm{mg} . \mathrm{L}^{-1}\right)$, se puede observar que el tiempo para degradar el 99,999\% de $E$. coli del APA es menor que los del cloro. 


\section{INTRODUCCIÓN}




\section{Cianobacterias}

\subsection{Generalidades de las cianobacterias}

Las cianobacterias son algas de carácter foto autótrofas de distribución mundial y con una alta incidencia en la calidad del agua destinada al consumo. Los diferentes componentes involucrados en la actividad y desarrollo de las prácticas humanas han resultado en las eutrofizaciones de los cuerpos de agua en el mundo, donde una de tantas consecuencias son el aumento de la biomasa de estas especies y sus metabolitos secundarios, generando dificultades metodológicas en los tratamientos de aguas.

Este grupo de microorganismos son reconocidos por su habilidad para mantenerse en ambientes extremos, los cuales pueden incluir aguas termales de aproximadamente $80^{\circ} \mathrm{C}$, ecosistemas polares e inclusive pueden estar a varios grados bajo cero. A su vez, en muchos de estos ecosistemas adversos para otras formas de vida con altos índices de salinidad se pueden también encontrar cianobacterias. Tienen la habilidad de sobrevivir a largos períodos con poca disponibilidad de agua y algunas de sus especies pueden producir una vaina pigmentaria externa que les proporciona la habilidad de sobrevivir en ambientes de alta radiación UV (Graham y Wilcox, 2000).

Las cianobacterias en sus características generales son un grupo de microorganismos que está compuesto por más de 2000 especies, comprende distintos tamaño que van desde 0,5 a 40 micrones, los cuales pueden presentar formas unicelulares, coloniales o filamentosas; con o sin formación de mucilago, conteniendo en muchos casos vesículas de gas, las cuales les permiten elegir la profundidad en el cuerpo de agua según las necesidades nutricionales del medio, adaptándose a las distintas condiciones de luz y disponibilidad de nutrientes.

La morfología básica de las cianobacterias comprende formas unicelulares, coloniales multicelulares y las formas filamentosas. Las formas unicelulares como en el caso del orden Chroococcales, son células esféricas, ovoides o cilíndricas. El agregado celular se produce por la separación de las células hijas luego de la reproducción por fisión binaria, las células pueden agregarse en colonias irregulares que se mantienen unidas por la matriz viscosa secretada durante el crecimiento de la colonia, por medio de una serie más o menos regular de la división celular en combinación con las secreciones de la vaina, se pueden producir colonias más o menos ordenadas. Las formas más simples en las cianobacterias son la de organismos unicelulares, de vida libre incluida o no sobre una capa mucilaginosa. La subsecuente evolución resultó en la formación de una fila de células llamada tricomas. 


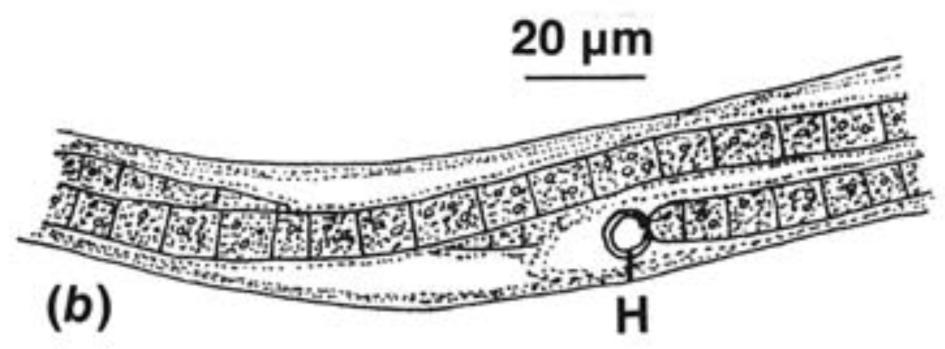

Figura 1. b. Desmonema wrangelii con un número de tricomas envueltos en una vaina (filamento) $\mathrm{H}$. Heterocisto. (Extraído de Lee, 1999).

Las células de cianobacterias no presentan núcleo delimitado ya que por su carácter de bacteria carece de membrana nuclear. Al ser un organismo procariota fotoautótrofo, realiza fotosíntesis con liberación de oxígeno al igual que organismos fotosintéticos superiores como las plantas. Su color característico verde azulado lo obtienen gracias a la presencia de pigmentos como la clorofila- $a$ que le aporta el color verde y las ficocianinas o ficobilinas las cuales aportan el color azul, estas ficobilinas pueden enmascarar en algunos casos a la clorofila (Chorus, 2001).

Las cianobacterias poseen una pared celular con distribución compleja, la cual puede variar de acuerdo a la especie. En general esta pared celular tiene componentes similares a los de las bacterias Gram negativas pero rodeada por cubiertas orgánicas mucilaginosas, siendo su principal componente el peptidoglicano, que puede llegar a constituir el 50\% del peso seco. Se han descrito de tres a seis capas integrantes de la pared celular pero sólo las dos más internas (Capa I y Capa II) son iguales en todas las cianobacterias. La estructura de la pared o cubierta exterior de la capa II depende de las condiciones medioambientales y de la cantidad de mucílago secretado. Esta capa de mucílago exterior es fibrilar y su función es proteger las células de la sequedad, aunque también está relacionada con la capacidad de realizar movimientos, ya que se ha visto que algunas cianobacterias realizan movimientos fotocinéticos, de importancia ecológica, secretando mucílago o bien realizando ondulaciones con la superficie de la célula (Lee, 1999).

La vaina o envoltura de las cianobacterias es una cápsula o agregado de sustancias poliméricas extracelulares (SPE), compuesta de mucílago y una pequeña cantidad de celulosa, esta envoltura se encuentra comúnmente presente en las colonias de cianobacterias (Figura 2). La vaina o envoltura 
protege a las células que puedan estar expuestas a condiciones de poca disponibilidad de agua (Nobles y col., 2001).

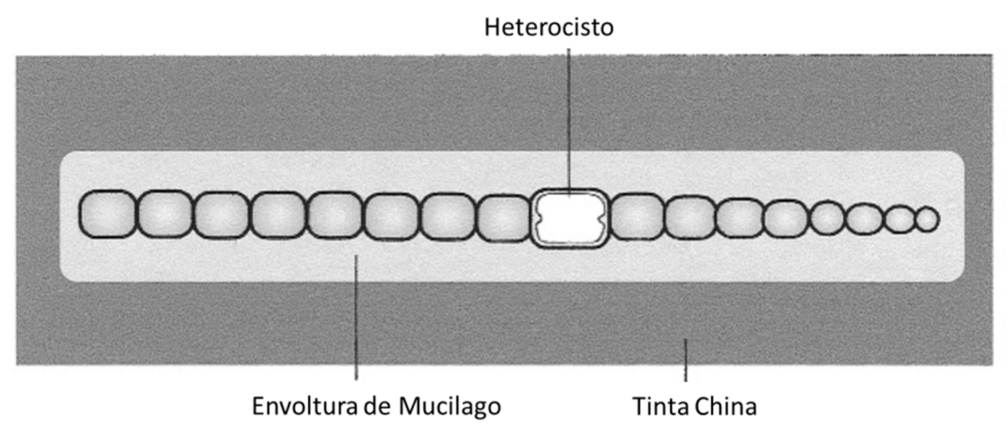

Figura 2. Dibujo de un filamento de Hyella sp. en tinta china. Este método muestra claramente la vaina mucilaginosa alrededor del filamento.

Muchas de las estructuras protoplasmáticas encontrados en las bacterias se pueden encontrar también en las cianobacterias. En el protoplasma central están las fibrillas circulares de ADN que no están asociadas a proteínas básicas (histonas). La cantidad de ADN en las cianobacterias unicelulares varía de $1.6 \times 10^{9}$ a $8,6 \times 10^{9}$ daltons, este tamaño es similar al genoma en otro tipo de bacterias ( $1.0 \times 10^{9}$ a $3,6 \times 10^{9}$ daltons) y es mayor que el tamaño del genoma en micoplasmas $\left(0.4 \times 10^{9}\right.$ a $0,5 \times 10^{9}$ daltons) (Herdman y col., 1979). El protoplasma periférico se compone principalmente de tilacoides y sus estructuras asociadas, los ficobilisomas (en los tilacoides se contienen las ficobiliproteínas) y gránulos de glucógeno. (Allen, 1984).

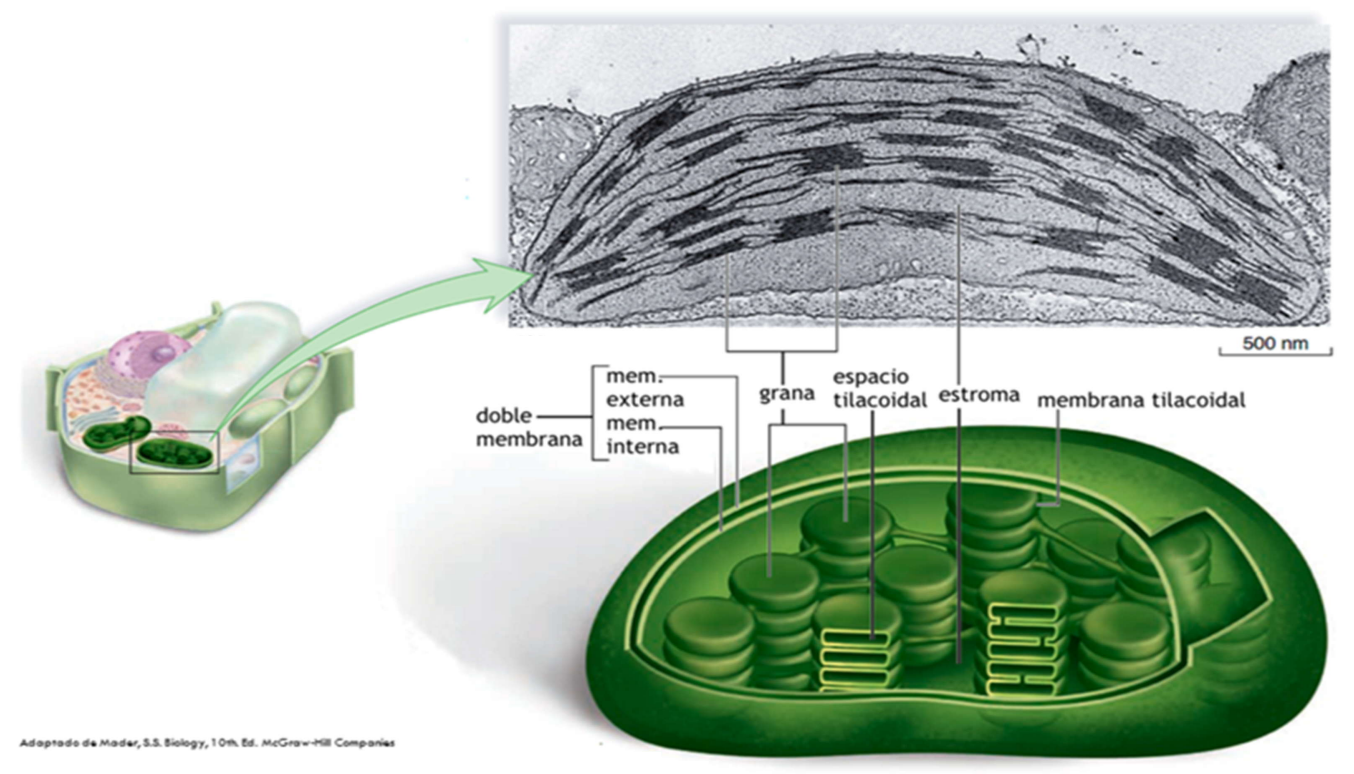

Figura 3. Imagen microscópica y diagrama de las partes de un tilacoide (Extraído de Mader., S.S Biology 10th Edition).

La cianoficina es un polímero semejante a una proteína pero que no es sintetizada ribosomalmente, la cianoficina se produce en el citoplasma en gránulos estructurados que están rodeados por una membrana (Aboulmagd y 
col., 2000; Sherman y col., 2000). La cianoficina funciona como una reserva temporal de nitrógeno en cianobacterias fijadoras de nitrógeno, esta reserva se va acumulando durante la transición entre la fase exponencial y la fase estacionaria y desaparece cuando se reanuda el crecimiento equilibrado. El nitrógeno se almacena en los ficobilisomas en aquellas cianobacterias que no fijan el nitrógeno (Li y col., 2001).

Los carboxisomas son cuerpos poliédricos similares a los carboxisomas en otras bacterias los cuales contienen el dióxido de carbono fijado a la enzima ribulosa1,5-bifosfato carboxilasa / oxigenasa, conocida por su abreviatura como (Rubisco). Hay dos tipos de carboxisomas, $a$-carboxisomas y $\beta$-carboxisomas, los cuales difieren en su composición proteica (Badger y col., 2002). Los carboxisomas también contienen la enzima anhidrasa carbónica que convierte $\mathrm{HCO}_{3}{ }^{-}$en dióxido de carbono, la única forma de carbono que es fijado por la Rubisco. El bicarbonato $\left(\mathrm{HCO}_{3}{ }^{-}\right)$se transporta en la célula y el carboxisoma. La anhidrasa carbónica en el carboxisoma convierte $\mathrm{HCO}_{3}{ }^{-}$en $\mathrm{CO}_{2}$ que se fija por acción de la Rubisco en los hidratos de carbono (Turpin y col., 1984).

Otra importante característica de las cianobacterias son las vacuolas de gas. Una vacuola de gas se compone de vesículas de gas o tubos cilíndricos huecos con extremos cónicos dentro del citoplasma de las cianobacterias (Oliver, 1994). Los principales componentes del sistema captador de luz fotosintética de las cianobacterias son la clorofila- $a$ en la membrana del tilacoide y las ficobiliproteínas, que son cromoproteínas solubles en agua reunidas en agregados moleculares macro (ficobilisomas), unido a la superficie exterior de las membranas de los tilacoides.

Las Cyanophyceae tiene cuatro ficobiliproteínas: C-ficocianina ( $\lambda$ Max en 620 $\mathrm{nm})$, aloficocianina ( $\lambda$ Max a $650 \mathrm{~nm})$, C-ficoeritrina $(\lambda \operatorname{Max}$ a $565 \mathrm{~nm})$ y ficoeritrocianina ( $\lambda$ Max en $568 \mathrm{~nm}$ ). Todas las cianobacterias contienen las dos primeras, mientras que C-ficoeritrina y ficoeritrocianinase produce sólo en algunas especies. Las ficobiliproteínas de las cianobacterias cambian su concentración en respuesta a la calidad de luz y las condiciones de crecimiento (Tandeau de Marsac, 1977).

Las cianobacterias son diazótrofos, es decir que son microorganismos capaces de fijar el nitrógeno atmosférico. Todos los organismos fijadores de nitrógeno conocidos son procariotas. En la fijación de nitrógeno, el $\mathrm{N}_{2}$ de la atmósfera se fija por la enzima nitrogenasa en presencia de amonio usando ATP como fuente de energía (Raymond y col., 2004). 


\subsection{Presencia de las Cianobacterias en agua}

Las cianobacterias son un frecuente componente de muchos de las aguas dulces y los ecosistemas marinos. Aquellas especies que viven dispersas en el agua son parte del fitoplancton, mientras que las que crecen en los sedimentos forman parte de los organismos fitobentónicos. Bajo ciertas condiciones, especialmente donde las aguas son ricas en nutrientes y se expone a la luz solar, las cianobacterias pueden multiplicarse a altas densidades una condición conocida como florecimiento de agua.

Las floraciones de cianobacterias de agua dulce son cada vez más comunes de lo que generalmente se piensa. La mayoría de las floraciones de cianobacterias de agua dulce se componen de Microcystis, Anabaena, Aphanizomenon, Gloeotrichia, Lyngbya y Oscillatoria. A pesar de encontrarlas en los lagos durante todo el año, es por lo general sólo a finales de verano y principios de otoño que alcanzan proporciones de floración. Esto debido a:

- La capacidad de captura de luz superior de las cianobacterias cuando la sombra en la columna de agua es más grande.

- Su alta afinidad por el nitrógeno y fósforo cuando la limitación de nutrientes es más grave.

- Su capacidad para regular su posición en la columna de agua por vacuolas de gas para tomar ventaja de las zonas más ricas en nutrientes y/o luz.

- Su mayor temperatura óptima para el crecimiento y la fotosíntesis (mayor de $20^{\circ} \mathrm{C}$ ) (Tang y col., 1997).

La composición de las aguas dulces depende de un número de factores ambientales, incluyendo la geología, topografía, clima y biota. Muchos de estos factores varían en diferentes escalas de tiempo, como el día a día, estaciones o incluso a través de lapsos de tiempo más largos. Por lo tanto, las variaciones naturales en la calidad del agua pueden ser observadas en cualquier sistema de agua dado. La variación de algunos de los nutrientes, en especial fósforo y nitrógeno es conocido como eutrofización.

\subsection{Eutrofización}

La eutrofización es el aumento del proceso natural de la producción biológica en ríos, lagos y embalses, causada por el incremento de los niveles de nutrientes, por lo general de fósforo y compuestos nitrogenados. La eutrofización puede ocasionar proliferación de cianobacterias o de algas a simple vista, espumas superficiales, esteras vegetales flotantes y agregaciones de macrófitos bentónicos. La descomposición de esta materia orgánica puede conducir al agotamiento del oxígeno disuelto en el agua, que a su vez puede causar problemas secundarios tales como mortalidad de los peces por falta de 
oxígeno y la liberación de sustancias toxicas. Los fosfatos liberados de los sedimentos acelera la eutrofización, cerrando así un ciclo de retroalimentación positiva. Algunos lagos son naturalmente eutróficos, pero en muchos otros el exceso de entrada de nutrientes es de origen antropogénico, como un resultado de las descargas de aguas residuales o la escorrentía de fertilizantes y abonos extendido en las zonas agrícolas (Oliver y col., 2000).

Las sustancias unidas a los sedimentos pueden acumularse y ser liberados de nuevo en el agua, y se puede llevar aguas abajo. Este proceso es importante para el fósforo. Los lagos generalmente tienen tiempos de retención de agua más largos en comparación con los ríos y lagunas, por su naturaleza tienden a acumularse sedimentos y los productos químicos asociados con ellos.

Los ambientes acuáticos reciben diferentes denominaciones según la concentración de nutrientes y la producción primaria (densidad y biomasa de algas) que presentan:

- Oligotrófico: aguas claras, baja concentración de nutrientes, poco desarrollo planctónico, baja productividad, pocas plantas acuáticas, elevada concentración de oxígeno disuelto.

- Mesotrófico: moderado enriquecimiento con nutrientes, moderado crecimiento planctónico, escasa acumulación de sedimentos en la mayor parte del fondo.

- Eutrófico: elevado enriquecimiento con nutrientes y crecimiento planctónico, alta productividad en relación a las condiciones naturales, baja transparencia, extensas áreas cubierta con plantas acuáticas, gran acumulación de sedimentos en el fondo, bajos niveles de oxígeno disuelto en el fondo, interferencias en los usos múltiples del agua.

- Hipereutrófico: cuerpo de agua significativamente afectado por las elevadas concentraciones de materia orgánica y nutrientes, floraciones de algas, mortandad de peces, con limitaciones en sus usos.

Mientras la palabra eutrofización describe el proceso de fertilización del ecosistema acuático, los términos oligotrófico, mesotrófico, eutrófico e hipertrófico son utilizados para describir los posibles estados a lo largo del proceso, delineando un gradiente desde aquellos pobres en nutrientes biológicamente disponibles y con escasa biomasa fitoplanctónica o vegetal (oligotrófico), hasta aquellos con alta concentración de nutrientes y elevada biomasa (eutrófico o hipertrófico). Para describir el estado trófico de un ecosistema acuático pueden utilizarse criterios químicos (concentración de nutrientes inorgánicos disueltos o totales en el agua), biológicos (concentración de clorofila- $a$, biomasa de plantas o presencia de especies indicadoras) y/o 
físicos (turbidez del agua). Otros indicadores incluyen la tasa de producción primaria e índices de biodiversidad (Tabla 1).

Tabla 1. Clasificación trófica de lagos, con sus correspondientes concentraciones de fósforo, clorofila y transparencia del agua (Vollenweidery Kerekes, 1982, Wetzel, 2001).

\begin{tabular}{|ccccccc|}
\hline & Fósforo Total $\left(\mu g \mathrm{~L}^{-1}\right)$ & \multicolumn{2}{c}{ Clorofila a $\left(\mu g \mathrm{~L}^{-1}\right)$} & \multicolumn{2}{c|}{ Profundidad Secchi $(\mathrm{m})$} \\
\hline & Media & Máximo & Media & Máximo & Media & Máximo \\
\hline Ultra-oligotrófico & $<5$ & $<4$ & $<1$ & $<2.5$ & $>12$ & $>6$ \\
\hline Oligo-mesotrófico & $5-10$ & $4-10$ & $<2.5$ & $<8$ & $>6$ & $>3$ \\
\hline Meso-eutrófico & $10-30$ & $10-35$ & $2.5-8$ & $8-25$ & $6-3$ & $3-1.5$ \\
\hline Eutrófico & $30-100$ & $35-100$ & $8-25$ & $27-75$ & $3-1.5$ & $1.5-0.7$ \\
\hline Hipereutrófico & $>100$ & $>100$ & $>25$ & $>75$ & 1.5 & $<0.7$ \\
\hline
\end{tabular}

\subsection{Florecimientos}

Las cianobacterias, las algas eucariotas y todas aquellas especies pertenecientes al fitoplancton pueden aumentar su biomasa bruscamente bajo determinadas condiciones ambientales aumentando su concentración a valores significativos con respecto a la concentración original. Este fenómeno se llama floración, en inglés: "Bloom" (Smayda, 1997).

Las cianobacterias tienen una serie de propiedades especiales que determinan su importancia relativa en comunidades de fitoplancton. Sin embargo, el comportamiento de diferentes especies de cianobacterias en la naturaleza no es homogéneo debido a que sus propiedades ecofisiológicas son diferentes. La comprensión de su respuesta a factores ambientales es fundamental para el establecimiento de factores de prevención y toma de decisiones en los sistemas de gestión del agua.

Cada floración puede estar formada por una o varias especies. El fenómeno de las floraciones puede generarse en períodos que van desde pocas horas a varios días y desaparecer en tiempos variados. Sin embargo, algunas de estas floraciones de cianobacterias pueden permanecer por períodos más largos, durante todo el año o incluso en forma permanente dependiendo se las características del cuerpo de agua. (Chorus y Bartram, 1999). 


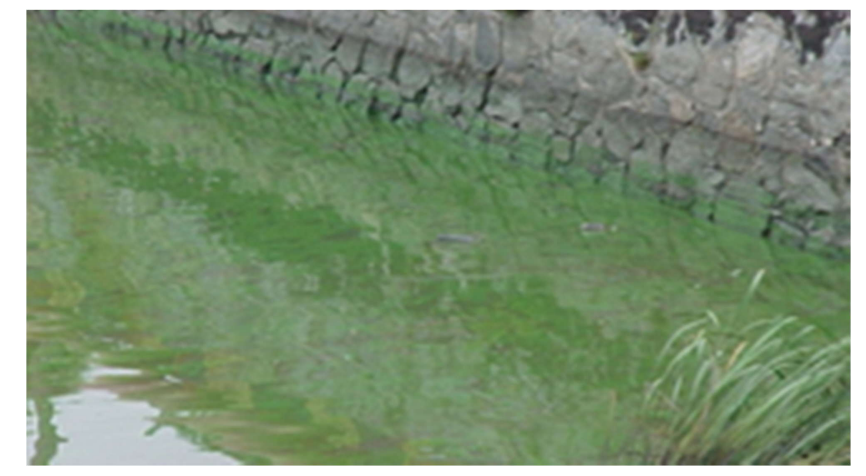

Figura 6. Florecimiento, Punta Lara, Ensenada.

Una alta concentración de biomasa encontrada en las floraciones, sumada a la presencia de las cianotoxinas puede representar un problema para los otros organismos del medio acuático y para el ser humano. Se considera que existe un florecimiento cuando las concentraciones celulares están en niveles superiores a 20.000 células. $\mathrm{mL}^{-1}$, que se correspondería a $10 \mathrm{mg} \cdot \mathrm{m}^{-3}$ de clorofila-a (Oh y col., 2001).

Aproximadamente el $75 \%$ de las floraciones de cianobacterias pueden ser toxicas y a veces puede estar presente más de una toxina (Chorus y Bartram, 1999). Es posible que en una floración se encuentren cepas de cianobacterias tóxicas y no tóxicas al mismo tiempo. No existe un método simple para distinguir las cianobacterias tóxicas de las no tóxicas, factor que aumenta la peligrosidad de las floraciones, haciendo necesario el control de las mismas para evitar situaciones no deseadas (Falconer, 1999). La muerte de las cianobacterias, favorece la liberación de las toxinas, por lisis celular (Shapiro, 1990).

\subsection{Toxinas}

Las cianotoxinas son un variado grupo de compuestos naturales, revisten importancia tanto desde la parte química como desde el punto de vista toxicológico. A pesar de su origen acuático, la mayoría de las cianotoxinas que han sido identificadas hasta el momento parecen ser más peligrosas para los mamíferos terrestres que para los microorganismos de la biota acuática. Las cianobacterias producen una variedad de metabolitos inusuales, de los cuales su función natural es poco clara, aunque algunos, tal vez sólo por casualidad, sea el de inducir efectos sobre la biota circundante. Las investigaciones respecto a este tema se han centrado principalmente en compuestos que tienen un impacto sobre los seres humanos y animales, ya sea como toxinas o sustancias con probable actividad farmacológica.

Algunas de las cianobacterias pueden llegar a producir toxinas, también llamadas cianotoxinas. De acuerdo a su lugar de acción, existen básicamente 
dos tipos de cianotoxinas: neurotoxinas y hepatotoxinas. Estos metabolitos también se pueden dividir en tres grandes grupos de acuerdo a su estructura química: péptidos cíclicos, alcaloides y lipopolisacáridos (LPS) (Carmichael, 1992; Codd, 1994; Codd y col., 1997). El presente trabajo aborda estudios sobre una de estas toxinas, la hepatotoxinas, por ello, se describe en forma resumida estas toxinas.

\subsubsection{Hepatotoxinas}

Está demostrado que las hepatotoxinas producidas por algunas cianobacterias son fuertes inhibidores de protein fosfatasas 1 y $2 \mathrm{~A}$ (Arment y Carmichael, 1996) lo cual afecta a los hepatocitos, generando un sangrado en el hígado de animales y el hombre. Los signos clínicos incluyen debilidad, vómitos, diarrea y extremidades frías. Las cianobacterias producen dos tipos de hepatotoxinas, las microcistinas y nodularinas, que se producen a través de una vía similar (Rinehart y col., 1994). Un aspecto particular de este tipo de toxinas es que algunas no son específicas de una especie determinada de cianobacterias sino que una misma toxina puede ser producida por varias especies. Las microcistinas son sintetizadas por especies de Microcystis, Anabaena, Nostoc, Nodularia, y Oscillatoria mientras que los nodularinas son producidos por especies de Nodularia (Bolch y col., 1999) (Tabla 2).

Tabla 2. Géneros cianobacterianos potencialmente productores de toxinas. Extraído y adaptado de (Codd y col., 2005).

\begin{tabular}{|cc|}
\hline Anabaena & $\begin{array}{c}\text { TOXINA QUE PRODUCE } \\
\text { Microcistinas, anatoxina-a, anatoxina-a (s), } \\
\text { saxitoxinas y cilindrospermopsina }\end{array}$ \\
\hline Anabaenopsis & Microcistinas \\
\hline Cylindrospermopsis & Saxitoxinas y cilindrospermopsina \\
\hline Hapalosiphon & Microcistinas \\
\hline Microcystis & Microcistinas \\
\hline Nostoc & Microcistinas \\
\hline Oscillatoria & Microcistinas, Anatoxina-a, Lingbiatoxina-a y \\
& Apliatoxina \\
\hline Planktothrix & Microcistinas y Saxitoxin \\
\hline Synechocystis & Microcistinas \\
\hline Woronichinia & Microcistinas \\
\hline
\end{tabular}

La mayor importancia de las cianotoxinas es en aguas dulces donde las cianobacterias son ingeridas en el agua potable por los animales y el hombre, al ser ingeridas, las algas expuestas a la digestión se lisan y liberan sus toxinas al tracto intestinal. Las cianotoxinas son responsables de la pérdida de un gran número de animales cada año en todo el mundo, por lo general en los meses de verano cuando las floraciones de cianobacterias son visibles en el agua. En 
raras ocasiones el hombre toma como fuente de agua destinada al consumo un agua con florecimientos por parecer riesgoso o poco atractivo. De este modo, el envenenamiento del hombre por cianotoxinas es relativamente raro, en parte también por la producción de sustancias odoríferas en el agua como la geosmina y el metilisoborneol (MIB) producido por las cianobacterias.

Algunas cianobacterias son las responsables de deteriorar la calidad organoléptica del agua destinada al consumo por la producción de compuestos volátiles, generando olores y sabores desagradables. Estos compuestos como la geosmina (E-1,10-dimetil-E-9-decalol) y MIB (2-metilisoborneol) son terpenoides (isoprenoides) producidos por algunas cianobacterias (Juttner $y$ Watson, 2007). Estos terpenoides son llamados compuestos orgánicos volátiles $(\mathrm{COV})$, tienen un aroma a tierra, humedad o barro muy potente y representan la mayor parte de los olores desagradables en el agua potable. Tienen concentraciones o umbral de olor cerca de $10 \mathrm{ng} \cdot \mathrm{L}^{-1}$. Tanto la geosmina y el MIB resisten el tratamiento de agua convencional, y su bioacumulación en peces y mariscos son causa de mal sabor, ya sea que se exploten en condiciones de granja o formas más silvestres. Ni la geosmina ni el MIB son tóxicos para los vertebrados (incluyendo los humanos). La baja incidencia de envenenamientos humanos por cianotoxinas se ha atribuido a la alerta que causa en el agua los olores producidos por geosmina y MIB. Estos compuestos orgánicos volátiles producidos por las cianobacterias puede actuar como infoquímicos atrayendo nematodos a las colonias de cianobacterias, donde se alimentan los nematodos y depositan sus huevos (Hockelmann y col., 2009).

Se sugiere que una de las funciones de las cianotoxinas es la de actuar como productos químicos que las protejan de herbívoros invertebrados en el medio ambiente acuático. El consumo de algas por parte de algunos invertebrados causa que Microcystis aeruginosa aumente la producción de sus toxinas (Jang y col., 2007). Las cianotoxinas también pueden inhibir el crecimiento de otras algas, a esto se le llama una interacción alelopática donde un organismo afecta el crecimiento de un segundo organismo. Un ejemplo de esto es la inhibición de la Peridinium gatunense dinoflagelado de agua dulce por parte de la microcistina producida por cepas de Microcystis en el Lago Kineret (Mar de Galilea), Israel. La microcistina disminuye drásticamente la actividad de la anhidrasa carbónica en el dinoflagelado y por tanto inhibe su crecimiento. Debido a esto la microcistina se clasifica como un aleloquímico actuando como especie de alguicida (Sukenik y col., 2002).

En muchos casos, condiciones ambientales de estrés pueden estimular la producción de cianotoxinas (Ross y col., 2006). A su vez, puede suceder que para la misma especie de cianobacteria algunas cepas produzcan toxinas y 
otras no (Quesada y col., 2004). Por ejemplo, las floraciones de cianobacterias pueden tener una duración de pocos días y sobre el final de la floración, cuando las células comienzan a morir, se pueden registrar los máximos niveles de cianotoxinas disueltas en el agua. Por este motivo, los métodos de remoción de cianobacterias que impliquen lisis celular pueden ser contra producentes ya que favorecen la liberación de las toxinas al medio acuático. Una vez liberadas al ambiente, las cianotoxinas tienen una persistencia variable (pocos días a meses) antes de ser biodegradadas o destruidas mediante fotólisis 0 biodegradación por bacterias (Edwards y col., 2008).

La importancia sobre la salud pública se conoce desde hace décadas debido a la muerte de seres humanos (Jochimsen y col., 1998) y animales después de beber agua conteniendo cianobacterias productoras de toxinas en Australia (Francis., 1878), Argentina (Ringuelet y col., 1955) y en todo el mundo (Codd, 1994). Resulta significativo en los últimos años, el aumento de la frecuencia e intensidad de estos fenómenos a nivel mundial produciendo fuertes impactos sanitarios, económicos y ambientales al afectar un recurso vital como el agua.

\subsubsection{Microcistinas}

Las microcistinas son hepatotoxinas con más de 60 variantes, las cuales químicamente se describen como heptapéptidos cíclicos de estructura general ciclo (D-Ala-X-DMeAsp-Y-Adda-D-Glu-Mdha), donde $\mathbf{X}$ e $\mathbf{Y}$ son aminoácidos variables, Mdha esMetildehidroalanina, ADDA es un aminoácido característico de 20 carbonos (ácido 3-amino-9-metoxi-2,6,8-trimetil-10-fenildeca-4,6dienoico) (Botes y col., 1985).

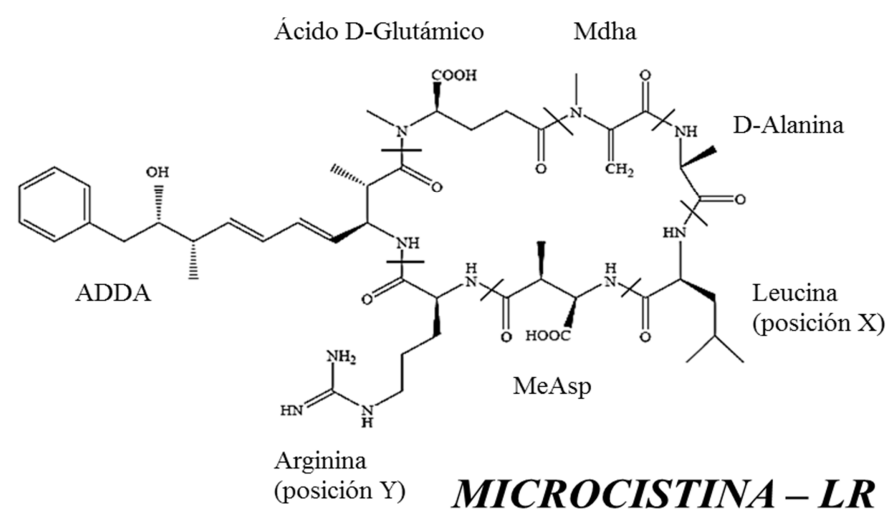

Figura 7. Molécula de Microcistina $L R$

Las distintas variantes de microcistinas han sido identificadas, las principales diferencias radican principalmente en el grado de metilación, la configuración del ADDA o los aminoácidos que ocupan las posiciones $\mathbf{X} \circ \mathbf{Y}$. Estas diferencias estructurales generan diferencias particulares en la molécula que hacen que las distintas toxinas varíen entre sí, incluso pude variar incluso en su toxicidad (Rinehart, 1994). La mayoría de las variantes estructurales de microcistinas y 
nodularinas son altamente tóxicas, presentando en el ratón una dosis letal 50 (DL50) por vía intraperitoneal, que varía entre 50-300 $\mu \mathrm{g} . \mathrm{kg}$ de peso corporal (Sivonen y Jones, 1999).

Los péptidos cíclicos en general son solubles en agua y, por tanto, incapaces de atravesar directamente las membranas lipídicas de los animales, plantas y bacterias, para lo cual utilizan transportadores. Los transportadores más utilizados son los que se encuentran en los ácidos biliares y, por ello, el hígado es el órgano diana de estas toxinas (Carmichael y col., 1990; Codd, 2000). Pero investigaciones recientes han demostrado que las microcistinas pueden afectar a las membranas celulares de los invertebrados y plantas sin utilizar, necesariamente, transportadores de ácidos biliares (Codd, 2000).

La Microcistina LR ha sido identificada como una de las toxinas de mayor prioridad a ser estudiadas. Esta prioridad se basa en cuatro criterios: los efectos sobre la salud humana, su ocurrencia en cuerpos de agua, susceptibilidad a los tratamientos dados en las plantas potabilizadoras y estabilidad de la toxina (USEPA, 2001). En 1998, la Organización Mundial de la Salud alertó sobre el potencial importancia de la presencia de Microcystinas en el agua de red y

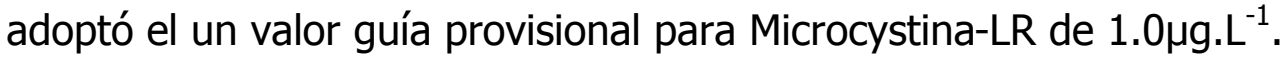

Los métodos actualmente disponibles para la detección y cuantificación de estas toxinas incluyen bioensayos en ratón, concentración en fase sólida seguida por detección empleando equipos de cromatografía liquida con detectores específicos. Un método sensible es la inhibición de fosfatasa que permite detectar niveles de MC suficientemente bajas.

En estudios de toxicidad aguda, las microcistinas son absorbidas en el torrente sanguíneo y transportadas al hígado donde ocurre el daño. El análisis patológico revela disrupción masiva de la arquitectura lobular y sinusoidal del hígado con hemorragia intrahepática. La muerte se puede producir en unas pocas horas (4-24 horas) o en unos días y ésta viene precedida por un cuadro de choque, es decir, coma, temblor muscular, palidez y dificultad en la respiración. Otros efectos observados son: diarrea sanguinolenta por la enteropatía aguda hemorrágica secundaria al choque y por la situación de hipocoagulabilidad que desencadena la insuficiencia hepática aguda, y hepatomegalia.

Los estudios de toxicidad subcrónicos y crónicos en mamíferos son muy escasos, motivado principalmente por la poca disponibilidad y alto costo de las toxinas. Ensayos realizados en animales de experimentación han demostrado daño hepático crónico tras una administración oral continuada de microcistinas 
y la promoción de tumores en piel e hígado de ratón, e hígado y colon de rata. La administración oral de extractos de Microcystis aeruginosa, a cerdos durante 44 días de dosis de 280, 800 y $1310 \mu \mathrm{g} . \mathrm{Kg}^{-1}$ de microcistina.día ${ }^{-1}$, ha dado lugar a lesiones hepáticas y alteración de enzimas séricas como: fosfatasa alcalina (PA), $\gamma$-glutamiltransferasa $(\gamma-\mathrm{GT})$, aspartato aminotransferasa (GOT) y alanina aminotransferasa (GPT) por encima de los niveles normales (Moreno y col., 2003).

Las microcistinas presentan posible actividad carcinogénica (Fujiki y col., 1996), confirmándose como promotoras de cáncer primario de hígado en algunas áreas de China. Aunque aún no han sido evaluadas definitivamente por la Agencia Internacional de Investigación en Cáncer (IARC). Se debe mencionar que la principal ruta de exposición del hombre las cianobacterias tóxicas es el consumo de agua de bebida siendo en menor proporción la exposición debida a la actividad recreacional en lagos y ríos (Falconer, 1999).

Uno de los primeros incidentes registrodos ocurrió en 1931 en Estados Unidos en las orillas del Rio Ohio, donde los síntomas más representativos fueron gastroenteritis no relacionadas con otros patógenos. Se sugirió que fue por causa de cianobacterias ya que hubo un florecimiento previo a la aparición de los síntomas en la población (Tisdale, 1931).

Un caso de relevancia similar al de Ohio en 1931 fue el de Harare, Zimbawe, en el que algunas áreas de la ciudad eran abastecidas de agua por un reservorio en especial. Las gastroenteritis se presentaban todos los años en la misma época, lo cual concordaba con un florecimiento de Microcystis spp. Estos síntomas no se presentaban en personas que consumían agua de otras reservas (Zilberg, 1966).

Uno de los casos más representativos y que cobró importancia debido a las muertes que causó fue en Bahía, Brasil en 1988. En esta ocasión se reportaron cerca de 2000 casos en un período de 42 días, donde cerca de 88 pacientes fallecieron. El estudio reveló evidencias de la presencia de cianobacterias de los generos Anabaena y Microcystis. (Teixera y col., 1993).

Sin duda el antecedente más conocido de intoxicación con cianotoxinas es el ocurrido en 1996 en Caruaru, Brasil. Donde 131 pacientes a los cuales se les realizaba diálisis con agua contaminada con cianotoxinas debido a un tratamiento insuficiente de la misma. 100 de esos pacientes desarrollaron rápidamente fallo hepático agudo y más de 50 murieron luego de la exposición al agua contaminada (Carmichael, 1996). En las muestras del sistema de purificación de agua se pudo confirmar la presencia de microcistina $L R$, y de 
acuerdo a esto se estimó una concentración de microcistinas de $19.5 \mu \mathrm{g} \cdot \mathrm{L}^{-1}$ en el agua empleada en la diálisis de estos pacientes (Carmichael y col., 2001; Azevedo y col., 2002).

Otra vía de exposición ya mencionada es la recreacional. Uno de los primeros casos es el ocurrido en la localidad de Saskatchewan, Canadá en 1959. En este caso 30 personas enfermaron luego realizar actividades recreacionales en un lago de esta ciudad en el cual se describió un florecimiento. Los síntomas que desarrollaron fueron dolores de cabeza y musculares, nausea, dolores abdominales y diarrea. Se pudieron identificar células de Microcystis spp y tricomas de Anabaena circinalis (Dillenberg y col., 1960).

Nuestro país por sus características hídricas y climáticas no es ajeno a este tipo de intoxicaciones con cianotoxinas. Recientemente se han podido reportar casos de intoxicación como el ocurrido en Concordia, Entre Ríos en 2007 donde una persona estuvo expuesta a un intenso florecimiento de Microcystis spp en la represa de Salto Grande. Este individuo estaba realizando deportes náuticos, cuando por un desperfecto de la moto de agua, termina en una bahía inmerso en un intenso florecimiento que él mismo refiere como una capa verde espesa similar a una "sopa de arvejas". En este caso los síntomas fueron dificultad respiratoria, taquipnea, fiebre, dolor abdominal, nauseas, vómitos y oliguria. Luego de la evaluación inicial el diagnóstico fue Neumonía atípica. El paciente mantuvo un estado grave por 2 o 3 días y luego comenzó a revertir su estado. La concentración de MC-LR en aguas fue de $46 \mu \mathrm{g} . \mathrm{L}^{-1}$ MC-LR (Giannuzzi y col., 2011).

En relación al consumo de suplementos dietarios a base de cianobacterias se ha reportado un caso ocurrido en Oregón donde una mujer de 34 años fue hospitalizada al presentar una disfunción hepática progresiva. Se confirmó un consumo crónico de suplementos a base de Anabaenaflos-aquae. Se analizaron remanentes de dos de los suplementos consumidos por la paciente encontrando niveles de 2,62 y 4,06 $\mathrm{\mu g}$ Microcistina-LReq.gr de peso seco de producto. También se analizó la presencia de Microcistina-LR en una muestra de hígado de la paciente encontrándose un resultado positivo a estas toxinas (Dietrich y col., 2007).

En nuestro medio, en particular en la cuenca del Río de la Plata, estudios previos llevados a cabo por el grupo de investigación donde se desarrolla la presente Tesis de Magister han informado por primera vez a Microcystis aeruginosa en el Río de la Plata y detectado niveles de microcistinas LR en agua de red de la ciudad de La Plata y Ensenada en niveles que variaron entre 0.1$7.8 \mu \mathrm{g} \cdot \mathrm{L}^{-1}$ superiores a los niveles guía dados de $1 \mu \mathrm{g} \cdot \mathrm{L}^{-1}$. En este estudio, los 
niveles de microcistinas LR en el agua que alimenta la planta proveniente del Río de la Plata varío entre $0.02-8.6 \mu \mathrm{g} \cdot \mathrm{L}^{-1}$. Lo anterior marca la necesidad de implementar estrategias de remoción de toxinas y evitar que la población esté en riesgo de consumo de estas toxinas (Giannuzzi y col., 2012).

Resulta importante recalcar que la empresa de agua que abastece a la ciudad de La Plata, Berisso y Ensenada no aplica tratamientos adicionales para la remoción de cianotoxinas en los momentos en que el Río de la Plata presenta florecimientos importantes. Al respecto, una foto del florecimiento ocurrido en enero del año 2014 en la toma de agua de la planta de potabilización de aguas (ABSA) se presenta a continuación (Fig 7).

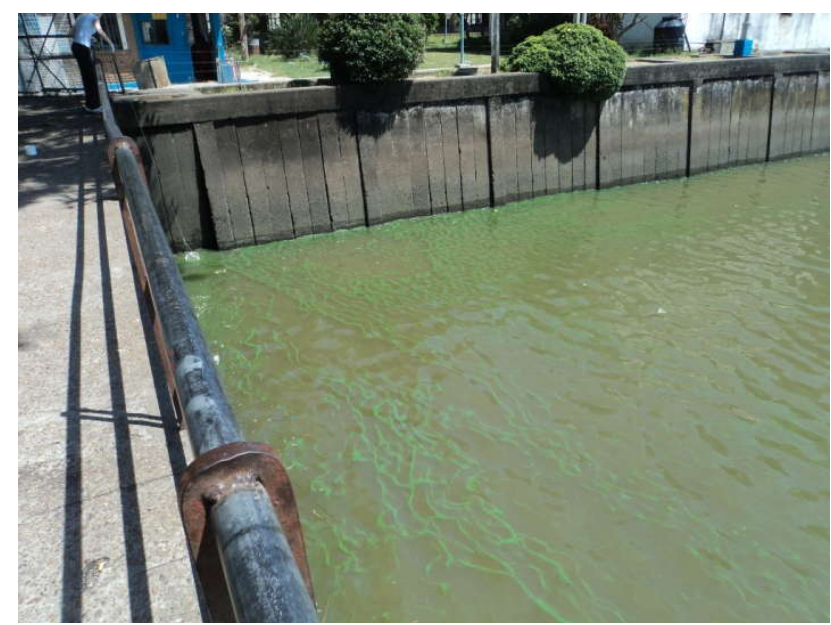

Figura 8. Florecimiento toma de agua, Ensenada.

Aplicando los criterios consensuados por la Organización Mundial de Salud (OMS), en "Toxic cyanobacteria in water", el riesgo relativo de tener problemas de salud en la Cuenca del Plata a causa de florecimientos de cianobacterias es elevado debido a que el sistema de tratamiento del agua potable no cumple dos condiciones que la OMS postula como básicos 1) el tratamiento del agua no utiliza los procesos tales como ozonización o filtros especiales de carbón activado 2) no se realizan monitoreos constantes a efectos de evaluar la presencia de cianobacterias y sus toxinas en los cuerpos de agua utilizados como fuentes de abastecimiento.

\subsection{Tratamientos de remoción}

En las plantas de tratamiento de agua hay tres estrategias de gestión de los servicios de agua potable que se pueden realizar para minimizar la exposición de los consumidores a cianotoxinas: (1) utilizar un suministro alternativo; (2) ajustar la profundidad de la entrada de agua a la planta; y (3) tratamiento de agua en la entrada. Para servicios de agua potable que tienen acceso a más de una fuente de agua la estrategia más simple es cambiar las fuentes, esto puede 
resultar poco práctico ya que la mayoría de los servicios públicos no tienen múltiples fuentes de un tamaño suficiente para abastecer el $100 \%$ de la demanda de agua en caso de floraciones. Una estrategia alternativa se basa en el conocimiento de la ecología de la floración y la dinámica de la fuente de agua (Hrudey y col., 1999). Algunas floraciones de cianobacterias se producen a profundidades específicas en la columna de agua y ya que las cianobacterias pueden regular su flotabilidad, es posible que esta herramienta de extraer agua a diferentes profundidades o en momentos específicos evitando sacar agua con células de cianobacterias sea útil.

Los sistemas de potabilización de agua convencionales tales como coagulación, floculación, o filtración pueden ser efectivos para toxinas intracelulares donde las células son parcialmente removidas, pero dejan de ser lo suficiente efectivos en remover toxinas extracelulares. Además, tales procesos simplemente transfieren las toxinas de una fase a otra (Acero, 2008). Por otra parte, una adecuada captación y coagulación seguida de filtración resulta claramente insuficiente durante los florecimientos. Por ello, resulta necesario desarrollar métodos efectivos de remoción de microcistinas de las aguas. Dado que el agua de consumo es la principal vía de exposición a las microcistinas, se han desarrollado y evaluado numerosas tecnologías para la efectividad de la remoción de estas toxinas, siendo la cloración una de ella. Ha sido usada intensamente en USA desde el año 2000 (AWWA, 2000) y ha servido como una manera accesible y fácil de inactivación de microcistinas.

Los oxidantes a menudo se añaden a la entrada para reducir los compuestos que producen mal sabor y olor, disminuir el crecimiento biológico en el tubo de admisión, reducir la producción de subproductos de desinfección, estimular la coagulación y eliminar compuestos químicos como el manganeso. La adición de un oxidante en la entrada plantea varias preguntas con respecto a la eliminación cianotoxinas. La primera preocupación es evitar la lisis de las células. El consenso general es que la eliminación de cianotoxinas se maximiza mediante la eliminación de células intactas (Falconer, 2005). La cuestión principal sigue siendo si el uso de un oxidante en la entrada no resulte en lisis celular y favorezca la liberación al medio de las toxinas, aunque también pueda eliminar las toxinas extracelulares ya disueltas. Las mayores dificultades de la cloración en la entrada ya no es una práctica común debido a la formación de subproductos clorados y el riesgo de lisis de células de cianobacterias (Newcombe, 2002).

La ozonización de Microcystis aeruginosa y Oscillatoria tenuisa resultó en daño de la pared celular e hizo que se liberara microcistina del citoplasma, sumado a la formación de compuestos volátiles que provocan mal sabor y olor (Miao y 
Tao, 2007). En contraste (Ho y col., 2009) demostraron que el Permanganato de potasio $\left(\mathrm{KMnO}_{4}\right)$ se puede utilizar en la entrada de la planta de tratamiento sin liberar saxitoxinas intracelulares o compuestos que puedan producir mal sabor y olor. Por otra parte (Cheng y col., 2009) informaron que el Permanganato de potasio $\left(\mathrm{KMnO}_{4}\right)$ inactivó células de Cylindrospermopsis sin liberación de toxinas. A continuación se describirán algunos de los procesos de remoción más usados en las plantas de tratamiento de aguas.

\subsubsection{Cloro}

El cloro ha jugado un papel importante en la desinfección del agua potable en los últimos 100 años. Más recientemente, el cloro se ha investigado para determinar si se puede utilizar como tratamiento auxiliar para los contaminantes orgánicos tales como las cianotoxinas. La inactivación de los contaminantes orgánicos por el cloro es generalmente dependiente del $\mathrm{pH}$ debido a que por ejemplo el $p K a$ del ácido hipocloroso es 7,6. Dos publicaciones proponen mecanismos de inactivación de cloro para varias variantes de microcistinas. (Acero y col., 2005) informaron que microcistinas $L R, R R$, y $Y R$ reaccionan con el cloro a la misma velocidad y tienen la misma reducción de la toxicidad, lo que sugiere que la hidroxilación del Adda es el sitio primario para la oxidación. En contraste, (Ho y col., 2006) informaron que las velocidades de reacción de cloro para microcistinas $Y R, R R, L R$, y $L A$ fueron diferentes, siguiendo este orden $Y R>R R>L R>L A$ sugiriendo que la oxidación de aminoácidos diferentes jugó un papel importante en la desactivación de las microcistinas. Independientemente del mecanismo, ambos artículos sugirieron que la cloración a $\mathrm{pH}<8,0$ es un mecanismo eficaz para la inactivación de estas toxinas.

Asimismo, es conocido que la inactivación de toxinas por cloro puede ser afectada por el pH del medio, la temperatura y otros parámetros (Xagoraraki y col., 2006). Sin embargo, la cuantificación y el modelado de la inactivación de microcistinas en conjunto con las variables que afectan la remoción como son $\mathrm{pH}$, dosis de cloro inicial, temperatura, presencia de materia orgánica en el agua no ha sido aún estudiada ni transferida a las plantas potabilizadoras de agua en términos de variables operativas del sistema de tratamiento convencional.

Las Microcistinas son destruidas rápidamente por una solución acuosa de cloro e hipoclorito de calcio, pero su remoción es menos eficaz para dosis equivalentes de hipoclorito de sodio. El cloro en solución acuosa y el hipoclorito de calcio consigue más del $95 \%$ de eliminación de toxinas a 30 minutos y dosis de $1 \mathrm{mg} . \mathrm{L}^{-1}$ de cloro o mayores. El hipoclorito de sodio logra aproximadamente el $40 \%$ de eliminación a dosis de $1 \mathrm{mg} \cdot \mathrm{L}^{-1}$ y el $70-80 \%$ de eliminación a dosis de 
cloro de $5 \mathrm{mg} \cdot \mathrm{L}^{-1}$ o mayor. Si el hipoclorito de sodio o el de calcio se utilizaran para la destrucción de la toxina en las aguas naturales, se espera que el pH no se pueda elevar en gran medida debido a la mayor capacidad de amortiguación de las aguas naturales. Sin embargo, si se utilizan altas dosis de hipoclorito de sodio o de calcio a valores de $\mathrm{pH}$ mayores a 8 , entonces será necesario un ajuste de $\mathrm{pH}$ para asegurar la eliminación de la toxina de manera adecuada (Nicholson y col., 1994).

El uso de dióxido de cloro para un proceso de oxidación causó una reducción de la concentración total de microcistina del 40,4\% (reducción del 78,2\% para las microcistinas intracelular y $\mathbf{1 7 . 2} \%$ de aumento para las formas disueltas). Estos resultados concuerdan con los resultados presentados por (Nicholson y col., 1994). Por otra parte Tsuji y col., 1997 demostraron que una dosis de cloro de $2,8 \mathrm{mg} \cdot \mathrm{L}^{-1}$ para un tiempo de contacto de $30 \mathrm{~min}$ era suficiente para una destrucción del 99\% de MC-LR.

Otras sustancias cloradas utilizadas en el tratamiento de agua son las cloroaminas, consideradas oxidantes pobres, pero usadas con frecuencia para proporcionar desinfectante residual para minimizar la formación de subproductos clorados tales como los trihalometanos. La cloroamina y el dióxido de cloro no son tratamientos eficaces para microcistina, cilindrospermopsina, anatoxina-a, y saxitoxinas. Servicios de tratamiento utilizan dióxido de cloro y cloroaminas para reducir los subproductos de desinfección, los cuales no tienen un buen tratamiento oxidante para la inactivación de cianotoxinas.

\subsubsection{Hidroperoxidos}

El peróxido de hidrógeno ha demostrado que disminuye cianobacterias y por consiguiente las concentraciones de microcistinas en varios ambientes (Rositano y col., 2001; Cornish y col., 2000; Drábková y col., 2007; Barrington y Ghadouani, 2008; Barrington y col., 2011; Matthijs y col., 2011).

El empleo de $\mathrm{H}_{2} \mathrm{O}_{2}$ podría resultar en un método de tratamiento eficaz en la eliminación cianobacterias y microcistinas en gran escala de aplicación, siendo también una alternativa ambientalmente sustentable dado que no se acumula en el medio ambiente debido a la descomposición rápida por medio de agentes biológicos, químicos y mecanismos fotoquímicos. Encontramos diferencias considerables en la respuesta a $\mathrm{H}_{2} \mathrm{O}_{2}$ por las cianobacterias, en comparación con algas verdes y diatomeas. El rendimiento fotosintético en $M$. aeruginosa fue inhibida con concentraciones de $\mathrm{H}_{2} \mathrm{O}_{2} 10$ veces menor que las concentraciones que fueron eficaces para $P$. subcapitata y $N$. seminulum. Por otra parte estos resultados sugieren que las concentraciones eficaces están en el intervalo de 
0,2 a $0,8 \mathrm{mg} \cdot \mathrm{L}^{-1}$ para $M$. aeruginosa. La dosis eficaz informada es de $0,27 \mathrm{mg} \cdot \mathrm{L}^{-1}$ pero podría ser mayor para especies formadoras de colonias en ambientes naturales como Microcystis. Sin embargo, se sugiere que los intervalos de concentración de 0,3 a $2 \mathrm{mg}^{-\mathrm{L}^{-1}}$ pueden afectar más a especies de cianobacterias y tener poco o ningún efecto sobre algas verdes y diatomeas. (Drábková y col., 2007).

El tratamiento con agua oxigenada aplicado en forma secuencial con el cloro implica un avanzado proceso de oxidación cuya efectividad en el tratamiento de aguas resulta interesante para ser analizada. Existen escasas referencias en la literatura acerca de este proceso conjunto de eliminación de cianotoxinas y microcistinas. Adicionalmente, la bibliografía analizada no muestra estudios en detalle acerca de las variables involucradas en los procesos de eliminación de microcistinas. Estas variables comprendidas en un proceso de purificación involucran aquellas propias del cuerpo de agua: carbono orgánico disuelto y total, $\mathrm{pH}$, salinidad (todas variables importantes en cuerpos de agua como el Río de La Plata), alcalinidad, luz UV, densidad del agua, presencia de metales pesados y la subsecuente formación de complejos, formación de biofilms en los filtros y estabilidad de las toxinas en estas condiciones.

\subsubsection{Otros peróxidos}

El ácido peracético o ácido peroxiacético (APA) es el peróxido del ácido acético. El APA es un oxidante fuerte y desinfectante. Su potencial de oxidación es mayor que el de cloro o dióxido de cloro. El APA está disponible comercialmente en forma de una mezcla en equilibrio cuaternario que contiene ácido acético, peróxido de hidrógeno, APA y agua como se muestra en la siguiente ecuación (Alasri y col., 1992; Gehr y col., 2002; Block, 1991):

$$
\mathrm{CH}_{3} \mathrm{CO}_{2} \mathrm{H}+\mathrm{H}_{2} \mathrm{O}_{2} \Rightarrow \mathrm{CH}_{3} \mathrm{CO}_{3} \mathrm{H}+\mathrm{H}_{2} \mathrm{O} \text { dónde: }
$$

$\mathrm{CH}_{3} \mathrm{CO}_{2} \mathrm{H}=$ ácido acético

$\mathrm{CH}_{3} \mathrm{CO}_{3} \mathrm{H}=$ ácido peracético

$\mathrm{H}_{2} \mathrm{O}_{2}=\quad$ peróxido de hidrógeno

Aunque el hidroperóxido es también un desinfectante que contribuye a la potencia de la desinfección de la mezcla del producto, el APA es un agente antimicrobiano más potente que el hidroperoxido, siendo rápidamente activo a concentraciones bajas contra un amplio espectro de microorganismos (Baldry, 1983; Baldry y French, 1989b; Fraser y col., 1984).

El APA combina las características de oxígeno activo de un peróxido dentro de una molécula de ácido acético y pertenece a la clase de los peróxidos orgánicos, que son sustancias químicas artificiales. Los peróxidos orgánicos 
pueden contener radicales peróxido (enlace oxígeno-oxígeno) que son una fuente de oxígeno. El peróxido es un compuesto por un estado de alta energía y, como tal, puede ser considerado termodinámicamente inestable (Block, 1991).

El APA es un líquido transparente, incoloro, sin capacidad de formación de espuma. Tiene un fuerte olor a ácido acético acre (el ácido acético es el componente principal del vinagre) y tiene un $\mathrm{pH}$ ácido de menos de 2. Presenta un alto potencial de oxidación de 1,87 volts lo cual lo convierte en un poderoso oxidante. Para una solución con una mezcla de APA 5\%, 20\%-24\% de hidroperóxido y $10 \%$ a $12 \%$ de ácido acético, el peso específico es de 1,10 (Solvay Interox, 2002a). Para una solución de $12 \%$ de APA, el punto de congelación es de $-40,3$ a $-42,0^{\circ} \mathrm{C}$, y el peso específico es de 1,11 (Solvay Interox, 2002b). El APA es soluble en agua en todas las proporciones y en disolventes orgánicos polares. Sin embargo, es ligeramente soluble en disolventes aromáticos (Solvay Interox, 2002a).

Su actividad desinfectante se basa en la liberación de oxígeno activo (Liberti y Notarnicola, 1999). Es probable que los enlaces sulfhidrilo y de azufre son sensibles de ser oxidados, por lo tanto las proteínas, enzimas, y otros metabolitos se oxidan, afectando la funcionalidad de las células.

Se sugiere que el APA interrumpe la función quimiosmótica de la membrana citoplasmática de las lipoproteínas y el transporte a través de la dislocación o ruptura de las paredes celulares (Baldry y Fraser, 1988; Leaper, 1984). Por lo tanto, puede ser eficaz frente a las lipoproteínas de la membrana externa, facilitando su acción contra las células gram negativas (Leaper, 1984). Su acción como desnaturalizante de proteínas puede ayudar a explicar sus características como esporicida y ovicida (Block, 1991). Además, el APA al interior de las células puede oxidar enzimas esenciales; alterar las rutas bioquímicas, el transporte activo a través de membranas, y alterar los niveles de soluto intracelulares (Fraser y col., 1984). Se demostró que el APA actúa sobre las bases de la molécula de ADN (Tutumi y col., 1973). Una ventaja importante del APA es que puede inactivar la catalasa, una enzima conocida para desintoxicar los radicales hidroxilo libres en las células (Block, 1991).

Se ha demostrado que el APA no produce o produce pocos subproductos tóxicos o mutagénicos después de la reacción con la materia orgánica presente en los efluentes de aguas residuales tratadas o aguas superficiales utilizadas para consumo (Baldry y Fraser, 1988; Monarca y col., 2001; Monarca y col, 2002). Monarca y col., 2001 informaron de que los subproductos aislados de aguas fluviales tratados con APA eran predominantemente ácidos carboxílicos, 
que no son reconocidos por ser mutagénicos. Los ácidos carboxílicos se forman a través de la oxidación de la materia orgánica natural por el contacto con el APA (Monarca y col., 2002). No se observó contenido de subproductos de desinfección halógenos (DBPs) para el agua tratada con APA (Monarca y col., 2002). Esta es una de las ventajas más importantes del uso de APA sobre otros desinfectantes químicos normalmente usados en el tratamiento de aguas residuales o agua para consumo como son el cloro gaseoso, Hipoclorito de sodio, dióxido de cloro u ozono. Los desinfectantes a base de cloro dan como resultado la formación de tóxicos y subproductos mutagénicos halogenados (clorados y/o bromados) después de la reacción de cloro con la materia orgánica. Además, sólo alrededor del $50 \%$ de los haluros orgánicos totales formados pueden ser identificados y cuantificados.

Teniendo en cuenta los antecedentes demostrados del APA en el tratamiento de aguas, se ubica como una alternativa viable de estudio y uso en la problemática de las cianobacterias y cianotoxinas. Es sabido que el ácido peracético (APA) ha sido aprobado por el ANMAT según Resolución 318/15 para el tratamiento de aguas. Sin embargo el lugar donde pueda ser aplicado no ha sido aún establecido y los operadores de las mismas sugieren la aplicación a la entrada de la planta en casos de florecimientos. También otros operadores de plantas indican que el mejor abordaje sería aplicarlo a la salida de la planta previa a la cloración, habida cuenta que a la entrada el APA podría producir la lisis de las células y liberar la toxina situación que empeoraría la problemática.

\subsubsection{Otros procesos}

Algunos procesos complementarios utilizados en la remoción de cianotoxinas son: la osmosis inversa, nanofiltración, ultrafiltración y procesos de separación de contaminantes por tamaño y carga en función de las características físico/químicas de la membrana son utilizados aunque no de manera tan amplia en las plantas. La nanofiltración y ósmosis inversa en estudios de filtración informan un $82 \%$ de remoción de microcistina (Muntisov, 1996). Un estudio de membrana de ósmosis inversa utilizando entre 10 y $130 \mu \mathrm{g} \cdot \mathrm{L}^{-1}$ de microcistina LR y RR eliminando más del $95 \%$ de las cianotoxinas del agua (Neumann, 1998). Otros procesos que ya se están implementando en algunos países con problemáticas particulares en sus cuerpos de agua son: carbón activado, UV, permanganato de potasio, ozono y procesos avanzados de oxidación. 
OBJETIVOS 


\section{Objetivo general}

Contribuir al conocimiento básico y aplicado sobre los procedimientos de remoción de cianotoxinas presentes en aguas a ser tratadas en plantas potabilizadoras.

\subsection{Objetivos específicos}

- Evaluar la cinética de inactivación de Microcistina-LR empleando cloro libre en ensayos de laboratorio.

- Determinar el efecto de $\mathrm{pH}$ y el cloro libre inicial sobre la velocidad de inactivación de Microcistina-LR.

- Analizar el efecto de un oxidante comercial (Bioxi B) sobre un cultivo de Microcystis aeruginosa.

- Estimar el efecto de diferentes concentraciones de un producto oxidante comercial (Bioxi B) sobre la degradación de Microcistina-LR.

- Calcular la velocidad de oxidación de Microcistoina-LR por cloro libre y un producto oxidante comercial en las condiciones estudiadas a efectos de modelar los resultados obtenidos y obtener las variables operativas que puedan ser trasferidas a las plantas potabilizadoras.

- Constatar la eficacia del producto Bioxi B a diferentes dosis y a distintos tiempo de contacto en un cultivo bacteriano de $E$. coli indicador de contaminación fecal. 


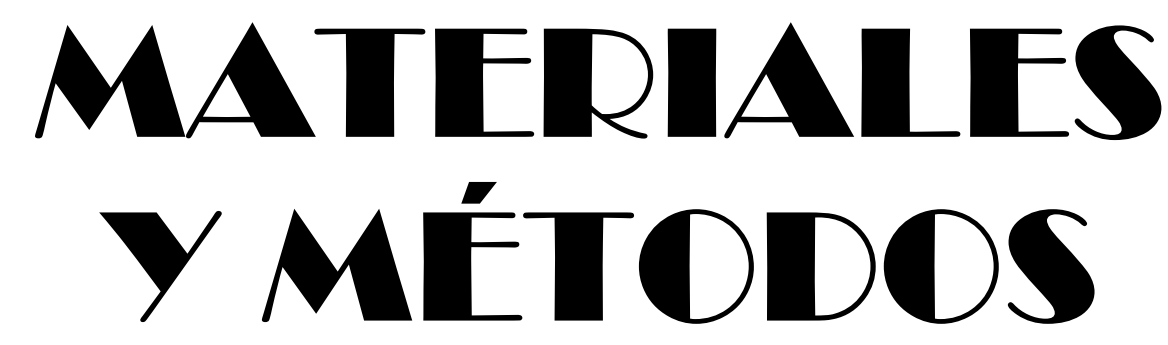




\subsection{Productos químicos oxidantes utilizados}

\subsubsection{Solución comercial de hipoclorito de sodio}

Se utilizó una solución comercial de hipoclorito de sodio con una concentración de cloro activo de $55 \mathrm{~g} \cdot \mathrm{L}^{-1}$ a la salida de la fábrica (Ayudin), con registro ANMAT RNPUD No 0250022 , las soluciones se mantuvieron a $4^{\circ} \mathrm{C}$ y protegidas de la luz para evitar que se afectara la concentración de cloro. Esta solución comercial se utilizó dentro los 120 días indicados por el fabricante para la utilización del producto a partir de la fecha de fabricación.

\subsection{2. Ácido Peracético}

Se prepararon diluciones de un producto comercial a base de ácido peracético (Bioxi B), SABINUR, el cual contiene Peróxido de hidrogeno 35\%, ácido peracético $15 \%$, utilizado como desinfectante de superficies, usado en la industria alimenticia. Este producto se encuentra en el listado de productos para la industria alimenticia, 30/11/2014 con el RNPUD No 0250028 del ANMAT (Administración Nacional de Medicamentos Alimentos y Tecnología Médica).

\subsection{Cepas de cultivo utilizadas}

\subsubsection{Cepa de Microcystis aeruginosa}

Para los ensayos de remoción de cianobacterias se replicó en medio BG110 (Tabla 1) un cultivo de cianobacterias (Microcystis aeruginosa) cepa CAAT2005 representativa de este grupo, obtenida del ambiente y perteneciente al Laboratorio de Toxicología, de la Facultad de Ciencias Exactas de la Universidad Nacional de la Plata. La cepa CAAT2005 fue obtenida por el grupo de investigación donde se desarrolla la presente Tesis de Magister de la localidad de Pila (Provincia de Buenos Aires). Dicha cepa es productora de una variante de Microcistina identificada como [D-Leu 1] microcistina-LR (Andrinolo y col., 2012).

Tabla 1. Composición del Medio BG110 para Microcystis aeruginosa

$\mathrm{BG} 11_{0}+\mathrm{NaNO} 3(2 \mathrm{mM})+\mathrm{NaHCO} 3(10 \mathrm{mM})$

\begin{tabular}{|lc|}
\hline Medio BG1 $11_{0}$ & $1000 \mathrm{~mL}$ \\
\hline $\begin{array}{l}\text { Solución 1M de Carbonato hidrogeno de } \\
\text { Sodio }\end{array}$ & $0,15 \mathrm{~g}$ \\
\hline Componentes BG11 & $10 \mathrm{~mL}$ \\
\hline Fosfato de hidrogeno Di potásico Trihidratado & Concentración del medio \\
\hline
\end{tabular}




\begin{tabular}{|c|c|}
\hline Sulfato de Magnesio Heptahidratado & $0,075 \mathrm{~g}$ \\
\hline Cloruro de Calcio Di hidratado & $0,036 \mathrm{~g}$ \\
\hline Solución $\mathrm{N}^{\circ} 1$ (Componentes) & $5 \mathrm{~mL}$ \\
\hline Citrato de Amonio Hierro (III) & $300 \mathrm{mg}$ \\
\hline Ácido cítrico Monohidratado & $300 \mathrm{mg}$ \\
\hline Agua destilada & $250 m L$ \\
\hline Solución N² (Componentes) & $5 \mathrm{~mL}$ \\
\hline Magnesio titriplex di hidratado & $0,1 g$ \\
\hline Agua Destilada & $500 m L$ \\
\hline Carbonato de Sodio & $0,04 \mathrm{~g}$ \\
\hline Solución Nº 3 (Componentes) & $\mathbf{1} \mathbf{m L}$ \\
\hline Ácido bórico & $2,86 g$ \\
\hline Cloruro de Magnesio Tetrahidratado & $1,81 \mathrm{~g}$ \\
\hline Sulfato de Zinc Heptahidratado & $0,222 g$ \\
\hline Molibdato de Sodio Dihidratado & $0,39 g$ \\
\hline Sulfato de Cobre (II) Pentahidratado & $0,079 \mathrm{~g}$ \\
\hline Nitrato de Cobalto (II) Hexahidratado & $0,049 \mathrm{~g}$ \\
\hline Agua destilada & $1000 \mathrm{~mL}$ \\
\hline
\end{tabular}

Solución 1M de Carbonato hidrogeno de Sodio

Bicarbonato de Sodio 25,29

Agua destilada

$300 \mathrm{~mL}$

Para la preparación del medio $\mathrm{BG} 11_{0}$, se adicionaron todos los componentes excepto la solución $1 \mathrm{M}$ de bicarbonato de sodio. El medio se autoclavó a $120^{\circ} \mathrm{C}$ por 20 minutos. La solución $1 \mathrm{M}$ de bicarbonato de sodio se autoclavó por separado a las mismas condiciones que las otras soluciones y fue incluido al medio antes de ser usado.

El repique de Microcystis aeruginosa se realizó con medio de cultivo $B G 11_{0}$ estéril en cuarto de cultivo a una temperatura de $27^{\circ} \mathrm{C} \pm 1$, sin agitación y ciclos de luz/oscuridad de 12/12 horas. En un Erlenmeyer estéril de 1 litro se 
agregaron $800 \mathrm{~mL}$ de medio $\mathrm{BG} 11_{0}$ estéril al que se le adicionó $100 \mathrm{~mL}$ de un inóculo denso, obtenido a partir de un cultivo de Microcystis aeruginosa. Adicional a las condiciones anteriormente descritas, al cultivo se le incorporó burbujeo de aire humidificado y filtrado por filtros de celulosa $0.22 \mu \mathrm{m}$ (osmonics). El tiempo de mantenimiento de cada repique fue de 15 días, tiempo en el cual se repicó de nuevo para mantener cultivo fresco.

\subsubsection{Cepa de E. coli}

En el caso de los ensayos con E. colise utilizó la cepa 25922 representativa de este grupo de microorganismos obtenida del laboratorio en el Centro de Investigación y Desarrollo en Criotecnología de Alimentos (CIDCA) de la Universidad Nacional de la Plata. La cepa fue mantenida y repicada en caldo nutritivo. Para cada ensayo la cepa fue repicada 12 horas antes en caldo nutritivo agregando $100 \mu \mathrm{L}$ del cultivo bacteriano en fase de latencia en un tubo con $9 \mathrm{~mL}$ de caldo nutritivo, de tal manera que al momento de cada ensayo el cultivo se encontrara en fase exponencial de crecimiento. La temperatura de incubación de la cepa en estufa de cultivo fue de $37^{\circ} \mathrm{C} \pm 1^{\circ} \mathrm{C}$. Los componentes utilizados para la preparación de 1 litro de caldo nutritivo se muestran a continuación en la Tabla 2.

Tabla 2. Componentes del caldo nutritivo utilizado para el mantenimiento y repique de la cepa de $E$. coli.

\begin{tabular}{|lc|}
\hline \multicolumn{1}{|c|}{ Coptona Caseína } & Concentración del Medio \\
\hline Extracto de Levadura & $5 \mathrm{~g}$ \\
\hline Glucosa & $2,5 \mathrm{~g}$ \\
\hline Agua destilada (1000mL) & $1 \mathrm{~g}$ \\
\hline pH final: $\mathbf{6 , 8} \mathbf{0} \mathbf{0 , 2}$ & \\
\hline
\end{tabular}

\subsection{Parámetros de evaluación en cultivo de Microcystis aeruginosa}

En la realización de los ensayos se utilizaron cultivos de $M$. aeruginosa que fueron diluidos en medio $B G 11_{0}$. La dilución de trabajo fue en relación 1:1 de cultivo en fase exponencial y medio $\mathrm{BG} 11_{0}$ estéril hasta alcanzar un rango de absorbancia entre 0,300 y 0,550 a $750 \mathrm{~nm}$. El cultivo fue crecido a temperatura de $27^{\circ} \mathrm{C} \pm 1$, sin agitación y ciclos de luz/oscuridad de $12 / 12$ horas. Las alícuotas tomadas a los distintos tiempos de crecimiento del cultivo de $M$. aeruginosa se sometieron a la determinación de los siguientes parámetros:

Turbidez

Proteínas totales

Clorofila- $a$

Recuento celular 
Viabilidad en placa

\subsubsection{Turbidez (método 2130 A-B APHA, 1998)}

El procedimiento para la determinación de turbidez se realizó incorporando en una celda espectrofotométrica $1 \mathrm{~mL}$ del cultivo y se determinó su densidad óptica (absorbancia) a 750nm en un espectrofotómetro marca METROLAB modelo 330.

\subsubsection{Determinación de proteínas totales por método Bradford (Bradford, 1976)}

Este método se basa en la unión del colorante Comassie Blue G-250 a las proteínas. El colorante, en solución ácida, existe en dos formas una azul y otra naranja. Las proteínas se unen a la forma azul para formar un complejo proteína-colorante con un coeficiente de extinción mayor que el colorante libre. Las muestras preparadas se leen a una longitud de onda entre $590-595 \mathrm{~nm}$. Las muestras del cultivo de $M$. aeruginosa se prepararon a partir de la extracción de una alícuota de $3 \mathrm{~mL}$ de cultivo para cada tiempo de crecimiento se procedió a centrifugar por 10 minutos, se retiró el sobrenadante y se llevó a cabo el procedimiento de sonicado para favorecer la lisis celular y la extracción de proteínas (Omni-Ruptor $400,15 \mathrm{~min}$, pulsos $50 \%$, potencia $60 \%$ ). Una vez terminado el proceso de sonicado se procedió a la preparación de las muestras con el reactivo de Bradford. Esta preparación consistió en la mezcla de un volumen de muestra de $10 \mu \mathrm{L}$ con $990 \mu \mathrm{L}$ de reactivo de Bradford. Para asegurar un correcto mezclado las muestras fueron pasadas por vortex antes de pasar a la cubeta espectrofotométrica y luego se leyó la absorbancia a 590-592nm.

Para determinar la cantidad de proteínas presentes en la muestra se debe hacer una curva de calibración, empleando una proteína patrón que en este caso es BSA albumina sérica bovina por sus siglas en español. La Tabla 3 muestra el protocolo propuesto para para la determinación de proteínas totales por el método Bradford.

Tabla 3. Volumen utilizado para realizar la curva de calibración para la determinación de proteínas totales por el método Bradford

\begin{tabular}{|cccc|}
\hline Tubo & $\mu g \cdot \mathrm{mL}^{-1}$ BSA & $\begin{array}{c}\text { Volumen de BSA } \\
\mu g \cdot \mu L^{-1}\end{array}$ & $\begin{array}{c}\text { Volumen de agua } \\
\mu L\end{array}$ \\
\hline $\mathbf{1}$ & 0.1 & 100 & 900 \\
\hline $\mathbf{2}$ & 0.2 & 200 & 800 \\
\hline $\mathbf{3}$ & 0.4 & 400 & 600 \\
\hline $\mathbf{4}$ & 0.6 & 600 & 400 \\
\hline
\end{tabular}


Teniendo en cuenta las concentraciones conocidas de BSA y haciendo una regresión lineal utilizando la ecuación de la recta producto de esta regresión, se halló el valor correspondiente de concentración para cada una de las muestras.

\subsubsection{Determinación de Clorofila-a (Método espectrofotométrico 10200-H, APHA, 1992)}

La extracción de clorofila-a se basa en la transferencia de este pigmento a un solvente orgánico sin provocar cambios químicos en la molécula. La concentración de clorofila- $a$ se cuantifica por absorbancia en un espectrofotómetro. La evaluación de la concentración de clorofila- $a$ en un volumen determinado de muestra puede utilizarse como indicador de la biomasa de cianobacterias. La clorofila- $a$ es soluble en solventes orgánicos, suele usarse acetona o metanol para su extracción, ya que rompen los puentes entre el pigmento y las proteínas logrando la solubilizando de las clorofilas.

La determinación espectrofotométrica de la clorofila- $a$ depende de la Ley de Lambert-Beer, la cual relaciona la intensidad de luz entrante en un medio con la intensidad saliente después de que en dicho medio se produzca cierta absorción. Se miden las densidades ópticas a diferentes longitudes de onda. Deben conocerse los coeficientes de absorción específica de los pigmentos puros a cada longitud de onda. La extracción de la clorofila debe realizarse en la oscuridad y a baja temperatura para reducir al mínimo la fotooxidación. Luego de procesar un volumen conocido de muestra se centrifuga, se elimina el sobrenadante y se coloca en freezer para facilitar la ruptura de las paredes celulares y la liberación del pigmento agregando el solvente de extracción (Metanol), se deja reposar en la oscuridad una noche, se procede a leer en el espectrofotómetro a 664 y $647 \mathrm{~nm}$.

En la misma cubeta se agrega una gota de $\mathrm{HCl} 1 \mathrm{~N}$ y luego de 1 minuto se vuelve a leer la absorbancia a ambas longitudes de onda. Cuando se obtiene un registro de absorbancias a diferentes longitudes de onda se está determinando la sumatoria de todos los pigmentos que absorben a esas longitudes. De los distintos tipos de clorofila. La clorofila-a se encuentra en todas las algas, ya que es esencial para la fotosíntesis.

Procedimiento:

La extracción de la clorofila se llevó a cabo en condiciones de baja luminosidad u oscuridad y a temperatura baja para reducir al mínimo la fotooxidación de los pigmentos. Se tomaron $3 \mathrm{~mL}$ de cultivo de $M$. aeruginosa y se concentró por centrifugado (Centrifuga Centrolit Selecta 4 minutos a 10000rpm). Se descartó el sobrenadante y se guardó el pellet de células agregando $1 \mathrm{~mL}$ de metanol. Se 
cubrieron los tubos con papel de aluminio y se almacenaron a $4^{\circ} \mathrm{C}$ durante 24 horas para favorecer la extracción.

Luego del tiempo de extracción se procedió a leer la absorbancia a 650 y $750 \mathrm{~nm}$. En la misma cubeta o celda y se agregó una gota de $\mathrm{HCl} 1 \mathrm{~N}$ y luego de un minuto se volvió a leer a las mismas longitudes de onda. Con este método se obtiene un registro de absorbancias a distintas longitudes de onda para determinar la sumatoria de todos los pigmentos.

Para la determinación de la concentración de clorofila-a por el método dicromático se utilizó la siguiente fórmula:

$[$ Clorofila $a]=F \times[($ Abs a $665-$ Abs a 750) $-($ Abs b $665-$ Abs b 750) $] \times k \times v$

Donde la clorofila- $a$ (sin feopigmentos) se expresa en $\mu \mathrm{g} \cdot \mathrm{L}^{-1}$, las absorbancias (a) son antes de la adición de $\mathrm{HCl}$ y las absorbancias (b) son las determinadas después de la acidificación. $F=2,43$ para el etanol y 2,72 para el metanol, $k=$ coeficiente de absorción específica, que es de 11,2 para el etanol y 11,62 para el metanol y $\mathrm{V}=$ volumen del extracto en $\mathrm{mL}$ de muestra.

\subsubsection{Recuento Celular}

Para el recuento celular se tomó una alícuota de $1 \mathrm{~mL}$ de las muestras incluyendo el control, se le adicionó $1,5 \mathrm{~mL}$ de agua destilada y una gota de lugol. Se almacenó a $4^{\circ} \mathrm{C}$ y se procedió a hacer el recuento total adicionando $8 \mu \mathrm{L}$ en cámara de Neubauer en la cuadricula utilizada para conteo de glóbulos rojos. El conteo se realizó en microscopio óptico marca Leica.

\subsubsection{Viabilidad celular (Siembra en placa)}

Se tomaron $100 \mu \mathrm{L}$ de las diluciones necesarias de un cultivo de M. aeruginosa a distintos tiempos de crecimiento. Estas muestras fueron sembradas en superficie en placas de Petry conteniendo medio $\mathrm{BG} 11_{0}$ sólido, la composición del medio $\mathrm{BG} 11_{0}$ se muestra en la Tabla 1. Las muestras fueron dispersas con perlas de vidrio estériles. Las placas inoculadas se incubaron a $27^{\circ} \mathrm{C}$ con periodos de luz /oscuridad (12/12 horas) durante 14 días. Trascurrido ese tiempo se contaron las colonias y los resultados se expresaron como Unidades Formadoras de Colonias por $\mathrm{mL}\left(\right.$ UFC. $\left.\mathrm{mL}^{-1}\right)$.

La preparación de las cajas de Petry se realizó agregando $15 \mathrm{~mL}$ de medio $B G 11_{0}$ liquido al $2 X$ estéril, $15 \mathrm{~mL}$ de Agar al $2 \mathrm{X}$ estéril, $300 \mu \mathrm{L}$ de Nitrato de sodio $\left(\mathrm{NaNO}_{3}\right) 2 \mathrm{mM}, 300 \mu \mathrm{L}$ de Bicarbonato de Sodio $\left(\mathrm{NaHCO}_{3}\right) 10 \mathrm{mM}$. En el caso de la solución de nitrato de sodio y el bicarbonato se utilizaron las mismas que fueron utilizadas en el medio BG11o líquido. Un paso previo de lavado fue requerido en el caso del Agar al $2 \mathrm{X}$, para esto el agar luego de ser pesado se 
lavó con agua destilada agitando fuertemente el Erlenmeyer y dejando decantar sacando el sobrenadante, este proceso se repitió 3 veces. Este proceso de lavado se realizó para eliminar posibles inhibidores que el agar pueda contener. Una vez realizado el proceso de lavado el Agar fue autoclavado $120^{\circ} \mathrm{C}$ durante 20 minutos.

\subsection{Proceso de extracción y purificación de MC-LR}

La toxina usada en este trabajo fue extraída de un cultivo de Microcystis aeruginosa (CAAT2005). Se partió de $500 \mathrm{~mL}$ de cultivo sobre los cuales se llevó a cabo la lisis celular mediante sonicado (Omni-Ruptor 400, 15min, pulsos al $50 \%$, potencia $60 \%$ ). El volumen sonicado se concentró filtrando por un cartucho Sep-Pack C18 (Waters) previamente activado con el fin de eliminar la mayor parte de pigmentos y retener las toxinas en el cartucho. La activación del cartucho se realiza pasando $10 \mathrm{~mL}$ de Metanol $100 \%, 10 \mathrm{~mL}$ de aire, $10 \mathrm{~mL}$ de agua destilada y finalmente $10 \mathrm{~mL}$ de aire. Luego de la activación del cartucho se pasó la muestra, una vez que se pasa todo el volumen de las muestras por el cartucho se procede a hacer la elución. Se realizó una primera elución con $10 \mathrm{~mL}$ de metanol $20 \%$ (donde se eliminaron pigmentos que hayan quedado retenidos y otras sustancias contaminantes) y luego se eluyeron las toxinas retenidas del filtro con $10 \mathrm{~mL}$ de metanol $80 \%$.

La purificación de toxina se realizó mediante la técnica de HPLC empleando el siguiente esquema: Columna Hyperprep HS C18 Thermo semi-preparativa (250 X $10 \mathrm{~mm}, 12 \mu \mathrm{m}$ ). Flujo: $3 \mathrm{~mL} \cdot \mathrm{min}^{-1}$. Al observarse el pico característico (tiempo de detección 10-11 min) la MC-LR fue colectada manualmente a la salida del detector UV-DAD marca Shimadzu modelo 20A, a una longitud de onda de 238nm (Tabla 4).

Las fracciones obtenidas en cada corrida fueron reunidas y concentradas en Roto Vapor Metrolab a fin de eliminar los solventes orgánicos, la temperatura del baño termostático fue de $80^{\circ} \mathrm{C}$, el proceso se mantuvo hasta que no se observó más destilado en la columna. El concentrado fue llevado a pH 6 con hidróxido de sodio $(\mathrm{NaOH})$ 0,5 N.

Para realizar la purificación se realizó la corrida según el siguiente gradiente de elución.

Tabla 4. Gradiente utilizado en las corridas de purificación

\begin{tabular}{|llllll|}
\hline Tiempo $(\mathrm{min})$ & 0 & 5 & 10 & 20 & 30 \\
\hline Solución A (\%) & 65 & 65 & 45 & 65 & 65 \\
\hline Solución B (\%) & 35 & 35 & 55 & 35 & 35 \\
\hline
\end{tabular}




\subsection{Determinación de toxinas mediante Cromatografía liquida de alta performance (HPLC)}

Al extracto purificado se procedió a la cuantificación en un cromatógrafo liquido de alta performance (HPLC) de fase reversa con detector UV (HPLC-UV) (Shimadzu LC- 20A, SPD-M20A, Shimadzu Scientific Instruments, Columbia, MD, USA) con una columna C18 Thermo de $5-\mu \mathrm{m}$ poro, $150 \times 4,60 \mathrm{~mm}$, (Hypersil-Keystone). La columna fue equilibrada con una mezcla compuesta por $65 \%$ de solución $A[0,05 \%(\mathrm{v} / \mathrm{v})$ ácido trifluoracetico (TFA) en agua] y $35 \%$ de solución $B[0,05 \%(v / v)$ TFA en acetonitrilo]. La fase móvil consistió en gradiente discontinuo de solución A y B. La velocidad de flujo fue de $1 \mathrm{~mL} \cdot \mathrm{min}^{-1}$. Se utilizaron Standards de MIcrocistina-LR provenientes de Sigma (St Louis, MO, USA). La Microcistina fue identificada sobre la base del tiempo de retención. La detección UV fue realizada a 238nm (Giannuzzi y col., 2012).

\subsection{Determinación de MC-LR por ensayo de inhibición de Protein-fosfatasa (PP1)}

El método de inhibición de protein fosfatasa 1 (PP1), se basa en que la MC inhibe en forma específica la protein fosfatasa (PP1). Si la MC se encuentra degradada por la acción de cualquier producto oxidante, la inhibición de la PP1 es menor. La actividad de la protein fosfatasa (PP1) se determinó midiendo el color asociado con la producción a $37^{\circ} \mathrm{C}$ de p-nitrofenol a partir de $\mathrm{p}$ nitrofenilfosfato (p-NPP), midiendo la absorbancia a $405 \mathrm{~nm}$.

El sustrato de la enzima p-NPP, se disolvió en un buffer de reacción conteniendo: $25 \mathrm{mM}$ Imidazol, $\mathrm{pH} \quad 7,4,0.1 \mathrm{mg} \cdot \mathrm{mL}^{-1}$ BSA, $1 \mathrm{mM}$ DTT (Dithiothreitol), $50 \mathrm{mM} \mathrm{NaCl}$. La proteína-fosfatasa $1(\mathrm{PP} 1)$ se disolvió en el buffer de dilución: 25mM Imidazol, pH 7,4, 0,1 mg. $\mathrm{mL}^{-1} \mathrm{BSA}, 1 \mathrm{mM}$ DTT, $50 \mathrm{mM}$ $\mathrm{NaCl}, 2 \mathrm{mM} \mathrm{MnCl}$.

El ensayo se llevó a cabo sobre $20 \mu \mathrm{L}$ de buffer de reacción al que se le añadió $10 \mu \mathrm{L}$ de enzima y luego $50 \mu \mathrm{L}$ de muestra para incubar durante 10 minutos a $30^{\circ} \mathrm{C}$. Luego de ese tiempo, se añadió $20 \mu \mathrm{L}$ de sustrato. La producción de color se midió a $405 \mathrm{~nm}$, después de incubar a $30^{\circ} \mathrm{C}$ durante 1 hora (Bouaicha y col.,

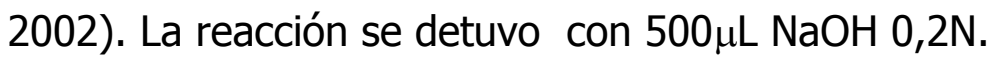

La absorbancia a 405nm se transformó en porcentaje de inhibición de la enzima Protein-fosfatasa 1 , asignando que no existe inhibición en el control negativo de cada ensayo, donde sólo está presente el sustrato $p$-nitrofenilfosfato ( $p$-NPP).

Sustrato: 10X mezcla de sustrato (10XSM): 250mM pNPP en buffer de reacción. 
Toda la manipulación de la enzima con los buffer y el agua destilada se realizó en baño de hielo hasta pre incubación. Además el sustrato una vez preparado fue protegió de la luz directa. La tabla 5 muestra el esquema de trabajo estandarizado en nuestro laboratorio para el ensayo de inhibición de la PP1.

Tabla 5. Esquema de trabajo para el ensayo de inhibición de la Protein fosfatasa 1 (PP1).

\begin{tabular}{|c|c|c|}
\hline & MUESTRA & BLANCO \\
\hline Enzima dil 1/20 & $5 \mu \mathrm{L}$ & - \\
\hline Buffer de reacción & $20 \mu \mathrm{L}$ & $20 \mu \mathrm{L}$ \\
\hline Muestra & $50 \mu \mathrm{L}$ & $50 \mu \mathrm{L}$ \\
\hline \multicolumn{3}{|l|}{$\begin{array}{l}\text { Preincubar a } 30-35^{\circ} \mathrm{C} \text { por } \\
10 \text { minutos }\end{array}$} \\
\hline \multicolumn{3}{|l|}{$\begin{array}{l}\text { Retirar el baño } \\
\text { termostático }\end{array}$} \\
\hline Sustrato & $20 \mu \mathrm{L}$ & $20 \mu \mathrm{L}$ \\
\hline \multicolumn{3}{|l|}{ Incubar a $35^{\circ} \mathrm{C}$ una hora } \\
\hline \multicolumn{3}{|l|}{$\begin{array}{l}\text { Retirar del baño } \\
\text { termostático }\end{array}$} \\
\hline Reactivo stop & $500 \mu \mathrm{L}$ & $500 \mu \mathrm{L}$ \\
\hline $\begin{array}{l}\text { Leer DO } 405 \mathrm{~nm} \text { (llevar a } 0 \\
\text { de absorbancia con } 600 \mu \mathrm{ll} \\
\text { RS) }\end{array}$ & & \\
\hline
\end{tabular}

\subsection{EFECTO DE OXIDANTES QUIMICOS SOBRE CULTIVO DE Microcystis aeruginosa Y MC-LR}

Entre los oxidantes convencionales el cloro es el agente representativo de la acción oxidante y sanitizante. Resulta conocido el efecto deletéreo de la acción del cloro sobre florecimientos o cultivos de Microcystis. Existen trabajos científicos que estudian el efecto del cloro sobre la remoción de altas concentraciones de MC-LR. Por ello es de interés estudiar el efecto del cloro sobre la remoción de bajas concentraciones de MC-LR como son las presentes en plantas potabilizadoras (Nicholson y col., 1994; Tsuji y col., 1997; Kull y col., 2004; Acero y col., 2005; Xagoraraki y col., 2006; Ho y col., 2006; Rodriguez y col., 2007). Esto abordara el presente trabajo de tesis.

Sin embargo el cloro presenta efectos nocivos al ponerse en contacto con materia orgánica debido a la formación de triahalometanos, por ello, otros oxidantes como el ácido peracetico se presentan como alternativas interesantes al cloro. Existe muy poca informacion referida a su acción sobre cultivos de cianobacterias como por ejemplo Microcystis aeruginosa y sus toxinas. Por ello, resulta interesante evaluar su acción sanitizante sobre microorganismos indicadores de contaminación fecal como es Escherichia coli. 


\subsubsection{Ensayos de remoción de MC-LR empleando cloro}

El efecto del cloro sobre la MC-LR se evaluó exponiendo soluciones acuosas con concentraciones de 10,20 y $50 \mu \mathrm{g} \cdot \mathrm{L}^{-1}$ de MC-LR a diversas concentraciones de cloro disuelto en dosis de $1,0,2,0$ y $5,0 \mathrm{mg} \cdot \mathrm{L}^{-1}$ de cloro libre a partir de soluciones con hipoclorito de sodio. Estas dosis fueron similares a las empleadas por las plantas potabilizadoras. De acuerdo con lo anterior, la relación de concentraciones de cloro libre a MC-LR será aproximadamente de 900 a 190.000 y la relación másica de cloro libre a toxina varió entre 60 y 13.000 .

Se partió el ensayo con la preparación de una solución madre de hipoclorito de sodio de $55 \mathrm{mg}^{-1} \mathrm{~L}^{-1}$ preparada a partir de una solución concentrada comercial con una concentración de $55 \mathrm{~g} \cdot \mathrm{L}^{-1}$, esta solución madre se preparó en un matraz tapado y mantenida a $4^{\circ} \mathrm{C}$ no más de 24 horas.

En un Erlenmeyer seco y limpio se mezclaron agua bidestilada con una solución purificada de MC-LR de $9 \mathrm{mg} \cdot \mathrm{L}^{-1}$ para obtener una concentración final de MC-LR de 10,20 y $50 \mu \mathrm{g} . \mathrm{L}^{-1}$ de MC-LR respectivamente. Finalmente se adicionó la solución madre de hipoclorito de sodio de $55 \mathrm{mg} \cdot \mathrm{L}^{-1}$ para obtener una concentración final de cloro en la solución de 1,0, 2,0 y 5,0 mg. $\mathrm{L}^{-1}$. El material de vidrio utilizado en los ensayos (Erlenmeyer, pipetas, vasos de precipitado y matraz) fueron lavados después de cada ensayo con jabón no iónico, agua destilada y secado en estufa a $120^{\circ} \mathrm{C}$ durante 24 horas antes de cada ensayo para evitar contaminaciones del material que pudieran interferir en los resultados. Este material de vidrio se separó y se utilizó únicamente para estos ensayos. La solución acuosa de MC-LR y cloro se mantuvieron en agitación constante hasta el final de cada ensayo.

Los tiempos de contacto fueron $0,1,20,40,60,80,100$ y 120 minutos, a los cuales se tomaron alícuotas del sistema neutralizando la acción del cloro con tiosulfato de sodio $0,1 \mathrm{~N}$ y se determinó la concentración de MC-LR remanente en la muestra mediante el ensayo de inhibición de la protein fosfatasa 1 (ver ítem 6).

En todos los tiempos de contacto se evaluó en forma simultanea el valor de cloro remanente el cual fue determinado mediante la técnica de DPD (dietil-pfenilen diamina) equivalente al método USEPA 330.5 para efluentes y al método 4500-Cl G del Standard Método para agua de bebida (APHA, 1994). La concentración de MC-LR remanente mediante ensayo de inhibición de la Protein-fosfatasa 1 (ver ítem 6). 


\subsubsection{Variación del pH sobre la efectividad del cloro y la degradación de MC-LR}

Para evaluar el efecto del pH sobre la degradación de MC-LR empleando cloro, las soluciones acuosas descritas en el ítem 7 a concentraciones de MC-LR de 10,20 y $50 \mu \mathrm{g} \cdot \mathrm{L}^{-1}$, concentraciones de cloro de 1,2 y $5 \mathrm{mg} \cdot \mathrm{L}^{-1}$ y tiempos de contacto de $0,1,20,40,60,80,100$ y 120 minutos fueron evaluadas a tres diferentes $\mathrm{pH}$ iniciales: $6,0,7,0$ y 8,0 . Para ello, el pH inicial se ajustó mediante el uso de soluciones de ácido clorhídrico $(\mathrm{HCl})$ e hidróxido de sodio $(\mathrm{NaOH})$ $0,01 \mathrm{M}$. Se neutralizó la acción del cloro con tiosulfato de sodio $0,1 \mathrm{~N}$ y se determinó la concentración de cloro mediante la técnica de DPD (dietil-p-fenilen diamina) y la de MC-LR remante en la muestra mediante la técnica de inhibición de la Protein fosfatasa 1 (PP1) (ítem 6).

\subsection{Efecto del ácido peracético sobre un cultivo de Microcystis aeruginosa}

El cultivo de trabajo de Microcystis aeruginosa en fase exponencial se preparó en Erlenmeyer estéril en medio $\mathrm{BG} 11_{0}$ a una temperatura de $27^{\circ} \mathrm{C} \pm 1$, sin agitación y ciclos de luz/oscuridad de 12/12 horas hasta alcanzar un rango de absorbancia entre 0,300 y 0,550 a $750 \mathrm{~nm}$.

En esta parte del trabajo se realizaron las correspondientes soluciones de trabajo de una solución comercial de ácido peracético, de tal modo que al mezclarlo con un volumen de cultivo de $M$. aeruginosa se obtuviera las siguientes concentraciones: $0,5,1,0,5,1015$ y $20 \mathrm{mg}^{-1} \mathrm{~L}^{-1}$. El cultivo tratado y el control se mantuvieron durante el ensayo a una temperatura de $27^{\circ} \mathrm{C} \pm 1$, sin agitación y ciclos de luz/oscuridad de 12/12 horas.

A los distintos tiempos de contacto $(0,1,2,3,4,8,24$ y 48 horas) se tomaron alícuotas del cultivo tratados y el control y se sometieron a la determinación de parámetros de crecimiento de cultivo como: turbidez (ítem 3.1), proteínas totales (ítem 3.2), clorofila (ítem 3.3), recuento celular (ítem 3.4), viabilidad celular por siembra en placa (ítem 3.5) y toxina mediante la técnica de cromatografía liquida de alta performance (HPLC); el proceso de extracción y cuantificación de toxina siguió el mismo protocolo expuesto en los ítems 4 y 5.

\subsection{Efecto del ácido peracético sobre la degradación de Microcistina-LR en solución acuosa}

Para evaluar el efecto oxidante del ácido peracético sobre la degradación de MC-LR se realizó un ensayo a una concentración de MC-LR de $20 \mu \mathrm{g} \cdot \mathrm{L}^{-1}$, una concentración 20 veces superior a la permitida por OMS en agua destinada al consumo humano. La concentración de MC-LR se midió mediante la técnica de inhibición de Protein fosfatasa 1 luego de la aplicación de una concentración de 
ácido peracético de $5 \mathrm{mg} \cdot \mathrm{L}^{-1}$ a $0,1,60,120$ y 180 minutos de tiempo de contacto. Para asegurar que el oxidante no siga actuando sobre la MC-LR y no afecte la enzima durante el ensayo de inhibición de la protein fosfatasa 1, para cada tiempo de contacto la muestra fue pasada por un cartucho Sep-Pack C18 (Waters) previamente activado con el fin de eliminar la mayor parte del oxidante y retener las toxinas en el filtro. La activación del cartucho siguió el procedimiento descripto en el ítem 4. Para este ensayo en un Erlenmeyer se agregó agua bidestilada y un volumen de MC-LR para obtener la concentración final deseada de $20 \mu \mathrm{g} \cdot \mathrm{L}^{-1}$ de MC-LR en solución acuosa. A la solución anterior se le agregó ácido peracético, de esta manera se obtuvo una solución final de trabajo con una concentración de ácido peracético en solución de $5 \mathrm{mg} \cdot \mathrm{L}^{-1}$.

\subsubsection{Efecto del pH sobre la degradación de MC-LR en solución acuosa utilizando una solución comercial de ácido peracético}

El efecto del pH sobre la degradación de Microcistina en solución acuosa se evaluó ajustando el pH con soluciones de ácido clorhídrico $(\mathrm{HCl})$ e hidróxido de sodio $(\mathrm{NaOH})$ 0,01M para lograr tres distintos $\mathrm{pH}(6,7$ y 8). A esta solución se agregó MC-LR en una concentración de $50 \mu \mathrm{g} \cdot \mathrm{L}^{-1}$ Seguidamente se agregó ácido peracético a una concentración de $10 \mathrm{mg}^{-1} \mathrm{~L}^{-1}$ y a diferentes tiempos de contacto de $0,1,20,40,60,80,100,120$ y 240 minutos se determinó la concentración de MC-LR remante en la muestra mediante la técnica de inhibición de la Protein fosfatasa 1 (PP1) (ítem 6).

\subsubsection{Neutralización del ácido peracético para la determinación de MC por ensayo de inhibición de Protein-fosfatasa 1 (PP1)}

Pruebas preliminares mostraron que el ácido peracético interfería en el ensayo de determinación de MC-LR por protein fosfatasa 1(como era de esperar, al tratarse de una enzima, susceptible no sólo de ser degradada, sino de ser afectada en su centro activo por oxidantes) por lo que se llevó a cabo la neutralización del mismo. Las muestras de Microcistina provenientes de cultivo y solución acuosa tratadas con ácido peracético a sus distintas concentraciones, se procesaron en cartuchos C18 (Waters), activados previamente según ítem 4. Luego de la activación del cartucho se eluyo la muestra, s por el cartucho y se procedió la elución según ítem 4. Esta neutralización del producto se realizó para todos los ensayos de Protein fosfatasa 1 y a todos los tiempos de contacto de los ensayos en los cuales se utilizó ácido peracético.

\subsection{Efecto del ácido Peracético sobre la viabilidad de $E$. coli}

Se partió de un cultivo de $E$. coli mantenido en caldo nutritivo, la composición del caldo nutritivo se muestra en la Tabla 2 . El recuento inicial de $E$. coli, se 
realizó mediante siembra en agar PCA (Plate Count Agar), la composición del medio PCA se muestra en la Tabla 6. Las diluciones necesarias para los ensayos se realizaron en agua peptonada $0,1 \%$. El método de siembra fue el Pour Plate Procedure, en el cual se sembró $1 \mathrm{~mL}$ de las diluciones hechas en agua peptonada $0,1 \%$ en placas de Petri vacías a las que se les agregó agar PCA fundido y tibio, homogenizando hasta su solidificación. Las placas se incubaron a $37^{\circ} \mathrm{C}$ durante 48 horas y los resultados se expresaron en UFC. $\mathrm{mL}^{-1}$.

Tabla 6. Composición del medio PCA (Plate Count Agar) para el recuento en placa de E. coli

\begin{tabular}{|cc|}
\hline Componentes & Concentración del Medio \\
\hline Peptona Caseína & $5 \mathrm{~g}$ \\
\hline Extracto de Levadura & $2,5 \mathrm{~g}$ \\
\hline Glucosa & $1 \mathrm{~g}$ \\
\hline Agar & $14 \mathrm{~g}$ \\
\hline Agua destilada (1000mL) & \\
\hline
\end{tabular}

Para evaluar la efectividad del ácido peracético sobre la viabilidad de $E$. coli, se colocaron $9 \mathrm{~mL}$ de un cultivo (107UFC. $\mathrm{mL}^{-1}$ ) en cuatro tubos rotulados de acuerdo a la concentración deseada $\left(0,5,10\right.$ y $\left.20 \mathrm{mg}^{-L^{-1}}\right)$ A partir de este agregado se cronometró los tiempos de contacto. A tiempos de contacto largos $(0,1,2,3$ y 4 horas) y para tiempos cortos $(0,1,2,3,4,5,10,15,20$ y $40 \mathrm{~min}$ ) se tomó una alícuota de $1 \mathrm{~mL}$, se traspasó a un eppendorf para detener la reacción del ácido peracético con tiosulfato se sodio $0,1 \mathrm{~N}$ estéril. La cantidad de tiosulfato adicionada se calculó de manera tal de mantener una relación 1:2 entre el oxidante y el tiosulfato respectivamente (Warner, 1988). Posteriormente se realizaron diluciones necesarias en agua peptona $0,1 \%$ y $1 \mathrm{~mL}$ de estas se sembró en placa de Petri vacía sobre la cual se vertió el medio PCA fundido y tibio, homogenizando suavemente hasta su solidificación. Las placas solidas se incubaron a $37^{\circ} \mathrm{C}$ durante 48 horas expresando los recuentos en UFC. $\mathrm{mL}^{-1}$.

\subsubsection{Efectividad del peracètico sobre $E$. coli en solución salina isotónica $0.9 \%$}

Sobre 1 litro de solución salina isotonica $0,9 \%$, se agregó $1 \mathrm{~mL}$ de un cultivo de E. coli $\left(10^{8} \mathrm{UFC} \cdot \mathrm{mL}^{-1}\right)$ a efectos de eliminar la matriz del caldo nutritivo sobre la efectividad del producto. Se eligió la solución salina isotónica $0,9 \%$ ya que mantiene las bacterias en condiciones fisiológicas óptimas sin cambiar la permeabilidad de la membrana y por tanto no interfiere en los recuentos finales. Sobre el litro de solución salina inoculada con $E$. coli, se le agregó una cantidad de ácido peracético en forma tal de obtener una concentración final de trabajo de $0,2,5,5,10,15$ y $20 \mathrm{mg} \cdot \mathrm{L}^{-1}$. 
A partir de este agregado se cronometró los tiempos de contacto. A cada tiempo de contacto $(2,10,20,30 \mathrm{~min})$ se tomó una alícuota de $1 \mathrm{~mL}$ y se traspasó a un eppendorf conteniendo tiosulfato $0,1 \mathrm{~N}$ a efectos de detener la acción oxidante. Luego de hacer las diluciones necesarias en agua peptonada $0,1 \%$ de la alícuota inactivada se agregó a una placa de Petry vacía sobre la cual se vertió el medio PCA fundido y tibio, homogenizando suavemente hasta su solidificación. Las placas solidas se incubaron a $37^{\circ} \mathrm{C}$ durante 48 horas expresando los recuentos en UFC. $\mathrm{mL}^{-1}$

Se aplicó el análisis estadístico ANOVA a efectos de evaluar la existencia de diferencias significativas empleando el programa SYSTAT. Para un nivel de significancia estadística de $p<0,05$ las diferencias fueron significativas. 


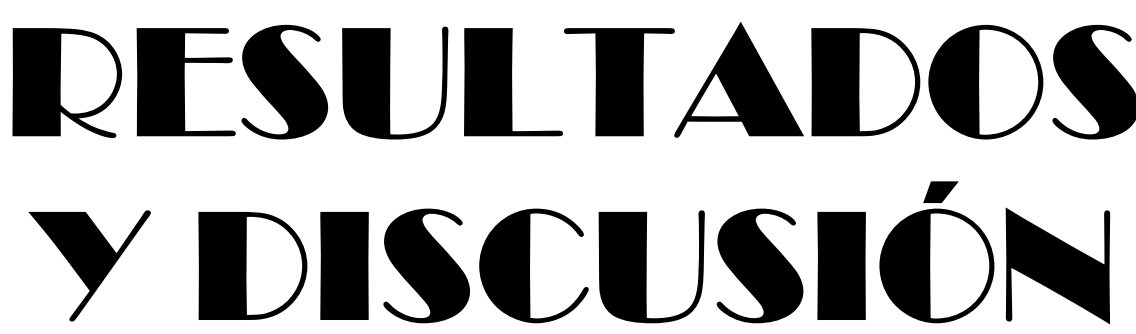




\subsubsection{Ensayos de remoción de MC-LR empleando cloro}

Entre los oxidantes convencionales el cloro es el agente representativo de la acción oxidante y sanitizante. Resulta conocido el efecto deletéreo de la acción del cloro sobre florecimientos o cultivos de Microcystis. Existen trabajos científicos que estudian el efecto del cloro sobre la remoción de altas concentraciones de MC-LR (Nicholson y col., 1994; Tsuji y col., 1997; Kull y col., 2004; Acero y col., 2005; Xagoraraki y col., 2006; Ho y col., 2006; Rodriguez y col., 2007; Merel y col., 2009). Por ello es de interés estudiar el efecto del cloro sobre la remoción de bajas concentraciones de MC-LR como son las presentes en plantas potabilizadoras. Esto abordará el presente trabajo de tesis.

Considerando que un cultivo de cianobacterias y el agregado de oxidante (cloro u otro) actúa degradando la materia orgánica, bacterias, cianobacterias, toxinas, etc; en la cual puede encontrarse predominantemente cianobacterias, resulta de interés evaluar la degradación de cloro que ocurre en forma simultánea. Por otra parte, en el ambiente, el curso de agua puede presentar un $\mathrm{pH}$ variable según las condiciones, por ello, el esquema de trabajo de la presentes tesis de Magister se realizó según los siguientes pasos.

En primer lugar se analizó el consumo de cloro a diferentes valores de $\mathrm{pH}(6,7$ y 8$)$, y concentraciones de cloro $(0,019,0,038$ y $0,095 \mathrm{mM})$, en los controles (sin el agregado de MC-LR) y a cada una de las concentraciones de MC-LR (10, 20 y $\left.50 \mu \mathrm{g} \cdot \mathrm{L}^{-1}\right)$. Los gráficos de consumo de cloro se expresaron en $\operatorname{Ln}\left(C / C_{0}\right)$ en función del tiempo de contacto en minutos.

\subsubsection{Cinética de la degradación de cloro}

La cinética de degradación de cloro muestra un decaimiento de la concentración de cloro en función del tiempo bajo diferentes condiciones iniciales, concentración de cloro inicial y pH.

Con el propósito de modelar el decaimiento de cloro en función del tiempo, se evaluaron varias cinéticas, encontrándose que la cinética de pseudo-primer orden fue la más apropiada.

$$
\frac{d C}{d t}=-K_{o} C \quad \text { ec. } 1
$$

Integrando la ecuación 1

$$
\ln \frac{C}{C o}=-K_{o} t
$$


Donde $\left(K_{0}\right)$ es la constante de decaimiento de pseudo primer orden $\left(\mathrm{min}^{-1}\right)$ con respecto al cloro, $C$ es la concentración de cloro al tiempo $(\mathrm{t}), C_{0}$ es la concentración inicial de cloro $\left(\mathrm{mg}^{-1} \mathrm{~L}^{-1}\right)$, y t es el tiempo (min). Empleando el modelo de regresión lineal, el valor de $\left(K_{0}\right)$ fue estimado mediante la representación de $\mathrm{Ln}(\mathrm{C} / \mathrm{Co})$ en función del tiempo. La ecuación propuesta fue aplicada exitosamente a los datos experimentales.

En primer lugar se aplicó la ecuación 2 a los datos experimentales correspondientes a la degradación de cloro sin agregado de MC-LR (control) a pH 6. Luego se aplicó la misma ecuación a la degradación de cloro en presencia de 10,20 y $50 \mu \mathrm{g} . \mathrm{L}^{-1} \mathrm{MC}-\mathrm{LR}$ a pH 6,7 y 8.

\subsubsection{CINETICA DE CLORO EN PRESENCIA DE MC- LR A TRES DIFERENTES PH: 6, 7 Y 8.}

\subsubsection{1.}

Degradación de cloro con distintos niveles iniciales de MC-LR a pH 6

La Figura $1 \mathrm{a}$, b c y d muestra el $\operatorname{Ln}\left(\mathrm{C} / \mathrm{C}_{0}\right)$ con respecto al tiempo para las tres concentraciones iniciales de cloro a pH 6 con una concentración de MC-LR de 0 , 10, 20 y $50 \mu \mathrm{g} . \mathrm{L}^{-1}$ respectivamente. En la Tabla 1 se muestran los parámetros cinéticos obtenidos al aplicar la ecuación 2 .

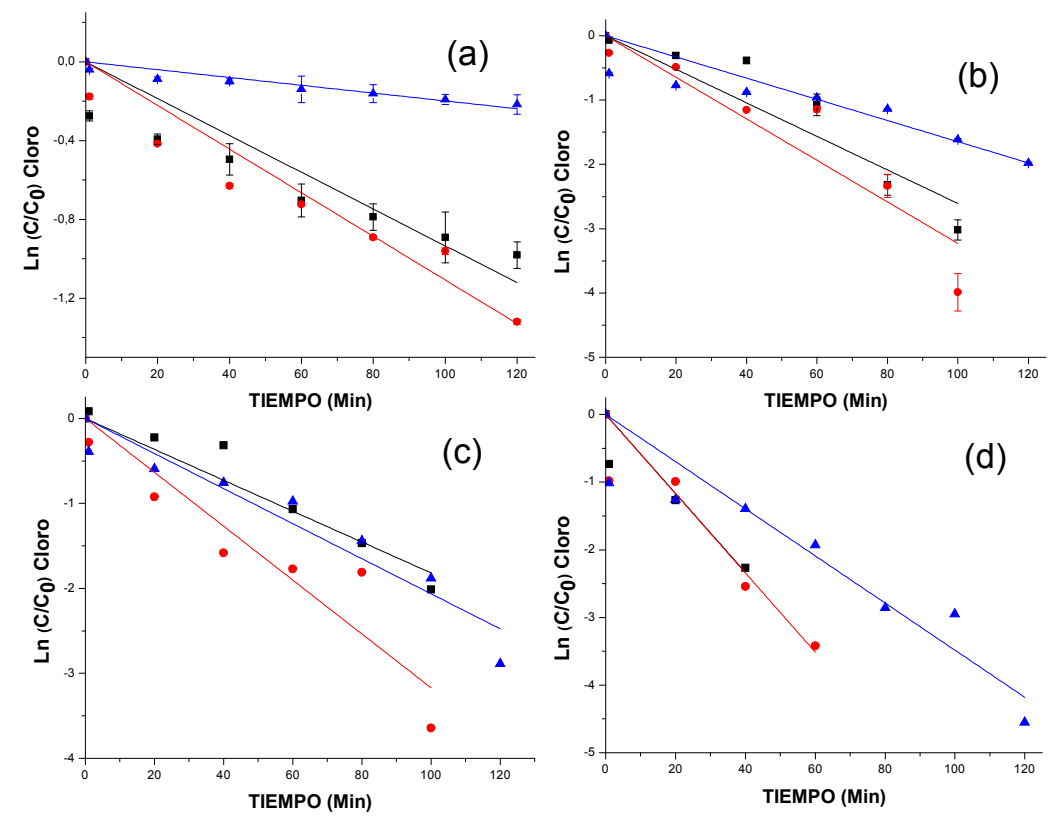

Figura 1. Cinética de degradación de cloro expresado como $\operatorname{Ln}\left(C / C_{0}\right)$ con respecto al tiempo para tres concentraciones de cloro inicial ( $(\mathbf{0} 0,019 \mathrm{mM}$, $-0,038 \mathrm{mM}, \Delta 0,095 \mathrm{mM}$ ) y diferentes concentraciones de MC-LR a) 0, b) $10, c$ ) 20 y d) $50 \mu g \cdot L^{-1}$ a $p H 6$ 
Tabla 1. Parámetros cinéticos de la degradación cloro a pH 6. Concentración de cloro inicial $(0,019,0,038$ y 0,095mM), concentración inicial de MC-LR (0, 10,20 y $50 \mu \mathrm{g} . \mathrm{L}^{-1}$ )

\begin{tabular}{|ccccc|}
\hline $\begin{array}{c}\text { MC-LR } \\
\left(\mu g \cdot L^{-1}\right)\end{array}$ & $\begin{array}{c}\text { CLORO } \\
(\mathrm{mM})\end{array}$ & $\mathrm{pH}$ & $K_{0} \mathrm{~min}^{-1}$ & $\mathrm{R}^{2}$ \\
\hline $\mathbf{0}$ & 0,019 & 6 & $0,009 \pm 0,001$ & 0,941 \\
\hline $\mathbf{0}$ & 0,038 & 6 & $0,011 \pm 0,001$ & 0,968 \\
\hline $\mathbf{0}$ & 0,095 & 6 & $0,001 \pm 0,001$ & 0,960 \\
\hline $\mathbf{1 0}$ & 0,019 & 6 & $0,018 \pm 0,003$ & 0,931 \\
\hline $\mathbf{1 0}$ & 0,038 & 6 & $0,032 \pm 0,003$ & 0,934 \\
\hline $\mathbf{1 0}$ & 0,095 & 6 & $0,016 \pm 0,002$ & 0,935 \\
\hline $\mathbf{2 0}$ & 0,019 & 6 & $0,026 \pm 0,001$ & 0,963 \\
\hline $\mathbf{2 0}$ & 0,038 & 6 & $0,032 \pm 0,003$ & 0,949 \\
\hline $\mathbf{2 0}$ & 0,095 & 6 & $0,021 \pm 0,001$ & 0,965 \\
\hline $\mathbf{5 0}$ & 0,019 & 6 & $0,058 \pm 0,009$ & 0,914 \\
\hline $\mathbf{5 0}$ & 0,038 & 6 & $0,059 \pm 0,006$ & 0,942 \\
\hline $\mathbf{5 0}$ & 0,095 & 6 & $0,035 \pm 0,003$ & 0,957 \\
\hline
\end{tabular}

Puede observarse que al aumentar la concentración de MC-LR a pH 6 las constantes de degradación de cloro $\left(K_{0}\right)$ resultan ser mayores.

El análisis de varianza (ANOVA) indico que la degradación de cloro en el control (sin MC-LR) no presento diferencias significativas $(p>0,05)$ a $\mathrm{pH} 6$ según la concentración de cloro utilizada. Por otra parte, con una concentración inicial de MC-LR de 10, 20 y $50 \mu \mathrm{g} . \mathrm{L}^{-1}$ se encontraron diferencias significativas entre la degradación de cloro y los diferentes tiempos de contacto a $\mathrm{pH} 6$ $(p<0,05)$. Al realizar el ANOVA para todo el tratamiento a $\mathrm{pH} 6$ se encontraron diferencias significativas $(p<0.05)$ entre los tratamientos con los diferentes niveles de cloro inicial y los tiempos de contacto, no así con los diferentes niveles de MC-LR inicial, ni en la interacción entre el tiempo y MC-LR ( $p>0.05)$ (ver anexo).

\subsubsection{Degradación de cloro con distintos niveles iniciales de MC-LR a pH 7}

La Figura $2 \mathrm{a}$, b c y $d$ muestra el $\operatorname{Ln}\left(\mathrm{C} / \mathrm{C}_{0}\right)$ con respecto al tiempo para las tres concentraciones iniciales de cloro a pH 7 con una concentración de MC-LR de 0 , 10, 20 y $50 \mu \mathrm{g} . \mathrm{L}^{-1}$ respectivamente. En la Tabla 2 se muestran los parámetros cinéticos obtenidos al aplicar la ecuación 2 . 

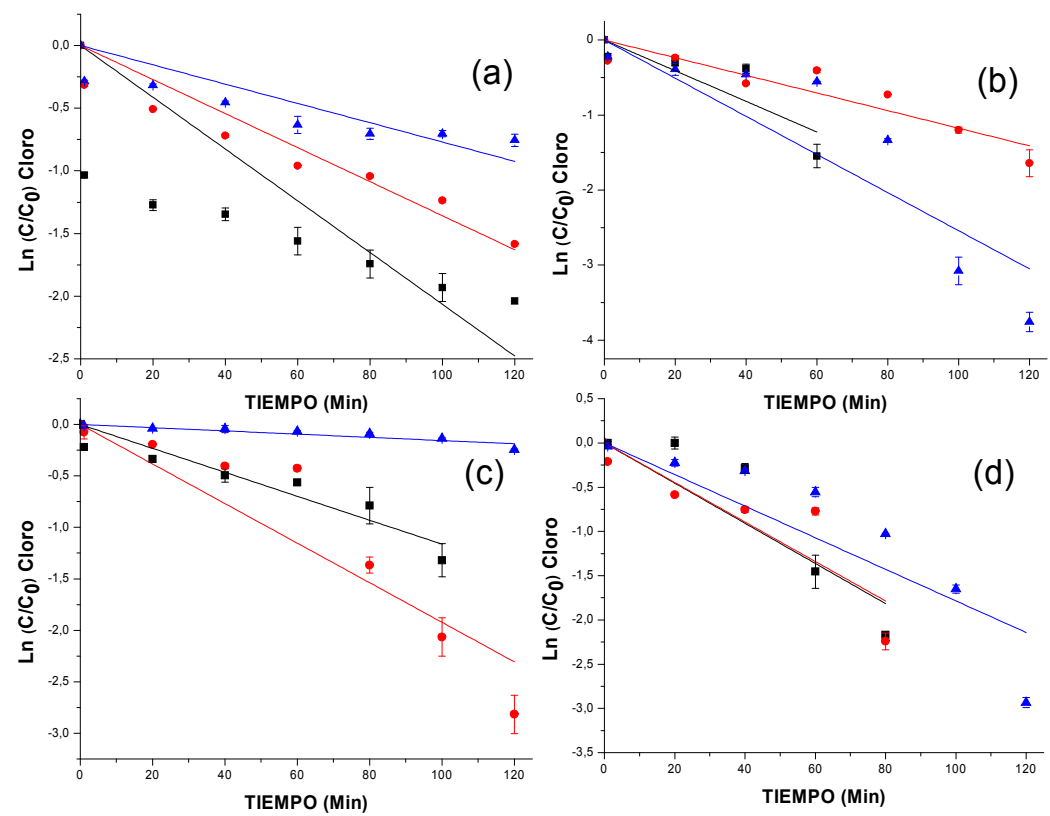

Figura 2. Cinética de degradación de cloro expresado como $\mathrm{Ln}\left(\mathrm{C} / \mathrm{C}_{0}\right)$ con respecto al tiempo para tres concentraciones de cloro inicial $(\mathbf{0} 0,019 \mathrm{mM}$, $\bullet 0,038 \mathrm{mM}, \Delta 0,095 \mathrm{mM}$ ) y diferentes concentraciones de MC-LR a) 0, b) 10, c) $20 \mathrm{yd}$ ) $50 \mu \mathrm{g} \cdot \mathrm{L}^{-1}$ a $\mathrm{pH} 7$

Tabla 2. Parámetros cinéticos de la degradación cloro a pH 7. Concentración de cloro inicial $(0,019,0,038$ y 0,095mM), concentración inicial de MC-LR (0, 10,20 y $\left.50 \mu \mathrm{g} . \mathrm{L}^{-1}\right)$

\begin{tabular}{|ccccc|}
\hline $\begin{array}{c}\text { MC-LR } \\
\left(\mu g . L^{-1}\right)\end{array}$ & $\begin{array}{c}\text { CLORO } \\
(\mathrm{mM})\end{array}$ & $\mathrm{pH}$ & $K_{0} \mathrm{~min}^{-1}$ & $\mathrm{R}^{2}$ \\
\hline $\mathbf{0}$ & 0,019 & 7 & $0,021 \pm 0,003$ & 0,860 \\
\hline $\mathbf{0}$ & 0,038 & 7 & $0,014 \pm 0,001$ & 0,964 \\
\hline $\mathbf{0}$ & 0,095 & 7 & $0,008 \pm 0,001$ & 0,904 \\
\hline $\mathbf{1 0}$ & 0,019 & 7 & $0,012 \pm 0,004$ & 0,839 \\
\hline $\mathbf{1 0}$ & 0,038 & 7 & $0,012 \pm 0,001$ & 0,941 \\
\hline $\mathbf{1 0}$ & 0,095 & 7 & $0,002 \pm 0,003$ & 0,887 \\
\hline $\mathbf{2 0}$ & 0,019 & 7 & $0,020 \pm 0,001$ & 0,956 \\
\hline $\mathbf{2 0}$ & 0,038 & 7 & $0,019 \pm 0,002$ & 0,920 \\
\hline $\mathbf{2 0}$ & 0,095 & 7 & $0,018 \pm 0,001$ & 0,928 \\
\hline $\mathbf{5 0}$ & 0,019 & 7 & $0,023 \pm 0,003$ & 0,874 \\
\hline $\mathbf{5 0}$ & 0,038 & 7 & $0,022 \pm 0,003$ & 0,890 \\
\hline $\mathbf{5 0}$ & 0,095 & 7 & $0,025 \pm 0,002$ & 0,889 \\
\hline
\end{tabular}

Puede observarse que al aumentar la concentración de MC-LR a pH 7 las constantes de degradación de cloro $\left(K_{0}\right)$ sufren variaciones que las hacen ir en aumento. 
Al elaborar el análisis de varianza para la degradación de cloro a pH 7, se encontraron diferencias significativas $(p>0,05)$ en la degradación de cloro del control (sin MC-LR). Para concentraciones de toxina inicial de 10 y $50 \mu \mathrm{g} \cdot \mathrm{L}^{-1}$ de $M C-L R$ se encontraron diferencias significativas $(p<0,05)$ entre la degradación de cloro y los tiempos de contacto. Para el caso de $20 \mu \mathrm{g} \cdot \mathrm{L}^{-1}$ de MC-LR inicial no se encontraron diferencias significativas entre la degradación de cloro y los tiempos de contacto. Al realizar el ANOVA para todos los datos de degradación de cloro a pH 7 se encontraron diferencias significativas $(p<0,05)$ entre los niveles de cloro y los tiempos de contacto, no así con los diferentes niveles de MC-LR ni en la interacción entre los tiempos de contacto y los niveles de MC-LR (ver anexo).

\subsubsection{Degradación de cloro a distintos niveles iniciales de MC-LR a pH 8}

La Figura 3 a, b c y d muestra el $\operatorname{Ln}\left(C / C_{0}\right)$ con respecto al tiempo para las tres concentraciones iniciales de cloro a pH 8 con una concentración de MC-LR de 0 , 10, 20 y $50 \mu \mathrm{g} . \mathrm{L}^{-1}$ respectivamente. En la Tabla 2 se muestran los parámetros cinéticos obtenidos al aplicar la ec 2 .
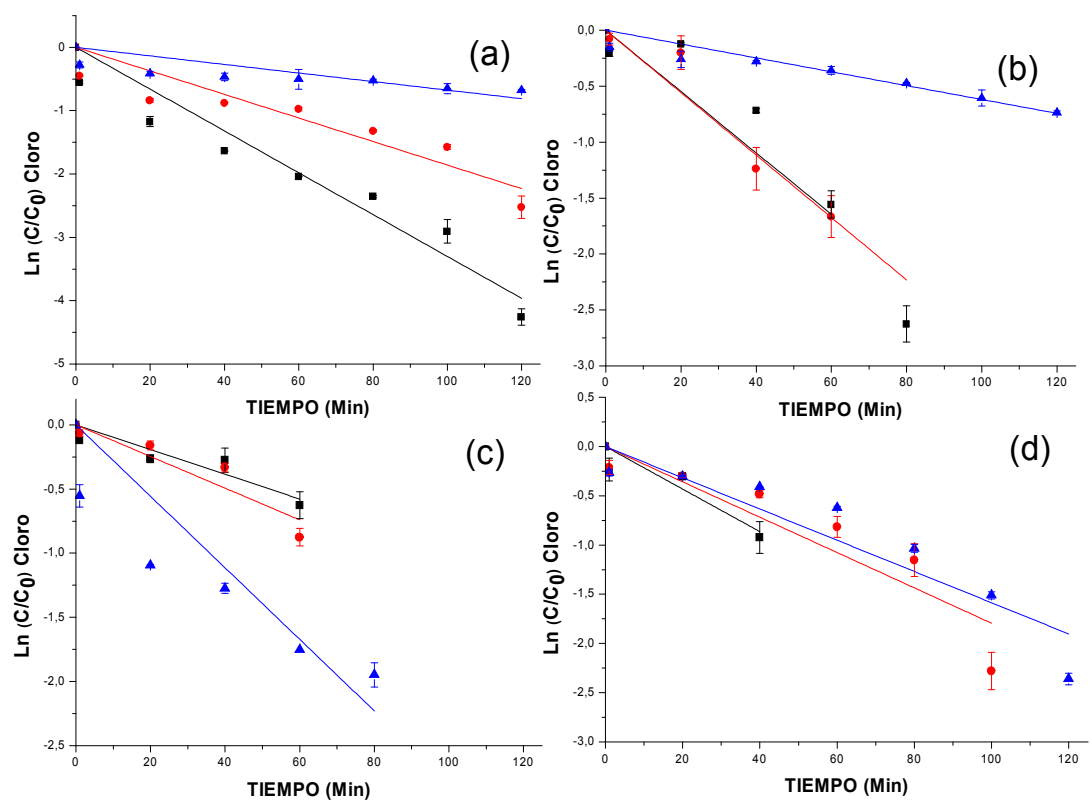

Figura 3. Cinética de consumo de cloro expresado como $L n\left(C / C_{0}\right)$ con respecto al tiempo para tres concentraciones de cloro inicial $(\square 0,019 \mathrm{mM}, 00,038 \mathrm{mM}$, $\Delta 0,095 \mathrm{mM}$ ) y diferentes concentraciones de $M C-L R$ a) 0, b) $10, c) 20$ yd) $50 \mu g . L^{-1}$ a $p H 8$

Tabla 3. Parámetros cinéticos de la degradación cloro a pH 8. Concentración de cloro inicial $(0,019,0,038$ y 0,095mM), concentración inicial de MC-LR $(0,10$, 20 y $\left.50 \mu g . \mathrm{L}^{-1}\right)$ 


\begin{tabular}{|ccccc|}
\hline $\begin{array}{c}M C-L R \\
\left(\mu g_{-L}{ }^{-1}\right)\end{array}$ & $\begin{array}{c}\text { CLORO } \\
(\mathrm{mM})\end{array}$ & $\mathrm{pH}$ & $K_{0} \mathrm{~min}^{-1}$ & $\mathrm{R}^{2}$ \\
\hline $\mathbf{0}$ & 0,019 & 8 & $0,033 \pm 0,002$ & 0,973 \\
\hline $\mathbf{0}$ & 0,038 & 8 & $0,019 \pm 0,002$ & 0,945 \\
\hline $\mathbf{0}$ & 0,095 & 8 & $0,007 \pm 0,001$ & 0,868 \\
\hline $\mathbf{1 0}$ & 0,019 & 8 & $0,010 \pm 0,003$ & 0,959 \\
\hline $\mathbf{1 0}$ & 0,038 & 8 & $0,012 \pm 0,003$ & 0,933 \\
\hline $\mathbf{1 0}$ & 0,095 & 8 & $0,006 \pm 0,001$ & 0,967 \\
\hline $\mathbf{2 0}$ & 0,019 & 8 & $0,022 \pm 0,001$ & 0,929 \\
\hline $\mathbf{2 0}$ & 0,038 & 8 & $0,018 \pm 0,002$ & 0,925 \\
\hline $\mathbf{2 0}$ & 0,095 & 8 & $0,016 \pm 0,003$ & 0,919 \\
\hline $\mathbf{5 0}$ & 0,019 & 8 & $0,027 \pm 0,003$ & 0,914 \\
\hline $\mathbf{5 0}$ & 0,038 & 8 & $0,028 \pm 0,002$ & 0,926 \\
\hline $\mathbf{5 0}$ & 0,095 & 8 & $0,028 \pm 0,001$ & 0,942 \\
\hline
\end{tabular}

Puede observarse al igual que en los resultados anteriores para $\mathrm{pH} 6$ y 7 , que al aumentar la concentración de MC-LR, en este caso a pH 8, las constantes de degradación de cloro $\left(K_{0}\right)$ resultan ser mayores.

En el análisis de varianza para la degradación de cloro a pH 8 no se encontraron diferencias significativas $(p>0,05)$ en dicha degradación, para el control (sin MC-LR). A su vez se encontraron diferencias significativas $(p<0,05)$ entre la degradación de cloro y los tiempos de contacto para los tres niveles iniciales de MC-LR $\left(10,20\right.$ y $\left.50 \mu \mathrm{g} \cdot \mathrm{L}^{-1}\right)$. Al realizar el ANOVA para el total de datos de degradación de cloro a $\mathrm{pH} 8$ se encontraron diferencias significativas $(p<0,05)$ entre los niveles de cloro y los tiempos de contacto, pero no entre los diferentes niveles de MC-LR, ni en la interacción entre los tiempos de contacto y los niveles de iniciales MC-LR (ver anexo).

Al realizar los análisis de varianza ANOVA para la totalidad de los datos para la degradación de cloro y el tiempo de contacto para los tratamientos control (Sin MC-LR) a todos los $\mathrm{pH}$ propuestos $(6,7$ y 8$)$, no se encontraron diferencias significativas $(p>0,05)$ entre la degradación de cloro en relación a los tiempos de contacto, $\mathrm{pH}$ ni en la interacción entre el tiempo y el pH (ver anexo).

Para el caso de la degradación de cloro con MC, una vez realizados los ANOVA para cada uno de los tres $\mathrm{pH}$ propuestos $(6,7$ y 8$)$, se procedió a analizar el conjunto de los datos. Este análisis de varianza evidenció diferencias significativas $(p<0,05)$ entre la degradación de cloro y los tiempos de contacto y la interacción entre la concentración inicial de $\mathrm{MC}$ y el $\mathrm{pH}$. A su vez, no se encontraron diferencias significativas $(p>0,05)$ entre los diferentes niveles de $\mathrm{pH}, \mathrm{MC}-\mathrm{LR}$ inicial, como tampoco entre las interacciones del tiempo de contacto 
y el $\mathrm{pH}$, tiempo y MC-LR ni en la interacción entre el tiempo de contacto, $\mathrm{pH}$ y MC-LR inicial (ver anexo).

Al analizar el modelo de degradación de cloro puede observarse que al aumentar la concentración de MC-LR las constantes de degradación de cloro $\left(K_{0}\right)$ resultan ser mayores. Se estudió la posible vinculación entre los valores de $K_{0}$ y los niveles iniciales de $\mathrm{pH}$. No se encontró una relación lineal entre los valores de $K_{0}$ con los niveles iniciales de cloro a los tres $\mathrm{pH}$ estudiados, por ello es probable que otras variables influyan en la degradación de cloro. Entre estas, resulta de interés evaluar la incidencia del ácido sin disociar (ácido hipocloroso) sobre la constante de degradación de cloro $\left(K_{0}\right)$.

\subsection{4. \\ Efecto de la concentración de ácido sin disociar (UAC) sobre la constante de degradación de cloro $\left(K_{0}\right)$}

Considerando que la degradación de cloro es dependiente del $\mathrm{pH}$ y de las concentraciones de MCs iniciales, se calculó el valor de la concentración de ácido sin disociar (ácido hipocloroso) (UAC) a efectos de evaluar la dependencia del UAC con respecto a la $K_{0}$ (constante de degradación de cloro). Para ello, se partió de la ecuación de Henderson-Hasselbalch la cual considera la ionización de un ácido débil (HA) con el valor de pKa. Esta ecuación relaciona el pH de una disolución de un ácido débil con su pKa y con el grado de ionización como se expresa en la siguiente ecuación, donde $K_{d}$ es la constante de disociación, $\left[\mathrm{ClO}^{-}\right.$es la concentración del anión hipoclorito] (UAC) es la concentración del ácido sin disociar, el ácido hipocloroso y $[\mathrm{H}+]$ es la concentración de hidrogeniones.

$$
=\frac{[\mathrm{l}]}{[\mathrm{]}} \quad \text { Ec } 3 .
$$

Reordenando la ec 3 se obtiene la siguiente ecuación para el cálculo del UAC.

$$
=\frac{[\quad]}{[]} \text {. Ec. } 4 \text {. }
$$

Donde UAC es la concentración de ácido sin disociar, CA es la concentración inicial de Hipoclorito de sodio en $\mathrm{mM},\left[\mathrm{H}^{+}\right]$es la concentración de hidrogeniones y $K d$ es la constante de disociación del ácido hipocloroso $(7,53)$.

En la Tabla 4 se resume (presentados en las Tablas 1, 2 y 3), la concentración de ácido sin disociar (UAC), el pH, la concentración inicial del cloro y la concentración inicial de MC-LR. 
Tabla 4. Concentración de MC-LR inicial, concentración inicial de cloro, $\mathrm{pH}$, concentración de ácido sin disociar UAC y la $K_{0}$ (constante de degradación de cloro)

\begin{tabular}{|ccccc|}
\hline $\begin{array}{c}\text { MC-LR } \\
\left(\mu g . L^{-1}\right)\end{array}$ & $\begin{array}{c}\text { CLORO } \\
(\mathrm{mM})\end{array}$ & $\mathrm{pH}$ & $\begin{array}{c}\text { UAC } \\
(\mathrm{mM})\end{array}$ & $\begin{array}{c}K_{0} \mathrm{~min}^{-1} \\
(\mathrm{Cl} / \mathrm{r} \text { ) }\end{array}$ \\
\hline $\mathbf{1 0}$ & 0,019 & 6 & 0,018 & 0,018 \\
\hline $\mathbf{1 0}$ & 0,038 & 6 & 0,037 & 0,032 \\
\hline $\mathbf{1 0}$ & 0,095 & 6 & 0,092 & 0,016 \\
\hline $\mathbf{2 0}$ & 0,019 & 6 & 0,018 & 0,026 \\
\hline $\mathbf{2 0}$ & 0,038 & 6 & 0,037 & 0,032 \\
\hline $\mathbf{2 0}$ & 0,095 & 6 & 0,092 & 0,021 \\
\hline $\mathbf{5 0}$ & 0,019 & 6 & 0,018 & 0,058 \\
\hline $\mathbf{5 0}$ & 0,038 & 6 & 0,037 & 0,059 \\
\hline $\mathbf{5 0}$ & 0,095 & 6 & 0,092 & 0,035 \\
\hline $\mathbf{1 0}$ & 0,019 & 7 & 0,015 & 0,012 \\
\hline $\mathbf{1 0}$ & 0,038 & 7 & 0,029 & 0,012 \\
\hline $\mathbf{1 0}$ & 0,095 & 7 & 0,073 & 0,002 \\
\hline $\mathbf{2 0}$ & 0,019 & 7 & 0,015 & 0,020 \\
\hline $\mathbf{2 0}$ & 0,038 & 7 & 0,029 & 0,019 \\
\hline $\mathbf{2 0}$ & 0,095 & 7 & 0,073 & 0,018 \\
\hline $\mathbf{5 0}$ & 0,019 & 7 & 0,015 & 0,023 \\
\hline $\mathbf{5 0}$ & 0,038 & 7 & 0,029 & 0,022 \\
\hline $\mathbf{5 0}$ & 0,095 & 7 & 0,073 & 0,025 \\
\hline $\mathbf{1 0}$ & 0,019 & 8 & 0,005 & 0,010 \\
\hline $\mathbf{1 0}$ & 0,038 & 8 & 0,010 & 0,012 \\
\hline $\mathbf{1 0}$ & 0,095 & 8 & 0,024 & 0,006 \\
\hline $\mathbf{2 0}$ & 0,019 & 8 & 0,005 & 0,022 \\
\hline $\mathbf{2 0}$ & 0,038 & 8 & 0,010 & 0,018 \\
\hline $\mathbf{2 0}$ & 0,095 & 8 & 0,024 & 0,016 \\
\hline $\mathbf{5 0}$ & 0,019 & 8 & 0,005 & 0,027 \\
\hline $\mathbf{5 0}$ & 0,038 & 8 & 0,010 & 0,028 \\
\hline $\mathbf{5 0}$ & 0,095 & 8 & 0,024 & 0,028 \\
\hline & & & & \\
\hline
\end{tabular}

La dependencia de la constante de degradación de cloro $\left(K_{0}\right)$ con la concentración de ácido sin disociar (UAC) a diferentes niveles iniciales de MC-LR se presenta a continuación en la Figura 4. 

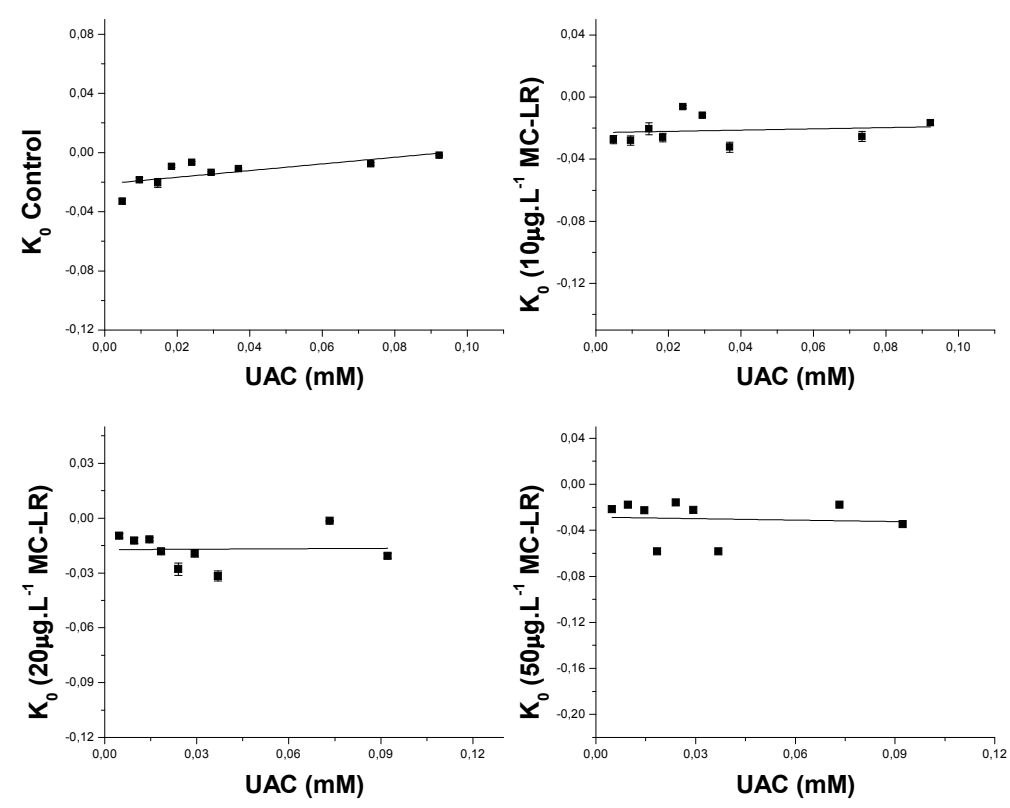

Figura 4. Variación de la constante de degradación de cloro $\left(K_{0}\right)$ con respecto a la concentración de ácido sin disociar (UAC) para diferentes niveles de MC-LR (a) Control, (b) $10 \mu \mathrm{g} \cdot \mathrm{L}^{-1}$, (c) $20 \mu \mathrm{g} \cdot \mathrm{L}^{-1}$ y (d) $50 \mu \mathrm{g} \cdot \mathrm{L}^{-1}$

Se puede observar que el consumo de cloro en los tratamientos varía a medida que la concentración inicial de MC-LR es mayor. Se observa una relación lineal entre los valores $K_{0}$ y los niveles de UAC para cada nivel de MC-LR inicial cuyas pendientes, resultan ser positivas, con excepción del tratamiento con la concentración más alta de MC-LR, como se muestra la Tabla 5. Se observa que para cada valor de MC-LR inicial a mayor UAC las $K_{0}$ son menores, lo que indica que el cloro se degrada con menor velocidad.

Tabla 5. Relación entre UAC y $K_{o}$ para los tratamientos con 10,20 y $50 \mu \mathrm{g} \cdot \mathrm{L}^{-1}$

\begin{tabular}{|cc|}
\hline MC-LR & Pendiente \\
\hline $\mathbf{1 0} \mathbf{\mu g} \cdot \mathbf{L}^{-1}$ & 0,040 \\
\hline $\mathbf{2 0} \mathbf{\mu g} \cdot \mathbf{L}^{-1}$ & 0,008 \\
\hline $\mathbf{5 0} \mathbf{\mu g} \cdot \mathbf{L}^{-\mathbf{1}}$ & $-0,042$ \\
\hline
\end{tabular}

La especie reaccionante más importante para la oxidación de MC-LR en solución acuosa es el ácido hipocloroso $(\mathrm{HOCl})$ y otra especie como el anión hipoclorito $\left(\mathrm{OCl}^{-}\right)$tiene menor participación en la oxidación de la toxina, razón por la cual no es tenido en cuenta como oxidante en este ensayo, al igual que fue demostrado en trabajos anteriores como el de Acero y col 2005, donde se afirma que la principal especie oxidante es el ácido hipocloroso sobre todo a pH menores a 9, esto se evidenció gracias a que el ácido hipocloroso es la principal especie electrofilica, por lo tanto la reactividad y participación del anión hipoclorito puede considerarse despreciable . 
Lo descrito en el párrafo anterior indica que a concentraciones mayores, en este caso con $50 \mathrm{\mu gL}^{-1} \mathrm{MC}$-LR pequeñas variaciones de UAC representa mayores variaciones sobre los valores de $K_{0}$ en comparación con lo obtenido para concentraciones menores 10 y $20 \mu \mathrm{g} . \mathrm{L}^{-1}$ de MC-LR.

El pH mantiene un efecto directo sobre la degradación de cloro ya que afecta el grado de protonación sobre las fracciones de MC-LR como las aminas neutras y los grupos fenólicos. Esto sugiere que un aumento en el $\mathrm{pH}$ reduce la mayor especie reactiva del cloro, en este caso el ácido hipocloroso. En resumen, la reacción del cloro con la MC-LR es controlada por una compleja interacción entre las especies de cloro presentes, el $\mathrm{pH}$, la estructura de la molécula de MC-LR y la fracción de ruptura o disociación de los grupos funcionales de la toxina.

Algunos autores afirman que dada la relación entre las concentraciones de cloro y MC-LR, esta relación se debe asumir constante durante el transcurso de los ensayos, es decir que el cloro no varía su concentración durante el transcurso del experimento (Nicholson, 1994; Tsuji, 1997; Acero, 2005; Xagoraraki, 2006), sin embargo, en nuestras condiciones de trabajo se pudo observar que el cloro sufre variaciones que deben ser consideradas en la remoción de cianotoxinas.

Este aspecto importante en los ensayos de remoción de toxina es fundamental para llegar de una manera más precisa, segura y eficiente a los valores máximos permitidos por la OMS para este tipo de toxinas $\left(1 \mu \mathrm{g} \cdot \mathrm{L}^{-1}\right)$. Muchos trabajos al respecto desprecian estas variaciones o las asumen constantes debido a que trabajan con concentraciones de MC-LR más altas (del orden de $\left.\mathrm{mg} \cdot \mathrm{L}^{-1}\right)$.

Nicholson, 1994, realizó los ensayos de cloración en un rango de concentración de cloro entre 0 y $30 \mathrm{mg}^{-L^{-1}}$ y una concentración de MC-LR entre 4 y $192 \mu \mathrm{g} \cdot \mathrm{L}^{-1}$, el tiempo de contacto para una completa degradación de MC-LR fue de 30 minutos manteniendo un pH menor a 8, la relación entre cloro y MC estuvo en un rango entre 146,52 y 1904,7. Tsuji, 1997, manejó concentraciones de cloro entre $0,7-2,8 \mathrm{mg} \cdot \mathrm{L}^{-1}$ y la concentración inicial de trabajo de MC-LR fue de $10 \mathrm{mg} \cdot \mathrm{L}^{-1}$ con una relación cloro- MC-LR entre 0,76 y 4,10. Hart 1998, trabajó con concentraciones de toxina inicial de $6,9 \mu \mathrm{g} \cdot \mathrm{L}^{-1}$ y aplicando una dosis de cloro de $1,7 \mathrm{mg} . \mathrm{L}^{-1}$ y una relación cloro-MC-LR de 4692,89, a pH 5 logrando una degradación de toxina del $93 \%$ a 30 minutos de tiempo de contacto. Para lograr esa misma degradación a pH 9 el tiempo de contacto necesario fue de 22 horas. Bruchet, 1998, observó degradaciones de $80 \%$ con $1 \mathrm{mg}^{-L^{-1}}$ inicial de cloro y una concentración de toxina de $500 \mu \mathrm{g} \cdot \mathrm{L}^{-1}$, y la relación entre cloro y MCLR fue de 38 para dos horas de tiempo de contacto. Carmichael, 2001, empleó 
un rango de concentraciones iniciales de cloro de $1-3 \mathrm{mg} \cdot \mathrm{L}^{-1}$ y concentraciones de MC-LR entre 1 y $17 \mu \mathrm{g} . \mathrm{L}^{-1}$ y una relación cloro-MC-LR de 3361,34 a 19047,61. Xagoraraki, 2006, realizó los ensayos de remoción de MC-LR con concentraciones de cloro de 1,3 y $9 \mathrm{mg} \cdot \mathrm{L}^{-1}$ y concentraciones de MC-LR de 1,2 y $8 \mu \mathrm{g} \cdot \mathrm{L}^{-1}$ en este caso la relación cloro- MC-LR fue de 21428 a 24761 . Acero, 2005, desarrolló en su trabajo un rango de concentración de cloro entre 49 $223 \mu \mathrm{M}\left(2,5-11,7 \mathrm{mg}^{-L^{-1}}\right)$ de cloro y un rango de concentración de MC-LR entre $1,5-3,5 \mathrm{mg} \cdot \mathrm{L}^{-1}$, en este caso la relación de cloro-MC-LR fue 32 a 63,7 , esta relación se propuso para evitar pasos de pre concentración de muestras.

En nuestras condiciones de trabajo se observó que la cinética de consumo de cloro cambia en función de la concentración de cloro inicial, el agregado de MC$\mathrm{LR}$ y el $\mathrm{pH}$, al contrario de los trabajos hechos por otros autores donde no se tiene en cuenta esta variación. En esta tesis de Magister la concentración de cloro fue mayor con respecto a la concentración de MC-LR, siendo relación de concentraciones de cloro libre a MC de 1900. Nuestro rango de trabajo de cloro fue 1,2 y $5 \mathrm{mg}^{-1} \mathrm{~L}^{-1}(0,019,0,038$ y $0,095 \mathrm{mM})$ y el de MC fue de 10,20 y $50 \mu \mathrm{g} . \mathrm{L}^{-1}$. Resulta importante recalcar que los trabajos anteriormente mencionados, no se ha vinculado la concentración de ácido sin disociar (UAC) con las constantes de degradación, lo cual es importante si se quiere llegar a los valores guías en la degradación de Microcistinas para agua de consumo. Otro aspecto a considerar es la degradación de MC-LR por cloro durante los ensayos, este aspecto se aborda en el próximo punto.

\subsection{Cinéticas de remoción de MC-LR y cloro}

La cinética de los experimentos de oxidación de MC-LR con cloro fue conducido a temperatura constante $\left(25^{\circ} \mathrm{C}\right)$. Las concentraciones iniciales de cloro fueron $0,019,0,038$ y 0,095mM, las concentraciones iniciales de MC-LR fueron 10, 20 y $50 \mu \mathrm{g} \cdot \mathrm{L}^{-1}$ y el rango de $\mathrm{pH}$ fue de 6,7 y 8.

La concentración de MC-LR mostro una disminución en función del tiempo para los diferentes niveles de cloro estudiados y los diferentes pH (Fig. 5, 6 y 7). Con el propósito de modelar la cinética de degradación de MC-LR en función del tiempo, se evaluaron varios ajustes a estas cinéticas encontrándose que un modelo exponencial decreciente fue el más apropiado, el cual es representado en la siguiente ecuación:

$$
=+(\quad) \quad \text { Ec. } 5
$$

Donde $\left(K_{1}\right)$ es la tangente al tiempo cero, lo que equivale a la constante de degradación de MC-LR a concentración y tiempo inicial, $C_{0}$ es la concentración inicial de MC-LR, $t$ es el tiempo y $A$ es una constante del modelo exponencial. Otro parámetro a considerar fue el tiempo en el cual la concentración de MC- 
LR es reducida a la mitad con respecto a la concentración inicial MC-LR $\left(\mathrm{t}_{1 / 2}\right)$. Empleando el modelo de ajuste exponencial (Ec. 5), el valor de $\left(K_{1}\right)$ fue estimado mediante la representación de la [MC-LR] en función del tiempo. La ecuación propuesta fue aplicada exitosamente a los datos experimentales.

La velocidad de oxidación de MC-LR por el cloro se puede predecir con la siguiente ecuación:

$$
=[\quad][\quad] \quad \text { Ec } 6 \text {. }
$$

Donde $r$ es la velocidad de la reacción, $K$ es la constante de velocidad de la reacción, [MC-LR] es la concentración de MC-LR, [Cloro] es la concentración de Cloro. Los índices $x$ e $y$ son los órdenes de la reacción para la degradación de cada reactivo. Esto aplica para las situaciones en las cuales el oxidante, en este caso el cloro está en exceso.

Como la concentración de cloro se encuentra en exceso con respecto a la de MC-LR, la ecuación 6 se puede dividir o simplificar en dos ecuaciones subsiguientes.

$$
\begin{array}{ll}
=\left[\begin{array}{ll} 
&
\end{array}\right] & \text { Ec 7. } \\
=[ & \text { Ec } 8 .
\end{array}
$$

Donde $K_{1}$ es la constante de pseudo-primer orden, [MC-LR] es la concentración de MC-LR y $x$ es el orden de la reacción. Para la ecuación 8 , ya fue definida $K_{1}$ como la constante de pseudo-primer orden, $K$ es la constante de velocidad de toda la reacción, [cloro] es la concentración de cloro e $y$ es el orden de la reacción.

De la ecuación 5 se deduce el tiempo de degradación media según la siguiente ecuación

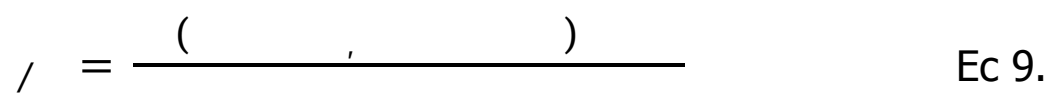

MC-LR $\mathrm{L}_{0,5}$ corresponde a la mitad de la concentración inicial es decir para una concentración inicial de 10,20 y $50 \mu \mathrm{g} . \mathrm{L}^{-1}$ corresponde a 5,10 y $25 \mu \mathrm{g} \cdot \mathrm{L}^{-1}$. MC$L R_{0}$ es la concentración inicial de MC-LR $\left(10,20\right.$ y $\left.50 \mu \mathrm{g} \cdot \mathrm{L}^{-1}\right) A$ y $K_{1}$ son definidos en la ecuación 5.

\subsubsection{Degradación de MC-LR a pH 6}

En la Figura 5 a, b, y c se puede observar la cinética de degradación de MC-LR $\left(10,20\right.$ y $\left.50 \mu \mathrm{g} \cdot \mathrm{L}^{-1}\right)$ en presencia de cloro $(0,019,0,038$ y $0,095 \mathrm{mM})$ a $\mathrm{pH} 6$. Puede observarse un buen ajuste de los datos experimentales al modelo propuesto. En la Tabla 6 se presenta los parámetros obtenidos del ajuste exponencial para los tratamientos realizados de cloro. El valor de $\mathrm{R}^{2}$ vario entre 0,934 y 0,986 lo que indica un buen ajuste del modelo propuesto. $K_{1}$ 
corresponde a la constante de primer orden para la degradación de MC-LR y el parámetro de $r_{0}$, es la velocidad de la reacción al tiempo cero.
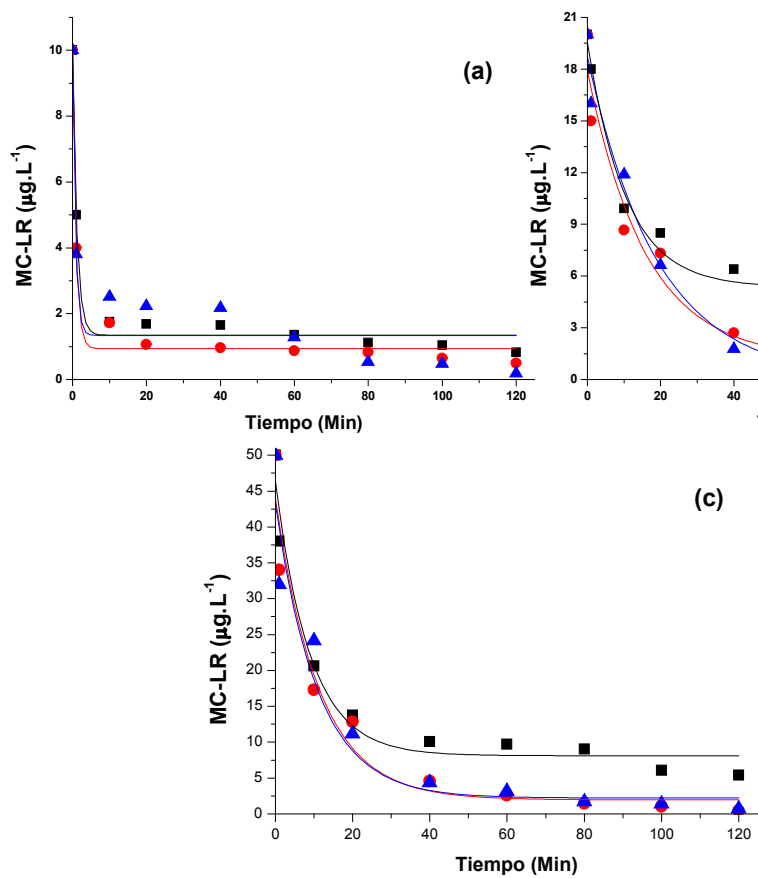

(b)

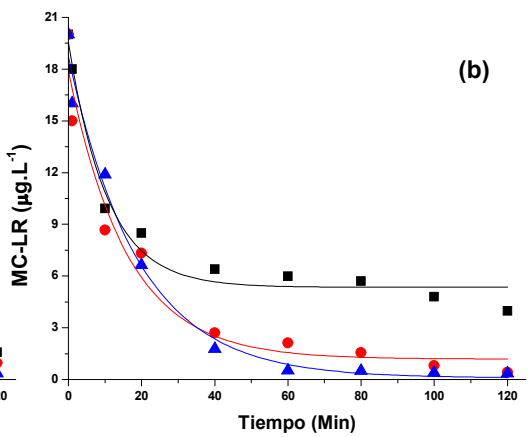

(c)

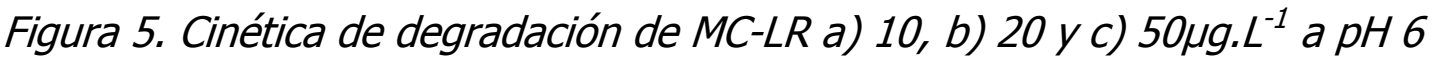
para tres concentraciones de cloro $(\mathbf{\square} 0,019 \mathrm{mM},-0,038 \mathrm{mM}, \mathbf{\Delta} 0,095 \mathrm{mM})$

Tabla 6. Parámetros de ajuste exponencial para la degradación de tres concentraciones de MC-LR 10, 20 y $50 \mu \mathrm{g} . \mathrm{L}^{-1}$ y tres concentraciones iniciales de cloro $(0,019,0,038$ y $0,095 \mathrm{mM})$ a $\mathrm{pH} 6$

\begin{tabular}{|c|c|c|c|c|c|c|}
\hline $\begin{array}{c}\text { MC-LR } \\
\left(\mu g \cdot L^{-1}\right)\end{array}$ & $\begin{array}{c}\text { CLORO } \\
(\mathrm{mM})\end{array}$ & $\mathrm{pH}$ & $K_{1}\left(\mathrm{~min}^{-1}\right)$ & $r_{0}\left(\mu g \cdot L_{\cdot} \min ^{-1}\right)$ & $\begin{array}{c}t_{1 / 2} \\
(\mathrm{~min})\end{array}$ & $\mathbf{R}^{2}$ \\
\hline 10 & 0,019 & 6 & 0,862 & $8,618 \pm 0,109$ & 1,001 & 0,986 \\
\hline 10 & 0,038 & 6 & 1,085 & $10,853 \pm 0,138$ & 0,740 & 0,984 \\
\hline 10 & 0,095 & 6 & 1,258 & $12,582 \pm 0,422$ & 0,684 & 0,978 \\
\hline 20 & 0,019 & 6 & 0,111 & $2,220 \pm 0,005$ & 7,292 & 0,968 \\
\hline 20 & 0,038 & 6 & 0,088 & $1,760 \pm 0,014$ & 7,274 & 0,955 \\
\hline 20 & 0,095 & 6 & 0,093 & $1,860 \pm 0,007$ & 6,788 & 0,983 \\
\hline 50 & 0,019 & 6 & 0,058 & $2,900 \pm 0,022$ & 14,073 & 0,965 \\
\hline 50 & 0,038 & 6 & 0,052 & $2,600 \pm 0,021$ & 11,550 & 0,945 \\
\hline 50 & 0,095 & 6 & 0,063 & $3,150 \pm 0,026$ & 9,335 & 0,934 \\
\hline
\end{tabular}

La tabla 6 nos muestra que a medida que aumenta la concentración de MC-LR los $t_{1 / 2}$ se hacen más largos, el $R^{2}$ del ajuste es bueno, con un rango entre 0,934 y 0,986 para las condiciones establecidas a pH 6 y la velocidad de la reacción $r_{0}$ varía al cambiar la relación entre las concentraciones de cloro y MCLR, lo que se explicará mejor en el análisis de la tabla 10. 
El análisis de varianza (ANOVA) para la degradación de MC-LR a pH 6 demostró diferencias significativas $(p<0,05)$ entre la remoción de MC-LR y los tiempos de contacto para todos los niveles iniciales de MC-LR $\left(10,20\right.$ y $\left.50 \mu \mathrm{g} \cdot \mathrm{L}^{-1}\right)$. Luego se realizó el ANOVA para la totalidad de los datos a este $\mathrm{pH}$, encontrando diferencias significativas $(p<0,05)$ entre la degradación de MC-LR y los tiempos de contacto, pero no con los diferentes niveles de cloro, ni entre la interacción del tiempo de contacto y el cloro inicial a pH 6 (ver anexo).

\subsubsection{Degradación de MC-LR a pH 7}
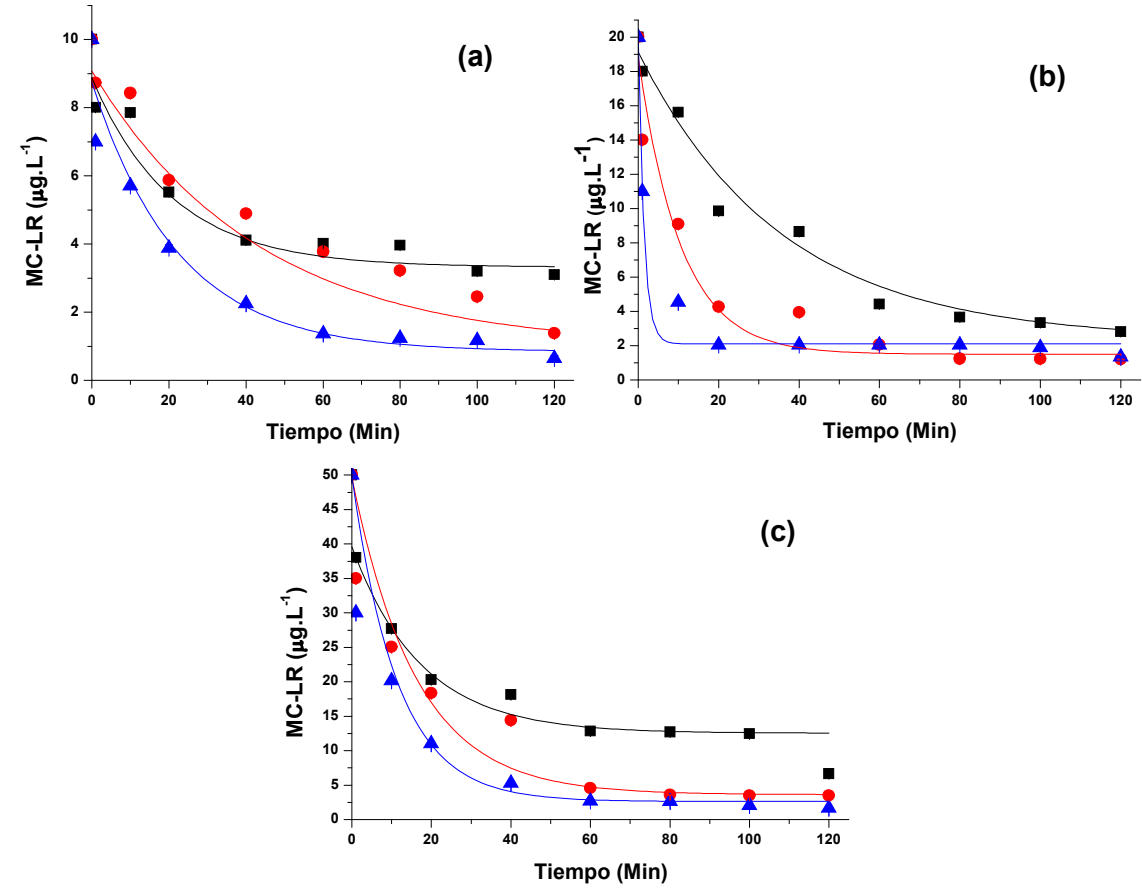

Figura 6. Cinética de degradación de MC-LR a) 10, b) 20 y c) $50 \mu \mathrm{g} \cdot \mathrm{L}^{-1}$ a $\mathrm{pH} 7$ para tres concentraciones de cloro $(\square 0,019 \mathrm{mM}, 00,038 \mathrm{mM}, \mathbf{\Delta} 0,095 \mathrm{mM})$

Tabla 7. Parámetros de ajuste exponencial para la degradación de MC-LR 10, 20 y $50 \mu \mathrm{g} \cdot \mathrm{L}^{-1}$ y tres concentraciones de cloro $(0,019,0,038$ y $0,095 \mathrm{mM})$ a $\mathrm{pH} 7$

\begin{tabular}{|c|c|c|c|c|c|c|}
\hline $\begin{array}{l}\text { MC-LR } \\
\left(\mu g \cdot L^{-1}\right)\end{array}$ & $\begin{array}{l}\text { CLORO } \\
(\mathrm{mM})\end{array}$ & pH & $K_{1}\left(\min ^{-1}\right)$ & $r_{0}(\mu g \cdot$ L.min & $\begin{array}{c}t_{1 / 2} \\
(\mathrm{~min})\end{array}$ & $\mathbf{R}^{2}$ \\
\hline 10 & 0,019 & 7 & 0,035 & $0,350 \pm 0,007$ & 17,739 & 0,920 \\
\hline 10 & 0,038 & 7 & 0,039 & $0,390 \pm 0,003$ & 17,508 & 0,981 \\
\hline 10 & 0,095 & 7 & 0,049 & $0,493 \pm 0,013$ & 13,309 & 0,942 \\
\hline 20 & 0,019 & 7 & 0,044 & $0,888 \pm 0,012$ & 19,049 & 0,934 \\
\hline 20 & 0,038 & 7 & 0,072 & $1,431 \pm 0,014$ & 9,913 & 0,970 \\
\hline 20 & 0,095 & 7 & 0,058 & $1,169 \pm 0,119$ & 1,413 & 0,975 \\
\hline 50 & 0,019 & 7 & 0,065 & $3,274 \pm 0,019$ & 13,941 & 0,921 \\
\hline 50 & 0,038 & 7 & 0,049 & $2,473 \pm 0,014$ & 12,450 & 0,925 \\
\hline 50 & 0,095 & 7 & 0,085 & $4,240 \pm 0,026$ & 6,736 & 0,912 \\
\hline
\end{tabular}


Observando los datos acumulados en la tabla 7 se puede mencionar que los datos se ajustaron al modelo propuesto, el $\mathrm{R}^{2}$ fue bueno con un rango entre 0,912 y 0,981 , en la medida que aumenta la concentración de MC-LR los tiempos de degradación media $\left(\mathrm{t}_{1 / 2}\right)$ son más largos y se observan variaciones en el $r_{0}$ que se analizarán al final de la tabla 10.

Para la degradación de MC-LR a pH 7, se encontraron diferencias significativas $(p<0,05)$ entre la degradación de MC-LR y los tiempos de contacto para los tres niveles iniciales de MC-LR $\left(10,20\right.$ y $\left.50 \mu \mathrm{g} . \mathrm{L}^{-1}\right)$. Al realizar el ANOVA para el total de datos de degradación de MC-LR a pH 7 se encontraron diferencias significativas $(p<0,05)$ entre la degradación de MC-LR y los tiempos de contacto y entre los niveles de cloro inicial, pero no se encontraron diferencias significativas en la interacción entre el tiempo de contacto y el cloro inicial (ver anexo).

\subsection{3.}

\section{Degradación de MC-LR a pH 8}
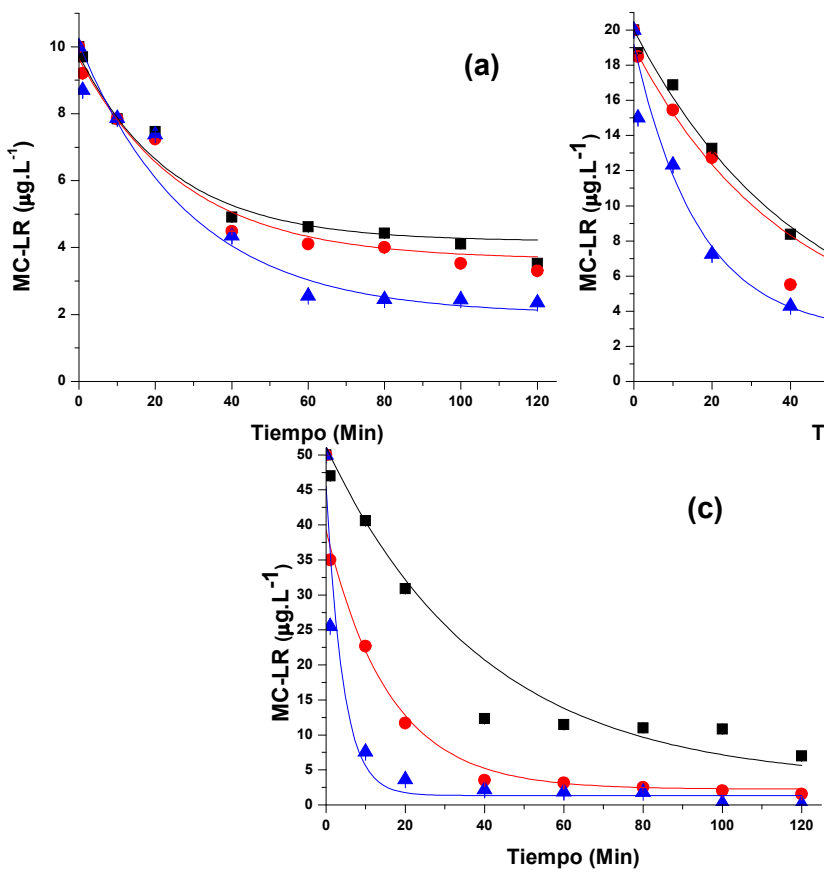

(b)

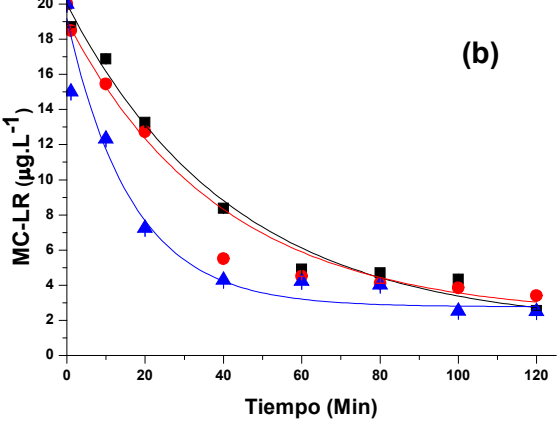

(c)

Figura 7. Cinética de degradación de MC-LR a) 10, b) 20 y c) $50 \mu \mathrm{g} \cdot \mathrm{L}^{-1}$ a pH 8 para tres concentraciones de cloro $(\square 0,019 \mathrm{mM}, \bullet 0,038 \mathrm{mM}, \Delta 0,095 \mathrm{mM})$

Tabla 8. Parámetros de ajuste exponencial para la degradación de MC-LR 10, 20 , y $50 \mu \mathrm{g} \cdot \mathrm{L}^{-1}$ y tres concentraciones de cloro $(0,019,0,038$ y $0,095 \mathrm{mM}$ de cloro) a pH 8 y el tiempo al cual la concentración de MC-LR se degrada a la mitad del valor inicial $\left(t_{1 / 2}\right)$

\begin{tabular}{ccccccc|}
$\begin{array}{c}\text { MC-LR } \\
\left(\mu \mathrm{L}^{-1}\right)\end{array}$ & $\begin{array}{c}\mathrm{CLORO} \\
(\mathrm{mM})\end{array}$ & $\mathrm{pH}$ & $K_{1}\left(\mathrm{~min}^{-1}\right)$ & $r_{0}\left(\mu g \cdot \mathrm{Lmin}^{-1}\right)$ & $\begin{array}{r}\mathrm{t}_{1 / 2} \\
(\mathrm{~min})\end{array}$ & $\mathrm{R}^{2}$ \\
\hline $\mathbf{1 0}$ & 19 & 8 & 0,030 & $0,300 \pm 0,014$ & 39,502 & 0,927 \\
\hline
\end{tabular}




\begin{tabular}{|ccccccc|}
\hline $\mathbf{1 0}$ & 38 & 8 & 0,045 & $0,450 \pm 0,006$ & 38,039 & 0,953 \\
\hline $\mathbf{1 0}$ & 95 & 8 & 0,026 & $0,257 \pm 0,007$ & 33,747 & 0,958 \\
\hline $\mathbf{2 0}$ & 19 & 8 & 0,025 & $0,497 \pm 0,004$ & 32,420 & 0,986 \\
\hline $\mathbf{2 0}$ & 38 & 8 & 0,035 & $0,697 \pm 0,006$ & 25,028 & 0,979 \\
\hline $\mathbf{2 0}$ & 95 & 8 & 0,058 & $1,166 \pm 0,013$ & 13,322 & 0,951 \\
\hline $\mathbf{5 0}$ & 19 & 8 & 0,036 & $1,796 \pm 0,007$ & 24,801 & 0,969 \\
\hline $\mathbf{5 0}$ & 38 & 8 & 0,064 & $3,175 \pm 0,015$ & 9,669 & 0,947 \\
\hline $\mathbf{5 0}$ & 95 & 8 & 0,091 & $4,552 \pm 0,104$ & 8,095 & 0,980 \\
\hline
\end{tabular}

De la tabla 8 podemos analizar que los datos se ajustaron satisfactoriamente al modelo propuesto con un $R^{2}$ bueno con un rango entre 0,927 y 0,986 , los $t_{1 / 2}$ son más largos en la medida que la concentración de MC-LR aumenta y el $r_{0}$ sufre variaciones en la medida que las concentraciones de cloro y MC-LR cambian durante el ensayo, lo que se analizará al final de la tabla 10.

El análisis de varianza para la degradación de MC-LR a pH 8 mostró diferencias significativas $(p<0,05)$ entre la degradación de MC-LR y los tiempos de contacto para los tres niveles iniciales de MC-LR $\left(10,20\right.$ y $\left.50 \mu \mathrm{g} . \mathrm{L}^{-1}\right)$. Al realizar el ANOVA para el total de datos de degradación de MC-LR a pH 8 se encontraron diferencias significativas $(p<0,05)$ entre los entre la degradación de MC-LR y los tiempos de contacto y entre los niveles de cloro inicial, pero no se encontraron diferencias significativas en la interacción entre el tiempo de contacto y el cloro inicial (ver anexo).

Una vez realizados los ANOVA para cada uno de los tres $\mathrm{pH}$ propuestos $(6,7 \mathrm{y}$ 8 ), se procedió a realizar el ANOVA para todos los $\mathrm{pH}$, concentraciones iniciales de MC-LR, niveles de cloro y tiempos de contacto. Este análisis de varianza evidenció la existencia de diferencias significativas $(p<0,05)$ entre la degradación de MC-LR y los tiempos de contacto y en la relación entre el cloro inicial. A su vez no se encontraron diferencias significativas entre los diferentes niveles de $\mathrm{pH}$, ni entre las interacciones entre el tiempo de contacto y el $\mathrm{pH}$, el tiempo de contrato y los niveles de cloro, entre el $\mathrm{pH}$ y el cloro inicial, como tampoco entre la interacción entre el tiempo de contacto $\mathrm{pH}$ y los niveles de cloro inicial (ver anexo).

\subsection{4.}

\section{Vinculación de los parámetros cinéticos de degradación de MC-LR con la concentración de inicial de cloro}

A efectos de vincular los parámetros de ajuste de la degradación de MC-LR con diferentes concentraciones de cloro se evaluó el efecto del ácido hipocloroso sin disociar expresado como concentración de ácido sin disociar (UAC) sobre los parámetros cinéticos de degradación de MC-LR. Entre estos parámetros, el 
tiempo de degradación a la mitad de la concentración inicial $\left(\mathrm{t}_{1 / 2}\right)$ resulta ser interesante de ser evaluado.

Tabla 9. Vinculación de los valores cinéticos en relación con los valores de cloro total, UAC y el tiempo al cual la concentración de MC-LR inicial se degrada a la $\operatorname{mitad}\left(\mathrm{t}_{1 / 2)}\right.$

\begin{tabular}{|ccccc|}
\hline MC-LR & pH & Cloro $(\mathrm{mM})$ & UAC $(\mathrm{mM})$ & $\begin{array}{c}\mathrm{t}_{1 / 2} \\
(\mathbf{m i n})\end{array}$ \\
\hline $\mathbf{1 0}$ & 6 & 0,019 & 0,018 & 1,001 \\
\hline $\mathbf{1 0}$ & 6 & 0,038 & 0,037 & 0,740 \\
\hline $\mathbf{1 0}$ & 6 & 0,095 & 0,092 & 0,684 \\
\hline $\mathbf{2 0}$ & 6 & 0,019 & 0,018 & 7,292 \\
\hline $\mathbf{2 0}$ & 6 & 0,038 & 0,037 & 7,274 \\
\hline $\mathbf{2 0}$ & 6 & 0,095 & 0,092 & 6,788 \\
\hline $\mathbf{5 0}$ & 6 & 0,019 & 0,018 & 14,073 \\
\hline $\mathbf{5 0}$ & 6 & 0,038 & 0,037 & 11,550 \\
\hline $\mathbf{5 0}$ & 6 & 0,095 & 0,092 & 9,335 \\
\hline $\mathbf{1 0}$ & 7 & 0,019 & 0,015 & 17,739 \\
\hline $\mathbf{1 0}$ & 7 & 0,038 & 0,029 & 17,508 \\
\hline $\mathbf{1 0}$ & 7 & 0,095 & 0,073 & 13,309 \\
\hline $\mathbf{2 0}$ & 7 & 0,019 & 0,015 & 19,049 \\
\hline $\mathbf{2 0}$ & 7 & 0,038 & 0,029 & 9,913 \\
\hline $\mathbf{2 0}$ & 7 & 0,095 & 0,073 & 1,413 \\
\hline $\mathbf{5 0}$ & 7 & 0,019 & 0,015 & 13,941 \\
\hline $\mathbf{5 0}$ & 7 & 0,038 & 0,029 & 12,450 \\
\hline $\mathbf{5 0}$ & 7 & 0,095 & 0,073 & 6,736 \\
\hline $\mathbf{1 0}$ & 8 & 0,019 & 0,005 & 39,502 \\
\hline $\mathbf{1 0}$ & 8 & 0,038 & 0,010 & 38,039 \\
\hline $\mathbf{1 0}$ & 8 & 0,095 & 0,024 & 33,747 \\
\hline $\mathbf{2 0}$ & 8 & 0,019 & 0,005 & 32,420 \\
\hline $\mathbf{2 0}$ & 8 & 0,038 & 0,010 & 25,028 \\
\hline $\mathbf{2 0}$ & 8 & 0,095 & 0,024 & 13,322 \\
\hline $\mathbf{5 0}$ & 8 & 0,019 & 0,005 & 24,801 \\
\hline $\mathbf{5 0}$ & 8 & 0,038 & 0,010 & 9,669 \\
\hline $\mathbf{5 0}$ & 8 & 0,095 & 0,024 & 8,095 \\
\hline & & & & \\
\hline & & & & \\
\hline
\end{tabular}

Para un mejor análisis de los valores cinéticos encontrados en el modelo se realizó una relación entre los valores de UAC y los parámetros de degradación de MC-LR. A continuación en la Figura 8 se vincula el Log del (UAC) con respecto al $\log (\mathrm{t} 1 / 2)$ para las tres concentraciones iniciales de MC-LR a) 10, b) 20 y c) $50 \mu g \cdot L^{-1}$. 


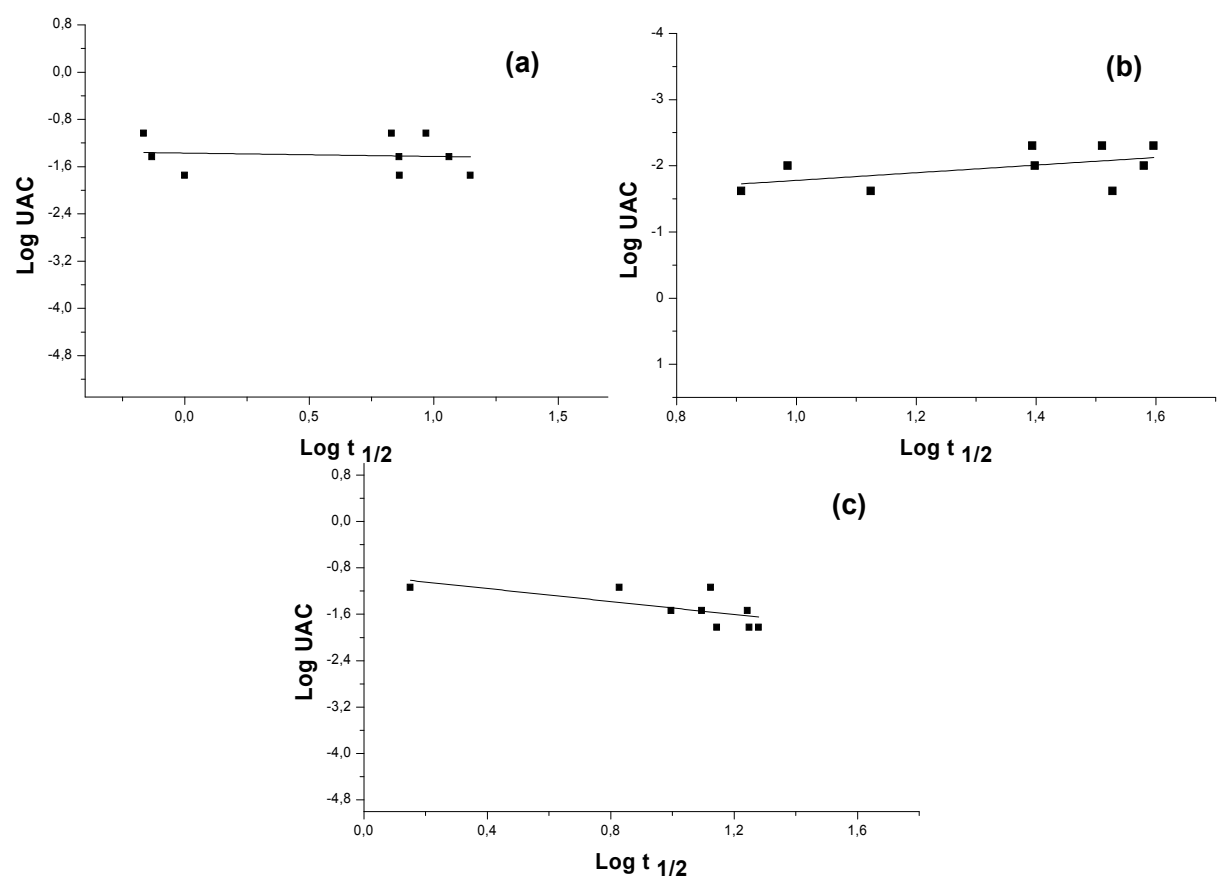

Figura 8. Relación de la concentración de ácido hipocloroso sin disociar con respecto al tiempo necesario para reducir a la mitad la concentración de MC-LR a) $10, b) 20$ y c) 50 $\mathrm{gg}^{-\mathrm{L}^{-1}}$ a tres concentraciones de cloro inicial $(0,019,0,038 \mathrm{y}$ $0,095 \mathrm{mM}$ de cloro) y tres $\mathrm{pH}(6,7$ y 8$)$

Los gráficos anteriores indican que a medida que la concentración de ácido sin disociar (UAC) aumenta, los tiempos para reducir a la mitad la concentración inicial de MC-LR $t_{1 / 2}$ son menores, confirmando que el agente activo encargado de la oxidación y degradación de MC-LR es el ácido hipocloroso.

Se ha propuesto que el cloro ataca al doble enlace conjugado del residuo Adda (3-amino-9-metoxi-10-fenil-2,6,8-trimetil-deca-4,6-ácido dienoico) de la Microcistina. Dado que todas las microcistinas tienen similitud en esta parte de la molécula, todas son susceptibles a la acción oxidante del cloro en este punto. Este modo de acción del cloro sobre la MC-LR fue reportado por Tsuji y col., 1997. Se identificó que el principal producto de oxidación formado por la acción del cloro es la Dihidroxymicrocisitna formada por la acción del ion cloruro sobre el Dieno conjugado del grupo Adda, seguido por una hidrolisis espontanea. Otros productos de la oxidación del cloro sobre la MC-LR pueden ser estereoisomeros o regioisomeros los cuales aparentemente no tiene efectos nocivos. La Figura 9 muestra el mecanismo de acción del cloro sobre la molécula de microcistina propuesto por Tsuji y col., 1997. 


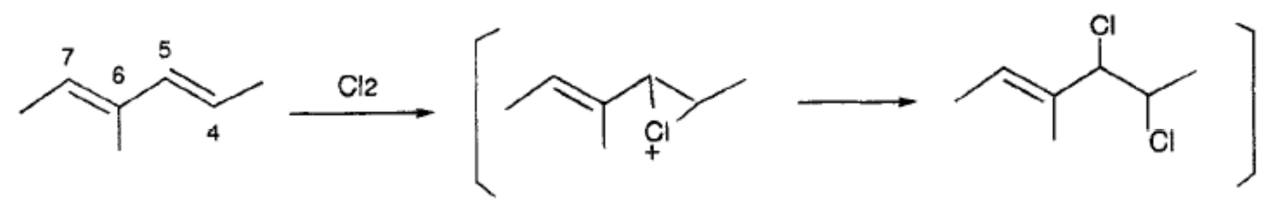

microcystin IR

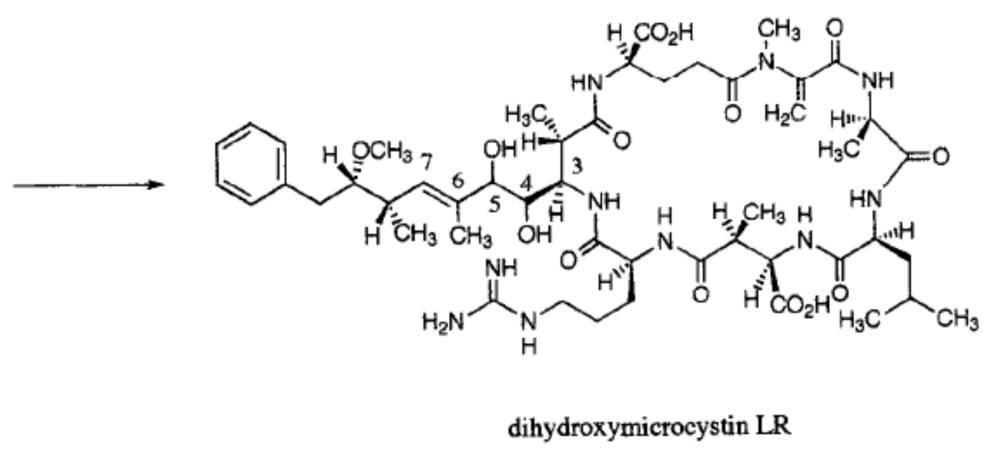

Figura 9. Mecanismo de acción propuesto para la formación de

Dihidroximicrocistina-LR luego del efecto de la oxidación con cloro.

Lo anterior indica que el cloro actúa sobre el grupo ADDA que es el que presenta acción toxica (inhibición de fosfatasa) de esa manera el cloro (en particular el acido hipocloroso) sería un agente efectivo en remover la toxicidad de la molécula de MC-LR según lo demostrado en este trabajo.

\subsubsection{Determinación del orden de la reacción para cloro y MC-LR}

Los órdenes de las reacciones se pueden definir vía logaritmo de las ecuaciones 7 y 8 , teniendo en cuenta la variación de las concentraciones iniciales de MC-LR y cloro en el diseño experimental como se expresa en la ecuación 10 y 11 . El orden de $x$ puede ser determinado mediante la aplicación del logaritmo a la ecuación 10. Variando la concentración inicial de MC-LR y midiendo la velocidad de la reacción.

$$
\log =+\log [\quad \text { Ec } 10 \text {. }
$$

El orden $y$ puede ser obtenido aplicando el logaritmo a la ecuación 8 y midiendo las velocidades de la reacción con varias concentraciones de cloro.

$$
\log =+\log [\quad] \quad \text { Ec } 11 \text {. }
$$

Al comienzo de todos los ensayos las concentraciones iniciales tanto de MC-LR y cloro son conocidas, el cálculo de las constantes y los parámetros cinéticos y de ajustes para todas las concentraciones de cloro $(0,019,0,038$ y $0,095 \mathrm{mM})$, MC$\operatorname{LR}\left(10,20\right.$ y $\left.50 \mu \mathrm{g} . \mathrm{L}^{-1}\right)$ y $\mathrm{pH}(6,7$ y 8$)$ son resumidos en la Tabla 10 . Para las velocidades iniciales de la reacciones se determinó que estas corresponden al 
valor de la tangente del ajuste exponencial a $\mathrm{t}=0$ en las curvas de degradación de MC-LR.

Para cada concentración de cloro y sus tres concentraciones correspondientes de MC-LR se graficó el logaritmo de la constante de la reacción a tiempo cero $\left(r_{0}\right)$ con respecto al logaritmo de la concentración de MC-LR, de esta manera se determinó luego de la regresión lineal para cada caso, la pendiente de dicha regresión, la cual evidencia el orden $x$ de la reacción. En todos los casos el valor de la pendiente fue cercano a 1 , indicando una reacción de primer orden con respecto a la concentración de MC-LR (Figura 10).

La segunda correlación fue la realizada entre la $K_{1}$ o constante de pseudoprimer orden y la concentración de cloro. En este caso se relacionó tres concentraciones de cloro $(0,019,0,038$ y $0,095 \mathrm{mM})$ con respecto a una concentración de MC-LR a todos los $\mathrm{pH}(6,7$ y 8$)$ para de esta manera confirmar el orden $y$ de la reacción, el cual fue cercano a 1 en todos los casos. En este caso se enfrentó la $K_{1}\left(\log K_{1}\right)$ con respecto a la concentración de cloro (Log UAC) (Figura 11).

La constante de velocidad para el total de la reacción se calculó reescribiendo la ecuación 6.

$$
=[\quad][\text { ] Ec } 12 \text {. }
$$

Esto quiere decir que la reacción es de segundo orden para el total de la reacción y una reacción de primer orden para cada uno de los reactivos, en este caso MC-LR y cloro. El termino $K$ constante de velocidad para toda la reacción se obtiene de la inversa de la pendiente entre el Log $K$ con respecto al Log de UAC.

Tabla 10. Parámetros cinéticos y constantes de reacción para concentraciones de cloro $(0,019,0,038$ y $0,095 \mathrm{mM})$, MC-LR $\left(10,20\right.$ y $\left.50 \mu \mathrm{g} . \mathrm{L}^{-1} 1\right)$ y $\mathrm{pH}(6,7$ y 8$)$

\begin{tabular}{|c|c|c|c|c|c|c|c|c|}
\hline $\begin{array}{l}\text { MC-LR } \\
\left(\mu g \cdot L^{-1}\right)\end{array}$ & pH & $\begin{array}{c}\text { Cloro } \\
\left(\mathrm{mg}^{-\mathrm{L}^{-1}}\right)\end{array}$ & $\begin{array}{l}\text { Cloro } \\
(\mathrm{mM})\end{array}$ & $\begin{array}{l}\text { UAC } \\
(\mathrm{mM})\end{array}$ & $\begin{array}{c}K_{1} \mathrm{MC}-L R \\
\left(\mathrm{~min}^{-1}\right)\end{array}$ & $r_{0}\left(\mu g \cdot L \cdot m i n^{-1}\right)$ & $\begin{array}{c}t_{1 / 2} \\
(\mathrm{~min})\end{array}$ & $\mathbf{R}^{2}$ \\
\hline 10 & 6 & 1 & 0,019 & 0,018 & 0,862 & $8,618 \pm 0,109$ & 1,001 & 0,986 \\
\hline 10 & 6 & 2 & 0,038 & 0,037 & 1,085 & $10,853 \pm 0,138$ & 0,740 & 0,984 \\
\hline 10 & 6 & 5 & 0,095 & 0,092 & 1,258 & $12,582 \pm 0,422$ & 0,684 & 0,897 \\
\hline 20 & 6 & 1 & 0,019 & 0,018 & 0,111 & $2,220 \pm 0,005$ & 7,292 & 0,968 \\
\hline 20 & 6 & 2 & 0,038 & 0,037 & 0,088 & $1,760 \pm 0,014$ & 7,274 & 0,955 \\
\hline 20 & 6 & 5 & 0,095 & 0,092 & 0,093 & $1,860 \pm 0,007$ & 6,788 & 0,983 \\
\hline 50 & 6 & 1 & 0,019 & 0,018 & 0,058 & $2,900 \pm 0,022$ & 14,073 & 0,965 \\
\hline 50 & 6 & 2 & 0,038 & 0,037 & 0,052 & $2,600 \pm 0,021$ & 11,550 & 0,945 \\
\hline 50 & 6 & 5 & 0,095 & 0,092 & 0,063 & $3,150 \pm 0,026$ & 9,335 & 0,934 \\
\hline
\end{tabular}




\begin{tabular}{|rllllllll|}
\hline $\mathbf{1 0}$ & 7 & 1 & 0,019 & 0,015 & 0,035 & $0,350 \pm 0,007$ & 17,739 & 0,920 \\
\hline $\mathbf{1 0}$ & 7 & 2 & 0,038 & 0,029 & 0,039 & $0,390 \pm 0,003$ & 17,508 & 0,981 \\
\hline $\mathbf{1 0}$ & 7 & 5 & 0,095 & 0,073 & 0,049 & $0,493 \pm 0,013$ & 13,309 & 0,942 \\
\hline $\mathbf{2 0}$ & 7 & 1 & 0,019 & 0,015 & 0,044 & $0,888 \pm 0,012$ & 19,049 & 0,934 \\
\hline $\mathbf{2 0}$ & 7 & 2 & 0,038 & 0,029 & 0,072 & $1,431 \pm 0,014$ & 9,913 & 0,970 \\
\hline $\mathbf{2 0}$ & 7 & 5 & 0,095 & 0,073 & 0,058 & $1,169 \pm 0,119$ & 1,413 & 0,975 \\
\hline $\mathbf{5 0}$ & 7 & 1 & 0,019 & 0,015 & 0,065 & $3,274 \pm 0,019$ & 13,941 & 0,921 \\
\hline $\mathbf{5 0}$ & 7 & 2 & 0,038 & 0,029 & 0,049 & $2,473 \pm 0,014$ & 12,450 & 0,925 \\
\hline $\mathbf{5 0}$ & 7 & 5 & 0,095 & 0,073 & 0,085 & $4,240 \pm 0,026$ & 6,736 & 0,912 \\
\hline $\mathbf{1 0}$ & 8 & 1 & 0,019 & 0,005 & 0,030 & $0,300 \pm 0,014$ & 39,502 & 0,927 \\
\hline $\mathbf{1 0}$ & 8 & 2 & 0,038 & 0,010 & 0,045 & $0,450 \pm 0,006$ & 38,039 & 0,953 \\
\hline $\mathbf{1 0}$ & 8 & 5 & 0,095 & 0,024 & 0,026 & $0,257 \pm 0,007$ & 33,747 & 0,958 \\
\hline $\mathbf{2 0}$ & 8 & 1 & 0,019 & 0,005 & 0,025 & $0,497 \pm 0,004$ & 32,420 & 0,986 \\
\hline $\mathbf{2 0}$ & 8 & 2 & 0,038 & 0,010 & 0,035 & $0,697 \pm 0,006$ & 25,028 & 0,979 \\
\hline $\mathbf{2 0}$ & 8 & 5 & 0,095 & 0,024 & 0,058 & $1,166 \pm 0,013$ & 13,322 & 0,951 \\
\hline $\mathbf{5 0}$ & 8 & 1 & 0,019 & 0,005 & 0,036 & $1,796 \pm 0,007$ & 24,801 & 0,969 \\
\hline $\mathbf{5 0}$ & 8 & 2 & 0,038 & 0,010 & 0,064 & $3,175 \pm 0,015$ & 9,669 & 0,947 \\
\hline $\mathbf{5 0}$ & 8 & 5 & 0,095 & 0,024 & 0,525 & $4,573 \pm 0,104$ & 8,095 & 0,980 \\
\hline
\end{tabular}

La tabla 10 nos permite evidenciar que los datos se ajustan apropiadamente al modelo propuesto, los tiempos de degradación media aumentan en la medida que la concentración de MC-LR también lo hace, el $R^{2}$ es bueno con un rango para el total de los resultados entre 0,897 y 0,986. En el caso de la velocidad de la reacción al tiempo cero $\left(r_{0}\right)$ podemos comentar que al inicio de la reacción entre la MC-LR y el cloro hay una caída abrupta de la concentración de toxina en los primeros tiempos de contacto que después se mantiene hasta el tiempo final de los tratamientos, estas variaciones están relacionadas con la capacidad oxidante del cloro sobre todo a pH 6 donde se encuentra la mayor concentración de UAC, por lo tanto existe más acido hipocloroso disponible en la reacción, razón por la cual el $r_{0}$ obtiene valores más altos a una concentración de MC-LR de $10 \mu \mathrm{g} \cdot \mathrm{L}^{-1}$ a pH 6. 
A modo de ejemplo para demostrar el orden de estas reacciones, se muestra en las Figuras 10 y 11 los gráficos que permiten hacer estas correlaciones.
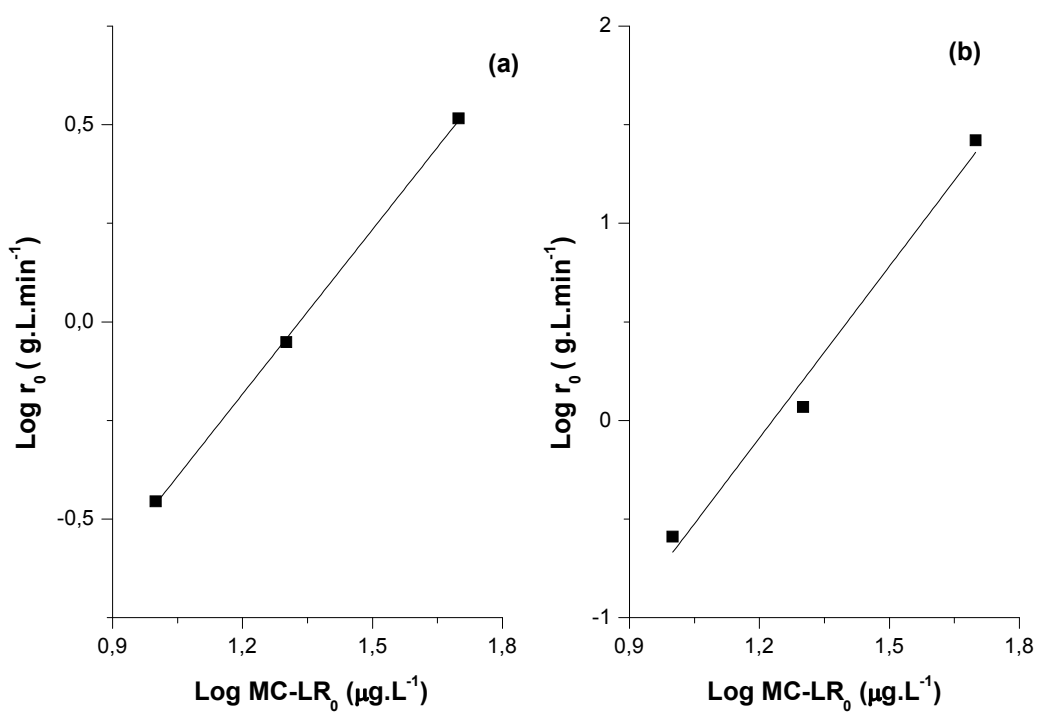

Figura 10. a) Velocidad inicial de la reacción ( $\log r_{0}$ ) con respecto a la concentración inicial de MC-LR ( Log MC-LRo) a una concentración de cloro

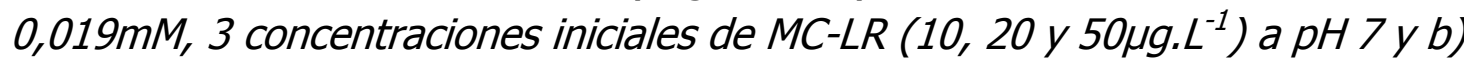
Concentración inicial de cloro de 0,095mM, 3 concentraciones iniciales de MC$\operatorname{LR}\left(10,20\right.$ y $\left.50 \mu \mathrm{g} \cdot \mathrm{L}^{-1}\right)$ a $\mathrm{pH} 8$.
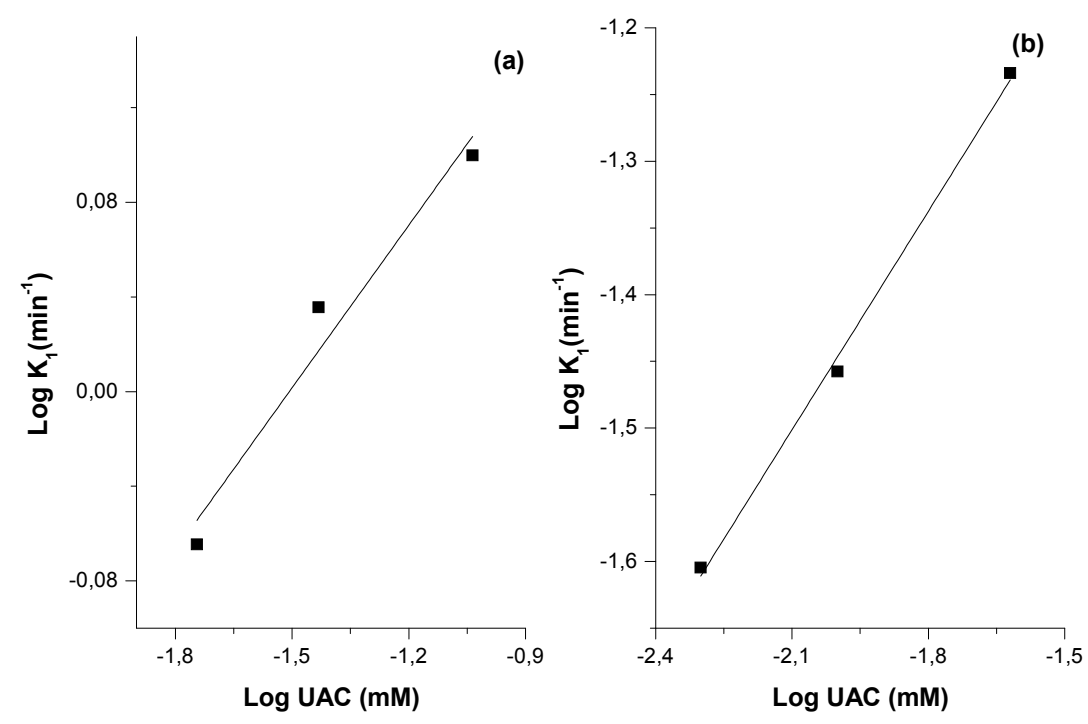

Figura 11. Constante de velocidad ( $\left.\log K_{1}\right)$ con respecto al UAC ( $\left.\log U A C\right)$ a) concentración de $10 \mu \mathrm{g} \cdot \mathrm{L}^{-1}$ de MC-LR, tres concentraciones de UAC a pH 6 y b) Concentración inicial de $20 \mu \mathrm{g} \cdot \mathrm{L}^{-1}$ de MC-LR, tres concentraciones de UAC a $\mathrm{pH} 8$ 


\subsection{Determinación del parámetro de concentración por tiempo (C.t)}

La acción de un desinfectante u oxidante, debe ser lo más eficiente posible, por ello, resulta necesario mantener una determinada concentración del desinfectante durante un período de tiempo. A tal efecto se emplea la expresión C.t, la cual representa la concentración del cloro durante el tiempo de contacto necesario para lograr una determinada degradación de MC-LR en nuestras condiciones de ensayo. En la siguiente ecuación se determinó la manera de calcular el C.t para cloro y MC.

$$
\frac{[\quad]}{[\quad]}=(\quad .) \quad \text { Ec. } 14
$$

Donde $[M C-L R]$ es la concentración de MC-LR, $[M C-L R]_{0}$ es la concentración de MC-LR inicial, $K^{\prime}$ es la constante de velocidad aparente, específica para cada $\mathrm{pH}$, $C$ es la concentración de cloro libre (residual) y $t$ es el tiempo de contacto.

A continuación en la figura 12 se muestra la relación entre la MC-LR y la MC-LR inicial con respecto al parámetro C.t para cada $\mathrm{pH}$ propuesto $(6,7$ y 8$)$.

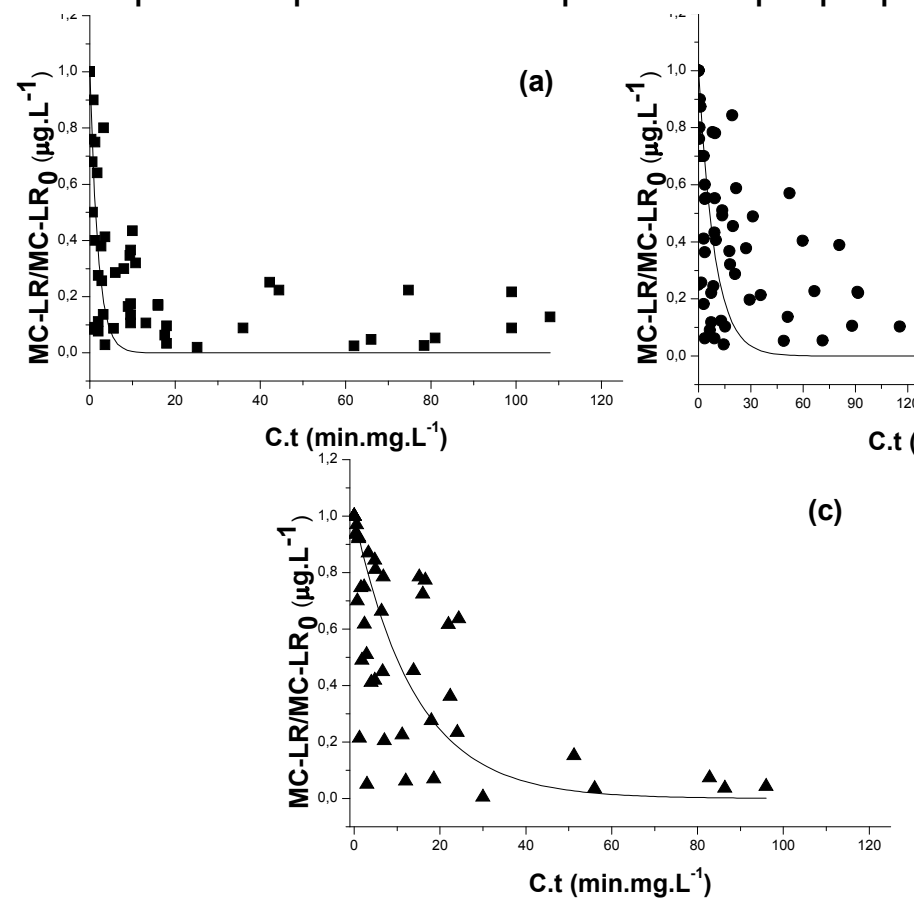

(b)

Figura 12. Gráfico de C.t para tres concentraciones iniciales de Cloro $(0,019 \mathrm{mM}$, $0,038 \mathrm{mM}, 0,095 \mathrm{mM})$, tres concentraciones de MC-LR $\left(10,20\right.$ y $\left.50 \mu \mathrm{g} \cdot \mathrm{L}^{-1}\right)$ a) $\mathrm{pH}$ 6, b) $\mathrm{pH} 7$ Yc) $\mathrm{pH} 8$

Analizando los gráficos de C.t para cada $\mathrm{pH}$, se puede observar que a medida que aumenta el pH los C.t son mayores, esto es importante y de utilidad tecnológica ya que en una planta de tratamiento en caso de un florecimiento cianobacteriano se puede obtener a partir de este tipo de información, variables operativas y de decisión para asegurar una óptima remoción de estas toxinas en el agua de consumo. A continuación en la Tabla 11 se muestra los valores 
de C.t para remover 50, 90 y $95 \%$ de MC-LR para los tres $\mathrm{pH}$ propuestos $(6,7$ y 8).

Tabla 11. Valores del C.t (min.mg. $\mathrm{L}^{-1}$ ) para reducir el 50,90 y $95 \%$ de MC-LR en los tratamientos con cloro

\begin{tabular}{|cccc|}
\hline & \multicolumn{3}{c|}{ AJUSTE ESTIMADO C.t } \\
& \multicolumn{3}{|c|}{$\left(\mathrm{min} \cdot \mathrm{mg}_{\mathbf{L}}{ }^{-1}\right)$} \\
\% DEGRADACION & PH 6 & PH 7 & PH 8 \\
\hline $\mathbf{5 0}$ & 0,049 & 1,505 & 2,025 \\
\hline $\mathbf{9 0}$ & 0,549 & 2,093 & 2,613 \\
\hline $\mathbf{9 5}$ & 0,603 & 2,147 & 2,667 \\
\hline
\end{tabular}

El cloro es el oxidante más usado por excelencia en las plantas de tratamiento de agua y es un método apropiado para la remoción de $\mathrm{MC}$ siempre que el $\mathrm{pH}$ al momento de realizar el tratamiento sea ligeramente acido ( $\mathrm{pH} 6)$. Analizando los antecedentes de remoción de MC utilizando cloro como agente oxidante se puede determinar que si bien las concentraciones de cloro son mayores a las de MC, no necesariamente se puede asumir que dichas concentraciones se mantienen constantes durante los ensayos. Los resultados de degradación de cloro y MC-LR permitieron inferir que el ácido hipocloroso resultó ser la especie oxidante más importante en este modelo de remoción de toxina. A medida que el $\mathrm{pH}$ aumenta la remoción de MC-LR, requiere una mayor concentración de cloro y mayores tiempos de degradación media $\left(\mathrm{t}_{1 / 2}\right)$. Se evidenció también que para aumentar el porcentaje de degradación y a su vez tener valores de C.t menores, el mejor $\mathrm{pH}$ fue 6. A medida que aumenta el $\mathrm{pH}$ el valor de C.t aumenta, por lo tanto, si esta condición se llegase a dar en el tratamiento de aguas con presencia de MC-LR se corre el riesgo de no llegar a una degradación óptima como lo pide la OMS de $1 \mu \mathrm{g} \cdot \mathrm{L}^{-1}$.

Como se puede observar en los resultados del C.t mostrados en la tabla 11, los valores más bajos de C.t para la degradación de 50, 90 y 95\% de MC-LR se logran a pH 6. Si tomamos como ejemplo la degradación del 50\% de $\mathrm{MC}$ a pH 6 , se necesita 41,3, 4,7 y 4,4 veces más C.t para lograr una degradación del 50, 90 y $95 \%$ respectivamente a $\mathrm{pH} 8$ (ver Tabla 11). Para una degradación del $50 \%$ para los tres $\mathrm{pH}$ propuestos se necesita un C.t menor a 2,025min.mg. $\mathrm{L}^{-1}$ para lograr esta degradación. Estos resultados tienen implicancia práctica para las plantas de tratamiento destinadas a abastecer agua para consumo humano. Los valores de C.t de este trabajo adoptan modelos similares a los trabajos citados, sin embargo los valores acá presentados son menores en comparación a otros trabajos. Acero y col 2005 informaron valores de C.t de 17,8 y 30,3 min.mg. $\mathrm{L}^{-1}$ para lograr una degradación del $98 \%$ partiendo de una concentración de MC-LR de 10 y $50 \mu \mathrm{g} . \mathrm{L}^{-1}$ respectivamente. Lo anterior radica en 
que el ensayo se hizo a concentraciones de cloro menores a las de la presente tesis $\left(0,5\right.$ y $\left.1 \mathrm{mg}^{-L^{-1}}\right)$ cuantificando la MC por HPLC. Cabe recordar que Acero y col 2005, desarrolló en su trabajo un rango de concentración de cloro entre 49

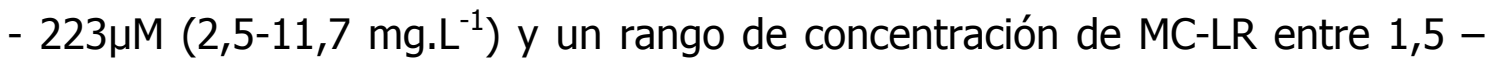
$3,5 \mathrm{mg} \cdot \mathrm{L}^{-1}$, en este caso la relación de cloro- MC-LR fue 32 a 63,7, esta relación se propuso para evitar pasos de pre concentración de muestras. Xagoraraki y col 2006, informaron valores de C.t para pH 6 de 11,35 y $46 \mathrm{~min} . \mathrm{mg}^{-\mathrm{L}^{-1}}$ para porcentajes de degradación de 50, 90 y $95 \%$ con concentraciones de cloro de 1,3 y $9 \mathrm{mg} \cdot \mathrm{L}^{-1}$ y concentraciones de MC-LR de 1,2 y $8 \mu \mathrm{g} \cdot \mathrm{L}^{-1}$. En este caso se realizó los ensayos de remoción con una relación cloro- MC-LR que fue de 21428 a 24761 . La diferencia de estos resultados respecto a los hallados en el presente estudio pueden ser debidos a la diferencia de concentraciones iniciales de cloro y MC-LR. En esta tesis de Magister la concentración de cloro fue mayor con respecto a la concentración de $M C-L R$, siendo la relación de concentraciones de cloro libre a MC de 1900 . Nuestro rango de trabajo de cloro fue 1,2 y $5 \mathrm{mg} \cdot \mathrm{L}^{-1}(0,019,0,038$ y $0,095 \mathrm{mM})$ y el de MC fue de 10,20 y $50 \mu \mathrm{g} . \mathrm{L}^{-}$ ${ }^{1}$. Otros investigadores no contemplan la variación del cloro residual a lo largo del ensayo, además de la demanda de cloro natural en el agua quedo evidenciada en los controles (sin MC-LR).

Por otra parte, resulta necesario considerar las técnicas de detección y cuantificación de MC a la hora de analizar los estudios de remoción y su comparación con datos bibliográficos, ya que los límites de detección de cada método cambian significativamente. Un método que presenta un límite de detección en el orden de los $\mathrm{mg} \mathrm{L}^{-1}$ requiere pasos previos de pre-concentración de las muestras a efectos de ser detectados con dichos límites. Un método con alta sensibilidad como el de la inhibición de la Protein fosfatasa 1 (PP1) en el cual podemos detectar $\mathrm{MC}$ en el orden de los $\mu \mathrm{g} \mathrm{L}^{-1}$ sin pasos previos de preconcentración puede ser usado para la detección y cuantificación de MC. Las concentraciones iniciales de MC en algunos trabajos se informan en el orden de $\mathrm{mg} . \mathrm{L}^{-1}$ y cuantificadas por HPLC con arreglo de Diodos, siendo necesaria la implementación de procesos de pre-concentración antes de la cuantificación, alejándose de la realidad de las toxinas disueltas presentes en los espejos de agua. En este trabajo se decidió utilizar la técnica de inhibición de la Protein fosfatasa 1 gracias a su alta sensibilidad de detección de las microcistinas y la eliminación de procesos previos para su cuantificación, cuantificando en el orden de los $\mu \mathrm{g} \cdot \mathrm{L}^{-1}$. Es un método rápido y versátil que puede ser de ayuda en la determinación de estas toxinas en agua destinada al consumo. Algunos autores nombrados a continuación debieron realizar un tratamiento previo de las muestras, ya que la toxina fue cuantificada mediante la técnica de HPLC con arreglo de diodos, técnica que tiene un límite de detección del orden de los $\mathrm{mg} . \mathrm{L}^{-1}$ detectando y cuantificando la toxina por HPLC al igual que Nicholson y 
col., 1994, Tsuji y col., 1997, Hart y col., 1998, Bruchet y col., 1998 y Acero y col., 2005, Por su parte Xagoraraki y col., 2006 realizó los ensayos de remoción de MC-LR asumiendo que las concentraciones de cloro se mantienen constantes durante el ensayo, utilizando como método de detección de MC kits comerciales de ELISA correlacionados con la técnica de HPLC con arreglo de diodos para darle mayor confiabilidad a la detección. Otro antecedente en los ensayos de cloración es el de $\mathrm{Ho}$ y col, 2006, quienes utilizaron concentraciones de cloro de $0,5,1$ y $1,5 \mathrm{mg} \cdot \mathrm{L}^{-1}$ y una concentración de $\mathrm{MC}$ de $20 \mu \mathrm{g} \cdot \mathrm{L}^{-1}$, preconcentrando la muestra y detectando la toxina mediante HPLC.

La toxina utilizada en nuestros ensayos fue extraída de una cepa recuperada del ambiente y mantenida en condiciones de laboratorio, la toxina producida por esta cepa es autóctona de nuestro país y está demostrado que cualquier variante en estas toxinas afecta la degradación de la misma. La utilización de esta toxina autóctona aporta al conocimiento de las cianotoxinas y aproxima a la realidad ambiental de nuestros recursos hídricos.

Cada planta de tratamiento debe realizar las cinéticas de degradación en sus propias condiciones y no extrapolar datos obtenidos en otras fuentes de agua. Se deben estudiar sus particularidades y ajustarlas para la remoción de cianotoxinas. Los monitoreos a la entrada de las plantas y la implementación de niveles de seguimiento y alerta deben ser aplicados como herramienta de decisión válida para las plantas que están enfrentadas a esta problemática de las cianobacterias y sus toxinas.

A modo de resumen se presentan en la Figura 13 los porcentajes de remoción de MC-LR agrupados de acuerdo a la concentración inicial de MC-LR a) 10, b) 20 y c) $50 \mu \mathrm{g} . \mathrm{L}^{-1}$ con respecto al tiempo. 


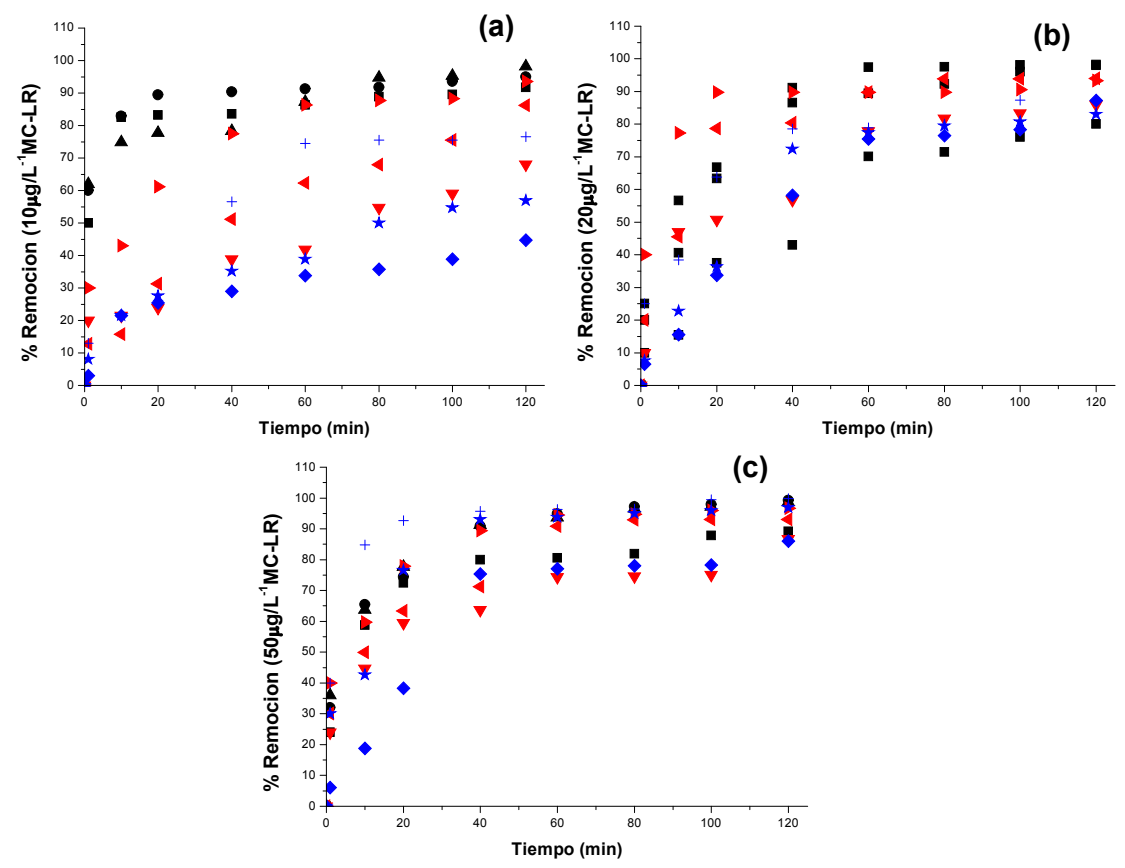

Figura 13. Remoción de MC-LR por cloro a diferentes $p H$. a) 10, b) 20 y c) $50 \mu \mathrm{g} . \mathrm{L}^{-1},(\mathbf{\square} 0,019 \mathrm{mM}, \bullet 0,038 \mathrm{mM}, \mathbf{\Delta} 0,095 \mathrm{mM}$ de cloro a $\mathrm{pH} 6),(\nabla 0,019 \mathrm{mM}$, $40,038 \mathrm{mM}, \triangleright 0,095 \mathrm{mM}$ de cloro a $\mathrm{pH} 7),(\diamond 0,019 \mathrm{mM}, \star 0,038 \mathrm{mM}$, $+0,095 \mathrm{mM}$ de cloro a $\mathrm{pH} 8$ )

En la figura 13 se puede observar que las concentraciones de cloro a $\mathrm{pH} 6$ alcanzan un \% de degradación de toxina cercano o superior al $90 \%$ en menor tiempo que las mismas concentraciones a $\mathrm{pH} 7$ u 8 . En la medida que aumenta el $\mathrm{pH}$ la remoción de MC-LR se logra menor remoción inclusive para la mayor concentración de cloro $(0,095 \mathrm{mM})$ y la menor concentración de MC-LR ensayada. Los tiempos de contacto son mayores en la medida que aumente la concentración de MC-LR junto con el pH. La dosis de cloro necesaria para llegar a un determinado porcentaje de remoción depende también de los parámetros de calidad del agua, debido a su influencia en la estabilidad de cloro. Esto es especialmente importante en aguas de rio, aguas superficiales o lagos eutróficos, los cuales de acuerdo a su composición físico-química (por ejemplo, temperatura, $\mathrm{pH}, \mathrm{MOD}$ (materia orgánica disuelta), amoniaco, bromuro) puede cambiar con frecuencia. En general, cualquier compuesto capaz de reaccionar con el cloro (materia orgánica disuelta, amoníaco, bromuro) disminuye la exposición al cloro, y por lo tanto, son necesarias dosis de oxidante superiores para alcanzar la eliminación de la toxina. Por lo tanto, es necesario estudiar y calibrar cada agua en particular con respecto a la tasa de consumo de cloro con el fin de determinar la dosis inicial que conduce a los porcentajes de remoción de MC-LR necesarios. 
Efecto de una solución comercial de Ácido Peracético sobre un cultivo de Microcystis aeruginosa productora de Microcistina [D-Leu 1] MC-LR

El cloro es uno de los agentes químicos más utilizados en el tratamiento de agua por su eficiencia y bajo costo. Sin embargo presenta efectos nocivos al ponerse en contacto con materia orgánica debido a la formación de triahalometanos, por ello, otros oxidantes como el ácido peracético se presentan como alternativas interesantes al cloro.

Es sabido que el ácido peracético (APA) ha sido aprobado por el ANMAT Resolución 318/15 para el tratamiento de aguas. Sin embargo el lugar donde pueda ser aplicado no ha sido aún establecido y los operadores de las mismas sugieren la aplicación a la entrada de la planta en casos de florecimientos. También otros operadores de plantas indican que el mejor abordaje sería aplicarlo a la salida de la planta previa a la cloración, habida cuenta que a la entrada el APA podría producir la lisis de las células y liberar la toxina situación que empeoraría la problemática.

Por ello estas estrategias se estudiarán en el presente capítulo evaluando el empleo del APA desde dos abordajes: sobre la degradación de un cultivo de cianobacterias (simulando la aplicación sobre un florecimiento a la entrada de la planta) y sobre la degradación de MC (simulando la aplicación a salida de la planta).

La primera estrategia de aplicación permite evaluar la acción del oxidante del APA sobre cultivos de cianobacterias como por ejemplo Microcystis aeruginosa y sus toxinas. Asimismo también resulta interesante evaluar la acción sanitizante del peracético sobre microorganismos indicadores de contaminación fecal como es Escherichia colital como se verá más adelante.

Primeramente se estudió la aplicación de APA sobre un cultivo de $M$. aeruginosa en la fase de crecimiento exponencial. Se evaluó el efecto de este oxidante sobre los siguientes parámetros del cultivo: turbidez medida a través de la densidad óptica (DO), proteínas totales, clorofila, recuento celular y toxina total.

\subsubsection{Efecto de una solución de ácido peracético sobre la turbidez (densidad óptica) expresado como absorbancia}


A continuación en la Figura 14 se presenta el efecto del APA sobre la turbidez

(DO) sobre un cultivo de $M$. aeruginosa en condiciones de laboratorio.

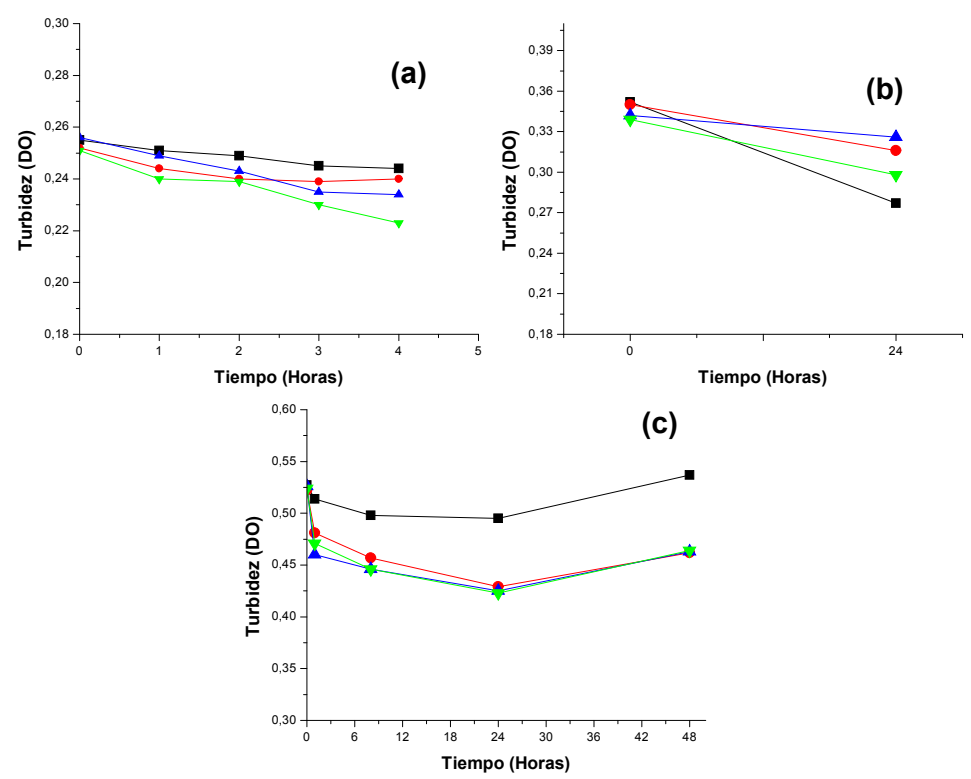

Figura 14. Efecto del APA sobre la turbidez (DO) de un cultivo de M. aeruginosa a diferentes concentraciones de producto a) Control, $05, \Delta 10, \nabla 20 \mathrm{mg}^{-1} \mathrm{~L}^{-1}$ ),

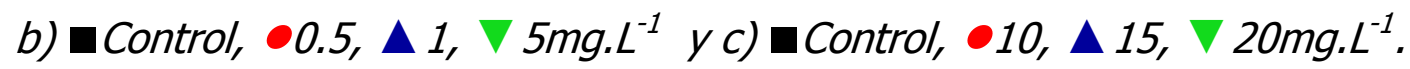

Se observan diferencias en la densidad óptica de los cultivos tratados con APA. En la medida que el tiempo de contacto y la concentración de APA aumenta, la densidad óptica disminuye. Esto puede deberse al poder oxidante que presenta el per acético $(1,87 \mathrm{~V})$. Es sabido que presenta amplio espectro biocida aun en presencia de materia orgánica (Rossi y col., 2007), cuya eficacia ha sido comprobada ante bacterias (Falsanisi y col., 2006), hongos (Baldry y col., 1989), virus (Rutala y col., 1999), y esporas (Kitis y col., 2004).

Para los cultivos tratados con 5,10 y $20 \mathrm{mg}^{-\mathrm{L}^{-1}}$ de APA a $0,1,2,3$ y 4 horas de tiempo de contacto se encontraron diferencias significativas $(p<0,05)$ en la turbidez (DO) de los tratamientos control (sin adición de APA) con respecto al tiempo de contacto. En el caso de los cultivos tratados se encontraron diferencias significativas $(p<0,05)$ en la densidad óptica en relación a las dosis de APA, el tiempo de contacto y en la interacción entre la concentración de peracético y los tiempos de contacto (ver anexo).

En el caso de los cultivos tratados con $0,5,1$ y $5 \mathrm{mg}^{-L^{-1}}$ de APA a 0 y 24 horas de tiempo de contacto, se encontraron diferencias significativas en la turbidez (DO) $(p<0,05)$ con respecto a la concentración de ácido peracético y los diferentes tiempos de contacto, de la misma manera existen diferencias 
significativas $(p<0,05)$ en la interacción entre las concentraciones de APA y los tiempos de contacto (ver anexo).

Cultivos tratados con 10,15 y $20 \mathrm{mg}^{-L^{-1}}$ de APA a $0,1,8,24$ y 48 horas de tiempo de contacto mostraron diferencias significativas $(p<0,05)$ en la turbidez (DO) de los tratamientos control (sin adición de ácido peracético) con respecto al tiempo de contacto. En el caso de los cultivos tratados, se encontraron diferencias significativas $(p<0,05)$ para la turbidez (DO) con respecto a los tiempos de contacto. Se encontraron diferencias significativas $(p<0,05)$ en relación a las dosis de ácido peracético, el tiempo, y en la interacción entre la concentración de APA y los tiempos (ver anexo). Al realizar la comparación de a pares se encontró que las concentraciones de APA son diferentes significativamente $(p<0,05)$.

Estas diferencias observadas podrían ser debidas a la acción del oxidante sobre las células de $M$. aeruginosa que produce lisis de las células y liberación de pigmentos en especial de la clorofila-a los cuales también pueden ser degradados.

\subsubsection{Efecto de una solución de APA sobre las proteínas totales expresadas en $\mu \mathrm{g} . \mathrm{\mu L}^{-1}$}

A continuación se presenta en la figura 15 el efecto del APA sobre las proteínas totales en un cultivo de $M$. aeruginosa en condiciones de laboratorio. 

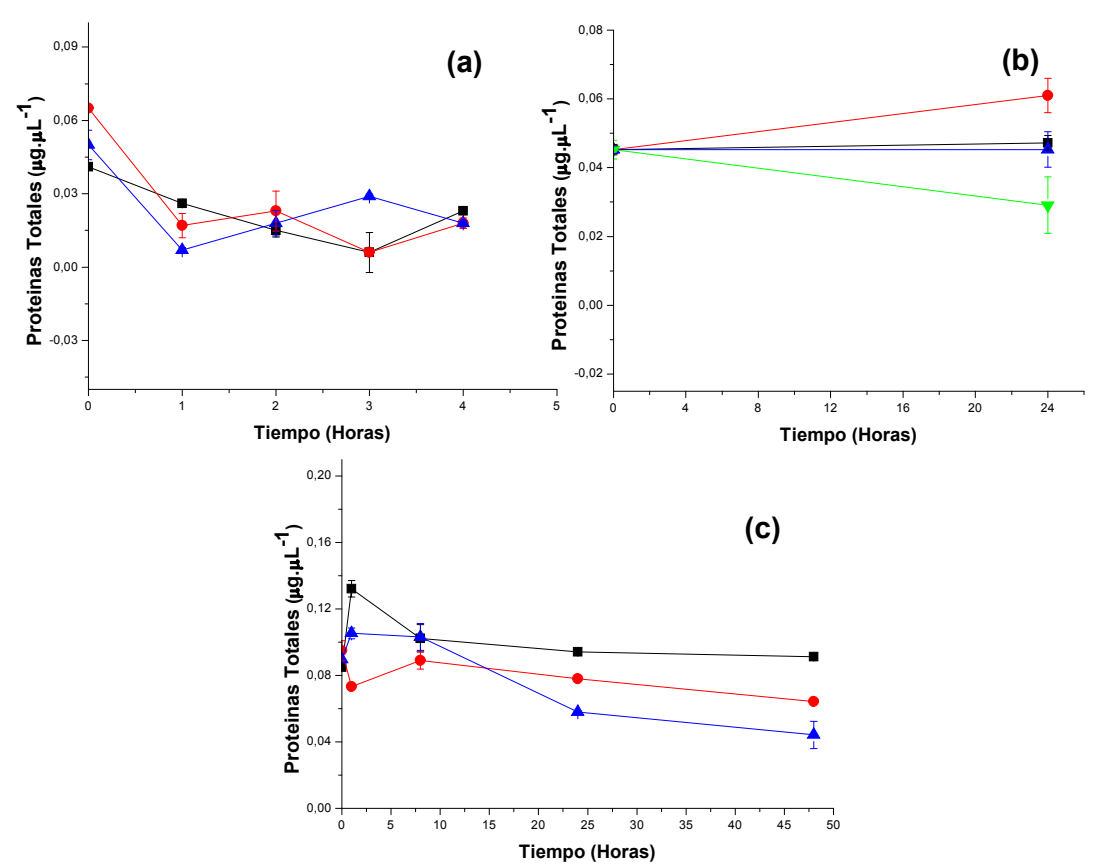

Figura 15. Efecto de una solución del APA sobre las proteínas totales de un cultivo de M. aeruginosa a diferentes concentraciones de producto a) $\mathbf{\square}$, 10 ,

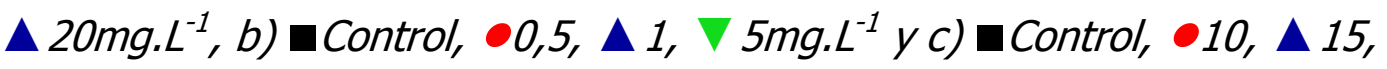 $\nabla 20 \mathrm{mg} \cdot \mathrm{L}^{-1}$}

Puede observarse que la concentración de proteínas disminuyen en relación a la dosis de APA y el tiempo de contacto, podemos deducir con esto que las proteínas son blanco de la acción del oxidante.

La reducción de las proteínas totales en los cultivos tratados con APA se debe a que las proteínas son susceptibles a la acción de los oxidantes. Cabe recordar que existen tres condiciones que afecta la degradación de proteínas como son: la temperatura, el pH y la fuerza iónica. En este caso en particular la acción del APA modifica la fuerza iónica de las proteínas de membrana alterando la permeabilidad de la misma y facilitando su degradación.

Los cultivos tratados con 5,10 y $20 \mathrm{mg}^{-1}$ de APA a $0,1,2,3$ y 4 horas de tiempo de contacto mostró diferencias significativas $(p<0,05)$ en las proteínas totales de los cultivos con respecto al tiempo de contacto. Se encontraron diferencias significativas $(p<0,05)$ para los diferentes tratamientos en relación a las dosis de ácido peracético, el tiempo de contacto y en la interacción entre la concentración de APA y los tiempos de contacto (ver anexo).

En otro de los tratamientos con 0,5, 1 y $5 \mathrm{mg} \cdot \mathrm{L}^{-1}$ de APA a 0 y 24 horas de tiempo de contacto, no se encontraron diferencias significativas en relación a las proteínas totales $(p>0,05)$ con respecto a los tiempos de contacto. Al 
realizar el análisis de varianza para el total de los datos de este tratamiento, se encontraron diferencias $(p<0,05)$ en el contenido de proteínas totales con respecto a la concentración de APA y en la interacción entre las concentraciones de APA y los tiempos de contacto (ver anexo).

En cultivos tratados con 10,15 y $20 \mathrm{mg}^{-L^{-1}}$ de APA a $0,1,8,24$ y 48 horas de tiempo de contacto, se encontraron diferencias significativas $(p<0,05)$ en las proteínas totales de los tratamientos control (sin adición de ácido peracético) con respecto al tiempo de contacto. En el caso de los cultivos tratados, se encontraron diferencias significativas $(p<0,05)$ para las proteínas totales con respecto a los tiempos de contacto, así como los tratamientos con APA, los tiempos de contacto y en la interacción entre la concentración de APA y los tiempos (ver anexo).

\subsubsection{Efecto del APA sobre la clorofila-a expresada en $\boldsymbol{\mu g} \cdot \mathbf{L}^{-1}$}

En el caso de las cianobacterias al ser organismos fotoautótrofos, la clorofila es fundamental para su ciclo de vida razón por la cual se evalúa su variación en cultivos de M. aeruginosa tratados a diferentes concentraciones de APA (Figura 16).
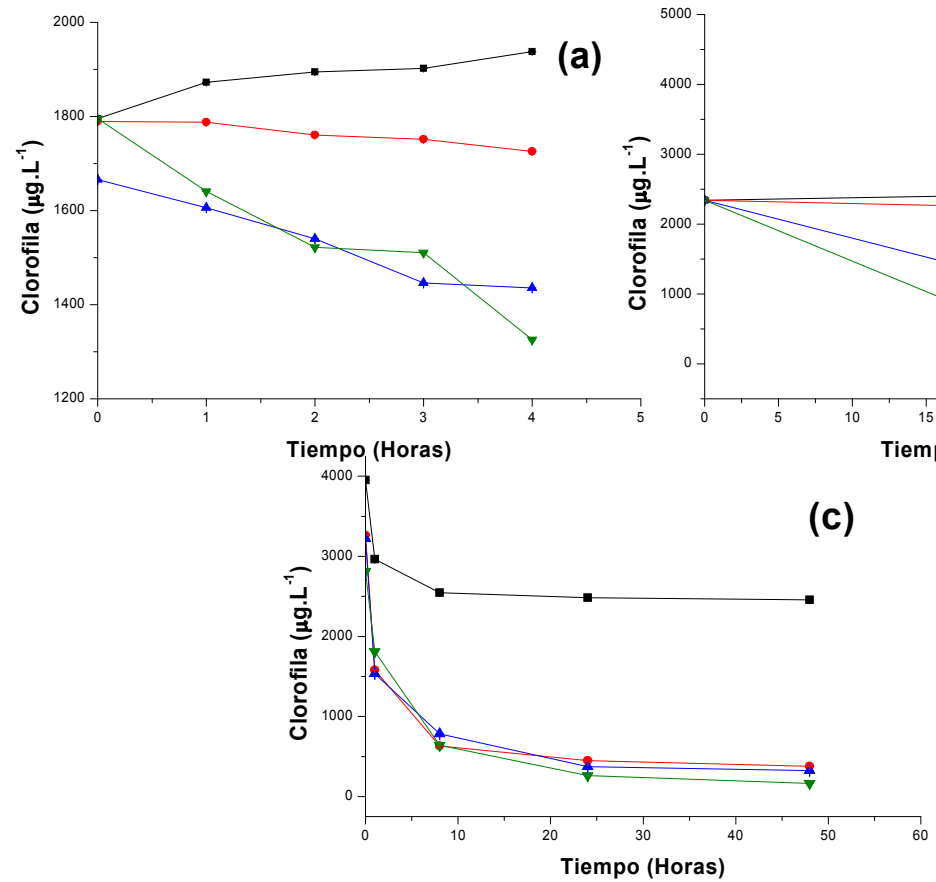

(b)

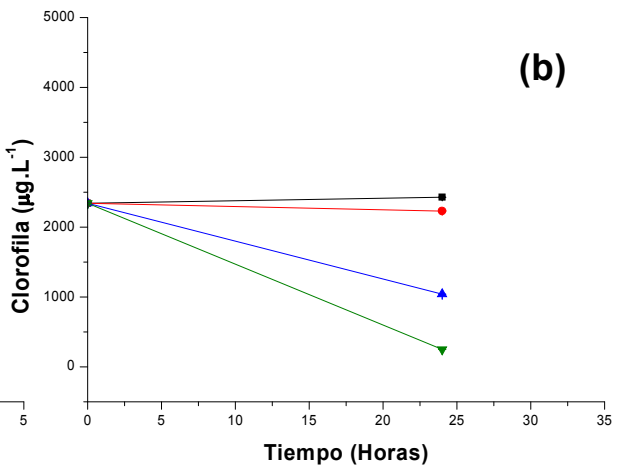

(c)

Figura 16. Efecto de una solución del APA sobre la clorofila-a de un cultivo de M. aeruginosa a diferentes concentraciones de producto a) control, •5,

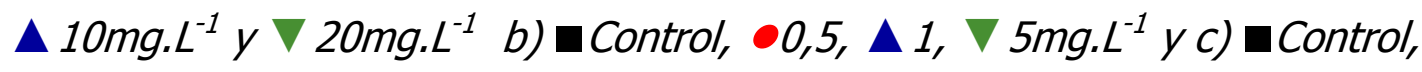
-10, $\Delta 15, \nabla 20 \mathrm{mg} \cdot \mathrm{L}^{-1}$ 
A efectos de un mejor análisis de la acción del APA sobre los valores de clorofila-a en los cultivos tratados, se evaluó la remoción de clorofila respecto del valor de clorofila- $a$ inicial mediante el porcentaje de reducción a 0, 1, 2, 3 y 4 horas de tiempo de contacto tratados con 5,10 y $20 \mathrm{mg}^{-1}{ }^{-1}$ de APA (Tabla 12).

Tabla 12. Porcentaje de degradación de clorofila-a a 0, 1, 2, 3 y 4 horas de tiempo de contacto y 5,10 y $20 \mathrm{mg}^{-L^{-1}}$ de concentración de APA

\begin{tabular}{|c|c|c|c|c|c|c|c|}
\hline Tiempo & Control & \multicolumn{2}{|c|}{$5 \mathrm{mg} \cdot \mathrm{L}^{-1}$} & \multicolumn{2}{c|}{$10 \mathrm{mg}_{\mathrm{L}}^{-1}$} & \multicolumn{2}{c|}{$20 \mathrm{mg}_{\mathrm{L}}^{-1}$} \\
\hline Horas & $\begin{array}{c}\text { Clorofila } \\
\mu \mathrm{g} \cdot \mathrm{L}^{-1}\end{array}$ & $\begin{array}{c}\text { Clorofila } \\
\mu \mathrm{g} \cdot \mathrm{L}^{-1}\end{array}$ & $\begin{array}{c}\% \\
\text { Degradación }\end{array}$ & $\begin{array}{c}\text { Clorofila } \\
\mu \mathrm{g} \cdot \mathrm{L}^{-1}\end{array}$ & $\begin{array}{c}\% \\
\text { Degradación }\end{array}$ & $\begin{array}{c}\text { Clorofila } \\
\mu \mathrm{g} \cdot \mathrm{L}^{-1}\end{array}$ & $\begin{array}{c}\% \\
\text { Degradación }\end{array}$ \\
\hline $\mathbf{0}$ & 1795 & 1789 & 0 & 1666 & 0 & 1795 & 0 \\
\hline $\mathbf{1}$ & 1872 & 1787 & 0,11 & 1605 & 3,6 & 1641 & 8,6 \\
\hline $\mathbf{2}$ & 1894 & 1760 & 1,6 & 1539 & 7,6 & 1522 & 15,2 \\
\hline $\mathbf{3}$ & 1902 & 1751 & 2,1 & 1446 & 13,2 & 1510 & 15,8 \\
\hline $\mathbf{4}$ & 1937 & 1726 & 3,5 & 1435 & 13,9 & 1325 & 26,1 \\
\hline
\end{tabular}

Se puede observar que la clorofila-a es susceptible de ser oxidada por la acción del APA y que esta degradación aumenta en la medida que la dosis de APA y tiempo de contacto es mayor. Con la dosis más alta de APA $\left(20 \mathrm{mg} \cdot \mathrm{L}^{-1}\right)$ se alcanza una degradación del $26 \%$ en comparación con las otra dosis de APA de (5-10 mg. $\left.\mathrm{L}^{-1}\right)$ donde solo se alcanzaron degradaciones de 3 y $13 \%$ respectivamente.

No se encontraron diferencias significativas $(p>0,05)$ en el contenido de clorofila- $a$ de los cultivos control (sin agregado de peracético) con respecto al tiempo. Para los cultivos que fueron tratados con la solución de ácido peracético no se encontraron diferencias significativas en la clorofila-a para los tratamientos con 5 y $10 \mathrm{mg} \cdot \mathrm{L}^{-1}(\mathrm{p}>0,05)$. Para el caso de los cultivos tratados con 20mg. $L^{-1}$ existen diferencias significativas $(p<0,05)$ entre la clorofila- $a$ con respecto al tiempo de contacto. Al realizar el ANOVA para el total de los datos de este tratamiento, se establecieron diferencias significativas en la clorofila- $a$ $(p<0,05)$ con respecto a la dosis de ácido peracético y en la interacción entre la concentración inicial de peracético y los tiempos de contacto.

Es de interés analizar la degradación de la clorofila-a respecto del valor inicial, al utilizar dosis de APA menores y tiempos de contacto de 24 horas (Fig. 16 b). Los porcentajes de reducción de clorofila-a se presentan en la tabla 13.

Tabla 13. Porcentaje de degradación de clorofila-a a 0 y 24 horas de tiempo de contacto y $0,5,1$ y $5 \mathrm{mg} . \mathrm{L}^{-1}$ de concentración de solución de ácido peracético. 


\begin{tabular}{|c|c|c|c|c|c|c|c|}
\hline Tiempo & CONTROL & 0.5 PPM & & 1 PPM & & 5 PPM & \\
\hline & $\begin{array}{c}\text { Clorofila } \\
\mu \mathrm{g} / \mathrm{L}\end{array}$ & $\begin{array}{c}\text { Clorofila } \\
\mu \mathrm{g} / \mu \mathrm{l}\end{array}$ & \% reducción & $\begin{array}{c}\text { Clorofila } \\
\mu \mathrm{g} / \mu \mathrm{l}\end{array}$ & \% reducción & $\begin{array}{c}\text { Clorofila } \\
\mu \mathrm{g} / \mu \mathrm{l}\end{array}$ & \% reducción \\
\hline (0 horas) & 2340,85 & 2340,85 & & 2340,85 & & 2340,85 & \\
\hline (24 horas) & 2340,85 & 2228,25 & 4,81 & 1043,01 & 52,17 & 248,90 & 89,360 \\
\hline
\end{tabular}

Como muestra la tabla 13, al utilizar dosis de APA más bajas y exponiendo el cultivo a tiempos de contacto de 24 horas se puede lograr reducción en la clorofila- $a$ de hasta $89 \%$ con $5 \mathrm{mg} \cdot \mathrm{L}^{-1}$ de APA. Con dosis menores de APA $(0,5 \mathrm{y}$ $1 \mathrm{mg} . \mathrm{L}^{-1}$ ) se logra una degradación de la clorofila-a de 4 y $52 \%$ respectivamente.

Se encontraron diferencias significativas $(p<0,05)$ en la relación entre la clorofila-a y los tiempos de contacto, la dosis de ácido peracético, y en la interacción entre la concentración inicial de peracético y los tiempos de contacto (ver anexo).

En la Figura 17 (fotografía) se observa el aspecto de los cultivos luego de 24 horas de tratamiento con las diferentes concertaciones del producto. Puede observarse que a las concentraciones $\left(1,0\right.$ y $\left.5,0 \mathrm{mg}^{-1} \mathrm{~L}^{-1}\right)$ el aspecto del cultivo es más claro indicando degradación de la clorofila-a.

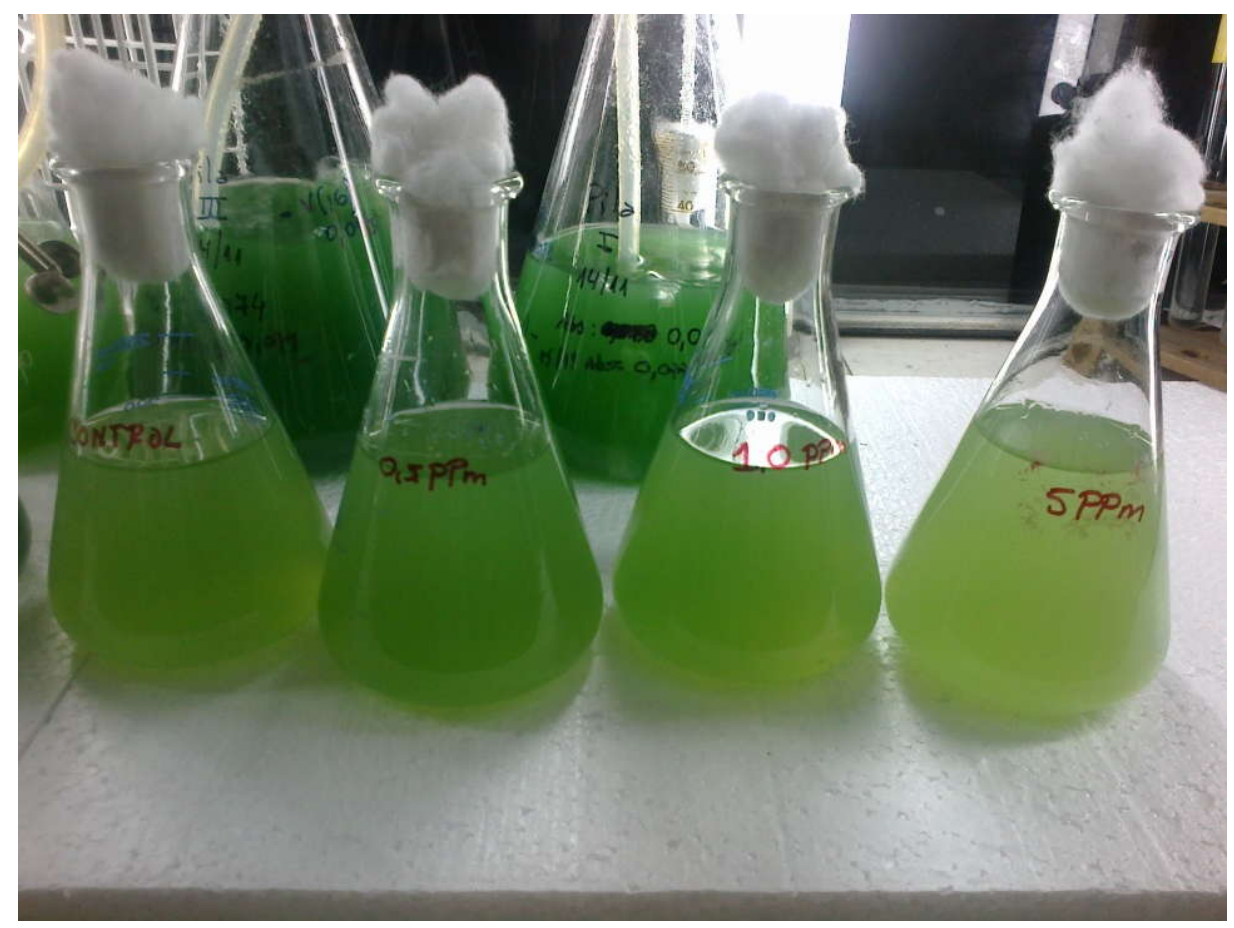

Figura 17. Fotografía que indica el aspecto de los cultivos luego de 24 horas de aplicación a 0, 0,5, 1 y 5mg. $\mathrm{L}^{-1}$ de solución de ácido peracético 
La degradación de clorofila-a resultó evidente utilizando diferentes concentraciones de APA en tiempos de hasta 48hs. El porcentaje de clorofila-a respecto del valor inicial en cultivos tratados, a una concentración de producto de 10,15 y $20 \mathrm{mg}^{-1} \mathrm{~L}^{-1}$ y $0,1,8,24$ y 48 horas de tiempo de contacto se presenta en la Tabla 14.

Tabla 14. Porcentaje de reducción de clorofila-a a 0, 1, 8, 24 y 48 horas de tiempo de contacto y 10,15 y $20 \mathrm{mg}^{-1} \mathrm{~L}^{-1}$ de concentración de ácido peracético

\begin{tabular}{|c|c|c|c|c|c|c|c|}
\hline \multirow{2}{*}{$\begin{array}{l}\text { Tiempo } \\
\text { Horas }\end{array}$} & \multirow{2}{*}{ Control } & \multicolumn{2}{|c|}{$10 \mathrm{mg} \cdot \mathrm{L}^{-1}$} & \multicolumn{2}{|c|}{$15 \mathrm{mg} \cdot \mathrm{L}^{-1}$} & \multicolumn{2}{|c|}{$20 \mathrm{mg} \cdot \mathrm{L}^{-1}$} \\
\hline & & Clorofila $\mu \mathrm{g} \cdot \mathrm{L}^{-1}$ & $\begin{array}{c}\% \\
\text { Degradación }\end{array}$ & Clorofila $\mu \mathrm{g} \cdot \mathrm{L}^{-1}$ & $\begin{array}{c}\% \\
\text { Degradación }\end{array}$ & $\begin{array}{c}\text { Clorofila } \\
\mu \mathrm{g} \cdot \mathrm{L}^{-1}\end{array}$ & $\begin{array}{c}\% \\
\text { Degradación }\end{array}$ \\
\hline 0 & 3950 & 3263 & 0 & 3223 & 0 & 2812 & 0 \\
\hline 1 & 2963 & 1580 & 51,5 & 1532 & 52,4 & 1809 & 35,6 \\
\hline 8 & 2544 & 632 & 80,6 & 782 & 75,7 & 640 & 77,2 \\
\hline 24 & 2481 & 450 & 86,1 & 371 & 88,4 & 260 & 90,7 \\
\hline 48 & 2457 & 379 & 88,3 & 322 & 90,1 & 163 & 94,2 \\
\hline
\end{tabular}

La mayor degradación de Clorofila-a se logró con $20 \mathrm{mg}^{-L^{-1}}$ de APA en 48 horas de tiempo de contacto en cultivos tratados siendo la degradación de 94,2\%. Resultados similares se pueden lograr con $15 \mathrm{mg}^{-L^{-1}}$ de APA luego de 48 horas de contacto, logrando una degradación del 90,1\%. Como era de esperar, con la dosis de $10 \mathrm{mg} \cdot \mathrm{L}^{-1}$ de APA se logró la degradación más baja con un $88,3 \%$.

El ANOVA indico la existencia de diferencias significativas en la clorofila-a $(p<0,05)$ con respecto a los diferentes tiempos de contacto y la concentración de APA. No se encontraron diferencias significativas la interacción entre la clorofila- $a$ y el tiempo de contacto $(p>0,05)$ para el total de los datos de clorofila-a (ver anexo).

La figura 18 permite mostrar el aspecto de los cultivos de $M$. aeruginosa tratados con 10,15 y $20 \mathrm{mg}^{-L^{-1}}$ de APA y 24 horas de tiempo de contacto. 


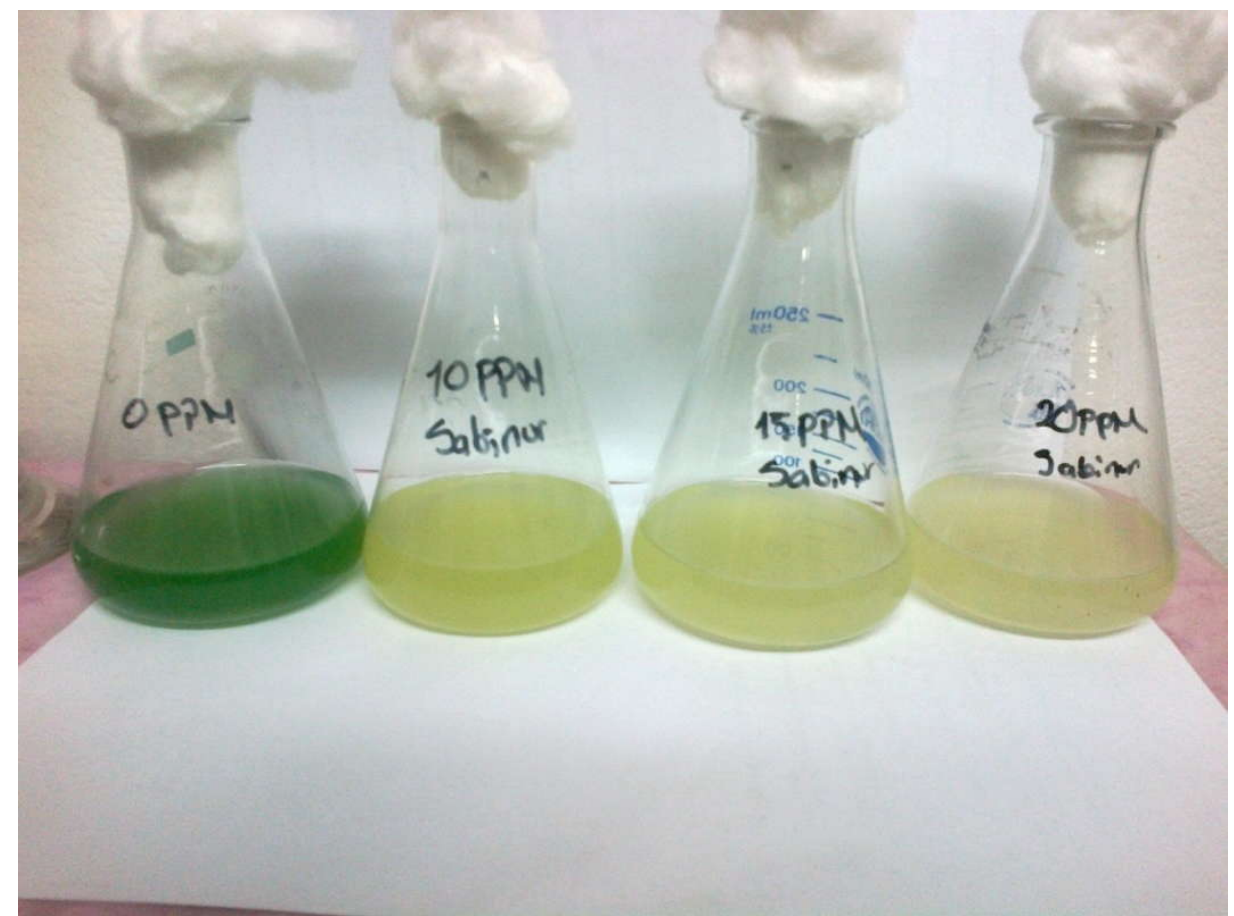

Figura 18. Fotografía que evidencia el efecto del APA sobre la clorofila- $a, a$ tiempos de contacto de 24 horas y concentraciones de producto de 10, 15 y 20 $m g \cdot L^{-1}$

4.4.4. Efecto de una solución de ácido peracético sobre el recuento celular expresado en $\mathrm{N}^{\circ}$ de células por $\mathrm{mL}^{-1}$ A continuación se presentan los resultados de la acción del APA sobre el recuento celular de cultivo de $M$. aeruginosa expresado en cel. $\mathrm{mL}^{-1}$ mediante microscopio.
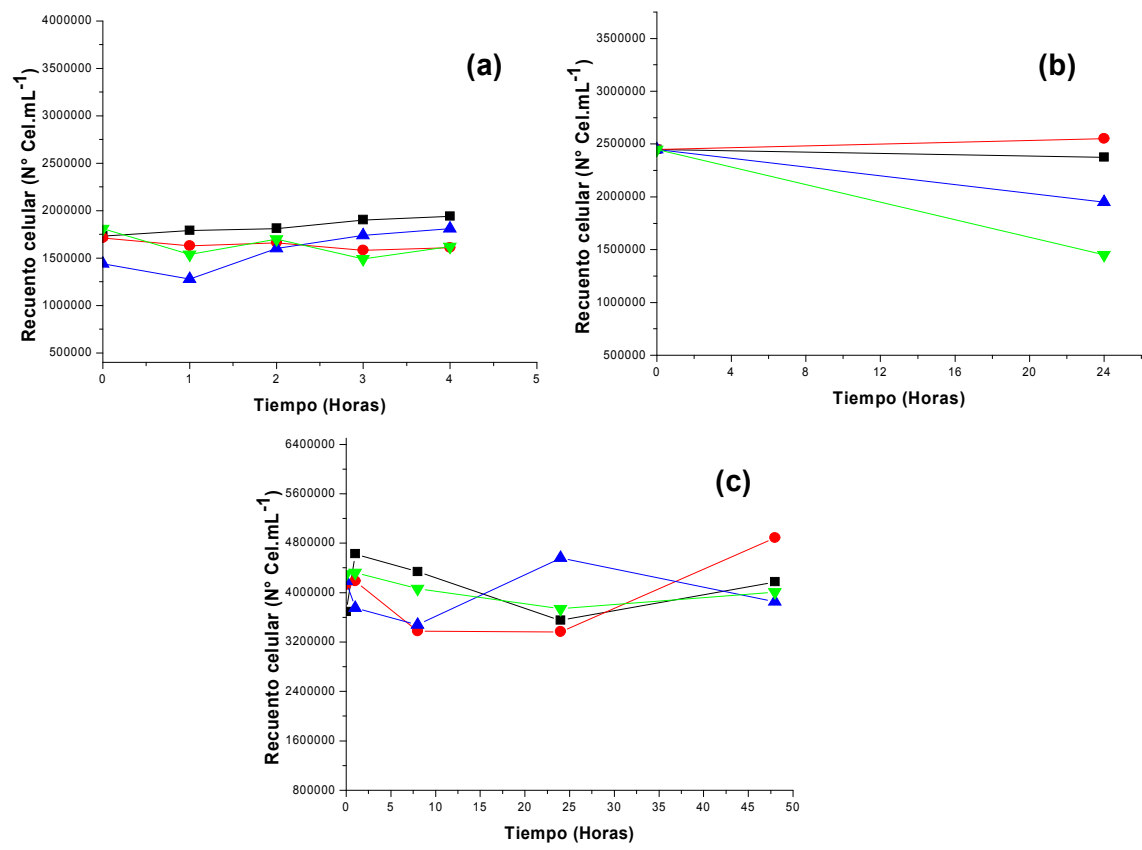
Figura 19. Efecto de una solución de APA sobre el recuento celular a) Control,

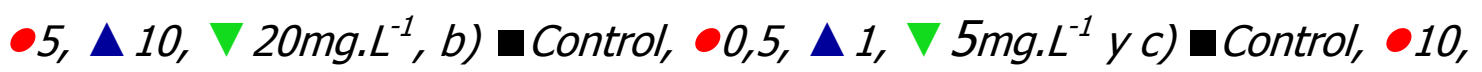
$\Delta 15, \nabla 20 \mathrm{mg}^{-1} \mathrm{~L}^{-1}$ a $0,1,8,24$ y 48 horas de tiempos de contacto.

De la figura 19 se puede observar que no hay variación en el número de cel. $\mathrm{mL}^{-1}$ debido a que este método no permite diferenciar células vivas de muertas, por tal razón, la viabilidad de las células para cada tratamiento se hizo por recuento en placa de petry como se muestra en el siguiente ítem.

En la Figura 20 se puede observar células al microscopio óptico de Microcystis aeruginosa tratada con $5 \mathrm{mg}^{-1} \mathrm{~L}^{-1}$ de una solución de APA durante 24 horas.

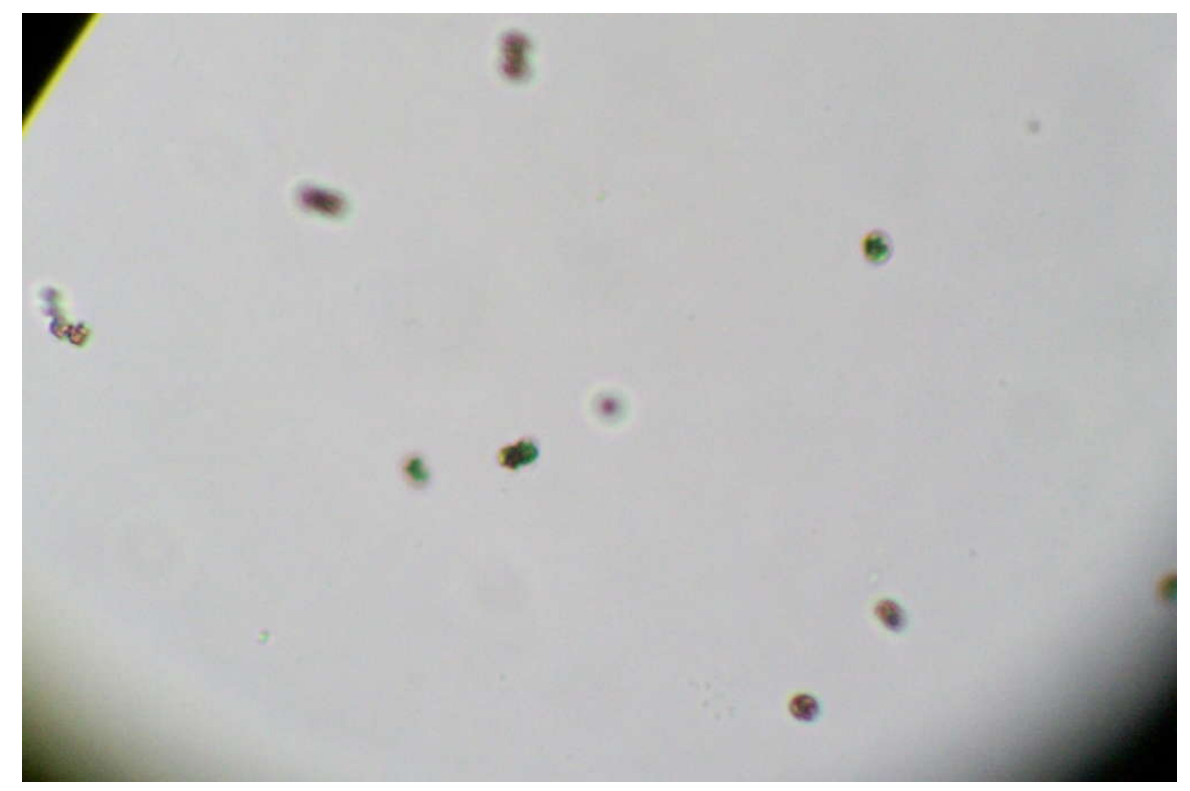

Figura 20. Fotografía de un cultivo de Microcystis aeruginosa tratada durante 24 horas con $5 \mathrm{mg} \cdot \mathrm{L}^{-1}$ de ácido peracético tomada con microscopio invertido

Diferentes concentraciones de APA no mostraron diferencias sobre el recuento celular durante los tiempos de contacto. Si se puede observar directamente en el microscopio óptico o invertido un cambio en la birrefringencia de las células de Microcystis aeruginosa, lo que supone cierto efecto sobre estas, confirmado con los otros parámetros que fueron estudiados en el presente trabajo como las proteínas, la densidad óptica del cultivo y la clorofila-a.

Tratamientos durante 24 horas con 1 y $5 \mathrm{mg}^{-1} \mathrm{~L}^{-1}$ este producto oxidante produce alteraciones en la morfología celular de las células de Microcystis aeruginosa dadas por pérdida de color y birrefringencia en el interior celular. 


\subsubsection{Efecto de una solución de APA sobre la viabilidad celular utilizando método de siembra en placa}

La viabilidad celular resulta interesante ser evaluada mediante el recuento en placa. Ello se presenta a continuación en la Figura 21.

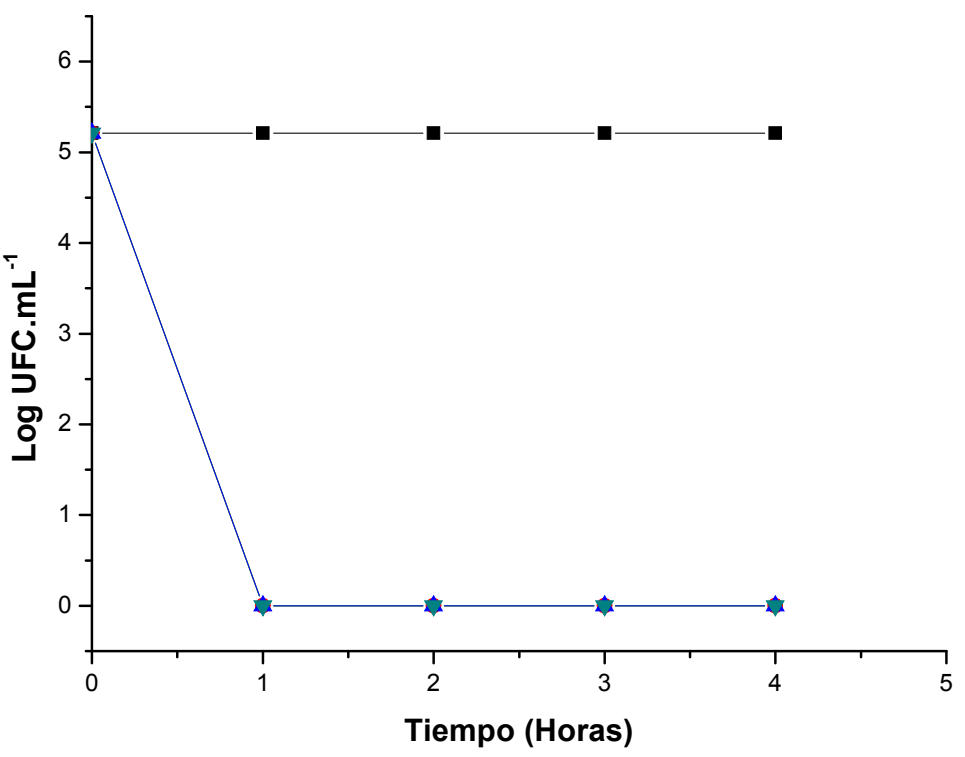

Figura 21. Viabilidad de un cultivo de Microcystis aeruginosa (siembra en placa de petry) en el Control y tratadas con $\bullet 5, \Delta 10, \nabla 20 \mathrm{mg}^{-1} \mathrm{~L}^{-1}$ de APA

Como muestra la Figura 21, los cultivos tratados a estas tres concentraciones $\left(5,10\right.$ y $\left.20 \mathrm{mg} . \mathrm{L}^{-1}\right)$ no mostraron viabilidad a partir de 1 hora de tiempo de contacto, inclusive a la dosis más baja con $5 \mathrm{mg} \cdot \mathrm{L}^{-1}$. Lo anterior indica que para este tratamiento se logró una reducción de 5 ciclos logarítmicos a partir de una hora de tiempo de contacto, 99,999\% de reducción de M. aeruiginosa.

Ello se debe al poderoso potencial de oxidación que presenta el peracetico $(1,87 \mathrm{~V})$ siendo su mecanismo principal de acción la capacidad de atravesar la membrana citoplasmática de las células, oxidando los componentes y destruyendo sistemas enzimáticos claves de la vida celular.

No se encontraron diferencias significativas $(p>0,05)$ en el número de viables expresado en Log UFC. $\mathrm{mL}^{-1}$ de los cultivos control (sin agregado de APA) con respecto al tiempo. Para los cultivos que fueron tratados con la solución de APA, no se encontraron diferencias significativas en el número de viables para los cultivos tratados con 5,10 y $20 \mathrm{mg}^{-1} \mathrm{~L}^{-1}(\mathrm{p}>0,05)$. Al realizar el ANOVA este tratamiento, se establecieron diferencias significativas en el número de viables $(p<0,05)$ con respecto al tiempo de contacto, la dosis de ácido peracético y en 
la interacción entre la concentración inicial de peracético y los tiempos de contacto (ver anexo).

Es de importancia estudiar el efecto del APA sobre la viabilidad celular de APA a dosis de oxidante más bajas. Tal como se muestra a continuación en la Figura 22.

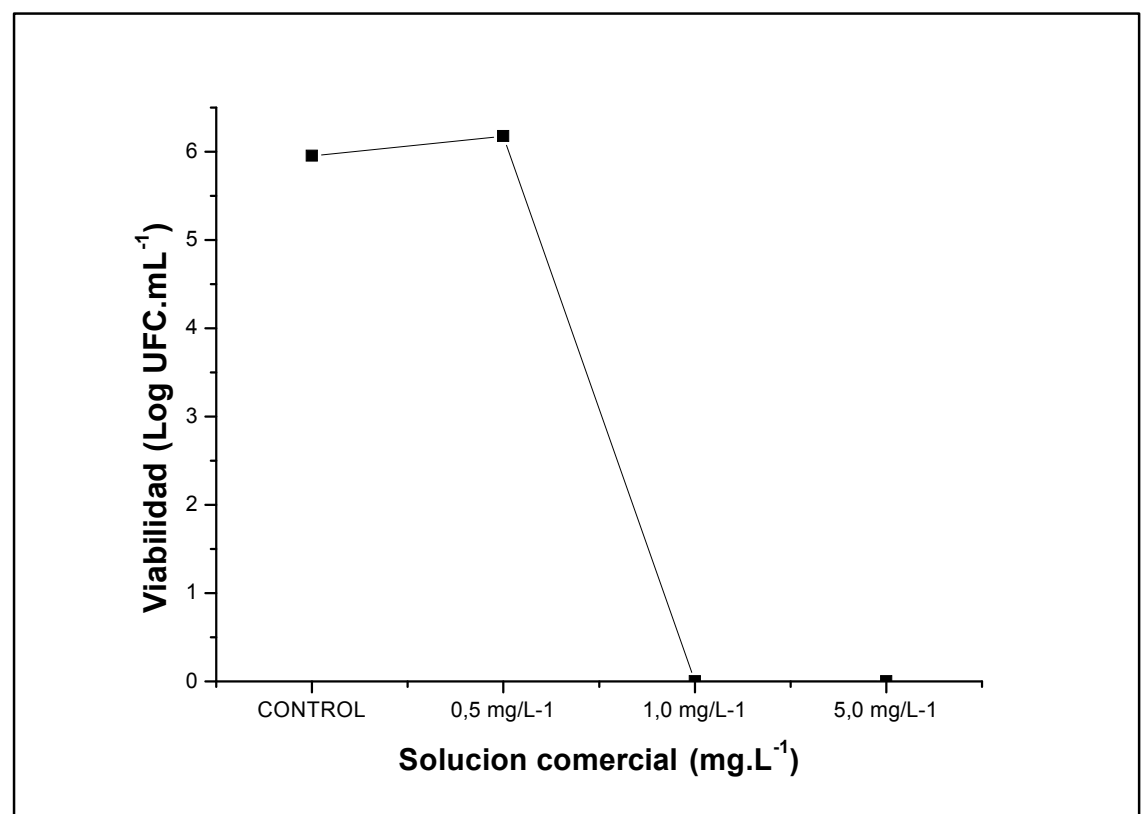

Figura 22. Viabilidad de un cultivo de Microcystis aeruginosa (mediante siembra en placa de petry) luego de 24 horas de tiempo de contacto a 0,5, 1 y $5 \mathrm{mg} \cdot \mathrm{L}^{-1}$ de APA

Con una dosis de $0,5 \mathrm{mg} \cdot \mathrm{L}^{-1}$ no se observa variaciones en el número de células viables de cultivos tratados, sin embargo, a partir de $1 \mathrm{mg}^{-L^{-1}}$ no se observa viabilidad, es decir que una concentración de APA de $1 \mathrm{mg}^{-L^{-1}}$ es suficiente para inhibir la viabilidad de $M$. aeruginosa.Se encontraron diferencias significativas $(p<0,05)$ en la relación entre el número de viables expresado en Log UFC. $\mathrm{mL}^{-1}$ y los tiempos de contacto, la dosis de ácido peracético, y en la interacción entre la concentración inicial de peracético y los tiempos de contacto para el total de los datos de este tratamiento (ver anexo). 


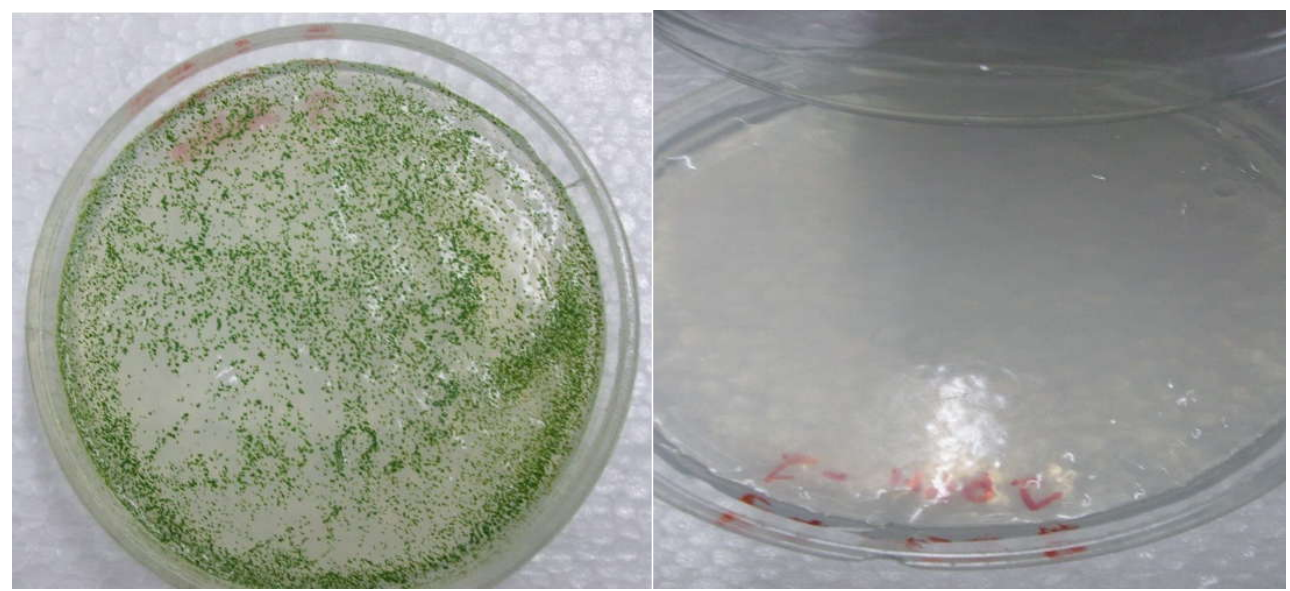

Figura 23. Fotografía de la viabilidad celular de Microcystis aeruginosa luego de resiembra de $100 \mu \mathrm{L}$ de cultivo en placa de Petry. Foto izquierda cultivo sin tratar. Foto derecha cultivo tratado durante 24 horas con $1,0 \mathrm{mg} \cdot \mathrm{L}^{-1}$ de APA. Se observa ausencia de crecimiento.

La variación de la viabilidad celular expresado en UFC. $\mathrm{mL}^{-1}$ mediante el método de siembra en placa de Petry luego de 24 horas de aplicado a diferentes concentraciones del producto mostró que la concentración de APA de $0,5 \mathrm{mg} \cdot \mathrm{L}^{-1}$ presentó una viabilidad similar al control. Se encontró una disminución significativa de la viabilidad celular a las concentraciones de producto de 1 y 5 $\mathrm{mg} \cdot \mathrm{L}^{-1}$. Con $1 \mathrm{mg} \cdot \mathrm{L}^{-1}$ no se observó crecimiento en la placa por lo cual este nivel de APA corresponde a la concentración inhibitoria mínima (CIM) del producto ensayado $\left(1 \mathrm{mg} \cdot \mathrm{L}^{-1}\right)$ que corresponde al límite inferior a la cual el producto evidencia una acción biocida en cultivo de Microcystis aeruginosa.

Resulta importante remarcar que no existen datos bibliográficos respecto a la acción anti-cianobacteriana referida al ácido peracético. Este es el primer reporte de CIM para M. aeruginosa.

Una vez realizadas las pruebas para los parámetros de cultivos tratados con APA, es necesario evaluar la acción del oxidante sobre la degradación de MCLR. Este análisis nos dará herramientas para decidir cuál es el mejor momento de agregar el APA en caso de un florecimiento cianobacteriano. 
4.4.6. Efecto de una solución de ácido peracético sobre la degradación de MC-LR en cultivo de Microcystis aeruginosa determinado por Cromatografía liquida de alta performance (HPLC)

La concentración inicial de MC-LR varió en cada ensayo de acuerdo a las características de crecimiento del cultivo, se encontró niveles que variaron entre $0,30-0,65 \mathrm{mg} \cdot \mathrm{L}^{-1}$.

La cromatografía liquida de alta resolución permite la identificación y cuantificación de las toxinas producidas por las cianobacterias siendo una metodología específica y sensible, aceptada internacionalmente. En la Figura 24 se muestra el efecto de diferentes concentraciones de una solución comercial de APA sobre la degradación de MC-LR a concentraciones de 5,10 y $20 \mathrm{mg}^{-L^{-1}}$ de APA y diferentes tiempos de contacto en un cultivo de $M$. aeruginosa.

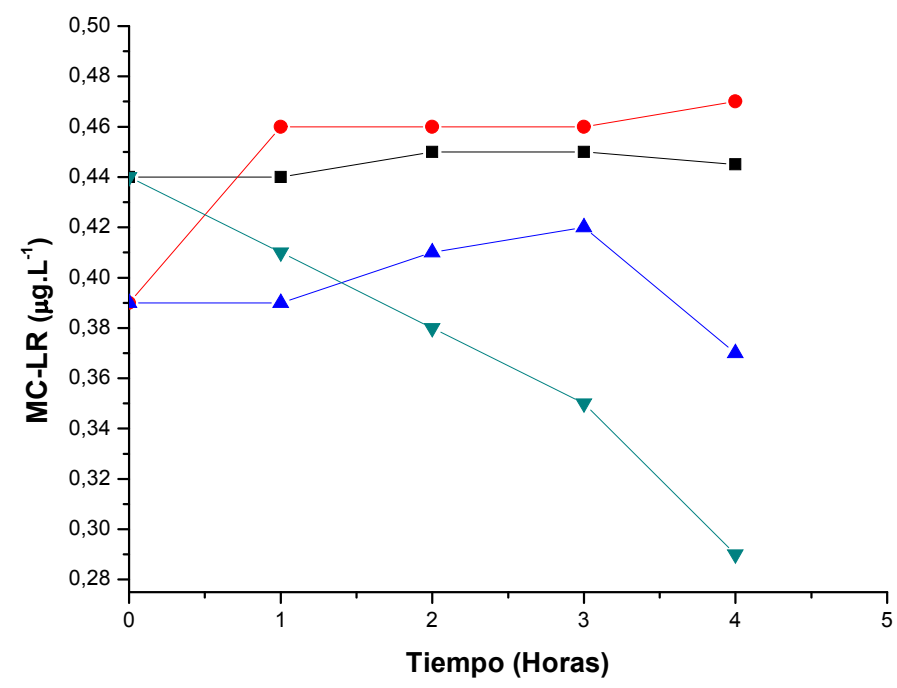

Figura 24. Efecto de una solución comercial de APA sobre la degradación de $M C-L R$ a concentraciones de $\mathbf{c}$ Control, $05, \triangle 10, \nabla 20 \mathrm{mg} \cdot L^{-1}$ de APA

En la Tabla 15 se muestran las variaciones en la cantidad de MC-LR en mg. $\mathrm{L}^{-1}$, evaluado mediante la técnica de Cromatografía Liquida de Alta Perfomance (HPLC) a los diferentes tiempos de contacto $(0,1,2,3$ y 4 horas) y concentración de APA $\left(5,10\right.$ y $\left.20 \mathrm{mg}^{-1} \mathrm{~L}^{-1}\right)$. En los casos en los que existe un aumento en la concentración de toxina total, el \% de reducción adquiere valores positivos.

Ec. 15. 
Tabla 15. Porcentaje de degradación MC-LR, realizados mediante la técnica de HPLC a 0, 1, 2, 3 y 4 horas de tiempo de contacto y concentraciones de APA 5,10 y $20 \mathrm{mg}^{-\mathrm{L}^{-1}}$ analizado mediante HPLC a un cultivo de Microcystis aeruginosa.

\begin{tabular}{|c|c|c|c|c|c|c|c|}
\hline Tiempo & Control & \multicolumn{2}{|c|}{$5 \mathrm{mg} \mathrm{L}^{-1} \mathrm{APA}$} & \multicolumn{2}{|c|}{$10 \mathrm{mg} \mathrm{L}^{-1} \mathrm{APA}$} & \multicolumn{2}{|c|}{$20 \mathrm{mg} \mathrm{L}^{-1}$ APA } \\
\hline & $\mathrm{mg} \cdot \mathrm{L}^{-1}$ & $m g \cdot L^{-1}$ & \%Degradación & $\mathrm{mg} \cdot \mathrm{L}^{-1}$ & \%Degradación & $\mathrm{mg} \cdot \mathrm{L}^{-1}$ & \%Degradación \\
\hline 0 horas & 0,45 & 0,39 & 0 & 0,39 & 0 & 0,44 & 0 \\
\hline 1 horas & 0,45 & 0,46 & $+17,94 \%$ & 0,39 & $0 \%$ & 0,41 & $6,81 \%$ \\
\hline 2 horas & 0,45 & 0,46 & $+17,94 \%$ & 0,41 & $+5 \%$ & 0,38 & $13,63 \%$ \\
\hline 3 horas & 0,44 & 0,46 & $+17,94 \%$ & 0,42 & $+7 \%$ & 0,35 & $20,45 \%$ \\
\hline 4 horas & 0,44 & 0,47 & $+20,51 \%$ & 0,37 & $5,00 \%$ & 0,29 & $34 \%$ \\
\hline
\end{tabular}

Puede observarse que a partir de 4 horas de aplicación de APA $\left(5 \mathrm{mg} \cdot \mathrm{L}^{-1}\right)$ sobre un cultivo de $M$. aeruginosa se observa un aumento en la concentración de toxina del $20,51 \%$ probablemente debido a la lisis provocada por el oxidante $y$ la consecuente liberación de la toxina intracelular. Con una concentración de APA de $10 \mathrm{mg}^{-1} \mathrm{~L}^{-1}$ y 4 horas de tiempo de contacto, se observa una degradación de la toxina total en cultivos tratados del $5 \%$. El porcentaje de degradación más alto en este ensayo se logra con $20 \mathrm{mg}^{-1} \mathrm{~L}^{-1}$ a 4 horas llegando a un $34 \%$.

El análisis de varianza (ANOVA) para los cultivos tratados con 5,10 y $20 \mathrm{mg} \cdot \mathrm{L}^{-1}$ de APA a 0, 1, 2, 3 y 4 horas de tiempos de contacto indica que en el tratamiento control (sin agregado de APA) con un $p>0.05$ no existen diferencias significativas entre la toxina del cultivo y los diferentes tiempos. En el caso de los cultivos tratados con 5,10 y $20 \mathrm{mg}^{-1}{ }^{-1}$ de APA, se encontraron diferencias significativas $p<0,05$ entre la concentración de toxina y los diferentes tiempos de contacto para los cultivos tratados de Microcystis aeruginosa. Al analizar todos los tratamientos, tiempos de contacto y dosis de APA, se encontraron diferencias significativas $p<0,05$ entre la toxina y los tiempos de contacto para las tres concentraciones de APA, entre las dosis de APA y en la interacción entre los tiempos de contacto y las dosis, para los cultivos tratados (ver anexo).

Resulta importante evaluar el efecto de diferentes concentraciones de APA sobre un cultivo de $M$. aeruginosa durante tiempos máximos de contacto de 24 hs. En la Figura 25 se presenta el efecto de una solución de ácido peracético a concentraciones de $0,5,1$ y $5 \mathrm{mg}^{-L^{-1}}$ sobre la degradación de MC-LR extraída de un cultivo tratado de Microcystis aeruginosa. 


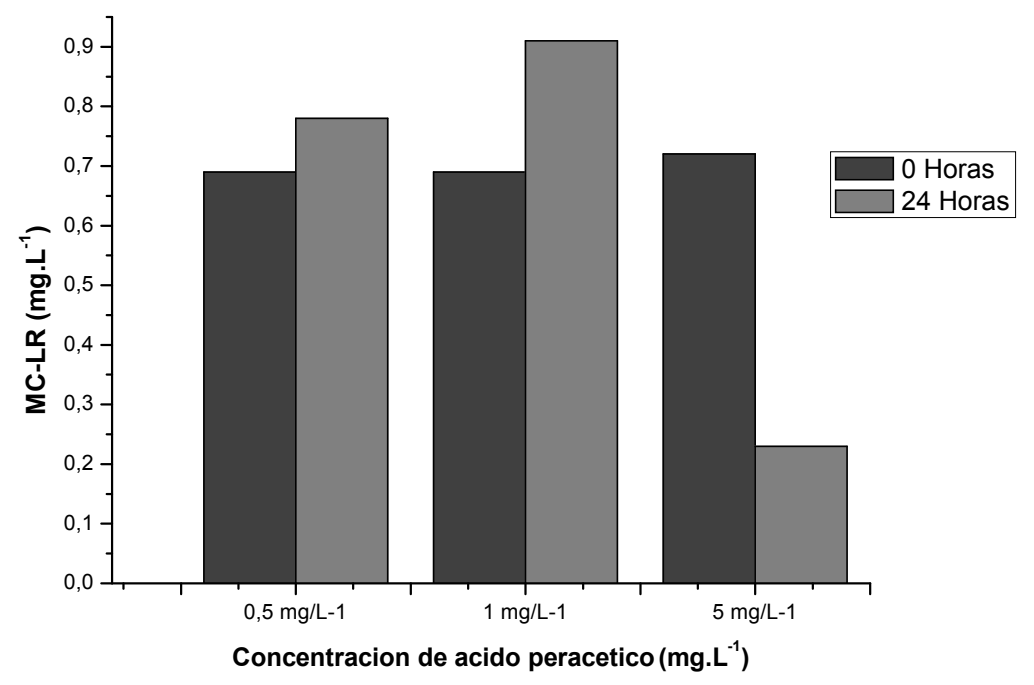

Figura 25. Efecto de una solución de ácido peracético sobre la MC-LR a 0 y 24 horas de tiempo de contacto y concentraciones de ácido peracético de 0,5, 1 y $5 \mathrm{mg} \cdot \mathrm{L}^{-1}$, mediante la técnica de HPLC sobre un cultivo de Microcystis aeruginosa.

Se observa que a concentraciones de 0,5 y $1 \mathrm{mg}^{-L^{-1}}$ y 24 horas de tiempo de contacto la concentración de toxina aumenta, lo que indica que causa un efecto sobre el cultivo que hace que se libere la toxina. A continuación se presenta en la Tabla 16. El porcentaje de degradación para este ensayo.

Tabla 16. Porcentaje de degradación MC-LR, realizados mediante la técnica de HPLC a 0 y 24 horas de tiempo de contacto y concentraciones de APA 0,5,1,0 y $5 \mathrm{mg} \cdot \mathrm{L}^{-1}$ analizado mediante HPLC a un cultivo de Microcystis aeruginosa.

\begin{tabular}{|c|c|c|c|c|c|c|c|}
\hline & \multicolumn{2}{|c|}{$0,5 \mathrm{mg} \cdot \mathrm{L}^{-1} \mathrm{APA}$} & \multicolumn{2}{|c|}{$1 \mathrm{mg}_{\mathrm{L}}^{-1} \mathrm{APA}$} & \multicolumn{2}{|c|}{$5 \mathrm{mg} \cdot \mathrm{L}^{-1} \mathrm{APA}$} \\
\hline $\mathbf{0}$ horas & 0,69 & 0,69 & 0 & 0,69 & 0 & 0,72 & 0 \\
\hline $\begin{array}{c}\mathbf{2 4} \\
\text { horas }\end{array}$ & 0,71 & 0,78 & $+13,04$ & 0,91 & $+31,88$ & 0,23 & 68,05 \\
\hline
\end{tabular}

La tabla 16 nos muestra que si aplicáramos las concentraciones más bajas de este tratamiento $\left(0,5\right.$ y $\left.1 \mathrm{mg} . \mathrm{L}^{-1}\right)$ sobre un cultivo a partir de 24 horas se aumentarían la concentración de toxina entre un 13,04 y $31,88 \%$ quizás debido a la lisis provocada por el oxidante. Con una concentración de APA de $5 \mathrm{mg}^{-\mathrm{L}^{-1}}$ y 24 horas de tiempo de contacto se evidencia una degradación de la toxina total en cultivos tratados, (68,05\% de remoción). 
El análisis de varianza (ANOVA) para los cultivos tratados con 0,51 , y $5 \mathrm{mg}^{-\mathrm{L}^{-1}}$ de APA a 0 y 24 horas de tiempos de contacto indica que se encontraron diferencias significativas $\mathrm{p}<0,05$ entre la concentración de toxina y los diferentes tiempos de contacto para los cultivos tratados de Microcystis aeruginosa (ver anexo).

Por otra parte al analizar todos los tratamientos, tiempos de contacto y dosis de APA, se encontraron diferencias significativas $p<0,05$ entre la toxina y los tiempos de contacto para las tres concentraciones de APA, entre las dosis de APA y en la interacción entre los tiempos de contacto y las dosis, para cultivos tratados (ver anexo).

Con la finalidad de continuar con el análisis de la acción del APA sobre la MC-LR se ensayaron mayores concentraciones de APA siendo el tiempo de contacto de 24 horas. En la Figura 26 se muestran las concentraciones de toxina en cultivos tratados con 10,15 y $20 \mathrm{mg}^{-\mathrm{L}^{-1}}$ a 0 y 24 horas de tiempo de contacto.

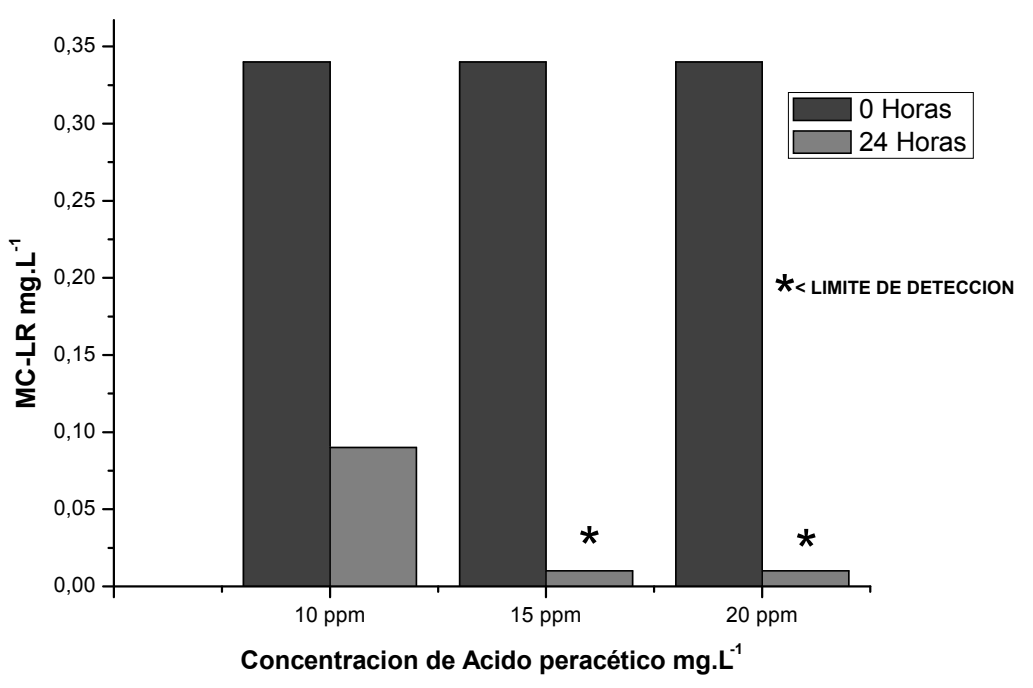

Figura 26. Efecto de una solución de ácido peracético sobre la degradación de $M C-L R$ a 0 y 24 horas de tiempo de contacto y concentraciones de ácido peracético de 10, 15 y 20mg. $\mathrm{L}^{-1}$. Mediante la técnica de HPLC sobre un cultivo de Microcystis aeruginosa.

Puede observarse que en la medida que la concentración de APA aumenta, la concentración de toxina tiende a disminuir, a continuación en la Tabla 17 se presentan los porcentajes de degradación para este ensayo. 
Tabla 17. Porcentaje de degradación MC-LR, realizados mediante la técnica de HPLC a 0 y 24 horas de tiempo de contacto y concentraciones de APA 0,5,1,0 y $5 \mathrm{mg} \cdot \mathrm{L}^{-1}$ analizado mediante HPLC a un cultivo de Microcystis aeruginosa.

\begin{tabular}{|c|c|c|c|c|c|c|c|}
\hline Tiempo & $\begin{array}{c}\text { Control } \\
\mathrm{mg} \cdot \mathrm{L}^{-1}\end{array}$ & \multicolumn{2}{|c|}{$10 \mathrm{mg} \cdot \mathrm{L}^{-1}$ APA } & \multicolumn{2}{|c|}{$15 \mathrm{mg} \cdot \mathrm{L}^{-1}$ APA } & \multicolumn{2}{|c|}{ 20mg. $\mathrm{L}^{-1}$ APA } \\
\hline $\mathbf{0}$ horas & 0,33 & 0,34 & 0 & 0,34 & 0 & 0,34 & 0 \\
\hline $\begin{array}{c}\mathbf{2 4} \\
\text { horas }\end{array}$ & 0,35 & 0,09 & 73,52 & 0,01 & 97,05 & 0,01 & 97,05 \\
\hline
\end{tabular}

La tabla 17 nos permite analizar que si aplicáramos la concentración más baja de este tratamiento $\left(10 \mathrm{mg}^{-L^{-1}}\right)$ sobre un cultivo a partir de 24 horas se logra una degradación del $73,52 \%$. A concentraciones de APA de $15 \mathrm{mg} \cdot \mathrm{L}^{-1}$ y $20 \mathrm{mg} \cdot \mathrm{L}^{-1}$ a 24 horas de tiempo de contacto se logra una degradación de la toxina total en cultivos tratados superior al $95 \%$.

El análisis de varianza (ANOVA) para los cultivos tratados con 10,15 y $20 \mathrm{mg}^{-\mathrm{L}^{-1}}$ de APA a 0 y 24 horas de tiempos de contacto indica que se encontraron diferencias significativas $\mathrm{p}<0,05$ entre la concentración de toxina y los diferentes tiempos de contacto para los cultivos tratados de Microcystis aeruginosa (ver anexo).

Por otra parte al analizar todos los tratamientos, tiempos de contacto y dosis de $A P A$, se encontraron diferencias significativas $p<0,05$ entre la toxina y los tiempos de contacto para las tres concentraciones de APA, entre las dosis de APA y en la interacción entre los tiempos de contacto y las dosis, para los cultivos tratados (ver anexo).

Como resumen de los resultados encontrados podemos decir que dosis de $0,5 \mathrm{y}$ $1 \mathrm{mg} \cdot \mathrm{L}^{-1}$ de APA entre 0 y 24 horas de tiempo de contacto, $5 \mathrm{mg} \cdot \mathrm{L}^{-1}$ entre 0 y 4 horas de tiempo de contacto y $10 \mathrm{mg}^{-1} \mathrm{~L}^{-1}$ entre 0 y 3 horas de tiempo de contacto incrementaron la concentración de MC-LR, pudiendo deberse a una liberación de toxina intracelular. Un tratamiento efectivo para la reducción de MC-LR puede ser el de $20 \mathrm{mg} \cdot \mathrm{L}^{-1}$ de APA a 4 horas de contacto, o a mayores tiempos de contacto generando tiempos de residencias mayores que los convencionales. Estos resultados indican la necesidad de aplicar el producto en un punto final del proceso de tratamiento o potabilización, previa realización de los procesos convencionales en plantas potabilizadoras (floculación, coagulación y filtración).

La aplicación de la solución de ácido peracético entre $1-15 \mathrm{mg} \cdot \mathrm{L}^{-1}$ altera los parámetros del cultivo, disminuye la turbidez (densidad óptica) por la acción oxidante sobre los pigmentos en especial la clorofila-a. Al observar los 
recuentos al microscopio se evidenciaron cambios en la morfología celular (birrefringencia) al interior de las células, disminución de la clorofila-a por el efecto oxidante del APA, y desnaturalización de las proteínas totales. Sin embargo en este rango de concentración de APA no se evidenció eficacia en la remoción de MC-LR evaluadas mediante la técnica de HPLC en cultivo de Microcystis aeruginosa.

Con el propósito representar otro escenario en el que la toxina se encuentre disuelta en el agua, situación que se podría presentar luego de la aplicación de los tratamientos convencionales en las plantas de tratamiento (floculación, sedimentación, filtración) se propuso analizar el efecto del APA sobre la MC-LR en soluciones acuosas tal como se presenta a continuación.

\subsection{Efecto de una solución comercial de Ácido Peracético sobre la MC-LR en solución acuosa}

Como se evidenció en los resultados de la acción del APA sobre un cultivo de $M$. aeruginosa, en caso de que ocurra un florecimiento y se aplique un oxidante al ingreso del agua en una planta de tratamiento, existe un alto riesgo de transferir la toxina de una fase del proceso de tratamiento a la otra, pudiendo encontrar MC en la salida del agua de la planta. Esta parte del presente trabajo pretende simular dicha situación analizando el efecto del APA sobre soluciones acuosas de MC-LR.

\subsubsection{Efecto del pH sobre la degradación de MC-LR en solución acuosa tratada con una solución de APA}

El pH del agua es un índice fundamental en los procesos de tratamiento de agua, ya que la mayoría de los insumos usados en estos tratamientos como floculantes, oxidantes, coagulantes entre otros, dependen del pH para ejercer su efectividad. En este capítulo se evaluó la degradación química de una solución acuosa de MC-LR por APA. En la Figura 27 se muestra el efecto del $\mathrm{pH}$ sobre la degradación de $50 \mu \mathrm{g} \cdot \mathrm{L}^{-1}$ de MC-LR tratada con $10 \mathrm{mg} \cdot \mathrm{L}^{-1}$ de APA. 


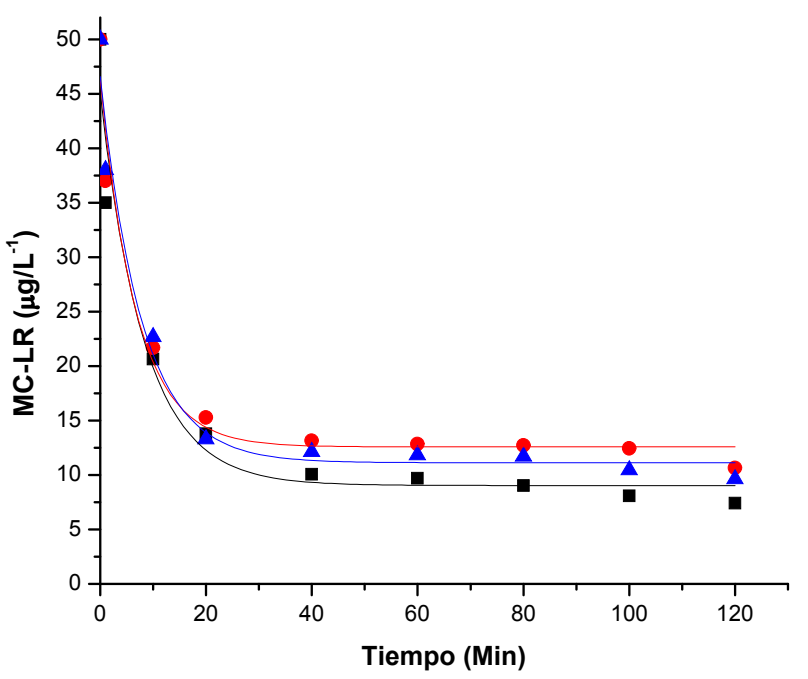

Figura 27. Cinética de degradación de MC-LR a una concentración inicial de MC$L R$ de $50 \mu \mathrm{g} \cdot \mathrm{L}^{-1}$, una concentración de APA de $10 \mathrm{mg} \cdot \mathrm{L}^{-1}$ y 3 diferentes $p H(-6$, .7 y $\Delta$ 8), en solución acuosa

Al igual que en los tratamientos con cloro, el modelo exponencial decreciente fue el que mejor se ajustó a los resultados. A continuación en la tabla 18 se presentan los resultados del ajuste y los parámetros cinéticos para evaluar la degradación de MC-LR con APA. Se calcularon además los parámetros cinéticos roy tiempo de degradación media descriptos por la ecuación 5 .

Tabla 18. Parámetros de ajuste exponencial para la degradación de MC-LR $50 \mu \mathrm{g} \cdot \mathrm{L}^{-1}$, una concentración de APA $\left(10 \mathrm{mg} \cdot \mathrm{L}^{-1}\right)$ y 3 diferentes $\mathrm{pH}(6,7$ y 8$)$

\begin{tabular}{|c|c|c|c|c|c|}
\hline MC-LR $\left(\mu g_{. L^{-1}}\right)$ & APA $\left(\mathrm{mg}_{.} \mathrm{L}^{-1}\right)$ & $\mathrm{pH}$ & $K_{1}\left(\mu g_{\cdot} \mathrm{L}_{-} \mathrm{min}^{-1}\right)$ & $\mathrm{R}^{2}$ & $\mathrm{t}_{1 / 2}(\mathrm{~min})$ \\
\hline $\mathbf{5 0}$ & 10 & 6 & $0,120 \pm 0,031$ & 0,965 & 6,783 \\
\hline $\mathbf{5 0}$ & 10 & 7 & $0,146 \pm 0,035$ & 0,944 & 6,840 \\
\hline $\mathbf{5 0}$ & 10 & 8 & $0,127 \pm 0,025$ & 0,929 & 7,388 \\
\hline
\end{tabular}

La tabla 18 muestra que los datos se ajustaron adecuadamente al modelo propuesto, el $R^{2}$ fue bueno encontrándose en un rango entre 0,929 y 0,965, los tiempos de degradación media son similares a los $3 \mathrm{pH}$ y la constante de degradación de MC-LR $\left(K_{1}\right)$ es similar a las tres condiciones de $\mathrm{pH}$ propuestas, indicando que las constantes de degradación no están en dependencia con el $\mathrm{pH}$.

Se observó a partir de la figura 27 que a los $3 \mathrm{pH}$ propuestos la degradación de MC-LR alcanzó la mitad de la concentración inicial $\left(\mathrm{t}_{1 / 2}\right)$ entre 6,783 y 7,388 minutos. La concentración final de MC-LR para cada tratamiento fue de 7,4, 10,6 y $9,6 \mu \mathrm{g} . \mathrm{L}^{-1}$ para $\mathrm{pH} 6,7$ y 8 respectivamente, en este caso la degradación 
no llega a $1 \mu \mathrm{g} \cdot \mathrm{L}^{-1}$ de $M C-L R$, por lo que sus niveles se mantienen arriba de los valores guías sugeridos para agua de consumo. Lo anterior indica que el APA debido a su poderoso potencial de oxidación $(1,87 \mathrm{~V})$ permite una degradación de MC-LR entre el 78,8-85,2\%.

El análisis de varianza demostró que existen diferencias significativas $(p<0,05)$ entre los datos de degradación de MC y los tiempos de contacto propuestos para los tres $\mathrm{pH}(6,7$ y 8$)$. A su vez se encontraron diferencias significativas entre los niveles de toxina y los tiempos de contacto, entre la toxina con respecto al pH, sin embargo la interacción entre los tiempos de contacto y el pH no mostraron diferencias significativas $(p>0,05)$, para el total de los datos de este tratamiento (ver anexo).

Resulta importante evaluar en posteriores estudios los posibles productos de oxidación de MC-LR. Para ello, se requiere de equipos de alta performance cono HPLC-MS a efectos de evaluar la estructura química de los productos degradación y así realizar propuestas de mecanismos de reacción química entre el oxidante (APA) y la MC-LR.

\subsubsection{Comparación del efecto del cloro y el ácido peracético sobre la degradación de MC-LR a una misma

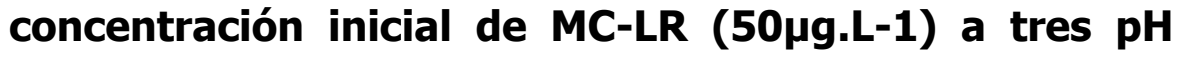 $(6,7$ y 8$)$}

A modo comparativo se seleccionó la concentración más alta de MC-LR de nuestro diseño experimental $\left(50 \mu \mathrm{g} \cdot \mathrm{L}^{-1}\right)$ a tres diferentes $\mathrm{pH}(6,7$ y 8$)$ y tres concentraciones de cloro $\left(1,2\right.$ y $\left.5 \mathrm{mg}^{-\mathrm{L}^{-1}}\right)$ para de esta manera contrastar el efecto oxidante sobre la MC-LR con respecto a una concentración de ácido peracético. La concentración propuesta en el tratamiento de aguas es la de $10 \mathrm{mg}$ L $^{-1}$ (Aranda y col., 2014). La Figura 28, muestra esta comparación entre el cloro y el ácido peracético. Los parámetros de ajuste exponencial y el tiempo al cual se reduce a la mitad la concentración inicial de MC-LR se presentan en la tabla 19. 


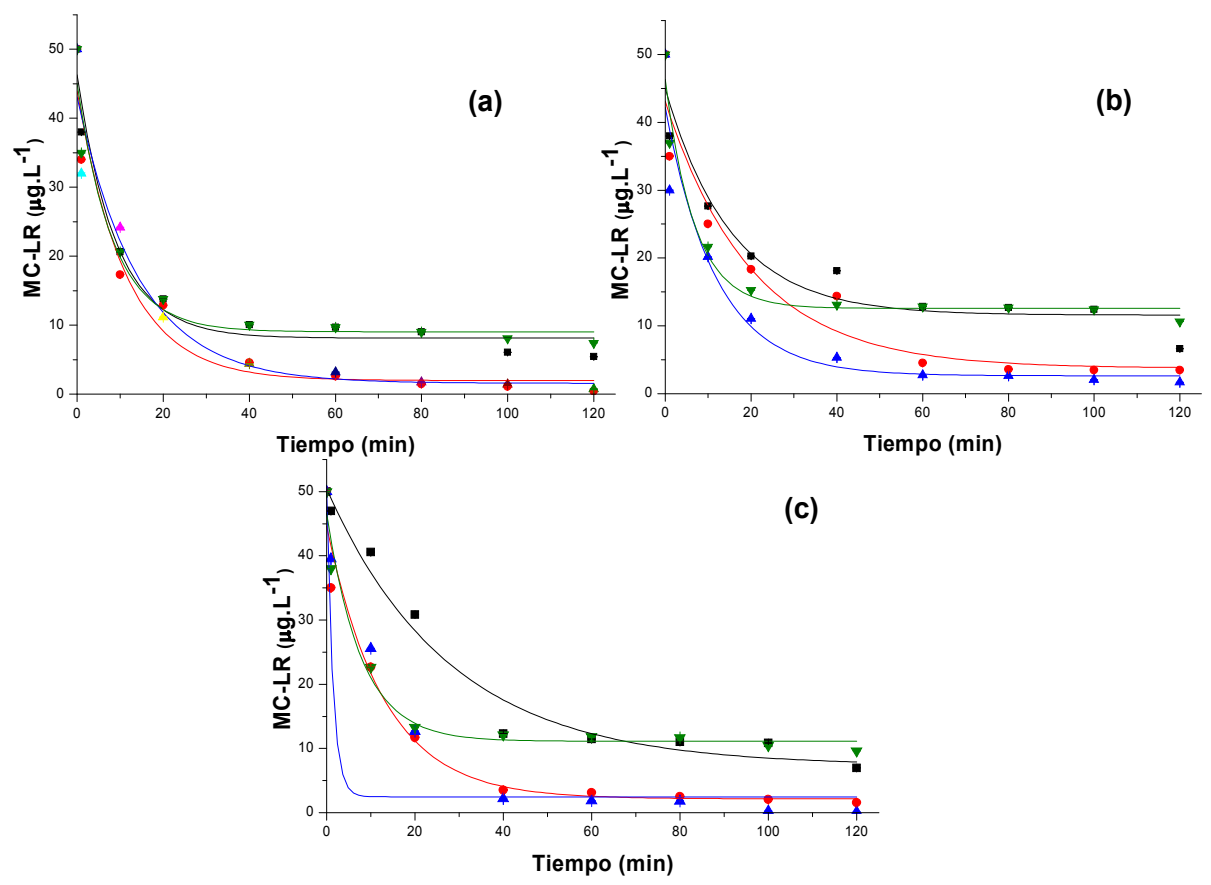

Figura 28. Cinética de degradación de MC-LR a una concentración inicial de MC$L R\left(50 \mu \mathrm{g} \cdot \mathrm{L}^{-1}\right)$, tres concentraciones de cloro y una de APA (- $1 \mathrm{mg} \cdot \mathrm{L}^{-1}, \cdot 2 \mathrm{mg} \cdot \mathrm{L}^{-1}$ y $\triangle 5 \mathrm{mg} \cdot \mathrm{L}^{-1}$ de cloro y $\mathbf{\nabla} 10 \mathrm{mg} \cdot \mathrm{L}^{-1}$ de APA) a) $\mathrm{pH}$ 6, b) $\mathrm{pH} 7$ y c) $\mathrm{pH} 8$.

Tabla 19. Parámetros de ajuste exponencial para la degradación de MC-LR $\left(50 \mu \mathrm{g} \cdot \mathrm{L}^{-1}\right)$, tres concentraciones de cloro $\left(1,2\right.$ y $\left.5 \mathrm{mg} \cdot \mathrm{L}^{-1}\right)$ y una de ácido peracético $\left(10 \mathrm{mg} \cdot \mathrm{L}^{-1} 1\right)$ a tres diferentes $\mathrm{pH}(6,7$ y 8$)$ y el tiempo al cual la concentración de MC-LR se degrada a la mitad del valor inicial $\left(\mathrm{t}_{1 / 2}\right)$

\begin{tabular}{|c|c|c|c|c|c|c|}
\hline MC-LR $\left(\mu \mathrm{g} \cdot \mathrm{L}^{-1}\right)$ & $\begin{array}{l}\text { Oxidante } \\
\left(m g . L^{-1}\right)\end{array}$ & pH & $K_{1}$ & $r_{0}\left(\mu \mathrm{g} \cdot \mathrm{L}_{\mathrm{min}}{ }^{-1}\right)$ & $t_{1 / 2}(\min )$ & $\mathbf{R}^{2}$ \\
\hline 50 & 1 Cloro & 6 & 0,058 & $2,900 \pm 0,022$ & 14,074 & 0,965 \\
\hline 50 & 2 Cloro & 6 & 0,052 & $2,600 \pm 0,021$ & 11,550 & 0,945 \\
\hline 50 & 5 Cloro & 6 & 0,063 & $3,150 \pm 0,026$ & 9,335 & 0,934 \\
\hline 50 & $10 \mathrm{APA}$ & 6 & 0,120 & $6,020 \pm 0,031$ & 6,761 & 0,949 \\
\hline 50 & 1 Cloro & 7 & 0,065 & $3,274 \pm 0,019$ & 13,941 & 0,921 \\
\hline 50 & 2 Cloro & 7 & 0,049 & $2,473 \pm 0,014$ & 12,450 & 0,925 \\
\hline 50 & 5 Cloro & 7 & 0,084 & $4,240 \pm 0,026$ & 6,736 & 0,912 \\
\hline 50 & $10 \mathrm{APA}$ & 7 & 0,147 & $7,335 \pm 0,035$ & 6,808 & 0,962 \\
\hline 50 & 1 Cloro & 8 & 0,035 & $1,796 \pm 0,007$ & 24,801 & 0,969 \\
\hline 50 & 2 Cloro & 8 & 0,063 & $3,175 \pm 0,015$ & 9,669 & 0,947 \\
\hline 50 & 5 Cloro & 8 & 0,091 & $4,573 \pm 0,104$ & 8,095 & 0,980 \\
\hline 50 & $10 \mathrm{APA}$ & 8 & 0,127 & $6,374 \pm 0,026$ & 7,362 & 0,970 \\
\hline
\end{tabular}

A partir de la figura 28 y la Tabla 19 se puede analizar que con el uso de APA se obtienen tiempos de degradación media para toxina más bajos que en los casos en los que se usó cloro, las constantes de degradación de MC-LR $\left(K_{1}\right)$ 
para el APA son similares a los tres $\mathrm{pH}$ propuestos a diferencia de los casos en los que se implementó el cloro, en donde si existió más variación de la $K_{1}$ y los valores de las constantes fueron inferiores a los del APA. En cuanto a la velocidad de la reacción al tiempo cero $\left(r_{0}\right)$ se encontró que el $r_{0}$ es más alto en los tratamientos con APA que en aquellos donde se implementó el cloro, donde a su vez aumentó con respecto a la cantidad de cloro adicionado.

Tomando como parámetro el tiempo al cual la concentración de MC-LR se reduce a la mitad de la inicial $\left(\mathrm{t}_{1 / 2}\right)$, a pH 6 las tres concentraciones de cloro $\mathrm{y}$ la de ácido peracético se comportan de manera diferente aun siendo este un $\mathrm{pH}$ donde se encuentra la mayor concentración de ácido sin disociar de cloro y donde el APA mostró $t_{1 / 2}$ menores. Comparando el tiempo de vida media del APA y el cloro a los diferentes pH propuestos, se observa que el APA es menos dependiente a las variaciones del $\mathrm{pH}$ con respecto al cloro.

Sin embargo si se compara el efecto del oxidante al final de cada tratamiento, el cloro permite obtener concentraciones finales de MC-LR menores que las alcanzadas por el APA. Los valores finales de MC-LR por acción del APA fueron de $7,4,10,6$ y $9,6 \mu \mathrm{g} . \mathrm{L}^{-1}$ para $\mathrm{pH} 6,7$ y 8 respectivamente, si lo comparamos con la concentración más baja de cloro $\left(1 \mathrm{mg} . \mathrm{L}^{-1}\right)$ se obtuvieron valores finales

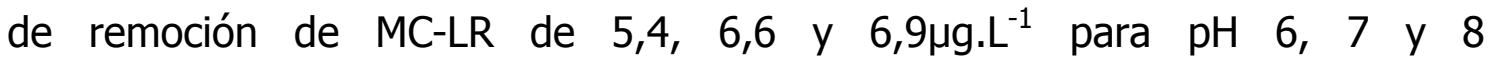
respectivamente, aun cuando los valores de $t_{1 / 2}$ fueron mayores para el APA que para el cloro.

Con el APA los niveles finales de MC-LR terminan siendo mayores a los permitidos por la OMS para agua de consumo humano. El comportamiento del ácido peracético durante los tratamientos en el tiempo es similar a la concentración más baja de cloro $\left(1 \mathrm{mg} \cdot \mathrm{L}^{-1}\right)$.

Esto es debido al potente poder oxidante del APA $(1,87 \mathrm{~V})$ mientras que el cloro libre presenta menor potencial oxidante $(1,36 \mathrm{~V})$ por ello, resulta ser mas efectivo en la remoción de MC-LR el APA.

El análisis de varianza muestra que para $\mathrm{pH} 6$ con un $\mathrm{p}<0,05$ se encontraron diferencias significativas entre los niveles de toxina y los tiempos de contacto, entre la toxina con respecto al oxidante usado y en la interacción entre los tiempos de contacto y la concentración de oxidante para este tratamiento (ver anexo).

En el caso de $\mathrm{pH} 7$ en el ANOVA se encontraron diferencias significativas $(p<0,05)$ entre los niveles de toxina y los tiempos de contacto, entre la toxina con respecto al oxidante utilizado y en la interacción entre los tiempos de 
contacto y la concentración de oxidante, para el total de los datos de este tratamiento (ver anexo).

Para el tratamiento a $\mathrm{pH} 8$ con un $\mathrm{p}<0,05$ se encontraron diferencias significativas entre los niveles de toxina y los tiempos de contacto, entre la toxina con respecto al oxidante aplicado y en la interacción entre los tiempos de contacto y la concentración de oxidante, para el total de los datos de este tratamiento (ver anexo).

Al realizar el análisis de varianza para todos los $\mathrm{pH}$ propuestos y con un $\mathrm{p}<0,05$ se encontraron diferencias significativas entre los niveles de toxina y los tiempos de contacto, entre el nivel de toxina con respecto al oxidante y entre el nivel de toxina y el $\mathrm{pH}$. En el caso de la interacciones, con un $\mathrm{p}<0,05$ se encontraron diferencias significativas entre los tiempos de contacto y el oxidante usado, entre los tiempos de contacto y el $\mathrm{pH}$, entre el oxidante y el $\mathrm{pH}$ y en la interacción entre el tiempo, oxidante y $\mathrm{pH}$, para el total de los datos de este tratamiento (ver anexo).

El ácido peracético es una opción viable para el tratamiento de agua para consumo en caso de florecimientos cianobacterianos y presencia de MC en el tratamiento de agua. El uso de este oxidante puede darse de manera seriada al uso del cloro (es decir primero agregar cloro, dejar actuar 20 minutos hasta su consumo y luego agregar APA). De esta manera se espera hacer más eficiente la remoción de las cianobacterias y sus metabolitos. La dependencia del cloro con respecto al pH en los procesos de potabilización son ya conocidos, como se pudo observar el APA no muestra la misma dependencia al pH que el cloro, razón por la cual puede sr utilizado en estos procesos.

Para completar el estudio del uso y efecto del APA en un proceso de potabilización de agua, es necesario comprobar su efecto bactericida sobre un indicador de contaminación fecal como la $E$. coli. En el siguiente capítulo se analizó el efecto del APA sobre un cultivo de E. coli, en condiciones de laboratorio.

\subsection{Efecto de una solución comercial de Ácido Peracético sobre la viabilidad de un cultivo de $E$. Coli}

Con el objetivo de completar el conocimiento obtenido del uso de ácido peracético en el tratamiento de aguas, se desarrollaron ensayos para demostrar la acción bactericida el APA sobre un microrganismo indicador de contaminación fecal en agua como es $E$. coli. 


\subsubsection{Evaluación de diferentes dosis y tiempos de contacto de una} solución comercial de ácido peracético sobre la viabilidad de $E$. coli en solución salina isotónica $0.9 \%$ y determinación de la concentración inhibitoria mínima (CIM)

A efectos de homogenizar los ensayos bactericidas con APA sobre el cultivo de E. coli, todos los cultivos partieron de un recuento de $10^{5} \mathrm{UFC}$. $\mathrm{mL}^{-1}$. La Figura 29, muestra a modo comparativo la viabilidad resultante luego de aplicar dos concentraciones de cloro $\left(0,5\right.$ y $\left.1 \mathrm{mg}^{-1} \mathrm{~L}^{-1}\right)$ y APA $(0,1-5 \mathrm{mg} \cdot \mathrm{L}-1)$.

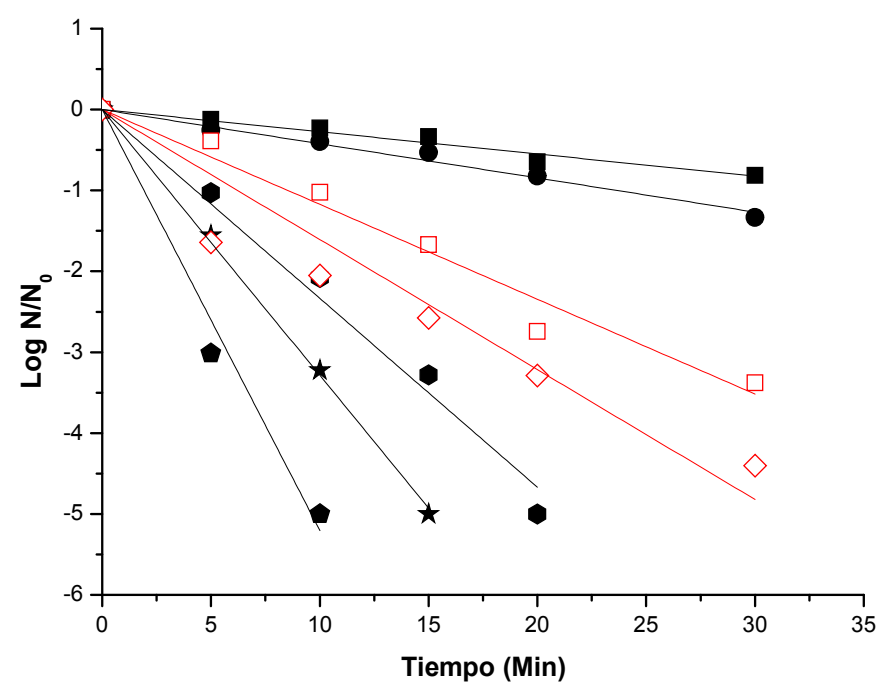

Figura 29. Efecto del APA sobre la viabilidad de E. coli expresada en ( $\left.\log N / N_{0}\right)$ a concentraciones de $\square 0,1, \bullet 0,3, \bullet 1, \star 1,5$ y $\bullet \mathrm{mg}^{-1} \mathrm{~L}^{-1}$ de $A P A$ y $\square 0,5$ y $\diamond 1 \mathrm{mg} . \mathrm{L}^{-1}$ de cloro a diferentes tiempos de contacto

Se observa que al aumentar la concentración de APA la viabilidad de $E$. coli disminuye, lo que evidencia la acción bactericida del APA. Si se compara dicha acción con un oxidante convencional en el tratamiento de agua como el cloro, podemos dilucidar que el APA es apto para ser usado en un sistema de potabilización de agua.

En la Figura 30 se presenta una fotografía que ilustra los recuentos en placa con agar PCA correspondiente a los ensayos de viabilidad de $E$. coli en solución salina isotónica $0.9 \%$ con una dosis de $0,1 \mathrm{mg}^{\mathrm{L}^{-1}}$ de APA a partir de 5 minutos de tiempo de contacto (a). No se observa recuento de $E$. coli en placa con agar PCA luego de ser tratada con 1,5 y $5 \mathrm{mg} \mathrm{L}^{-1}$ de APA en solución salina isotónica $0.9 \%$ (b). 


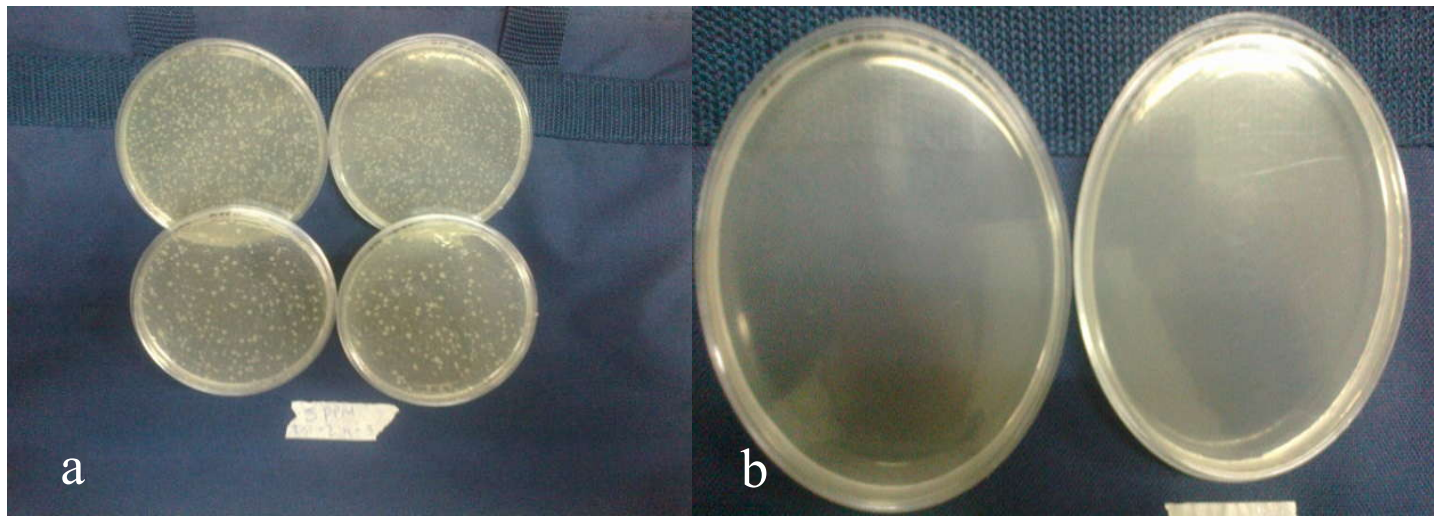

Figura 30. (a). Recuentos en placa con agar PCA correspondiente a los ensayos de viabilidad de E. coli con una dosis de $0,1 \mathrm{mg} \cdot \mathrm{L}^{-1}$ de APA a partir de 1 minuto. (b) recuento de E. coli en placa con agar PCA luego de ser tratada con $1,5 \mathrm{y}$ $5 \mathrm{mg} \cdot \mathrm{L}^{-1}$ de $A P A$

A una dosis de APA de $1 \mathrm{mg}^{-L^{-1}}$ se observa inhibición en los recuentos de $E$. coli a partir de 20 minutos de tiempo de contacto. Con este dato se logró concluir entonces que la concentración inhibitoria mínima (CIM) para E. coli en solución salina fisiológica $0.9 \%$ fue de $1 \mathrm{mg} \cdot \mathrm{L}^{-1}$. Si se comparan los resultados de APA con los de cloro a una misma concentración inicial de los dos oxidantes (1mg..' $\left.{ }^{1}\right)$, se puede observar que el tiempo para degradar el $99,999 \%$ del APA es menor que los del cloro (21,4 min para el APA y 31,1 minutos para el cloro).

Puede observarse que a medida que aumenta la concentración de APA, la efectividad antimicrobiana es mayor. Asimismo fue posible realizar las regresiones lineales que cada concentración de APA produce sobre la inactivación de $E$. coli. Con la ecuación de la recta es posible calcular el tiempo requerido para reducir la población microbiana un $99.999 \%$ los cuales se presentan en la tabla 20.

Tabla 20: Tiempo necesario para reducir la viabilidad de $E$. coli un $99.999 \%$ utilizando APA y cloro

\begin{tabular}{|c|c|c|}
\hline $\begin{array}{c}\text { Tiempo para reducir } \\
\text { el 99,999\% de la } \\
\text { viabilidad de } E_{\text {. coli }}\end{array}$ & $\begin{array}{c}\text { Concentración de } \\
\text { Oxidante } \\
(\mathbf{m i n})\end{array}$ & $\mathrm{R}^{2}$ \\
\hline $\mathbf{1 8 2}$ & $0,1 \mathrm{APA}$ & 0,983 \\
\hline $\mathbf{1 1 8}$ & $0,3 \mathrm{APA}$ & 0,992 \\
\hline $\mathbf{2 1 , 4}$ & $1 \mathrm{APA}$ & 0,993 \\
\hline $\mathbf{1 5 , 2}$ & $1,5 \mathrm{APA}$ & 0,998 \\
\hline $\mathbf{9 , 6}$ & 5 APA & 0,990 \\
\hline $\mathbf{4 2 , 6}$ & 0,5 Cloro & 0,987 \\
\hline $\mathbf{3 1 , 1}$ & 1 Cloro & 0,970 \\
\hline
\end{tabular}


Con los datos presentados en la tabla 20 se puede analizar que al aumentar la concentración de APA se reduce el tiempo para eliminar el 99,999\% la viabilidad de $E$. coli, el $\mathrm{R}^{2}$ es bueno con un rango entre 0,970 y 0,998 , y que a una misma concentración de APA y cloro $\left(1 \mathrm{mg} \cdot \mathrm{L}^{-1}\right)$ el APA muestra ser más eficiente para reducir la viabilidad con valores de 21,4 y $31,1 \mathrm{~min}$ respectivamente.

Al realizar el análisis de varianza se encontraron diferencias significativas entre la viabilidad de E.coli $(\mathrm{p}<0,05)$ con respecto a los tiempos de contacto, con respecto a la dosis de APA, y en la interacción entre los tiempos de contacto y las dosis de APA usadas (ver anexo).

Existen coincidencias en trabajos anteriores realizados en el país con productos de composición similar como es una mezcla cuaternaria 15\%(v/v) (ácido peracético /H2O2/ácido acético /agua) sobre la inhibición de coliformes (Flores y col, 2012). Estos autores encuentran una efectividad superior al $99,99 \%$ a los 5 minutos de tiempo de contacto con $6 \mathrm{mg} \cdot \mathrm{L}^{-1}$ de un producto ácido peracético /H2O2/ácido acético /agua) en solución isotónica en forma similar a nuestro trabajo (Flores y col., 2012).

Se hace necesario el estudio de la efectividad del APA en aguas más complejas analizando otras variables como DQO (demanda química de oxigeno) sólidos totales, $\mathrm{pH}$, conductividad, fosforo, nitratos, nitritos, entre otros para obtener más información y mejorar el proceso tecnológico en planta, en caso de usar este tipo de oxidantes en el tratamiento de agua para consumo. EL APA puede ser un método oxidante eficaz que permite degradar tanto la MC-LR y E.coli. 
CONCLUSIONES 
El método de la inhibición de la Protein fosfatasa 1 (PP1) puedo ser usado para la detección y cuantificación de $\mathrm{MC}$ en el orden de los $\mu \mathrm{g} \cdot \mathrm{L}^{-1}$ sin pasos previos de pre-concentración.

La degradación de cloro ajusto adecuadamente al modelo exponencial decreciente propuesto. Al aumentar la concentración de MC-LR las constantes de degradación de cloro $\left(K_{0}\right)$ resultaron ser mayores variando entre 0,002 y $0,059 \mathrm{~min}^{-1}$. No se encontró una relación lineal entre los valores de $K_{0}$ con los niveles iniciales de cloro a los tres $\mathrm{pH}$ estudiados, por ello es probable que otras variables influyan en la degradación de cloro.

El consumo de cloro en los tratamientos varía en la medida que la concentración inicial de MC-LR fue mayor. Existe una relación lineal entre los valores $K_{0}$ y los niveles de ácido hipocloroso sin disociar (UAC) para cada nivel de MC-LR inicial $\left(10,20\right.$ y $\left.50 \mu \mathrm{g} \cdot \mathrm{L}^{-1}\right)$. Se observó también que para cada valor de MC-LR inicial a mayor UAC las $K_{0}$ fueron menores, lo que indica que el cloro se degrada con menor velocidad.

La cinética de degradación de MC-LR ajusta al modelo propuesto de reacción de segundo orden para el total de la reacción y de primer orden para cada uno de los reactivos (Cloro y MC-LR). Los tiempos de degradación media $\left(t_{1 / 2}\right)$ aumentan en la medida que la concentración de MC-LR también lo hace, variando el $R^{2} 0,897$ y 0,986 .

Cuando la concentración de ácido hipocloroso sin disociar (UAC) aumenta, los tiempos para reducir a la mitad la concentración inicial de MC-LR $t_{1 / 2}$ son menores, confirmando que el agente activo encargado de la oxidación y degradación de MC-LR es el ácido hipocloroso.

La velocidad de la reacción al tiempo cero $\left(r_{0}\right)$ aumenta a pH 6 ya que a este $\mathrm{pH}$ es donde se encuentra la mayor concentración de UAC, por lo tanto existe más acido hipocloroso disponible en la reacción.

Pudo calcularse los valores de C.t a cada pH y se concluyó que este valor aumenta en la medida que aumenta el pH. Esto es importante y de utilidad tecnológica en una planta de tratamiento de aguas en caso de un florecimiento cianobacteriano. Para aumentar el porcentaje de degradación de MC-LR y a su vez tener valores de C.t menores, el mejor pH es 6.

La aplicación de una solución de ácido peracético entre $1-15 \mathrm{mg} \cdot \mathrm{L}^{-1}$ altera los parámetros del cultivo de $M$. aeruginosa, disminuye la turbidez (densidad 
óptica) por la acción oxidante sobre los pigmentos en especial la clorofila-a. Al observar los recuentos al microscopio se evidenciaron cambios en la morfología celular (birrefringencia) al interior de las células, disminución de la clorofila-a por el efecto oxidante del APA y desnaturalización de las proteínas totales.

La concentración inhibitoria mínima (CIM) del APA (1 $\mathrm{mg}^{\left.-L^{-1}\right)}$ corresponde al límite inferior a la cual el producto evidencia una acción biocida en cultivo de Microcystis aeruginosa. Este es el primer reporte de CIM para cultivos de M. aeruginosa.

La aplicación de 0,5 y $1 \mathrm{mg}^{-1} \mathrm{~L}^{-1}$ de APA entre 0 y 24 horas de tiempo de contacto así como $5 \mathrm{mg} \cdot \mathrm{L}^{-1}$ entre 0 y 4 horas de tiempo de contacto y $10 \mathrm{mg} \cdot \mathrm{L}^{-1}$ entre 0 y 3 horas de tiempo de contacto incrementaron la concentración de MC-LR en cultivos de $M$. aeruginosa, pudiendo deberse a una liberación de toxina intracelular. Un tratamiento efectivo para la reducción de MC-LR puede ser el de $20 \mathrm{mg}^{-1} \mathrm{~L}^{-1}$ de APA a 4 horas de contacto, o a mayores tiempos de contacto generando tiempos de residencias mayores que los convencionales. Estos resultados indican la necesidad de aplicar el producto en un punto final del proceso de tratamiento o potabilización, previa realización de los procesos convencionales en plantas potabilizadoras (floculación, coagulación y filtración).

La degradación de soluciones acuosas de MC-LR $\left(50 \mu \mathrm{g} \cdot \mathrm{L}^{-1}\right)$ utilizando APA y cloro se ajustó a un modelo exponencial decreciente. El $R^{2}$ varió entre 0,897 y 0,986 . La velocidad de la reacción al tiempo cero $\left(r_{0}\right)$ aumenta a pH 6 para el cloro ya que a este $\mathrm{pH}$ es donde se encuentra la mayor concentración de UAC, en el caso del APA el $r_{0}$ es mayor a los encontrados en el cloro.

El APA no muestra una dependencia al pH en la degradación de MC-LR en solución acuosa, en comparación al cloro que si muestra mayor dependencia al $\mathrm{pH}$.

La efectividad antimicrobiana de APA sobre $E$. coli indicó que al aumentar la concentración de APA se reduce el tiempo para eliminar el $99,999 \%$, el $R^{2}$ varió entre 0,970 y 0,998 , los tiempos para inhibir la viabilidad de $E$. coli estuvieron entre 182 y 9,6min. A modo comparativo, para una misma concentración de APA y cloro ( $1 \mathrm{mg}^{-1} \mathrm{~L}^{-1}$ ) el tiempo necesario para reducir $99,999 \%$ resultó ser más eficiente el APA que el cloro siendo de 21,4 y $31,1 \mathrm{~min}$ respectivamente.

EL APA puede ser un método oxidante eficaz que permite degradar tanto la MCLR como a bacterias indicadoras de contaminación fecal en aguas como E. coli. 


\section{BIBLIOGRAFÍA}


> Aboulmagd, E., Oppermann-Sanio, F. B., and Steinbuchel, A. 2000. Molecular characterization of the cyanophycin synthetase from Synechocystis sp. strain PCC6308. Arch. Microbiol. 174:297-306.

> Acero J., Rodriguez E., Meriluoto E. 2008. Kinetics of reactions between chlorine and the cyanobacterial toxins microcystins. Water Research 39, 1628-1638.

> Acero JL, Rodriguez E, Meriluoto J. 2005. Water Res 39:1628- 1638.

> Alasri A, Roques C, Michel G, Cabassud C, Aptel P. 1992. Bactericidal properties of peracetic acid and hydrogen peroxide, alone and in combination, and chlorine and formaldehyde against bacterial water strains. Can J Microbiol;38:635- 42.

> Allen, E. D. and Spence, D. H. N. 1981. The differential ability of aquatic plants to utilise the inorganic carbon supply in fresh waters. New Phytologist, 87, 269-83.

> Aranda O., Fernandez V., Sedan D., Rosso L., Crettaz-Minaglia M., Andrinolo D., Giannuzzi L. Vo Congreso Argentino de la Sociedad de Toxicología y Química Ambiental, "Producción sustentable y compromiso social para el cuidado del ambiente". Neuquén, Patagonia, Argentina 2225 Octubre 2014. Participación y presentación oral en mesa redonda. Estudio y Evaluación de un oxidante alternativo para la degradación de cianobacterias y cianotoxinas en plantas de tratamiento de agua.

> Arment, A.R. and Carmichael, W.W. 1996. Evidence that microcystin is a thio-template product. J. Phycol., 32, 591-597.

> AWWA (AMERICAN WATER WORKS ASSOCIATION) 2002. Calidad y tratamiento del agua. Manual de suministros de agua comunitaria. McGraw-Hill. Madrid.

> Azevedo, S., Carmichael, W., Jochimsen, E., Rinehart, K., Lau, S., Shaw, G., Eaglesham, G. 2002. Human intoxication by microcystins during renal dialysis treatment in Caruaru -Brazil. Toxicology 181-182, 441-446.

> Badger, M. R., Hanson, D., and Price, G. D. 2002. Evolution and diversity of $\mathrm{CO} 2$ concentrating mechanisms in cyanobacteria. Funct. Plant Biol. 29:161-73.

> Baldry MGC. 1983. The bactericidal, fungicidal, and sporicidal properties of hydrogen peroxide and peracetic acid. J Appl Bacteriol; 54: 417-23.

$>$ Baldry MGC., Fraser JAL. 1988. Disinfection with peroxygens. In: Payne KR, editor. Industrial biocides. NewYork,NY, USA:Wiley; p. 91-116.

> Baldry MGC, French MS. 1989a. Activity of peracetic acid against sewage indicator organisms. Water Sci Technol;21:1747-9.

> Baldry MGC, French MS. 1989b. Disinfection of sewage effluent with peracetic acid. Water Sci Technol; 21:203-6.

> Baldry MGC, French MS, Slater D. 1991. The activity of peracetic acid on sewage indicator bacteria and viruses. Water Sci Technol; 24:353-7. 
> Baldry MGC, Cavadore A, French MS, Massa G, Rodrigues LM, Schirch PFT, et al. 1995. Effluent disinfection in warm climates with peracetic acid. Water Sci Technol; 31:161-4.

> Bandala, E.R., Martínez, D., Martínez, E., Dionysiou., D.D. 2004. Degradation of microcystin-LR toxin by Fenton and Photo-Fenton processes, Toxicon 43 829-832.

> Banker, R., Carmeli, S., Werman,M., Teltsch, B., Porat, R., Sukenik, A., 2001. Uracil moiety is required for toxicity of the cyanobacterial hepatotoxin cylindrospermopsin. J. Toxicol. Environ. Health A 62 (4), 281-288.

> Barrington D.J., Ghadouani A., 2008. Application of hydrogen peroxide for the removal of toxic cyanobacteria and other phytoplankton from wastewater. Environ. Sci. Technol. 42, 8916.

> Barrington D.J., Ghadouani A., Ivey G.N., 2011. Environmental factors and the application of hydrogen peroxide for the removal of toxic cyanobacteria from waste stabilization ponds. J. Environ. Eng. 137, 952.

$>$ Bell SG., Codd, GA. 1994. Cyanobacterial toxins and human health. Rev. in Medical Microb. 5: 256-264.

> Block SS. Disinfection, sterilization, and preservation. 1991. 4th ed. Philadelphia: Lea\&Febiger Pubs.

> Bolch, C.J.S., Blackburn, S.I., Jones, G.J., Orr, P.T. and Grewe, P.M. 1997. Plasmid content and distribution in the toxic cyanobacterial genus Microcystis Kutzing ex Lemmermann (Cyanobacteria: Chroococcales). Phycologia, 36, 6-11.

> Botes, D.P., Wessels, P.L., Kruger, H., Runnegar, M.T.C., Santikarn, S., Smith, R.J., Barna, J.C.J. and Williams, D.H. 1985 Structural studies on cyanoginosins- $L R,-Y R,-Y A$, and $-Y M$, peptide toxins from Microcystis aeruginosa. J. Chem. Soc., Perkin Transactions, I, 2747-2748.

$>$ Bradford, M.M. 1976. A sensitive method for total protein determination using the principle of protein-dye binding. Anal. Biochem. 72, 249-251.

$>$ Bruchet, A., Bernazeu, F., Baudin, i. and Pierrone, P. 1998. Algal toxins in surface waters: analysis and treatment. Wat. Supply $16(1 / 2), 611-$ 623.

> Bouaïcha, N. Maatouk, I. Vincent, G. Levi, Y. 2002. Toxic Cyanoprokaryotes in resource waters: monitoring of their occurrence and toxin detection. Food Chem Toxicol 40 1677- 1683.

> Carmichael, W. W., N. A. Mahmood, and E. G. Hyde. 1990. Natural toxins from cyanobacteria (blue-green algae). En: Hall, S., Strichartz, G. (Eds.), Marine Toxins: Origin, Structure and Molecular Pharmacology, ACS-Symposium Series 418, American Chemical Society, Washington D.C, pp. 87. 
> Carmichael, W.W. 1992. A Status Report on Planktonic Cyanobacteria (Blue Green Algae) and their Toxins. EPA/600/R-92/079, Environmental Monitoring Systems Laboratory, Office of Research and Development, US Environmental Protection Agency, Cincinnati, Ohio.

> Carmichael, W.W., Azevedo, S.M.F.O., An, J.S., Molica, R.J.R., Jochimsen, E.M., Lau, S., Rinehart, K.L., Shaw, G.R., Eaglesham, G.K., 2001. Human fatalities from cyanobacteria: chemical and biological evidence for cyanotoxins. Environ. Health Perspect. 109, 663-668.

> Carmichael, WW. 1996. Liver failure and human deaths at a haemodialysis centre in Brazil: microcystins as a major contributing factor. Harm Alg News.15,11.

> Cheng X, Shi H, Adams CD, Timmons T, Ma Y. 2009. Water Sci Technol 60:689-698.

> Choi, H., Antoniou, MG., Pelaez, M., De la Cruz, AA., Shoemaker, J.A., Dionysiou, D.D. 2007. Mesoporous nitrogen-doped TiO2 for the photocatalytic destruction of the cyanobacterial toxin microcystin-LR under visible light irradiation, Environ. Sci. Technol. 41 7530-7535.

$>$ Chorus, I. 2001. Cyanotoxins: occurrence, causes, consequences. In - S. \& V. Bderlin (Eds.), (pp. 75-82). Heidelberg, Germany.

$>$ Chorus, I., Bartram, J. (Eds.), 1999. Toxic Cyanobacteria in Water: A Guide to their Public Health Consequences, Monitoring and Management. E \& FN Spon, London. Upper Saddle River, New Jersey: Prentice Hall; p. 97-131.

> Codd, G. A. 2000. Cyanobacterial toxins, the perception of water quality, and the prioritisation of eutrophication control. Ecological Engineering 16: 51-60.

> Codd, G.A, Ward, C.J. and Bell, S.G. 1997. Cyanobacterial toxins: occurrence, modes of action, health effects and exposure routes. In: J.P. Seiler and E. Vilanova [Eds] Applied Toxicology: Approaches through Basic Science. Archives of Toxicology Supplement 19, Springer-Verlag, Berlin, 399-410.

> Codd, G.A. 1994. Blue-green algal toxins: water-borne hazards to health. in Golding A.M.B., Noah N. and Stanwell-Smith R. Eds., Water and Public Health, pp 271-278. Smith-Gordon, UK.

$>$ Codd, G.A. 1994. Blue-green algal toxins: water-borne hazards to health. in Golding A.M.B., Noah N. and Stanwell-Smith R. Eds., Water and Public Health, pp 271-278. Smith-Gordon, UK.

> Cornish B., Lawton L.A., Robertson P.K.J., 2000. Hydrogen peroxide enhanced photocatalytic oxidation of microcystin-LR using titanium dioxide. Appl. Catal. B 25, 59.

$>$ Dietrich D, Ernest B, Day. B. 2007. Human consumer death and algal supplement consumption: a post mortem assessment of potential 
microcystin intoxication via microcystin inmunohistochemical (MC-IHC) analyses. Oral presentation 7th International Conference of Toxic Cyanobacteria. Brasil; 132.

> Dillenberg, H.O. and Dehnel, M.K. 1960. Toxic water bloom in Saskatchewan 1959. Can. Med. Assoc. J., 83, 1151-1154.

> Drábková M., Admiraal W., Marsálek B., 2007a. Combined exposure to hydrogen peroxide and light - Selective effects on cyanobacteria, green algae, and diatoms. Environ. Sci. Technol. 41, 309.

> Edwards, C., Graham D., Fowler N. and Lawton N. A. 2008. Biodegradation of microcystins and nodularin in freshwaters. Chemosphere 73: 1315-1321.

$>$ F., Codd G. A. and Bergman B. 2005. Diverse taxa of cyanobacteria produce beta-N-methylamino-Lalanine, a neurotoxic amino acid. Proceedings of the National Academy Society 102: 5074- 5078

> Falconer IR. 2005. Cyanobacterial toxins of drinking water supplies: cylindrospermopsins and microcystins. CRC, Boca Raton.

$>$ Falconer, I. 1999. An overview of problems caused by toxic blue-green algae (Cyanobacteria) in drinking and recreational water. Environ. Toxicol. 14:5-12

> Falconer, I. 1999. An overview of problems caused by toxic blue-green algae (Cyanobacteria) in drinking and recreational water. Environ. Toxicol. 14:5-12.

> Falsanisi D, Gehr R, Santoro D, Dell'Erba A, Notarnicola M, Liberti L. 2006 Kinetics of PAA demand and its implications on disinfection of wastewaters. Water Qual. Res. J. Canada, Volume 41, 398-409.

> Flores, M. Nieres, P. Cassano, A. Labas, M. 2011. Desinfección de agua con ácido peracético: Una alternativa económica y ecológica. Congreso; V Congreso Iberoamericano sobre Desarrollo y Ambiente, V CISDA y V Jornadas de la Asociación Argentino Uruguaya de Economía Ecológica, "Gestión Ambiental, Producción e Innovación Tecnológica para el Desarrollo Sustentable en Iberoamérica.

> Francis, G. 1878. Poisonous Australian lake. Nature, 18: 11-12.

$>$ Fraser JAL. Novel applications of peracetic acid in industrial disinfection. Specialty Chem 1987;7:178-86.

> Fraser JAL, Godfree AF, Jones F. Use of peracetic acid in operational sewage sludge disposal to pasture. Water Sci Technol 1984;17:451-66.

> Fujiki, H., Sueoka, E., Suganuma. 1996. Carcinogenesis of Microcystins. En: Watanabe MF, Harada K, Carmichael WW, Fujiki H. Toxic Microcystis. CRC Press, Boca Raton, pp. 203-232.

> Gehr R, Cochrane D, French M. 2002. Peracetic acid as a disinfectant for municipal wastewaters: encouraging performance results from 
physicochemical as well as biological effluents. Proc of the US water environment federation disinfection conference.

> Giannuzzi L., Carvajal G., Corradini M., Araujo Andrade C., Echenique R., Andrinolo D. 2012. Occurrence of toxic cyanobacterial blooms in Río de la Plata estuary, Argentina - Field study and data análisis. Journal of Toxicology, Article ID 373618, 15 pages, doi:10.1155/2012/37361.

> Giannuzzi, L., Sedan, D., Echenique, R. and Andrinolo, D. 2011. An Acute Case of Intoxication with Cyanobacteria and Cyanotoxins in Recreational Water in Salto Grande Dam, Argentina. Mar. Drugs 2011, 9.

$>$ Hart, J., Fawell, J.K., Croll, B., 1998. The fate of both intra and extracellular toxins during drinking water treatment. Water Supply 16, 611-616.

> Herdman, M., Janvier, M., Rippka, R., and Stanier, R. Y. 1979. Genome size of cyanobacteria. J. Gen. Microbiol. 111:73-85.

> Ho L, Tanis-Plant P, Kayal N, Slyman N, Newcombe G. 2009. J Water Health 7:544-556

> Ho L., Slyman N., Kaeding U. and Newcombe G. 2008. Optimizing powdered activated carbon and chlorination practices for cylindrospermopsin removal. Journal of the American Water Works Association 100, 88-96.

> Ho Lionel., Onstad G., Von Gunten Urs., Rinck-Pfeiffer S., Craig K., Newcombe G. 2006. Differences in the chlorine reactivity of four microcystin analogues. Water Research.

> Ho, L., Tanis-Plant, P., Kayal, N., Slyman, N., Newcombe, G., 2009. Optimising water treatment practices for the removal of Anabaena circinalis and its associated metabolites, geosmin and saxitoxins. Journal of Water and Health 7 (4), 544e556.

> Hockelmann, C., Becher P. G., von Reuss S. H. and Juttner F. 2009. Sesquiterpenes of the geosmin producing cyanobacterium Calothrix PCC 7507 and their toxicity to invertebrates. Zeitschrift fur Naturforschung $\mathrm{C}$ 64: 49-55.

> Hrudey S, Burch M, Drikas M, Gregory R. 1999 In: Chorus I, Bartram J (eds) Toxic cyanobacteria in water: a guide to their public health consequences, monitoring and management. Spon, London.

> Jang, M.H., Jung J. M. and Takamura N. 2007. Changes in microcystin production in cyanobacteria exposed to zooplankton at different population densities and infochemical concentrations. Limnology and Oceanography 52: 1454 - 1466.

> Jochimsen, E. M., Carmichael W.W., Ann J. S., Cardo D. M., Cookson D. M. Holmes, C. M. Antunes C. m. de Melo Filho D. A., Lyra, T. M., Barreto, Azevedo S.M. and Jarvis W.R. 1998. Liver failure and death after 
exposure to microcystins at a haemodialysis center in Brazil. N. Engl. J. Med., 338:873-878.

> Jurczak, T., Tarczynskaa, M., Izydorczyk, K., Mankiewicz, J., Zalewski, M and Meriluoto, J. 2005. Elimination of microcystins by water treatment processes examples from Sulejow Reservoir, Poland. Water Research 39 2394-2406.

> Juttner, F. and Watson S.B. 2007. Biochemical and ecological control of off-flavours of aquatic cyanobacteria and algae. Appl. Environ. Microbiol. 73(14):4395-4406.

> Kitis, M. 2004. Disinfection of wastewater with peracetic acid: a review. Environment International 30, 47-55.

> Kull, T.P.J., Backlund, P.H., Karlsson, K.M., Meriluoto, J., 2004. Oxidation of the cyanobacterial hepatotoxin microcystin-LR by chlorine dioxide: reaction kinetics, characterization, and toxicity of reaction products. Environ. Sci. Technol. 38 (22), 6025-6031.

> Kull, T.P.J., Sjo" vall, O.T., Tammenkoski, M.K., Backlund, P.H., Meriluoto, J.A.O., 2006. Oxidation of the cyanobacterial hepatotoxin microcystin-LR by chlorine dioxide: influence of natural organic matter. Environ. Sci. Technol. 40 (5), 1504-1510.

$>$ Lee, R. 1997. Phycology. Cambridge, Cambridge University Press.

$>$ Lee, S.-H., Motomura, T., and Ichimura, T. 2000. Nuclear phase alternation in the life cycle of Derbesia (Chlorophyta). Phycologia 39:441-7.

> Li, R., Carmichael, W. W., Britain, S., et al. 2001b. First report of the cyanotoxins cylindrospermopsin and deoxycylindrospermopsin from Raphidiopsis curvava (Cyanobacteria). J. Phycol. 37:1121-6.

> Liang W, Qu J, Wang K, Wang J, Liu H, Lei P. 2008. Environ Eng Sci 25:635-642.

> Liu, I., Lawton, L.A., Robertson, P.K.J. 2003. Mechanistic studies of the photocatalytic oxidation of microcystin-LR: an investigation of byproducts of the decomposition process, Environ. Sci. Technol. 37 3214-3219.

$>$ Leaper S. 1984. Synergistic killing of spores of Bacillus subtilis by peracetic acid and alcohol. J Food Technol; 19:355-60.

$>$ Lefevre F, Audic JM, Ferrand F. 1992. Peracetic acid disinfection of secondary effluents discharged off coastal seawater. Water Sci Technol; 25:155-64.

> Liberti L, Notarnicola M. 1999. Advanced treatment and disinfection for municipal wastewater reuse in agriculture. Water Sci Technol;40: 23545.

> Liberti L, Lopez A, Notarnicola M, Barnea N, Pedahzur R, Fattal B. 2000. Comparison of advanced disinfecting methods for municipal wastewater reuse in agriculture. Water Sci Technol;42:215- 20. 
> Matthijs H.C.P., Visser P.M., Reeze B., Meeuse J., Slot P.C., Wijn, G., Talens, R., Huisman, J., 2011. Selective suppression of harmful cyanobacteria in an entire lake with hydrogen peroxide. Water Res.

> Miao H, Tao W. 2007. Sep Purif Technol 66:7.

> Monarca S, Feretti D, Collivignarelli C, Guzzella L, Zerbini I, Bertanza G, et al. 2000. The influence of different disinfectants on mutagenicity and toxicity of urban wastewater. Water Res;34:4261-9.

> Monarca S, Feretti D, Zerbini I, Zani C, Alberti A, Richardson SD, et al. 2001. Studies on mutagenicity and disinfection by-products in river drinkingwater disinfected with peracetic acid or sodium hypochlorite. Proc ofIWA world conference, Berlin, Germany.

> Monarca S, Richardson SD, Feretti D, Grottolo M, Thruston AD, Zani C, et al. 2002. Mutagenicity and disinfection by-products in surface drinking water disinfected with peracetic acid. Environ Toxicol Chem;21: 309-18.

> Moreno I, Repetto G y Cameán A. 2003. Interés toxicológico de las microcistinas. Rev. Toxicol. 20: 159-165.

> Muntisov M, Trimboli P. 1996. Water 23:34.

> Negri, A.P., Jones, G.J., Blackburn, S.I., Oshima, Y. and Onodera, H. 1997. Effect of culture and bloom development and of sample storage on paralytic shellfish poisons in the cyanobacterium Anabaena circinalis. J. Phycol., 33, 26-35.

> Neumann, U. and Weckesser, J. 1998. Elimination of microcystin peptide toxins from water by reverse osmosis. Environ. Toxicol. Water Qual., 13.

$>$ Newcombe G. 2002. Removal of algal toxins from drinking waterusing ozone and GAC. AWWA Research Foundation, Denver, p 133.

> Nicholson B.C., Rositano J. and Burch M.D. 1994. Destruction of cyanobacterial peptide hepatotoxins by chlorine and chloramine. Wat. Res. 28, 1297-1303.

> Nobles, D. R., Romanovicz, D. K., and Brown, R. M. 2001. Cellulose in cyanobacteria. Origin of plantellulose synthase Plant Physiol. 127:52942.

$>$ Oh, H.M., Lee S.J., Kim, J.H. Kim, H.S. and Yoon, B.D. 2001. Seasonal variation and indirect monitoring of microcystin concentrations in daechung reservoir, Korea. Applied and Environmental Microbiology 67: 1484-1489.

$>$ Oliver, R. L. 1994. Floating and sinking in gas vacuolate cyanobacteria. J. Phycol. 30:161-73.

> Oliver, R. L., Thomas, R. H., Reynolds, C. S., and Walsby, A. E. 1985. The sedimentation of buoyant Microcystis colonies caused by precipitation with an iron-containing colloid. Proc. R. Soc. Lond. [B] 223:511-28. 
> Oliver, RL., Ganf, GG. 2000. Freshwater blooms. The ecology of Cyanobacteria: their Diversity in Time and Space (ed: Whitton BA, y Potts M). Kluwer Academic Publishers. Dordrecht pp. 149-194.

> Onstad, G.D., Strauch, S., Meriluoto, J.A.O., Codd, G.A., von Gunten, U., 2007. Selective oxidation of key functional groups in cyanotoxins during drinking water ozonation. Environ. Sci. Technol., in press.

> Qiao, R.P., Li, N., Qi, X.H., Wang, Q.S., Zhuang., Y.Y. 2005. Degradation of microcystin- RR by UV radiation in the presence of hydrogen peroxide, Toxicon 45 745-752.

> Quesada, A., Sanchis D. and Carrasco D. 2004. Cyanobacteria in Spanish reservoirs. How frequently are they toxic? Limnetica 23: 109-118.

> Raymond, J., Siefert, J. L., Staples, C. R., and Blankenship, R.E. 2004. The natural history of nitrogen fixation. Mol. Biol. Evol. 21:541-54.

$>$ Rinehart, K.L., Namikoshi, M. and Choi, B.W. 1994. Structure and biosynthesis of toxins from blue-green algae (Cyanobacteria). J. App. Phycol., 6, 159-176.

> Rinehart, K.L., Namikoshi, M. and Choi, B.W. 1994. Structure and biosynthesis of toxins from blue-green algae (Cyanobacteria). J. App. Phycol., 6, 159-176.

$>$ Ringuelet R. 1955. Panorama zoogeográfico de la provincia de Buenos Aires. Notas Del Museo, Zoología 18(156):1-45.

> Rodriguez E, Sordo A, Metcalf JS, Acero JL. 2007. Water Res 41:20482056.

> Rositano, J., Newcombe, G., Nicholson, B., Sztajnbok, P., 2001. Ozonation of NOM and algal toxins in four treated waters. Water Res. 35, 23-32.

$>$ Ross, C., Santiago-Vazquez L. and Paul V. 2006. Toxin release in response to oxidative stress and programmed cell death in the cyanobacterium Microcystis aeruginosa. Aquatic Toxicology 78: 66-73.

> Rutala W; Gergen M; Weber D. 1998. Comparative evaluation of the sporicidal activity of new-lowtemperatura sterilization technologies: Ethylene oxide, 2 plasma sterilization systems, and liquid peracetic acid. Infection control and Epidemiology, Inc. 17/46/87595.

> Shapiro, J. 1990. Current beliefs regarding dominance by blue-greens: The case for the importance of $\mathrm{CO} 2$ and $\mathrm{pH}$. Verh. Intern. Verein. Limnol. 24:38-54.

> Sherman, D. M., Tucker, D., and Sherman, L. A. 2000. Heterocyst development and localization of cyanophycin in N2-fixing cultures of Anabaena sp. PCC 7120 (Cyanobacteria). J. Phycol. 36:932-41.

> Sivonen K, Jones G. 1999. Cyanobacterial toxins. - In: Chorus \& Bertram, J. (eds.) Toxic Cyanobacteria in Water: a Guide to Public Health Significance, Monitoring and Management. 
> Skulberg, O.M. 1995. Biophotolysis, hydrogen production and algal culture technology. In: Y. Yürüm [Ed.] Hydrogen Energy System. Production and Utilization of Hydrogen and Future Aspects. NATO ASI Series E, Applied Sciences, Vol. 295, Kluwer Academic Publishers, Dordrecht, 95-110.

> Smayda, T.J., 1997. Harmful phytoplankton blooms: their ecophysiology and general relevance. Limnol. Oceanogr. 42, 1137-1153.

$>$ Solvay Interox. Product information for ProxitaneR EQ liquid sanitizer. http://www.solvayinterox.com; 2002.

$>$ Solvay Interox. Product information for ProxitaneR WW-12. http:// www.solvayinterox.com; 2002.

> Sukenik, A., Eshkol, R., Livine, A., and Hadas, O. 2002. Inhibition of growth and photosynthesis of the dinoflagellate Peridinium gatunense by Microcystis sp. (cyanobacteria): a novel allelopathic mechanism. Limnol. Ocean. 47:1656-63.

$>$ Tandeau de Marsac, N. 1977. Occurrence and nature of chromatic adaptation in cyanobacteria. J. Bacteriol. 130:82-91.

> Tang, E. P. Y., Tremblay, R., and Vincent, W. F. 1997. Cyanobacterial dominance of polar fresh water ecosystems: are high-latitude matformers adapted to low temperature. J. Phycol. 33:171-81.

> Teixera, M., Costa, M., Carvalho, V., Pereira, M., Hage, E., 1993. Gastroenteritis epidemic in the area of the Itaparica Dam, Bahia, Brazil. Bull.Pan Am. Health Org. 27, 244- 253.

> Tisdale J. 1931. Epidemic of intestinal disorders in Charleston (West Virginia) occurring simultaneously with unprecedented water supply conditions. Am J Pub Health. 21:198-200.

> Tsuji K, Naito S, Kondo F, Ishikawa N, Watanabe MF. 1994. Environ Sci Technol 28:173.

> Tsuji, K., Watanuki, T., Kondo, F., Watanabe, M. F., Nakazawa, H., Suzuki, M., Uchida, H., and Harada, K. 1997. "Stability of microcystins from cyanobacteria. IV: Effect of chlorination on decomposition." Toxicon, 357[1], 1033-1041.

> Turpin, D. H., Miller, A. G., and Canvin, D. T. 1984. Carboxysome content of Synechococcus leopoliensis (Cyanophyta) in response to organic carbon. J. Phycol. 20:249-53.

> Tutumi M, Imamura K, Hatano S, Watanabe T. 1973. Antimicrobial action of peracetic acid. J Food Hyg Soc;15:116-20.

> US Environmental Protection Agency (USEPA). 2001. Disinfectants and Disinfection By-Products: Final Rule. Federal Register, 63(24) 69478.

> Vollenweider, R.A. and Kerekes J. 1982. Eutrophication of Waters. Monitoring Assessment and Control. Organization for Economic CoOperation and Development (OECD), París. 156 p. 
> Von Gunten U, Hoigne J. 1994. Environ Sci Technol 28:1234.

> Von Gunten U., 2003. Ozonation of drinking water: Part I. Oxidation kinetics and product formation. Water Res. 37, 1443-1467.

> Warner, Susan C. 1988. "Surrogate and Matrix Spike Recoveries in Chlorinated Samples Using Sodium Thiosulfate, Sodium Arsenite and LAscorbic Acid as Dechlorinating Agents", Environmental Protection Agency, Publication number EPA-903/9-89-001.

> Wagner M, Brumelis D, Gehr R. 2002. Disinfection of wastewater by hydrogenperoxide or peracetic acid: Development of procedures for measurement of residual disinfectant and application to a physicochemically treated municipal effluent. Water Environ Res, 74:3350.

> Wetzel, R.G. 2001. Limnology. Academic Press, New York. 1006 p.

> Xagoraraki I., Harrington G., Zulliger K. Zeier B. and Krick B. 2006. Inactivation Kinetics of the Cyanobacterial Toxin Microcystin-LR by Free Chlorine. Journal of Environmental Engineering, 828-823.

> Zilberg, B. 1966. Gastroenteritis in Salisbury European children - a five yearstudy. Centr Afr J Med. 12:164-68. 
ANEXOS 


\section{DEGRADACION DE CLORO RESIDUAL}

1.1. Control pH 6

\begin{tabular}{|llllll|}
\hline Variables & \multicolumn{5}{c|}{ Niveles } \\
\hline & 0.000 & 1.000 & 2.000 & 3.000 & 4.000 \\
\hline & 5.000 & 6.000 & 7.000 & & \\
\hline
\end{tabular}

\begin{tabular}{|ll|}
\hline Variable dependiente & CONTL6 \\
\hline N & 48 \\
\hline Multiple R & 0.185 \\
\hline Squared Multiple R & 0.034 \\
\hline
\end{tabular}

\section{Análisis de Varianza}

\begin{tabular}{|llllll|}
\hline Source & Type III SS & df & Mean Squares & F-ratio & p-value \\
\hline TIEMPO & 4.967 & 7 & 0.710 & 0.202 & 0.983 \\
\hline Error & 140.342 & 40 & 3.509 & & \\
\hline
\end{tabular}

\subsection{Control pH: 7}

\begin{tabular}{|llllll|}
\hline TIEMPO (8 Niveles) & 0.000 & 1.000 & 2.000 & 3.000 & 4.000 \\
\hline & 5.000 & 6.000 & 7.000 & & \\
\hline
\end{tabular}

\begin{tabular}{|ll|}
\hline Variable dependiente & CONTL6 \\
\hline N & 48 \\
\hline Multiple R & 0.390 \\
\hline Squared Multiple R & 0.152 \\
\hline
\end{tabular}

\begin{tabular}{|llllll|}
\hline Análisis de varianza & & & & \\
Source & Type III SS & df & Mean Squares & F-ratio & p-value \\
\hline TIEMPO & 13.442 & 7 & 1.920 & 1.024 & 0.429 \\
\hline Error & 74.987 & 40 & 1.875 & & \\
\hline
\end{tabular}

\subsection{Control pH 8}

\begin{tabular}{|llllll|}
\hline Tariables & \multicolumn{5}{c|}{ Niveles } \\
\hline & 0.000 & 1.000 & 2.000 & 3.000 & 4.000 \\
\hline & 5.000 & 6.000 & 7.000 & & \\
\hline
\end{tabular}

\section{Variable dependiente CONTL 8}

\begin{tabular}{|ll|}
\hline N & 48 \\
\hline Multiple R & 0.373 \\
\hline Squared Multiple R & 0.139 \\
\hline
\end{tabular}

\section{Análisis de varianza}

\begin{tabular}{|llllll|}
\hline Source & Type III SS & df & Mean Squares & F-ratio & p-value \\
\hline TIEMPO & 13.372 & 7 & 1.910 & 0.922 & 0.500 \\
\hline Error & 82.918 & 40 & 2.073 & & \\
\hline
\end{tabular}


1.4. Control todos los niveles de cloro a $3 \mathrm{pH}(6,7$ y 8$)$

\begin{tabular}{|llllll|}
\hline Variables & & \multicolumn{5}{c|}{ Niveles } \\
\hline TIEMPO (8 Niveles) & 0.000 & 1.000 & 2.000 & 3.000 & 4.000 \\
\hline PH (3 Niveles) & 5.000 & 6.000 & 7.000 & & \\
\hline
\end{tabular}

\begin{tabular}{|llll|}
\hline Effect & Initial df & Lost df & Final df \\
\hline TIEMPO & 7 & 6 & 1 \\
\hline PH & 2 & 2 & 0 \\
\hline TIEMPO*PH & 14 & 8 & 6 \\
\hline
\end{tabular}

\begin{tabular}{|ll|}
\hline Variable dependiente & CLORO \\
\hline N & 48 \\
\hline Multiple R & 0.185 \\
\hline Squared Multiple R & 0.034 \\
\hline
\end{tabular}

\begin{tabular}{|lllllll|}
\hline Análisis de Varianza & & & & \\
\hline Source & Type III SS & df & Mean Squares & F-ratio & p-value \\
\hline Model & 4.967 & 7 & 0.710 & 0.202 & 0.983 & \\
\hline Error & 140.342 & 40 & 3.509 & & & \\
\hline Variables & & Niveles & & & & \\
\hline & & 1,000 & 2,000 & 3,000 & 4,000 \\
\hline TODOSTIEMPOS (8 Niveles) & 0,000 & 6,000 & 7,000 & & \\
\hline & 5,000 & 7,000 & 8,000 & \\
\hline TRESPH (3 Niveles) & 6,000 & & &
\end{tabular}

Variable dependiente Cloro residual

\begin{tabular}{|ll|}
\hline N & 144 \\
\hline Multiple R & 0,336 \\
\hline Squared Multiple R & 0,113 \\
\hline
\end{tabular}

\begin{tabular}{|lllllc|}
\hline Análisis de Varianza & Type III SS & df & $\begin{array}{l}\text { Mean } \\
\text { Squares }\end{array}$ & F-ratio & p-value \\
\hline TODOSTIEMPOS & 26,245 & 7 & 3,749 & 1,469 & 0,185 \\
\hline TRESPH & 9,015 & 2 & 4,507 & 1,766 & 0,175 \\
\hline TODOSTIEMPOS*TRESPH & 3,720 & 14 & 0,266 & 0,104 & 1,000 \\
\hline Error & 306,247 & 120 & 2,552 & & \\
\hline
\end{tabular}




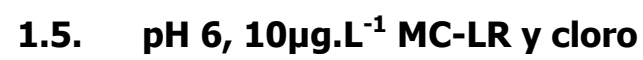

\begin{tabular}{|llllll|}
\hline Variables & \multicolumn{5}{c|}{ Niveles } \\
\hline TPO Niveles) & 0.000 & 1.000 & 2.000 & 3.000 & 4.000 \\
\hline & 5.000 & 6.000 & 7.000 & & \\
\hline
\end{tabular}

\begin{tabular}{|ll|}
\hline Variable dependiente & CLORO \\
\hline N & 48 \\
\hline Multiple R & 0.673 \\
\hline Squared Multiple R & 0.452 \\
\hline
\end{tabular}

Análisis de varianza

\begin{tabular}{|llllll|}
\hline Source & Type III SS & df & Mean Squares & F-ratio & p-value \\
\hline TPO & 27.806 & 7 & 3.972 & 4.720 & 0.001 \\
\hline Error & 33.662 & 40 & 0.842 & & \\
\hline
\end{tabular}

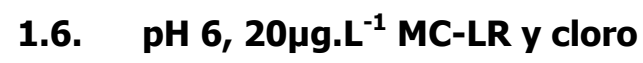

\begin{tabular}{|llllll|}
\hline Variables & \multicolumn{5}{c|}{ Niveles } \\
\hline TPO20 (8 levels) & 0.000 & 1.000 & 2.000 & 3.000 & 4.000 \\
\hline & 5.000 & 6.000 & 7.000 & & \\
\hline
\end{tabular}

\begin{tabular}{|ll|}
\hline Variable dependiente & CLORO \\
\hline N & 48 \\
\hline Multiple R & 0.675 \\
\hline Squared Multiple R & 0.456 \\
\hline
\end{tabular}

\begin{tabular}{|llllll|}
\hline Análisis de Varianza & & & & \\
Source & Type III SS & df & Mean Squares & F-ratio & p-value \\
\hline TPO20 & 31.980 & 7 & 4.569 & 4.790 & 0.001 \\
\hline Error & 38.148 & 40 & 0.954 & & \\
\hline
\end{tabular}

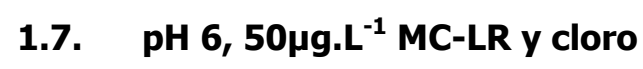

\begin{tabular}{|llllll|}
\hline Variables & \multicolumn{5}{c|}{ Niveles } \\
\hline TP050 (8 Niveles) & 0.000 & 1.000 & 2.000 & 3.000 & 4.000 \\
\hline & 5.000 & 6.000 & 7.000 & \\
\hline
\end{tabular}

\begin{tabular}{|ll|}
\hline Variable dependiente & CLORO \\
\hline N & 48 \\
\hline Multiple R & 0.766 \\
\hline Squared Multiple R & 0.587 \\
\hline & \\
\hline
\end{tabular}

\begin{tabular}{|llllll|}
\hline Análisis de Varianza & & & & \\
Source & Type III SS & df & Mean Squares & F-ratio & p-value \\
\hline TPO50 & 32.559 & 7 & 4.651 & 8.126 & 0.015 \\
\hline Error & 22.897 & 40 & 0.572 & & \\
\hline
\end{tabular}




\subsection{TODOS LOS NIVELS DE CLORO Y MC-LR A pH 6}

\begin{tabular}{|llllll|}
\hline Variables & \multicolumn{5}{c|}{ Niveles } \\
\hline TPO (8 Niveles) & 0.000 & 1.000 & 2.000 & 3.000 & 4.000 \\
\hline & 5.000 & 6.000 & 7.000 & & \\
\hline MC (3 Niveles) & 10.000 & 20.000 & 50.000 & \\
\hline
\end{tabular}

\begin{tabular}{|ll|}
\hline Variable dependiente & CLORO \\
\hline N & 144 \\
\hline Multiple R & 0.710 \\
\hline Squared Multiple R & 0.505 \\
\hline
\end{tabular}

\section{Análisis de Varianza}

\begin{tabular}{|llllll|}
\hline Source & Type III SS & df & Mean Squares & F-ratio & p-value \\
\hline TPO & 90.406 & 7 & 12.915 & 16.364 & 0.024 \\
\hline MC & 4.167 & 2 & 2.083 & 2.640 & 0.076 \\
\hline TPO*MC & 1.939 & 14 & 0.139 & 0.176 & 1.000 \\
\hline Error & 94.707 & 120 & 0.789 & & \\
\hline
\end{tabular}

1.9. $\mathrm{pH} 7,10 \mu g . \mathrm{L}^{-1}$ MC-LR y cloro

\begin{tabular}{|llllll|}
\hline Variables & \multicolumn{5}{c|}{ Niveles } \\
\hline TIEMPO10 (8 Niveles) & 0,000 & 1,000 & 2,000 & 3,000 & 4,000 \\
\hline & 5,000 & 6,000 & 7,000 & \\
\hline
\end{tabular}

\begin{tabular}{|ll|}
\hline Variable dependiente & CLORO_RES10 \\
\hline N & 48 \\
\hline Multiple R & 0,691 \\
\hline Squared Multiple R & 0,477 \\
\hline
\end{tabular}

\begin{tabular}{|llllll|}
\hline Análisis de varianzza & & & & \\
\hline Source & Type III SS & df & Mean Squares & F-ratio & p-value \\
\hline TIEMPO10 & 32,246 & 7 & 4,607 & 5,217 & 0,029 \\
\hline Error & 35,322 & 40 & 0,883 & & \\
\hline
\end{tabular}

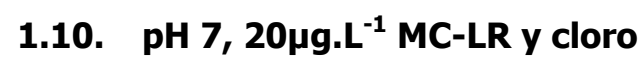

\begin{tabular}{|llllll|}
\hline Variables & \multicolumn{5}{c|}{ Niveles } \\
\hline TIEMPO20 (8 Niveles) & 0,000 & 1,000 & 2,000 & 3,000 & 4,000 \\
\hline & 5,000 & 6,000 & 7,000 & \\
\hline
\end{tabular}

\section{Variable dependiente CLORO_RES20}

\begin{tabular}{|ll|}
\hline N & 48 \\
\hline Multiple R & 0,457 \\
\hline Squared Multiple R & 0,209 \\
\hline
\end{tabular}




\begin{tabular}{|llllll|}
\hline Análisis de varianza & & & & \\
\hline Source & Type III SS & df & Mean Squares & F-ratio & p-value \\
\hline TIEMPO20 & 18,318 & 7 & 2,617 & 1,508 & 0,193 \\
\hline Error & 69,435 & 40 & 1,736 & & \\
\hline
\end{tabular}

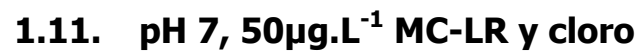

\begin{tabular}{|llllll|}
\hline Variables & \multicolumn{5}{c|}{ Niveles } \\
\hline & 0,000 & 1,000 & 2,000 & 3,000 & 4,000 \\
\hline & 5,000 & 6,000 & 7,000 & \\
\hline
\end{tabular}

\begin{tabular}{|ll|}
\hline Variable dependiente & CLORO_RES50 \\
\hline N & 48 \\
\hline Multiple R & 0,648 \\
\hline Squared Multiple R & 0,420 \\
\hline
\end{tabular}

\begin{tabular}{|llllll|}
\hline Análisis de varianza & & & & \\
Source & Type III SS & df & Mean Squares & F-ratio & p-value \\
\hline TIEMPO50 & 33,394 & 7 & 4,771 & 4,144 & 0,002 \\
\hline Error & 46,045 & 40 & 1,151 & & \\
\hline
\end{tabular}

\subsection{TODOS LOS NIVELS DE CLORO Y MC-LR A PH 7}

\begin{tabular}{|llllll|}
\hline Variables & \multicolumn{5}{c|}{ Levels } \\
\hline TIEMPO_ACUM (8 Niveles) & 0,000 & 1,000 & 2,000 & 3,000 & 4,000 \\
\hline & 5,000 & 6,000 & 7,000 \\
\hline MC_ACUM (3 Niveles) & 10,000 & 20,000 & 50,000 \\
\hline
\end{tabular}

\begin{tabular}{|ll|}
\hline Variable dependiente & CLORO_RES_ACUM \\
\hline N & 144 \\
\hline Multiple R & 0,608 \\
\hline Squared Multiple R & 0,370 \\
\hline
\end{tabular}

\begin{tabular}{|llllll|}
\hline Análisis de varianza & Type III SS & df & Mean Squares & F-ratio & p-value \\
\hline TIEMPO_ACUM & 82,169 & 7 & 11,738 & 9,341 & 0,036 \\
\hline MC_ACUM & 4,704 & 2 & 2,352 & 1,872 & 0,158 \\
\hline TIEMPO_ACUM*MC_ACUM & 1,789 & 14 & 0,128 & 0,102 & 1,000 \\
\hline Error & 150,802 & 120 & 1,257 & & \\
\hline
\end{tabular}

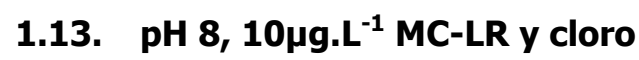

\begin{tabular}{|llllll|}
\hline Variables & \multicolumn{5}{c|}{ Niveles } \\
\hline TIEMPO10 (8 Niveles) & 0,000 & 1,000 & 2,000 & 3,000 & 4,000 \\
\hline & 5,000 & 6,000 & 7,000 & \\
\hline
\end{tabular}




\begin{tabular}{|ll|}
\hline Variable dependiente & CLORO_RESID10 \\
\hline N & 48 \\
\hline Multiple R & 0,561 \\
\hline Squared Multiple R & 0,314 \\
\hline
\end{tabular}

\begin{tabular}{|llllll|}
\hline Análisis de varianza & & & & \\
\hline Source & Type III SS & df & Mean Squares & F-ratio & p-value \\
\hline TIEMPO10 & 23,790 & 7 & 3,399 & 2,620 & 0,025 \\
\hline Error & 51,896 & 40 & 1,297 & & \\
\hline
\end{tabular}

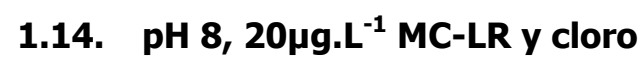

\begin{tabular}{|llllll|}
\hline Variables & \multicolumn{5}{c|}{ Niveles } \\
\hline TIEMPO20 (8 Niveles) & 0,000 & 1,000 & 2,000 & 3,000 & 4,000 \\
\hline & 5,000 & 6,000 & 7,000 & \\
\hline
\end{tabular}

\begin{tabular}{|ll|}
\hline Variable dependiente & CLORO_RESID20 \\
\hline N & 48 \\
\hline Multiple R & 0,790 \\
\hline Squared Multiple R & 0,624 \\
\hline
\end{tabular}

\begin{tabular}{|llllll|}
\hline Análisis de varianza & & & & \\
\hline Source & Type III SS & df & Mean Squares & F-ratio & p-value \\
\hline TIEMPO20 & 35,626 & 7 & 5,089 & 9,503 & 0,036 \\
\hline Error & 21,423 & 40 & 0,536 & & \\
\hline
\end{tabular}

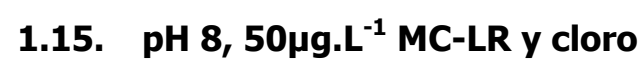

\begin{tabular}{|llllll|}
\hline Variables & & \multicolumn{4}{c|}{ Niveles } \\
\hline TIEMPO50 (8 Niveles) & 0,000 & 1,000 & 2,000 & 3,000 & 4,000 \\
\hline & 5,000 & 6,000 & 7,000 & \\
\hline
\end{tabular}

\begin{tabular}{|ll|}
\hline Variable dependiente & CLORO_RESTID50 \\
\hline N & 48 \\
\hline Multiple R & 0,654 \\
\hline Squared Multiple R & 0,428 \\
\hline
\end{tabular}

\begin{tabular}{|llllll|}
\hline Análisis de varianza & & & & \\
\hline Source & Type III SS & df & Mean Squares & F-ratio & p-value \\
\hline TIEMPO50 & 28,984 & 7 & 4,141 & 4,281 & 0,001 \\
\hline Error & 38,691 & 40 & 0,967 & & \\
\hline
\end{tabular}

\subsection{TODOS LOS NIVELS DE CLORO Y MC-LR A pH 8}

\begin{tabular}{|llllll|}
\hline Variables & & \multicolumn{5}{c|}{ Niveles } \\
\hline TIEMPO_ACUM (8 Niveles) & 0,000 & 1,000 & 2,000 & 3,000 & 4,000 \\
\hline MC_ACUM (3 Niveles) & 5,000 & 6,000 & 7,000 & & \\
\hline
\end{tabular}




\begin{tabular}{|ll|}
\hline Variable dependiente & CLORO_RESID_ACU- \\
N & 144 \\
\hline Multiple R & 0,673 \\
\hline Squared Multiple R & 0,453 \\
\hline
\end{tabular}

Análisis de varianza

\begin{tabular}{|llllll|}
\hline Source & Type III SS & df & Mean Squares & F-ratio & p-value \\
\hline TIEMPO_ACUM & 87,036 & 7 & 12,434 & 13,321 & 0,000 \\
\hline MC_ACUM & 4,547 & 2 & 2,273 & 2,435 & 0,092 \\
\hline TIEMPO_ACUM*MC_ACUM & 1,364 & 14 & 0,097 & 0,104 & 1,000 \\
\hline Error & 112,011 & 120 & 0,933 & & \\
\hline
\end{tabular}

\subsection{ANOVA DE DEGRADACION DE CLORO RESIDUAL PARA TODOS LOS PH, TODAS LAS CONCENTRACIONES INICIALES DE MC-LR Y TODOS LOS TIEMPOS PROPUESTOS}

\begin{tabular}{|c|c|c|c|c|c|}
\hline \multirow{2}{*}{$\begin{array}{l}\text { Variables } \\
\text { TIEMPO (8 Niveles) }\end{array}$} & \multicolumn{5}{|c|}{ Niveles } \\
\hline & 0,000 & 1,000 & 2,000 & 3,000 & 4,000 \\
\hline & 5,000 & 6,000 & 7,000 & & \\
\hline PH (3 Niveles) & 6,000 & 7,000 & 8,000 & & \\
\hline MC (3 Niveles) & 10,000 & 20,000 & 50,000 & & \\
\hline
\end{tabular}

\begin{tabular}{|ll|}
\hline Variable dependiente & CLORO_RESID \\
\hline N & 432 \\
\hline Multiple R & 0,664 \\
\hline Squared Multiple R & 0,441 \\
\hline
\end{tabular}

\section{Análisis de varianza}

\begin{tabular}{|llllll|} 
Source & Type III SS & df & Mean Squares & F-ratio & p-value \\
\hline TIEMPO & 258,292 & 7 & 36,899 & 37,155 & 0,020 \\
\hline PH & 4,112 & 2 & 2,056 & 2,070 & 0,128 \\
\hline MC & 2,394 & 2 & 1,197 & 1,205 & 0,301 \\
\hline TIEMPO*PH & 1,318 & 14 & 0,094 & 0,095 & 1,000 \\
\hline TIEMPO*MC & 0,689 & 14 & 0,049 & 0,050 & 1,000 \\
\hline PH*MC & 11,024 & 4 & 2,756 & 2,775 & 0,027 \\
\hline TIEMPO*PH*MC & 4,403 & 28 & 0,157 & 0,158 & 1,000 \\
\hline Error & 357,520 & 360 & 0,993 & & \\
\hline
\end{tabular}

2. ANOVA PARA LA DEGRADACION DE MC-LR

2.1. pH $6,10 \mu g . \mathrm{L}^{-1} \mathrm{MC}-\mathrm{LR}$ y 3 concentraciones de cloro

\begin{tabular}{|llllll|}
\hline Variables & \multicolumn{5}{c|}{ Niveles } \\
\hline & 5,000 & 1,000 & 2,000 & 3,000 & 4,000 \\
\hline
\end{tabular}




\begin{tabular}{|ll|}
\hline Variable Dependiente & MC10 \\
\hline N & 54 \\
\hline Multiple R & 0,992 \\
\hline Squared Multiple R & 0,985 \\
\hline
\end{tabular}

\section{Análisis de varianza}

\begin{tabular}{|llllll|}
\hline Source & Type III SS & df & Mean Squares & F-ratio & p-value \\
\hline TIEMPO & 437,340 & 8 & 54,668 & 367,727 & 0,001 \\
\hline Error & 6,690 & 45 & 0,149 & & \\
\hline
\end{tabular}

2.2. pH $6,20 \mu g . \mathrm{L}^{-1} \mathrm{MC}-\mathrm{LR}$ y 3 concentraciones de cloro

\begin{tabular}{|llllll|}
\hline Variables & \multicolumn{5}{c|}{ Niveles } \\
\hline TIEMPO20 (9 Niveles) & 0,000 & 1,000 & 2,000 & 3,000 & 4,000 \\
\hline & 5,000 & 6,000 & 7,000 & 8,000 \\
\hline
\end{tabular}

\begin{tabular}{|ll|}
\hline Variable dependiente & MC20 \\
\hline N & 54 \\
\hline Multiple R & 0,968 \\
\hline Squared Multiple R & 0,937 \\
\hline
\end{tabular}

\begin{tabular}{|llllll|}
\hline Analysis of Variance & & & & \\
Source & Type III SS & df & Mean Squares & F-ratio & p-value \\
\hline TIEMPO20 & $2.203,042$ & 8 & 275,380 & 83,120 & 0,016 \\
\hline Error & 149,087 & 45 & 3,313 & & \\
\hline
\end{tabular}

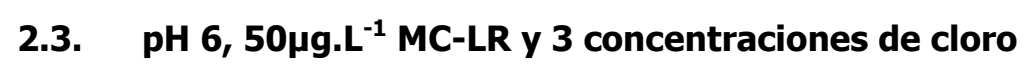

\begin{tabular}{|llllll|}
\hline Variables & \multicolumn{5}{c|}{ Niveles } \\
\hline TIEMPO50 (9 levels) & 0,000 & 1,000 & 2,000 & 3,000 & 4,000 \\
\hline & 5,000 & 6,000 & 7,000 & 8,000 & \\
\hline
\end{tabular}

\begin{tabular}{|ll|}
\hline Variable dependiente & MC50 \\
\hline N & 54 \\
\hline Multiple R & 0,988 \\
\hline Squared Multiple R & 0,976 \\
\hline
\end{tabular}

\begin{tabular}{|llllll|}
\hline Análisis de varianza & & & & \\
\hline Source & Type III SS & df & Mean Squares & F-ratio & p-value \\
\hline TIEMP050 & $13.510,491$ & 8 & $1.688,811$ & 229,329 & 0,002 \\
\hline Error & 331,386 & 45 & 7,364 & & \\
\hline
\end{tabular}




\subsection{ANOVA PARA 3 CONCENTRACIONES DE MC-LR Y R CONCENTRACIONES DE CLORO A pH 6}

\begin{tabular}{|lrrrrr|}
\hline Variables & \multicolumn{5}{c|}{ Levels } \\
\hline TIEMPO_ACUM (9 levels) & 0,000 & 1,000 & 2,000 & 3,000 & 4,000 \\
\hline CLORO_INIC_ACUM (3 levels) & 1,000 & 2,000 & 5,000 & \\
\hline
\end{tabular}

\begin{tabular}{|ll|}
\hline Dependent Variable & CM_ACUM \\
\hline N & 162 \\
\hline Multiple R & 0,735 \\
\hline Squared Multiple R & 0,540 \\
\hline
\end{tabular}

\section{Análisis de varianza}

\begin{tabular}{|llllll} 
Source & Type III SS & df & Mean Squares & F-ratio & p-value \\
\hline TIEMPO_ACUM & $11.113,487$ & 8 & $1.389,186$ & 19,210 & 0,002 \\
\hline CLORO_INIC_ACUM & 200,774 & 2 & 100,387 & 1,388 & 0,253 \\
\hline TIEMPO_ACUM*CLORO_INIC_ACUM & 127,322 & 16 & 7,958 & 0,110 & 1,000 \\
\hline Error & $9.762,658$ & 135 & 72,316 & & \\
\hline
\end{tabular}

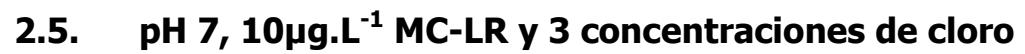

\begin{tabular}{|llllll|}
\hline TIEMPO10 (9 Niveles) & 0,000 & 1,000 & 2,000 & 3,000 & 4,000 \\
\hline & 5,000 & 6,000 & 7,000 & 8,000 & \\
\hline
\end{tabular}

\begin{tabular}{|ll|}
\hline Variable dependiente & MC_10 \\
\hline N & 54 \\
\hline Multiple R & 0,943 \\
\hline Squared Multiple R & 0,890 \\
\hline
\end{tabular}

\begin{tabular}{|llllll|}
\hline Análisis de varianzza & & & & \\
Source & Type III SS & df & Mean Squares & F-ratio & p-value \\
\hline TIEMP010 & 402,908 & 8 & 50,363 & 45,596 & 0,004 \\
\hline Error & 49,705 & 45 & 1,105 & & \\
\hline
\end{tabular}

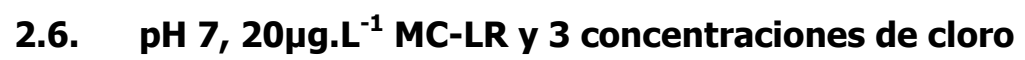

\begin{tabular}{|llllll|}
\hline Variables & \multicolumn{5}{c|}{ Niveles } \\
\hline TIEMPO20 (9 levels) & 0,000 & 1,000 & 2,000 & 3,000 & 4,000 \\
\hline & 5,000 & 6,000 & 7,000 & 8,000 & \\
\hline
\end{tabular}

\section{Variable dependiente MC_20}

\begin{tabular}{|ll|}
\hline N & 54 \\
\hline Multiple R & 0,930 \\
\hline Squared Multiple R & 0,866 \\
\hline
\end{tabular}

\section{Análisis de varianza}

Source Type III SS df Mean Squares F-ratio p-value




\begin{tabular}{|llllll|}
\hline TIEMPO20 & $1.963,038$ & 8 & 245,380 & 36,226 & 0,004 \\
\hline Error & 304,813 & 45 & 6,774 & & \\
\hline
\end{tabular}

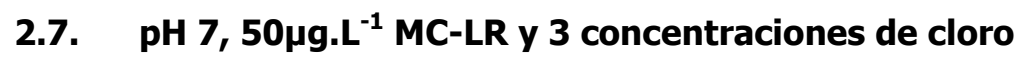

\begin{tabular}{|llllll|}
\hline Variables & \multicolumn{5}{c|}{ Niveles } \\
\hline TIEMPO_50 (9 levels) & 0,000 & 1,000 & 2,000 & 3,000 & 4,000 \\
\hline & 5,000 & 6,000 & 7,000 & 8,000 & \\
\hline
\end{tabular}

\begin{tabular}{|ll|}
\hline Variable dependiente & MC_50 \\
\hline N & 54 \\
\hline Multiple R & 0,968 \\
\hline Squared Multiple R & 0,938 \\
\hline
\end{tabular}

\begin{tabular}{|llllll|}
\hline Análisis de varianza & & & & \\
Source & Type III SS & df & Mean Squares & F-ratio & p-value \\
\hline TIEMPO_50 & $11.819,271$ & 8 & $1.477,409$ & 84,495 & 0,001 \\
\hline Error & 786,832 & 45 & 17,485 & & \\
\hline
\end{tabular}

\subsection{ANOVA PARA 3 CONCENTRACIONES DE MC-LR Y R CONCENTRACIONES DE CLORO A PH 7}

\begin{tabular}{|lrrrrr|}
\hline Variables & \multicolumn{5}{c|}{ Niveles } \\
\hline TIEMPO_ACUM (9 Niveles) & 0,000 & 1,000 & 2,000 & 3,000 & 4,000 \\
\hline CLORO_INI_ACUM (3 Niveles) & 5,000 & 6,000 & 7,000 & 8,000 & \\
\hline
\end{tabular}

\begin{tabular}{|ll|}
\hline Variable dependiente & MCLR_ACUM \\
\hline N & 162 \\
\hline Multiple R & 0,721 \\
\hline Squared Multiple R & 0,520 \\
\hline
\end{tabular}

\section{Análisis de varianza}

\begin{tabular}{|llllll|}
\hline Source & $\begin{array}{l}\text { Type III } \\
\text { SS }\end{array}$ & df & $\begin{array}{l}\text { Mean } \\
\text { Squares }\end{array}$ & $\begin{array}{l}\text { F- } \\
\text { ratio }\end{array}$ & p-value \\
\hline TIEMPO_ACUM & $9.928,166$ & 8 & $1.241,021$ & 16,993 & 0,004 \\
\hline CLORO_INI_ACUM & 617,059 & 2 & 308,529 & 4,225 & 0,017 \\
\hline TIEMPO_ACUM*CLORO_INI_ACUM & 152,413 & 16 & 9,526 & 0,130 & 1,000 \\
\hline Error & $9.859,357$ & 135 & 73,032 & & \\
\hline
\end{tabular}

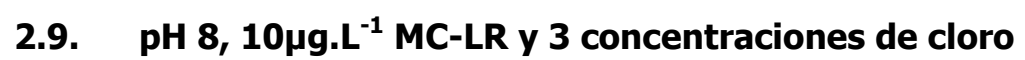

\begin{tabular}{|llllll|}
\hline Variables & \multicolumn{5}{c|}{ Niveles } \\
\hline TIEMPO10 (9 Niveles) & 0,000 & 1,000 & 2,000 & 3,000 & 4,000 \\
\hline & 5,000 & 6,000 & 7,000 & 8,000 & \\
\hline
\end{tabular}




\begin{tabular}{|ll|}
\hline Variable dependiente & MCLR_10 \\
\hline N & 54 \\
\hline Multiple R & 0,980 \\
\hline Squared Multiple R & 0,960 \\
\hline
\end{tabular}

\begin{tabular}{|llllll|}
\hline Análisis de varianza & & & & \\
Source & Type III SS & df & Mean Squares & F-ratio & p-value \\
\hline TIEMPO10 & 357,620 & 8 & 44,703 & 136,496 & 0,005 \\
\hline Error & 14,738 & 45 & 0,328 & & \\
\hline
\end{tabular}

2.10. pH $8,20 \mu g . L^{-1} M C-L R$ y 3 concentraciones de cloro

\begin{tabular}{|llllll|}
\hline Variables & \multicolumn{5}{c|}{ Niveles } \\
\hline TIEMPO20 (9 Niveles) & 0,000 & 1,000 & 2,000 & 3,000 & 4,000 \\
\hline & 5,000 & 6,000 & 7,000 & 8,000 & \\
\hline
\end{tabular}

\begin{tabular}{|ll|}
\hline Variable dependiente & MCLR_20 \\
\hline N & 54 \\
\hline Multiple R & 0,975 \\
\hline Squared Multiple R & 0,951 \\
\hline
\end{tabular}

\begin{tabular}{|llllll|}
\hline Análisis de varianza & & & & \\
Source & Type III SS & df & Mean Squares & F-ratio & p-value \\
\hline TIEMPO20 & $2.084,454$ & 8 & 260,557 & 109,843 & 0,025 \\
\hline Error & 106,743 & 45 & 2,372 & & \\
\hline
\end{tabular}

2.11. pH $8,50 \mu g . L^{-1}$ MC-LR y 3 concentraciones de cloro

\begin{tabular}{|llllll|}
\hline Variables & & \multicolumn{4}{c|}{ Levels } \\
\hline TIEMPO_50 (9 Niveles) & 0,000 & 1,000 & 2,000 & 3,000 & 4,000 \\
\hline & 5,000 & 6,000 & 7,000 & 8,000 & \\
\hline
\end{tabular}

\begin{tabular}{|ll|}
\hline Variable dependiente & MCLR_50 \\
\hline N & 54 \\
\hline Multiple R & 0,908 \\
\hline Squared Multiple R & 0,825 \\
\hline
\end{tabular}

\begin{tabular}{|llllll|}
\hline Análisis de varianza & & & & \\
Source & Type III SS & df & Mean Squares & F-ratio & p-value \\
\hline TIEMPO_50 & $13.444,888$ & 8 & $1.680,611$ & 26,521 & 0,024 \\
\hline Error & $2.851,649$ & 45 & 63,370 & & \\
\hline
\end{tabular}


2.12. ANOVA PARA 3 CONCENTRACIONES DE MC-LR Y R CONCENTRACIONES DE CLORO A pH 8

\begin{tabular}{|lrrrrr|}
\hline Variables & \multicolumn{5}{c|}{ Niveles } \\
\hline TIEMPO_ACUM (9 Niveles) & 0,000 & 1,000 & 2,000 & 3,000 & 4,000 \\
\hline CLORO_INI_ACUM (3 Niveles) & 1,000 & 2,000 & 5,000 & 6,000 & \\
\hline
\end{tabular}

\section{Variable dependiente MCLR_ACUM}

\begin{tabular}{|ll|}
\hline N & 162 \\
\hline Multiple R & 0,738 \\
\hline Squared Multiple R & 0,545 \\
\hline
\end{tabular}

\section{Análisis de varianza}

\begin{tabular}{|llllll}
\hline Source & Type III SS & df & Mean Squares & F-ratio & p-value \\
\hline TIEMPO_ACUM & $10.666,947$ & 8 & $1.333,368$ & 17,955 & 0,016 \\
\hline CLORO_INI_ACUM & 943,334 & 2 & 471,667 & 6,352 & 0,027 \\
\hline TIEMPO_ACUM*CLORO_INI_ACUM & 411,370 & 16 & 25,711 & 0,346 & 0,991 \\
\hline Error & $10.025,128$ & 135 & 74,260 & &
\end{tabular}

\subsection{ANOVA DE DEGRADACION DE MC-LRPARA TODOS LOS PH, TODAS LAS CONCENTRACIONES INICIALES DE MC-LR Y TODOS LOS TIEMPOS PROPUESTOS}

\begin{tabular}{|lrrrrr|}
\hline Variables & \multicolumn{5}{c|}{ Niveles } \\
\hline TIEMPO (9 Niveles) & 0,000 & 1,000 & 2,000 & 3,000 & 4,000 \\
\hline & 5,000 & 6,000 & 7,000 & 8,000 & \\
\hline PH (3 Niveles) & 6,000 & 7,000 & 8,000 & & \\
\hline CLORO_INICIAL (3 Niveles) & 1,000 & 2,000 & 5,000 & \\
\hline
\end{tabular}

\begin{tabular}{|ll|}
\hline Variable dependiente & MCLR_ACUM \\
\hline N & 486 \\
\hline Multiple R & 0,734 \\
\hline Squared Multiple R & 0,538 \\
\hline
\end{tabular}

\begin{tabular}{|llllll|}
\hline Análisis de varianza & Type III SS & df & Mean Squares & F-ratio & p-value \\
\hline TIEMPO & $31.502,679$ & 8 & $3.937,835$ & 53,793 & 0,017 \\
\hline PH & 394,326 & 2 & 197,163 & 2,693 & 0,069 \\
\hline CLORO_INICIAL & $1.549,781$ & 2 & 774,890 & 10,586 & 0,012 \\
\hline TIEMPO*PH & 205,921 & 16 & 12,870 & 0,176 & 1,000 \\
\hline TIEMPO*CLORO_INICIAL & 291,724 & 16 & 18,233 & 0,249 & 0,999 \\
\hline PH*CLORO_INICIAL & 211,386 & 4 & 52,846 & 0,722 & 0,577 \\
\hline TIEMPO*PH*CLORO_INICIAL & 399,381 & 32 & 12,481 & 0,170 & 1,000 \\
\hline Error & $29.647,142$ & 405 & 73,203 & & \\
\hline
\end{tabular}


3. ANOVA DE LA TURBIDEZ PARA EL TRATAMIENTO DE UN CULTIVO DE Microcystis aeruginosa con ácido peracético (APA).

3.1. ANOVA CULTIVO (CONTROL) A 0-4 HORAS DE TIEMPO DE CONTACTO

\begin{tabular}{|ll|}
\hline Variables & \\
\hline TIEMPO (5 Niveles) & 0,000 \\
\hline & \\
\hline Variable dependiente & DO \\
\hline N & 10 \\
\hline Multiple R & 0,994 \\
\hline Squared Multiple R & 0,987 \\
\hline
\end{tabular}

\section{Análisis de varianza}

\begin{tabular}{|llllll|}
\hline Source & Type III SS & df & Mean Squares & F-ratio & p-value \\
\hline TIEMPO & 0,000 & 4 & 0,000 & 95,250 & 0,012 \\
\hline Error & 0,000 & 5 & 0,000 & & \\
\hline
\end{tabular}

3.2. ANOVA DE LA TURBIDEZ CULTIVO TRATADO CON APA CON $5 \mathrm{mg}^{-1} \mathrm{~L}^{-1}$ ENTRE O Y 4 HORAS DE TIEMPO DE CONTACTO

\begin{tabular}{|c|c|c|c|c|c|c|}
\hline Variables & & & & Niveles & & \\
\hline TIEMPO_5 & 5 levels) & 0,000 & 1,000 & $2,000 \quad 3$ & $3,000 \quad 4,00$ & \\
\hline Variable de & pendiente & DO_5 & & & & \\
\hline $\mathbf{N}$ & & 10 & & & & \\
\hline Multiple R & & 0,996 & & & & \\
\hline Squared Mt & Itiple R & 0,992 & & & & \\
\hline Análisis de & farianza & & & & & \\
\hline Source & Type III SS & S df & Mean & Squares & F-ratio & p-value \\
\hline TIEMPO_5 & 0,000 & 4 & 0,000 & & 147,250 & 0,024 \\
\hline Error & 0,000 & 5 & 0,000 & & & \\
\hline
\end{tabular}

\subsection{ANOVA DE LA TURBIDEZ DE UN CULTIVO TRATADO CON APA CON 10mg.. ${ }^{-1}$ ENTRE O Y 4 HORAS DE TIEMPO DE CONTACTO}

\begin{tabular}{|ll|}
\hline Variables & \\
\hline TIEMPO_10 (5 Niveles) & $\mathbf{0 , 0 0 0}$ \\
\hline & \\
\hline Variable dependiente & DO_10 \\
\hline N & 10 \\
\hline Multiple R & 0,997 \\
\hline Squared Multiple R & 0,993 \\
\hline
\end{tabular}




\begin{tabular}{|llllll|}
\hline Análisis de varianza & & & \\
Source & Type III SS & df & Mean Squares & F-ratio & p-value \\
\hline TIEMPO_10 & 0,001 & 4 & 0,000 & 183,650 & 0,018 \\
\hline Error & 0,000 & 5 & 0,000 & & \\
\hline
\end{tabular}

3.4. ANOVA DE LA TURBIDEZ DE CULTIVO TRATADO CON APA CON 20mg. $\mathrm{L}^{-1}$ ENTRE O Y 4 HORAS DE TIEMPO DE CONTACTO

\begin{tabular}{|c|c|}
\hline Variables & \\
\hline TIEMPO_20 (5 Niveles) & 0,000 \\
\hline Variable dependiente & DO_20 \\
\hline $\mathbf{N}$ & 10 \\
\hline Multiple R & 0,997 \\
\hline Squared Multiple R & 0,993 \\
\hline
\end{tabular}

\begin{tabular}{|llllll|}
\hline Análisis de varianza & & & & \\
Source & Type III SS & df & Mean Squares & F-ratio & p-value \\
\hline TIEMPO_20 & 0,001 & 4 & 0,000 & 188,154 & 0,028 \\
\hline Error & 0,000 & 5 & 0,000 & & \\
\hline
\end{tabular}

3.5. ANOVA DE LA TURBIDEZ DE UN CULTIVO TRATADO CON TRES CONCENTRACIONES DE APA ENTRE $O$ Y 4 HORAS DE TIEMPO DE CONTACTO

\begin{tabular}{|llllll|}
\hline Variables & \multicolumn{5}{c|}{ Niveles } \\
\hline APA_ACUM (4 Niveles) & 0,000 & 5,000 & 10,000 & 20,000 & \\
\hline TIEMPO_ACUM (5 Niveles) & 0,000 & 1,000 & 2,000 & 3,000 & 4,000 \\
\hline
\end{tabular}

\begin{tabular}{|ll|}
\hline Variable dependiente & DO_ACUM \\
\hline N & 40 \\
\hline Multiple R & 0,997 \\
\hline Squared Multiple R & 0,995 \\
\hline
\end{tabular}

\begin{tabular}{|llllll|}
\hline Análisis de varianza & & & & & \\
\hline Source & Type III SS & df & Mean Squares & F-ratio & p-value \\
\hline TIEMPO_ACUM & 0,001 & 3 & 0,000 & 328,118 & 0,010 \\
\hline APA_ACUM*TIEMPO_ACUM & 0,002 & 4 & 0,000 & 568,548 & 0,018 \\
\hline Error & 0,000 & 12 & 0,000 & 36,398 & 0,022 \\
\hline
\end{tabular}


3.6. ANOVA DE LA TURBIDEZ DE UN CULTIVO TRATADO CON TRES CONCENTRACIONES (0,5 1 Y 5 mg. . $^{-1}$ DE APA) ENTRE O Y 24 HORAS DE TIEMPO DE CONTACTO

\begin{tabular}{|lllll|}
\hline Variables & \multicolumn{5}{c|}{ Niveles } \\
\hline TIEMPO (2 Niveles) & 0,000 & 1,000 \\
\hline APA (4 Niveles) & 0,000 & 0,500 & 1,000 & 5,000 \\
\hline
\end{tabular}

\begin{tabular}{|ll|}
\hline Variable dependiente & DO \\
\hline N & 16 \\
\hline Multiple R & 0,998 \\
\hline Squared Multiple R & 0,997 \\
\hline
\end{tabular}

\begin{tabular}{|llllll|}
\hline Análisis de varianza & & & & \\
\hline Source & Type III SS & df & Mean Squares & F-ratio & p-value \\
\hline TIEMPO & 0,007 & 1 & 0,007 & $1.710,545$ & 0,014 \\
\hline APA & 0,001 & 3 & 0,000 & 88,768 & 0,018 \\
\hline TIEMPO*APA & 0,002 & 3 & 0,001 & 143,636 & 0,032 \\
\hline Error & 0,000 & 8 & 0,000 & & \\
\hline
\end{tabular}

3.7. ANOVA DE LA TURBIDEZ DE UN CULTIVO CONTROL PARA TRES CONCENTRACIONES (10,15 Y 20mg. $\mathrm{L}^{-1}$ DE APA) A 0, 1, 8, 24 Y 48 HORAS DE TIEMPO DE CONTACTO

\begin{tabular}{|ll|}
\hline Variables & \\
\hline TIEMPO (5 Niveles) & $0,000 \quad 1,00$ \\
\hline & \\
\hline Variable dependiente & DO \\
\hline N & 10 \\
\hline Multiple R & 1,000 \\
\hline Squared Multiple R & 0,999 \\
\hline
\end{tabular}

\begin{tabular}{|llllll|}
\hline Análisis de varianza & & & & \\
Source & Type III SS & df & Mean Squares & F-ratio & p-value \\
\hline TIEMPO & 0,003 & 4 & 0,001 & $1.612,250$ & 0,028 \\
\hline Error & 0,000 & 5 & 0,000 & & \\
\hline
\end{tabular}

3.8. ANOVA DE LA TURBIDEZ DE UN CULTIVO TRATADO CON $10 \mathrm{mg} . \mathrm{L}^{-1}$ DE APA A $0,1,8,24$ Y 48 HORAS DE TIEMPO DE CONTACTO

\begin{tabular}{|ll|}
\hline Variables & \\
\hline TIEMPO_10 (5 Niveles) & $\mathbf{0 , 0 0 0}$ \\
\hline & \\
\hline Variable dependiente & DO_10 \\
\hline N & 10 \\
\hline Multiple R & 1,000 \\
\hline Squared Multiple R & 0,999 \\
\hline
\end{tabular}




\begin{tabular}{|llllll|}
\hline Análisis de varianza & & & & \\
Source & Type III SS & df & Mean Squares & F-ratio & p-value \\
\hline TIEMPO_10 & 0,010 & 4 & 0,002 & $1.714,893$ & 0,027 \\
\hline Error & 0,000 & 5 & 0,000 & & \\
\hline
\end{tabular}

3.9. ANOVA DE LA TURBIDEZ DE UN CULTIVO TRATADO CON $15 \mathrm{mg} . \mathrm{L}^{-1}$ DE APA A $0,1,8,24$ Y 48 HORAS DE TIEMPO DE CONTACTO

\begin{tabular}{|ll|}
\hline Variables & \\
\hline TIEMPO_15 (5 Niveles) & $\mathbf{0 , 0 0 0}$ \\
\hline Variable dependiente & DO_15 \\
\hline N & 10 \\
\hline Multiple R & 1,000 \\
\hline Squared Multiple R & 0,999 \\
\hline
\end{tabular}

\begin{tabular}{|llllll|}
\hline Análisis de varianza & & & & \\
Source & Type III SS & df & Mean Squares & F-ratio & p-value \\
\hline TIEMPO_15 & 0,012 & 4 & 0,003 & $1.950,433$ & 0,019 \\
\hline Error & 0,000 & 5 & 0,000 & & \\
\hline
\end{tabular}

3.10. ANOVA DE LA TURBIDEZ DE UN CULTIVO TRATADO CON $20 \mathrm{mg} . \mathrm{L}^{-1}$ DE APA A $0,1,8,24$ Y 48 HORAS DE TIEMPO DE CONTACTO

\begin{tabular}{|ll|}
\hline Variables & \\
\hline TIEMPO_20 (5 Niveles) & 0,000 \\
\hline & \\
\hline Variable dependiente & DO_20 \\
\hline N & 10 \\
\hline Multiple R & 1,000 \\
\hline Squared Multiple R & 0,999 \\
\hline
\end{tabular}

\section{Análisis de varianza}

\begin{tabular}{|llllll|}
\hline Source & Type III SS & df & Mean Squares & F-ratio & p-value \\
\hline TIEMPO_20 & 0,011 & 4 & 0,003 & $1.911,567$ & 0,036 \\
\hline Error & 0,000 & 5 & 0,000 & & \\
\hline
\end{tabular}

3.11. ANOVA DE LA TURBIDEZ DE UN CULTIVO TRATADO CON 10, 15 y 20mg. L $^{-1}$ DE APA A 0, 1, 8, 24 Y 48 HORAS DE TIEMPO DE CONTACTO

\begin{tabular}{|llllll|}
\hline Variables & \multicolumn{5}{c|}{ Niveles } \\
\hline TIEMPO_ACUM (5 Niveles) & 0,000 & 1,000 & 2,000 & 3,000 & 4,000 \\
\hline APA_ACUM (4 Niveles) & 0,000 & 10,000 & 15,000 & 20,000 & \\
\hline
\end{tabular}

\begin{tabular}{|ll|}
\hline Variable dependiente & DO_ACUM \\
\hline N & 40 \\
\hline Multiple R & 1,000 \\
\hline Squared Multiple R & 1,000 \\
\hline
\end{tabular}




\begin{tabular}{|llllll|}
\hline Análisis de varianza & Type III SS & df & Mean Squares & F-ratio & p-value \\
\hline TIEMPO_ACUM & 0,030 & 4 & 0,008 & $6.271,385$ & 0,019 \\
\hline APA_ACUM & 0,018 & 3 & 0,006 & $4.922,472$ & 0,025 \\
\hline TIEMPO_ACUM*APA_ACUM & 0,005 & 12 & 0,000 & 364,747 & 0,012 \\
\hline Error & 0,000 & 20 & 0,000 & & \\
\hline
\end{tabular}

4. ANOVA PARA LAS PROTEINAS TOTALES DE UN CULTIVO DE Microcystis aeruginosa TRATADO CON ACIDO PERACETICO (APA).

4.1. ANOVA DE LAS PROTEINAS TOTALES DE UN CULTIVO TRATADO CON 5mg. L $^{-1}$ DE APA A 0, 1, 2, 3, Y 4 HORAS DE TIEMPO DE CONTACTO

\begin{tabular}{|ll|}
\hline Variables & \\
\hline TIEMPO_5 (5 Niveles) & $0,000 \quad 1,000$ \\
\hline & \\
\hline Variable dependiente & PROTEINA_5 \\
\hline N & 10 \\
\hline Multiple R & 0,997 \\
\hline Squared Multiple R & 0,995 \\
\hline
\end{tabular}

\section{Análisis de varianza}

\begin{tabular}{|llllll|}
\hline Source & Type III SS & df & Mean Squares & F-ratio & p-value \\
\hline TIEMPO_5 & 0,001 & 4 & 0,000 & 247,692 & 0,019 \\
\hline Error & 0,000 & 5 & 0,000 & & \\
\hline
\end{tabular}

4.2. ANOVA DE LAS PROTEINAS TOTALES DE UN CULTIVO TRATADO CON 10mg. -1 $^{-1}$ E APA A 0, 1, 2, 3, Y 4 HORAS DE TIEMPO DE CONTACTO

\begin{tabular}{llllll} 
Variables & \multicolumn{5}{c}{ Niveles } \\
TIEMPO_10 (5 Niveles) & 0,000 & 1,000 & 2,000 & 3,000 & 4,000
\end{tabular}

\begin{tabular}{|ll|}
\hline Variable dependiente & PROTEINAS_10 \\
\hline N & 10 \\
\hline Multiple R & 0,999 \\
\hline Squared Multiple R & 0,998 \\
\hline
\end{tabular}

\begin{tabular}{|llllll|}
\hline Análisis de varianza & & & & \\
Source & Type III SS & df & Mean Squares & F-ratio & p-value \\
\hline TIEMPO_10 & 0,004 & 4 & 0,001 & 567,083 & 0,026 \\
\hline Error & 0,000 & 5 & 0,000 & & \\
\hline
\end{tabular}


4.3. ANOVA DE LAS PROTEINAS TOTALES DE UN CULTIVO TRATADO CON 20mg.. ${ }^{-1}$ DE APA A $0,1,2,3, Y 4$ HORAS DE TIEMPO DE CONTACTO

\begin{tabular}{|llllll|}
\hline Variables & \multicolumn{5}{c|}{ Niveles } \\
\hline TIEMPO_20 (5 Niveles) & 0,000 & 1,000 & 2,000 & 3,000 & 4,000 \\
\hline
\end{tabular}

\begin{tabular}{|ll|}
\hline Variable dependiente & PROTEINAS_20 \\
\hline N & 10 \\
\hline Multiple R & 0,997 \\
\hline Squared Multiple R & 0,995 \\
\hline
\end{tabular}

\section{Analisis de varianza}

\begin{tabular}{|llllll|}
\hline Source & Type III SS & df & Mean Squares & F-ratio & p-value \\
\hline TIEMPO_20 & 0,002 & 4 & 0,001 & 243,326 & 0,001 \\
\hline Error & 0,000 & 5 & 0,000 & & \\
\hline
\end{tabular}

4.4. ANOVA DE LAS PROTEINAS TOTALES DE UN CULTIVO TRATADO CON 5,

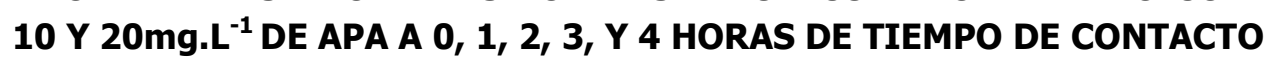

\begin{tabular}{|llllll|}
\hline Variables & \multicolumn{5}{c|}{ Niveles } \\
\hline TIEMPO_ACUM (5 Niveles) & 0,000 & 1,000 & 2,000 & 3,000 & 4,000 \\
\hline APA_ACUM (3 Niveles) & 5,000 & 10,000 & 20,000 & & \\
\hline
\end{tabular}

\begin{tabular}{|ll|}
\hline Variable dependiente & PROTEINAS_ACUM \\
\hline N & 30 \\
\hline Multiple R & 0,998 \\
\hline Squared Multiple R & 0,996 \\
\hline
\end{tabular}

\section{Análisis de varianza}

\begin{tabular}{|llllll|}
\hline Source & Type III SS & df & Mean Squares & F-ratio & p-value \\
\hline TIEMPO_ACUM & 0,006 & 4 & 0,002 & 835,306 & 0,010 \\
\hline APA_ACUM & 0,000 & 2 & 0,000 & 17,389 & 0,012 \\
\hline TIEMPO_ACUM*APA_ACUM & 0,002 & 8 & 0,000 & 110,792 & 0,029 \\
\hline Error & 0,000 & 15 & 0,000 & & \\
\hline
\end{tabular}

4.5. ANOVA DE LAS PROTEINAS TOTALES DE UN CULTIVO TRATADO CON 0,5, 1 y 5mg. L $^{-1}$ DE APA A $O$ Y 24 HORAS DE TIEMPO DE CONTACTO

\begin{tabular}{|lllll|}
\hline Variables & \multicolumn{5}{c|}{ Niveles } \\
\hline TIEMPO (2 Niveles) & 0,000 & 1,000 \\
\hline APA (4 Niveles) & 0,000 & 0,500 & 1,000 & 5,000 \\
\hline
\end{tabular}

\begin{tabular}{|ll|}
\hline Variable dependiente & PROTEINAS \\
\hline N & 16 \\
\hline Multiple R & 0,991 \\
\hline Squared Multiple R & 0,981 \\
\hline
\end{tabular}




\begin{tabular}{|llllll|}
\hline Análisis de varianza & & & & \\
\hline Source & Type III SS & df & Mean Squares & F-ratio & p-value \\
\hline TIEMPO & 0,000 & 1 & 0,000 & 1,102 & 0,324 \\
\hline APA & 0,000 & 3 & 0,000 & 65,958 & 0,031 \\
\hline TIEMPO*APA & 0,001 & 3 & 0,000 & 74,514 & 0,015 \\
\hline Error & 0,000 & 8 & 0,000 & & \\
\hline
\end{tabular}

4.6. ANOVA DE LAS PROTEINAS TOTALES DE UN CULTIVO CONTROL A 0, 1, 8, 24 Y 48 HORAS DE TIEMPO DE CONTACTO

\begin{tabular}{llllll} 
Variables & \multicolumn{5}{c}{ Niveles } \\
TIEMPO (5 Niveles) & 0,000 & 1,000 & 2,000 & 3,000 & 4,000
\end{tabular}

\begin{tabular}{|ll|}
\hline Variable dependiente & PROTEINAS \\
\hline N & 10 \\
\hline Multiple R & 0,997 \\
\hline Squared Multiple R & 0,993 \\
\hline
\end{tabular}

\begin{tabular}{|llllll|}
\hline Análisis de varianza & & & & \\
\hline Source & Type III SS & df & Mean Squares & F-ratio & p-value \\
\hline TIEMPO & 0,003 & 4 & 0,001 & 185,525 & 0,012 \\
\hline Error & 0,000 & 5 & 0,000 & & \\
\hline
\end{tabular}

4.7. ANOVA DE LAS PROTEINAS TOTALES DE UN CULTIVO TRATADO CON 10mg. L $^{-1}$ A 0, 1, 8, 24 Y 48 HORAS DE TIEMPO DE CONTACTO

\begin{tabular}{llllll} 
Variables & \multicolumn{5}{c}{ Niveles } \\
TIEMPO_10 (5 Niveles) & $\mathbf{0 , 0 0 0}$ & $\mathbf{1 , 0 0 0}$ & $\mathbf{2}, 000$ & 3,000 & 4,000
\end{tabular}

\begin{tabular}{|ll|}
\hline Variable dependiente & PROTEINAS_10 \\
\hline N & 10 \\
\hline Multiple R & 0,990 \\
\hline Squared Multiple R & 0,980 \\
\hline
\end{tabular}

\begin{tabular}{|llllll|}
\hline Análisis de varianza & & & & \\
Source & Type III SS & df & Mean Squares & F-ratio & p-value \\
\hline TIEMPO_10 & 0,001 & 4 & 0,000 & 61,356 & 0,010 \\
\hline Error & 0,000 & 5 & 0,000 & & \\
\hline
\end{tabular}

4.8. ANOVA DE LAS PROTEINAS TOtALES DE UN CULTIVO TRATADO CON 15mg. L $^{-1}$ A 0, 1, 8, 24 Y 48 HORAS DE TIEMPO DE CONTACTO

\begin{tabular}{|c|c|c|c|c|}
\hline Variables & \multicolumn{4}{|c|}{ Niveles } \\
\hline TIEMPO_15 (5 Niveles) & $0,000 \quad 1,000$ & 2,000 & 3,000 & 4,000 \\
\hline Variable dependiente & PROTEINAS_15 & & & \\
\hline $\mathbf{N}$ & 10 & & & \\
\hline Multiple R & 0,998 & & & \\
\hline
\end{tabular}




\begin{tabular}{|llllll|}
\hline \multicolumn{2}{|l|}{ Squared Multiple R } & 0,995 & & & \\
& & & & & \\
\hline Análisis de varianza & & & & \\
\hline Source & Type III SS & df & Mean Squares & F-ratio & p-value \\
\hline TIEMPO_15 & 0,006 & 4 & 0,002 & 265,658 & 0,018 \\
\hline Error & 0,000 & 5 & 0,000 & & \\
\hline
\end{tabular}

4.9. ANOVA DE LAS PROTEINAS TOTALES DE UN CULTIVO TRATADO CON 20mg. L $^{-1}$ A 0, 1, 8, 24 Y 48 HORAS DE TIEMPO DE CONTACTO

\begin{tabular}{|c|c|}
\hline Variables & $\mathbf{N i}$ \\
\hline TIEMPO_20 (5 Niveles) & $0,000 \quad 1,000 \quad 2$ \\
\hline Variable dependiente & PROTEINAS_20 \\
\hline $\mathbf{N}$ & 10 \\
\hline Multiple R & 0,996 \\
\hline Squared Multiple R & 0,993 \\
\hline
\end{tabular}

\begin{tabular}{|llllll|}
\hline Analysis of Variance & & & & \\
Source & Type III SS & df & Mean Squares & F-ratio & p-value \\
\hline TIEMPO_20 & 0,003 & 4 & 0,001 & 171,623 & 0,005 \\
\hline Error & 0,000 & 5 & 0,000 & & \\
\hline
\end{tabular}

4.10. ANOVA DE LAS PROTEINAS TOTALES DE UN CULTIVO TRATADO CON 10, 15 Y 20mg. $\mathrm{L}^{-1}$ A 0, 1, 8, 24 Y 48 HORAS DE TIEMPO DE CONTACTO

\begin{tabular}{|llllll|}
\hline Variables & \multicolumn{5}{c|}{ Niveles } \\
\hline TIEMPOS_ACUM (5 Niveles) & 0,000 & 1,000 & 2,000 & 3,000 & 4,000 \\
\hline APA_ACUM (4 Niveles) & 0,000 & 10,000 & 15,000 & 20,000 & \\
\hline
\end{tabular}

\begin{tabular}{|ll|}
\hline Variable dependiente & PROTEINAS_ACUM \\
\hline N & 40 \\
\hline Multiple R & 0,997 \\
\hline Squared Multiple R & 0,994 \\
\hline
\end{tabular}

\begin{tabular}{|llllll|}
\hline Análisis de varianza & Type III SS & df & Mean Squares & F-ratio & p-value \\
\hline TIEMPOS_ACUM & 0,008 & 4 & 0,002 & 379,720 & 0,003 \\
\hline APA_ACUM & 0,003 & 3 & 0,001 & 230,596 & 0,005 \\
\hline TIEMPOS_ACUM*APA_ACUM & 0,006 & 12 & 0,001 & 105,214 & 0,010 \\
\hline Error & 0,000 & 20 & 0,000 & & \\
\hline
\end{tabular}

5. ANOVA DE LA CLOROFILA-a DE UN CULTIVo DE Microcystis aeruginosa TRATADO CON ACIDO PERACETICO (APA). 
5.1. ANOVA DE LA CLOROFILA-a DE UN CULTIVo CONTROL A 0, 1, 2, 3, Y 4 HORAS DE TIEMPO DE CONTACTO

\begin{tabular}{|llllll|}
\hline Variables & \multicolumn{5}{c|}{ Niveles } \\
\hline TIEMPOS (5 Niveles) & 0,000 & 1,000 & 2,000 & 3,000 & 4,000 \\
\hline
\end{tabular}

\begin{tabular}{|ll|}
\hline Variable dependiente & CLOROFILA \\
\hline N & 10 \\
\hline Multiple R & 0,636 \\
\hline Squared Multiple R & 0,405 \\
\hline
\end{tabular}

\section{Análisis de varianza}

\begin{tabular}{|llllll|}
\hline Source & Type III SS & df & Mean Squares & F-ratio & p-value \\
\hline TIEMPOS & $32.366,450$ & 4 & $8.091,613$ & 0,851 & 0,550 \\
\hline Error & $47.552,272$ & 5 & $9.510,454$ & & \\
\hline
\end{tabular}

5.2. ANOVA DE LA CLOROFILA-a DE UN CULTIVO TRATADO CON $5 \mathrm{mg}^{-\mathrm{L}^{-1} \mathrm{DE}}$ APA A 0, 1, 2, 3, Y 4 HORAS DE TIEMPO DE CONTACTO

\begin{tabular}{|c|c|}
\hline Variables & $\mathbf{N}$ \\
\hline TIEMPO_5 (5 Niveles) & $0,000 \quad 1,000$ \\
\hline Variable dependiente & CLOROFILA_5 \\
\hline $\mathbf{N}$ & 10 \\
\hline Multiple R & 0,749 \\
\hline Squared Multiple R & 0,562 \\
\hline
\end{tabular}

\begin{tabular}{|llllll|}
\hline Análisis de varianza & & & & \\
Source & Type III SS & df & Mean Squares & F-ratio & p-value \\
\hline TIEMPO_5 & $318.350,671$ & 4 & $79.587,668$ & 1,602 & 0,306 \\
\hline Error & $248.432,630$ & 5 & $49.686,526$ & & \\
\hline
\end{tabular}

5.3. ANOVA DE LA ClOROFILA-a DE UN CULTIVO TRATADO CON $10 \mathrm{mg} \cdot \mathrm{L}^{-1}$ DE APA A 0, 1, 2, 3, Y 4 HORAS DE TIEMPO DE CONTACTO

\begin{tabular}{|c|c|}
\hline Variables & $\mathbf{N}$ \\
\hline TIEMPO_10 (5 Niveles) & $0,000 \quad 1,000 \quad 2$ \\
\hline Variable dependiente & CLOROFILA_10 \\
\hline $\mathbf{N}$ & 10 \\
\hline Multiple R & 0,152 \\
\hline Squared Multiple $\mathbf{R}$ & 0,023 \\
\hline
\end{tabular}

\begin{tabular}{|llllll|}
\hline Análisis de varianza & & & & \\
Source & Type III SS & df & Mean Squares & F-ratio & p-value \\
\hline TIEMPO_10 & $5.956,326$ & 4 & $1.489,081$ & 0,029 & 0,998 \\
\hline Error & $252.652,175$ & 5 & $50.530,435$ & & \\
\hline
\end{tabular}


5.4. ANOVA DE LA CLOROFILA-a DE UN CULTIVO TRATADO CON $20 \mathrm{mg} \cdot \mathrm{L}^{-1}$ DE APA A 0, 1, 2, 3, Y 4 HORAS DE TIEMPO DE CONTACTO

\begin{tabular}{llllll}
\hline Variables & \multicolumn{5}{c}{ Niveles } \\
TIEMPO_20 (5 Niveles) & 0,000 & 1,000 & 2,000 & 3,000 & 4,000
\end{tabular}

\begin{tabular}{|ll|}
\hline Variable dependiente & CLOROFILA_20 \\
\hline N & 10 \\
\hline Multiple R & 0,988 \\
\hline Squared Multiple R & 0,977 \\
\hline
\end{tabular}

\section{Análisis de varianza}

\begin{tabular}{|llllll|}
\hline Source & Type III SS & df & Mean Squares & F-ratio & p-value \\
\hline TIEMPO_20 & $614.288,095$ & 4 & $153.572,024$ & 52,780 & 0,003 \\
\hline Error & $14.548,353$ & 5 & $2.909,671$ & & \\
\hline
\end{tabular}

5.5. ANOVA DE LA ClOROFILA-a DE UN CULTIVO TRATADO CON 5, $10 \mathrm{Y}$ 20mg. L $^{-1}$ DE APA A 0, 1, 2, 3, Y 4 HORAS DE TIEMPO DE CONTACTO

\begin{tabular}{|llllll|}
\hline Variables & \multicolumn{5}{c|}{ Niveles } \\
\hline TIEMPO_ACUM (5 Niveles) & 0,000 & 1,000 & 2,000 & 3,000 & 4,000 \\
\hline APA_ACUM (4 Niveles) & 0,000 & 5,000 & 10,000 & 20,000 & \\
\hline
\end{tabular}

\begin{tabular}{|ll|}
\hline Variable dependiente & CLOROFILA_ACUM \\
\hline N & 40 \\
\hline Multiple R & 0,859 \\
\hline Squared Multiple R & 0,738 \\
\hline
\end{tabular}

\section{Análisis de varianza}

\begin{tabular}{|llllll|}
\hline Source & Type III SS & df & Mean Squares & F-ratio & p-value \\
\hline TIEMPO_ACUM & $88.624,496$ & 4 & $22.156,124$ & 0,787 & 0,547 \\
\hline APA_ACUM & $618.981,895$ & 3 & $206.327,298$ & 7,327 & 0,002 \\
\hline TIEMPO_ACUM*APA_ACUM & $882.337,046$ & 12 & $73.528,087$ & 2,611 & 0,028 \\
\hline Error & $563.185,430$ & 20 & $28.159,272$ & &
\end{tabular}

5.6. ANOVA DE LA CLOROFILA-a DE UN CULTIVO TRATADO CON 0,5, 1 Y $5 \mathrm{mg} \cdot \mathrm{L}^{-1}$ DE APA A $O$ Y 24 HORAS DE TIEMPO DE CONTACTO

\begin{tabular}{|lllll|}
\hline Variables & \multicolumn{4}{c|}{ Niveles } \\
\hline TIEMPO (2 Niveles) & 0,000 & 1,000 \\
\hline APA (4 Niveles) & 0,000 & 0,500 & 1,000 & 5,000 \\
\hline
\end{tabular}

\begin{tabular}{|ll|}
\hline Variable dependiente & CLOROFILA \\
\hline N & 16 \\
\hline Multiple R & 1,000 \\
\hline Squared Multiple R & 1,000 \\
\hline
\end{tabular}




\begin{tabular}{|llllll|}
\hline Análisis de varianza & & & & \\
Source & Type III SS & df & Mean Squares & F-ratio & p-value \\
\hline TIEMPO & $3.084 .361,375$ & 1 & $3.084 .361,375$ & $9.383,635$ & 0,010 \\
\hline APA & $2.942 .378,039$ & 3 & $980.792,680$ & $2.983,892$ & 0,022 \\
\hline TIEMPO*APA & $2.942 .378,039$ & 3 & $980.792,680$ & $2.983,892$ & 0,034 \\
\hline Error & $2.629,566$ & 8 & 328,696 & & \\
\hline
\end{tabular}

5.7. ANOVA DE LA CLOROFILA-a DE UN CULTIVO CONTROL A 0, 1, 8, 24 Y 48 HORAS DE TIEMPO DE CONTACTO

\begin{tabular}{llllll} 
Variables & \multicolumn{5}{c}{ Niveles } \\
TIEMPO (5 Niveles) & 0,000 & 1,000 & 2,000 & 3,000 & 4,000
\end{tabular}

\begin{tabular}{|ll|}
\hline Variable dependiente & CLOROFILA \\
\hline N & 10 \\
\hline Multiple R & 0,815 \\
\hline Squared Multiple R & 0,664 \\
\hline
\end{tabular}

\begin{tabular}{|llllll|}
\hline Análisis de varianza & & & & \\
\hline Source & Type III SS & df & Mean Squares & F-ratio & p-value \\
\hline TIEMPO & $23.719 .816,251$ & 4 & $5.929 .954,063$ & 2,466 & 0,175 \\
\hline Error & $12.025 .768,782$ & 5 & $2.405 .153,756$ & & \\
\hline
\end{tabular}

5.8. ANOVA DE LA CLOROFILA-a DE UN CULTIVO TRATADO CON $10 \mathrm{mg} \cdot \mathrm{L}^{-1}$ DE APA A 0, 1, 8, 24 Y 48 HORAS DE TIEMPO DE CONTACTO

\begin{tabular}{|c|c|}
\hline Variables & \\
\hline TIEMPOS_10 (5 Niveles) & 5) $0,000 \quad 1,000$ \\
\hline Variable dependiente & CLOROFILA_10 \\
\hline $\mathbf{N}$ & 10 \\
\hline Multiple R & 0,999 \\
\hline Squared Multiple R & 0,998 \\
\hline
\end{tabular}

\begin{tabular}{|llllll|}
\hline Análisis de varianza & & & & \\
Source & Type III SS & df & Mean Squares & F-ratio & p-value \\
\hline TIEMPOS_10 & $11.375 .692,268$ & 4 & $2.843 .923,067$ & 822,008 & 0,006 \\
\hline Error & $17.298,624$ & 5 & $3.459,725$ & & \\
\hline
\end{tabular}

5.9. ANOVA DE LA ClOROFILA-a DE UN CULTIVO TRATADO CON $15 \mathrm{mg} \cdot \mathrm{L}^{-1}$ DE APA A 0, 1, 8, 24 Y 48 HORAS DE TIEMPO DE CONTACTO

\begin{tabular}{llllll|}
\hline Variables & \multicolumn{5}{c}{ Niveles } \\
\hline TIEMPO_15 (5 niveles) & 0,000 & 1,000 & 2,000 & 3,000 & 4,000 \\
\hline
\end{tabular}

\section{Variable dependiente CLOROFILA_15}

\begin{tabular}{|ll|}
\hline $\mathbf{N}$ & 10 \\
\hline Multiple R & 1,000 \\
\hline
\end{tabular}


Squared Multiple R $\quad 0,999$

\section{Análisis de varianza}

\begin{tabular}{|llllll|} 
Source & Type III SS & df & Mean Squares & F-ratio & p-value \\
\hline TIEMPO_15 & $11.259 .200,907$ & 4 & $2.814 .800,227$ & $2.010,911$ & 0,018 \\
\hline Error & $6.998,819$ & 5 & $1.399,764$ & & \\
\hline
\end{tabular}

5.10. ANOVA DE LA CLOROFILA-a DE UN CULTIVO TRATADO CON $20 \mathrm{mg}^{-1} \mathrm{~L}^{-1}$ DE APA A 0, 1, 8, 24 Y 48 HORAS DE TIEMPO DE CONTACTO

\begin{tabular}{|c|c|}
\hline Variables & n \\
\hline TIEMPO_20 (5 Niveles) & $0,000 \quad 1,000$ \\
\hline Variable dependiente & CLOROFILA_20 \\
\hline $\mathbf{N}$ & 10 \\
\hline Multiple R & 1,000 \\
\hline Squared Multiple R & 0,999 \\
\hline
\end{tabular}

\begin{tabular}{|llllll|}
\hline Análisis de varianza & & & & \\
Source & Type III SS & df & Mean Squares & F-ratio & p-value \\
\hline TIEMPO_20 & $10.225 .760,476$ & 4 & $2.556 .440,119$ & $2.427,026$ & 0,012 \\
\hline Error & $5.266,610$ & 5 & $1.053,322$ & & \\
\hline
\end{tabular}

5.11. ANOVA DE LA CLOROFILA-a DE UN CULTIVO TRATADO CON 10, $15 \mathrm{Y}$ 20mg. L $^{-1}$ DE APA A 0, 1, 8, 24 Y 48 HORAS DE TIEMPO DE CONTACTO

\begin{tabular}{|llllll|}
\hline Variables & \multicolumn{5}{c|}{ Niveles } \\
\hline TIEMPO_ACUM (5 Niveles) & 0,000 & 1,000 & 2,000 & 3,000 & 4,000 \\
\hline APA_ACUM (4 Niveles) & 0,000 & 10,000 & 15,000 & 20,000 & \\
\hline
\end{tabular}

\begin{tabular}{|ll|}
\hline Variable dependiente & CLOROFILA_ACUM \\
\hline N & 40 \\
\hline Multiple R & 0,940 \\
\hline Squared Multiple R & 0,883 \\
\hline
\end{tabular}

\section{Análisis de varianza}

\begin{tabular}{|llllll|}
\hline Source & Type III SS & df & Mean Squares & F-ratio & p-value \\
\hline TIEMPO_ACUM & $52.710 .059,149$ & 4 & $13.177 .514,787$ & 21,862 & 0,010 \\
\hline APA_ACUM & $34.534 .030,231$ & 3 & $11.511 .343,410$ & 19,098 & 0,009 \\
\hline TIEMPO_ACUM*APA_ACUM & $3.870 .410,752$ & 12 & $322.534,229$ & 0,535 & 0,867 \\
\hline Error & $12.055 .332,835$ & 20 & $602.766,642$ & &
\end{tabular}

6. ANOVA DE LA VIBILIDAD CELULAR DE UN CULTIVO DE M. aeruginosa TRATADO CON ACIDO PERACETICO

6.1. ANOVA DE LA VIABILIDAD DE UN CULTIVO TRATADO CON 5, $10 \mathrm{Y}$ $20 \mathrm{mg} . \mathrm{L}^{-1}$ DE APA A 0, 1, 2, 3 Y 4 HORAS DE TIEMPO DE CONTACTO 


\begin{tabular}{|llllll|}
\hline Variables & \multicolumn{5}{c|}{ Niveles } \\
\hline TIEMPO (5 Niveles) & 0,000 & 1,000 & 2,000 & 3,000 & 4,000 \\
\hline APA (4 Niveles) & 0,000 & 5,000 & 10,000 & 20,000 \\
\hline
\end{tabular}

\begin{tabular}{|ll|}
\hline Variable dependiente & VIABLES \\
\hline N & 40 \\
\hline Multiple R & 1,000 \\
\hline Squared Multiple R & 1,000 \\
\hline
\end{tabular}

\section{Análisis de varianza}

\begin{tabular}{|llllll|}
\hline Source & Type III SS & df & Mean Squares & F-ratio & p-value \\
\hline TIEMPO & $9,216 \mathrm{E}+010$ & 4 & $2,304 \mathrm{E}+010$ & $8,444 \mathrm{E}+015$ & 0,022 \\
\hline APA & $1,229 \mathrm{E}+011$ & 3 & $4,096 \mathrm{E}+010$ & $1,501 \mathrm{E}+016$ & 0,006 \\
\hline TIEMPO*APA & $3,072 \mathrm{E}+010$ & 12 & $2,560 \mathrm{E}+009$ & $9,382 \mathrm{E}+014$ & 0,019 \\
\hline Error & 0,000 & 20 & 0,000 & & \\
\hline
\end{tabular}

\subsection{ANOVA DE LA VIABILIDAD DE UN CULTIVO TRATADO CON 0,5, 1 Y 5mg.L- ${ }^{1}$ DE APA A $O$ Y 24 HORAS DE TIEMPO DE CONTACTO}

\begin{tabular}{|lllll|}
\hline Variables & \multicolumn{5}{c|}{ Niveles } \\
\hline TIEMPO_(2 Niveles) & 0,000 & 1,000 \\
\hline APA_(4 Niveles) & 0,000 & 0,500 & 1,000 & 5,000 \\
\hline
\end{tabular}

\begin{tabular}{|ll|}
\hline Variable dependiente & VIABLES_ \\
\hline N & 16 \\
\hline Multiple R & 1,000 \\
\hline Squared Multiple R & 1,000 \\
\hline
\end{tabular}

\begin{tabular}{|llllll|}
\hline Análisis de varianza & & & & \\
Source & Type III SS & df & Mean Squares & F-ratio & p-value \\
\hline TIEMPO_ & $1,960 \mathrm{E}+010$ & 1 & $1,960 \mathrm{E}+010$ & $1,444 \mathrm{E}+014$ & 0,027 \\
\hline APA_ & $1,917 \mathrm{E}+012$ & 3 & $6,390 \mathrm{E}+011$ & $4,708 \mathrm{E}+015$ & 0,022 \\
\hline TIEMPO_*APA_ & $1,960 \mathrm{E}+010$ & 3 & $6,533 \mathrm{E}+009$ & $4,813 \mathrm{E}+013$ & 0,010 \\
\hline Error & 0,001 & 8 & 0,000 & & \\
\hline
\end{tabular}

7. ANOVA DE LAS TOXINAS TOTALES EN UN CULTIVO DE $M$. aeruginosa TRATDO CON DIFERENTES CONCENTRACIONES DE ACIDO PERACETICO

7.1. ANOVA DE LAS TOXINAS TOTALES DE UN CULTIVO CONTROL A 0, 1, 2, 3 Y 4 HORAS DE TIEMPO DE CONTACTO

\begin{tabular}{|ll|}
\hline Variables & \\
\hline TIEMPO (5 Niveles) & $0,000 \quad 1,000$ \\
\hline & \\
\hline Variable dependiente & TOXINA \\
\hline N & 10 \\
\hline Multiple R & 0,000 \\
\hline
\end{tabular}


Squared Multiple R $\quad 0,000$

\section{Análisis de varianza}

\begin{tabular}{|llllll|} 
Source & Type III SS & df & Mean Squares & F-ratio & p-value \\
\hline TIEMPO & 0,000 & 4 & 0,000 & 0,000 & 1,000 \\
\hline Error & 0,000 & 5 & 0,000 & & \\
\hline
\end{tabular}

7.2. ANOVA DE LAS TOXINAS TOTALES DE UN CULTIVO TRATADO CON 5mg.'${ }^{1}$ DE APA A 0, 1, 2, 3 Y 4 HORAS DE TIEMPO DE CONTACTO

\begin{tabular}{|ll|}
\hline Variables & \\
\hline TIEMPO_5 (5 Niveles) & $0,000 \quad 1,000$ \\
\hline & \\
\hline Variable dependiente & TOXINA_5 \\
\hline N & 10 \\
\hline Multiple R & 1,000 \\
\hline Squared Multiple R & 1,000 \\
\hline
\end{tabular}

\section{Analisis de varianza}

\begin{tabular}{|llllll|}
\hline Source & Type III SS & df & Mean Squares & F-ratio & p-value \\
\hline TIEMPO_5 & 0,008 & 4 & 0,002 & $1,126 \mathrm{E}+016$ & 0,015 \\
\hline Error & 0,000 & 5 & 0,000 & & \\
\hline
\end{tabular}

7.3. ANOVA DE LAS TOXINAS TOTALES DE UN CULTIVO TRATADO CON 10mg. L $^{-1}$ DE APA A 0, 1, 2, 3 Y 4 HORAS DE TIEMPO DE CONTACTO

\begin{tabular}{|ll|}
\hline Variables & \\
\hline TIEMPO_10 (5 Niveles) & $0,000 \quad 1,000$ \\
\hline & \\
\hline Variable dependiente & TOXINA_10 \\
\hline N & 10 \\
\hline Multiple R & 1,000 \\
\hline Squared Multiple R & 1,000 \\
\hline
\end{tabular}

\begin{tabular}{|llllll|}
\hline Análisis de varianza & & & & \\
Source & Type III SS & df & Mean Squares & F-ratio & p-value \\
\hline TIEMPO_10 & 0,003 & 4 & 0,001 & $1,126 \mathrm{E}+016$ & 0,018 \\
\hline Error & 0,000 & 5 & 0,000 & & \\
\hline
\end{tabular}

7.4. ANOVA DE LAS TOXINAS TOTALES DE UN CULTIVO TRATADO CON 20mg. . $^{-1}$ DE APA A 0, 1, 2, 3 Y 4 HORAS DE TIEMPO DE CONTACTO

\begin{tabular}{llllll|} 
Variables & \multicolumn{5}{c|}{ Niveles } \\
TIEMPO_20 (5 Niveles) & 0,000 & 1,000 & 2,000 & 3,000 & 4,000 \\
\hline
\end{tabular}

\section{Variable dependiente TOXINA_20}

$\mathbf{N} 10$ 


\begin{tabular}{|ll|}
\hline Multiple R & 0,999 \\
\hline Squared Multiple R & 0,998 \\
\hline
\end{tabular}

\section{Análisis de varianza}

\begin{tabular}{|llllll|}
\hline Source & Type III SS & df & Mean Squares & F-ratio & p-value \\
\hline TIEMPO_20 & 0,027 & 4 & 0,007 & 553,756 & 0,015 \\
\hline Error & 0,000 & 5 & 0,000 & & \\
\hline
\end{tabular}

7.5. ANOVA DE LAS TOXINAS TOTALES DE UN CULTIVO TRATADO CON 5, $10 \mathrm{Y}$

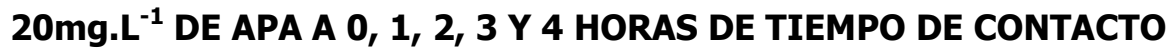

\begin{tabular}{|llllll|} 
VIIEMPO_ACUM (5 Niveles) & 0,000 & 1,000 & 2,000 & 3,000 & 4,000 \\
\hline APA_ACUM (4 Niveles) & 0,000 & 5,000 & 10,000 & 20,000 & \\
\hline
\end{tabular}

\section{Variable dependiente TOXINA_ACUM}

\begin{tabular}{|ll|}
\hline N & 39 \\
\hline Multiple R & 0,980 \\
\hline Squared Multiple R & 0,961 \\
\hline
\end{tabular}

\section{Análisis de varianza}

\begin{tabular}{|llllll|}
\hline Source & Type III SS & df & Mean Squares & F-ratio & p-value \\
\hline TIEMPO_ACUM & 0,004 & 4 & 0,001 & 7,978 & 0,001 \\
\hline APA_ACUM & 0,031 & 3 & 0,010 & 76,683 & 0,026 \\
\hline TIEMPO_ACUM*APA_ACUM & 0,022 & 12 & 0,002 & 13,816 & 0,009 \\
\hline Error & 0,003 & 19 & 0,000 & & \\
\hline
\end{tabular}

7.6. ANOVA DE LAS TOXINAS TOTALES DE UN CULTIVO TRATADO CON 0,5, 1 Y $5 \mathrm{mg}^{\circ} \mathrm{L}^{-1}$ DE APA A $O$ Y 24 HORAS DE TIEMPO DE CONTACTO

\begin{tabular}{|llll|}
\hline Variables & \multicolumn{3}{c|}{ Niveles } \\
\hline TIEMPO (2 Niveles) & 0,000 & 1,000 \\
\hline APA (3 Niveles) & 0,500 & 1,000 & 5,000 \\
\hline
\end{tabular}

\begin{tabular}{|ll|}
\hline Variable dependiente & TOXINA \\
\hline N & 12 \\
\hline Multiple R & 0,999 \\
\hline Squared Multiple R & 0,998 \\
\hline
\end{tabular}

\section{Análisis de varianza}

\begin{tabular}{|llllll|}
\hline Source & Type III SS & $\mathbf{d f}$ & Mean Squares & F-ratio & p-value \\
\hline TIEMPO & 0,007 & 1 & 0,007 & 32,314 & 0,011 \\
\hline APA & 0,245 & 2 & 0,122 & 575,821 & 0,025 \\
\hline TIEMPO*APA & 0,302 & 2 & 0,151 & 710,439 & 0,009 \\
\hline Error & 0,001 & 6 & 0,000 & & \\
\hline
\end{tabular}


7.7. ANOVA DE LAS TOXINAS TOTALES DE UN CULTIVO TRATADO CON 10, 15 Y $20 \mathrm{mg}^{-L^{-1}}$ DE APA A $O$ Y 24 HORAS DE TIEMPO DE CONTACTO

\begin{tabular}{|lll|}
\hline Variables & & Nive \\
\hline TIEMPO_3 (2 Niveles) & 0,000 & 1,000 \\
\hline APA_3 (3 Niveles) & 10,000 & 15,000 \\
\hline & \\
\hline & Variable dependiente & TOXINA_3 \\
\hline N & 12 \\
\hline Multiple R & 1,000 \\
\hline Squared Multiple R & 0,999 \\
\hline
\end{tabular}

\section{Análisis de varianza}

\begin{tabular}{|llllll|}
\hline Source & Type III SS & df & Mean Squares & F-ratio & p-value \\
\hline TIEMPO_3 & 0,269 & 1 & 0,269 & $11.021,191$ & 0,009 \\
\hline APA_3 & 0,004 & 2 & 0,002 & 84,126 & 0,013 \\
\hline TIEMPO_3*APA_3 & 0,004 & 2 & 0,002 & 79,935 & 0,018 \\
\hline Error & 0,000 & 6 & 0,000 & & \\
\hline
\end{tabular}

8. ANOVA DE LA DEGRADACIÓN DE MC-LR EN SOLUCIONES ACUOSAS CON DIFERENTES CONCENTRACIONES DE ACIDO PERACETICO

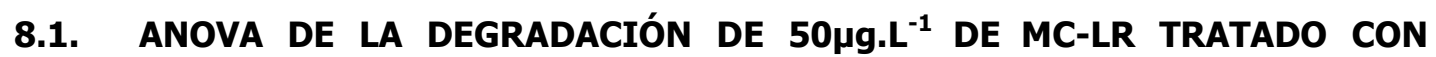
$10 \mathrm{mg}^{-\mathrm{L}^{-1}}$ DE APA A PH 6 Y DIFERENTES TIEMPOS DE CONTACTO

\begin{tabular}{|lrrrrr|}
\hline Variables & \multicolumn{5}{c|}{ Niveles } \\
\hline & 5,000 & 1,000 & 2,000 & 3,000 & 4,000 \\
\hline & 6,000 & 7,000 & 8,000 & \\
\hline
\end{tabular}

\section{Variable dependiente MC_PH6}

\begin{tabular}{|ll|}
\hline N & 18 \\
\hline Multiple R & 1,000 \\
\hline Squared Multiple R & 1,000 \\
\hline
\end{tabular}

\section{Análisis de varianza}

\begin{tabular}{|llllll|}
\hline Source & Type III SS & df & Mean Squares & F-ratio & p-value \\
\hline TIEMPO_PH6 & $3.521,635$ & 8 & 440,204 & $352.163,500$ & 0,005 \\
\hline Error & 0,011 & 9 & 0,001 & & \\
\hline
\end{tabular}

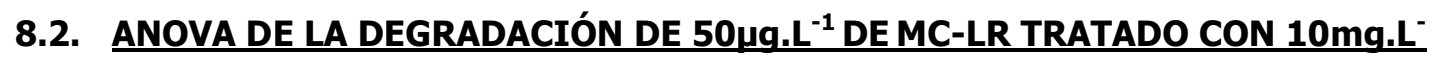
${ }^{1}$ DE APA A PH 7 Y DIFERENTES TIEMPOS DE CONTACTO

\begin{tabular}{|lrrrrr|}
\hline Variables & \multicolumn{5}{c|}{ Niveles } \\
\hline TIEMPO_PH7 (9 Niveles) & 0,000 & 1,000 & 2,000 & 3,000 & 4,000 \\
\hline & 5,000 & 6,000 & 7,000 & 8,000
\end{tabular}




\begin{tabular}{|ll|}
\hline Variable dependiente & MC_PH7 \\
\hline N & 18 \\
\hline Multiple R & 1,000 \\
\hline Squared Multiple R & 1,000 \\
\hline
\end{tabular}

\begin{tabular}{|llllll|}
\hline Análisis de varianza & & & & \\
Source & Type III SS & df & Mean Squares & F-ratio & p-value \\
\hline TIEMPO_PH7 & $3.013,426$ & 8 & 376,678 & $301.342,570$ & 0,014 \\
\hline
\end{tabular}

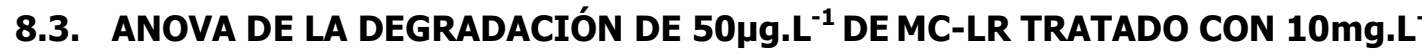
${ }^{1}$ DE APA A PH 8 Y DIFERENTES TIEMPOS DE CONTACTO

\section{Variables}

Niveles

\begin{tabular}{|lrrrrr|}
\hline TIEMPO_PH8 (9 Niveles) & 0,000 & 1,000 & 2,000 & 3,000 & 4,000 \\
\hline & 5,000 & 6,000 & 7,000 & 8,000 & \\
\hline
\end{tabular}

\begin{tabular}{|ll|}
\hline Variable dependiente & MC_PH8 \\
\hline N & 18 \\
\hline Multiple R & 1,000 \\
\hline Squared Multiple R & 1,000 \\
\hline
\end{tabular}

\begin{tabular}{|llllll|}
\hline Análisis de varianza & & & & \\
Source & Type III SS & df & Mean Squares & F-ratio & p-value \\
\hline TIEMPO_PH8 & $3.344,242$ & 8 & 418,030 & $334.424,182$ & 0,015 \\
\hline Error & 0,011 & 9 & 0,001 & & \\
\hline
\end{tabular}

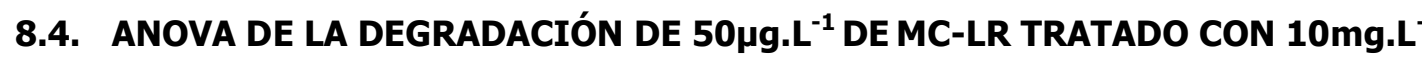
${ }^{1}$ DE APA A PH 6, 7 y 8 Y DIFERENTES TIEMPOS DE CONTACTO

Variables Niveles

\begin{tabular}{|lrrrrr|}
\hline TIEMPO_ACUM (9 Niveles) & 0,000 & 1,000 & 2,000 & 3,000 & 4,000 \\
\hline & 5,000 & 6,000 & 7,000 & 8,000 & \\
\hline PH_ACUM (3 Niveles) & 6,000 & 7,000 & 8,000 & & \\
\hline
\end{tabular}

\section{Variable dependiente MC_ACUM}

\begin{tabular}{|ll|}
\hline N & 54 \\
\hline Multiple R & 1,000 \\
\hline Squared Multiple R & 1,000 \\
\hline
\end{tabular}

\section{Análisis de varianza}

\begin{tabular}{|llllll|}
\hline Source & Type III SS & df & Mean Squares & F-ratio & p-value \\
\hline TIEMPO_ACUM & $9.854,486$ & 8 & $1.231,811$ & $985.448,587$ & 0,005 \\
\hline PH_ACUM & 57,832 & 2 & 28,916 & $23.132,706$ & 0,009 \\
\hline TIEMPO_ACUM*PH_ACUM & 24,817 & 16 & 1,551 & $1.240,832$ & 0,002 \\
\hline Error & 0,034 & 27 & 0,001 & & \\
\hline
\end{tabular}




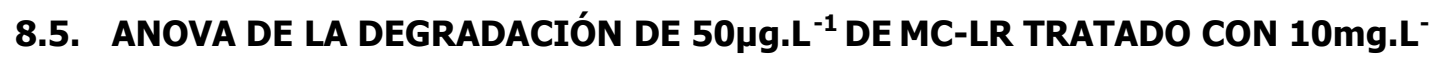

1 DE APA A PH 6 COMPARADO CON TRES CONCENTRACIONES DE CLORO (1, 2 Y 5mg. $\left.\mathrm{L}^{-1}\right)$ Y DIFERENTES TIEMPOS DE CONTACTO

\begin{tabular}{|llllll|}
\hline Variables & & \multicolumn{4}{c|}{ Niveles } \\
\hline TIEMPO (9 niveles) & 0,000 & 1,000 & 2,000 & 3,000 & 4,000 \\
\hline CONCENTRACION_OXIDANTE (4 Niveles) & 5,000 & 6,000 & 7,000 & 8,000 & \\
\hline
\end{tabular}

\section{Variable dependiente DEGRADACION_MC}

\begin{tabular}{|ll|}
\hline N & 72 \\
\hline Multiple R & 1,000 \\
\hline Squared Multiple R & 1,000 \\
\hline
\end{tabular}

\section{Análisis de varianza}

\begin{tabular}{|llllll|}
\hline Source & Type III SS & df & Mean Squares & F-ratio & p-value \\
\hline TIEMPO & $16.964,487$ & 8 & $2.120,561$ & $1.705 .954,873$ & 0,012 \\
\hline CONCENTRACION_OXIDANTE & 301,466 & 3 & 100,489 & $80.841,333$ & 0,018 \\
\hline TIEMPO*CONCENTRACION_OXIDANTE & 203,590 & 24 & 8,483 & $6.824,369$ & 0,020 \\
\hline Error & 0,045 & 36 & 0,001 & & \\
\hline
\end{tabular}

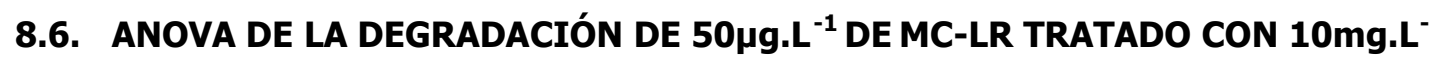
${ }^{1}$ DE APA A PH 7 COMPARADO CON TRES CONCENTRACIONES DE CLORO $\left(1,2 \mathrm{Y}^{5} \mathrm{mg}^{-\mathrm{L}^{-1}}\right)$ Y DIFERENTES TIEMPOS DE CONTACTO

\begin{tabular}{|lllll|}
\hline Variables & & \multicolumn{3}{c|}{ Niveles } \\
\hline TIEMPO_2 (9 Niveles) & 0,000 & 1,000 & 2,000 & 3,000 \\
\hline & 5,000 & 6,000 & 7,000 & 8,000 \\
\hline OXIDANTE_2 (4 Niveles) & 1,000 & 2,000 & 5,000 & 10,000 \\
\hline & & & \\
\hline & & & & \\
\hline Nariable dependiente & DEERADACION_MC-2 & \\
\hline Multiple R & 72 & & & \\
\hline Squared Multiple R & 1,000 & & & \\
\hline
\end{tabular}

\begin{tabular}{|c|c|c|c|c|c|}
\hline \multicolumn{6}{|l|}{ Análisis de varianza } \\
\hline Source & Type III SS & df & Mean Squares & F-ratio & p-value \\
\hline TIEMPO_2 & $14.662,657$ & 8 & $1.832,832$ & $5.255 .968,270$ & 0,012 \\
\hline OXIDANTE_2 & 701,173 & 3 & 233,724 & $670.245,240$ & 0,011 \\
\hline TIEMPO_2*OXIDANTE_2 & 360,304 & 24 & 15,013 & $43.051,480$ & 0,016 \\
\hline Error & 0,013 & 36 & 0,000 & & \\
\hline
\end{tabular}




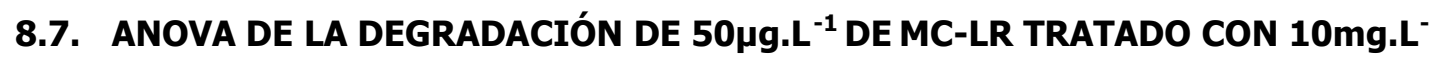

1 DE APA A PH 8 COMPARADO CON TRES CONCENTRACIONES DE CLORO (1, 2 Y 5mg. $\left.\mathrm{L}^{-1}\right)$ Y DIFERENTES TIEMPOS DE CONTACTO

\begin{tabular}{|c|c|c|c|c|c|}
\hline \multirow{2}{*}{$\begin{array}{l}\text { Variables } \\
\text { TIEMPO_3 (9 Niveles) }\end{array}$} & \multicolumn{3}{|c|}{ Niveles } & & \\
\hline & $0,000 \quad 1,000$ & 2,000 & 03,000 & & \\
\hline \multirow[b]{2}{*}{ OXIDANTE_3 (4 Niveles) } & $5,000 \quad 6,000$ & 7,000 & 8,000 & & \\
\hline & $1,000 \quad 2,000$ & 5,000 & 10,000 & & \\
\hline Variable dependiente & \multicolumn{2}{|c|}{ DEGRADACION_MC_-3 } & & & \\
\hline $\mathbf{N}$ & 72 & & & & \\
\hline Multiple R & 1,000 & & & & \\
\hline Squared Multiple R & 1,000 & & & & \\
\hline \multicolumn{6}{|l|}{ Análisis de varianza } \\
\hline Source & Type III SS & df & Mean Squares & F-ratio & p-value \\
\hline TIEMPO_3 & $16.628,201$ & 8 & $2.078,525$ & $2.771 .982,836$ & 0,003 \\
\hline OXIDANTE_3 & $2.075,728$ & 3 & 691,909 & $922.750,909$ & 0,009 \\
\hline TIEMPO_3*OXIDANTE_3 & $1.098,447$ & 24 & 45,769 & $61.038,419$ & 0,005 \\
\hline Error & 0,027 & 360 & 0,001 & & \\
\hline
\end{tabular}

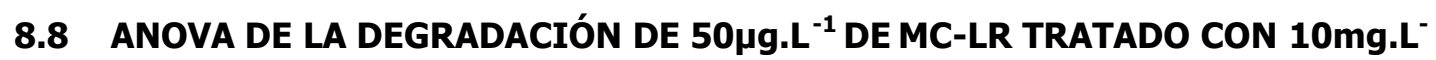

${ }^{1}$ DE APA A PH 6, 7 Y 8 COMPARADO CON TRES CONCENTRACIONES DE CLORO (1, 2 Y 5mg. $\left.\mathrm{L}^{-1}\right)$ Y DIFERENTES TIEMPOS DE CONTACTO

\begin{tabular}{|lrrrrr|}
\hline Variables & \multicolumn{5}{c|}{ Niveles } \\
\hline TIEMPO_ACUM (9 niveles) & 0,000 & 1,000 & 2,000 & 3,000 & 4,000 \\
\hline & 5,000 & 6,000 & 7,000 & 8,000 & \\
\hline OXIDANTE_ACUM (4 niveles) & 1,000 & 2,000 & 5,000 & 10,000 & \\
\hline PH_ACUM (3 niveles) & 6,000 & 7,000 & 8,000 & \\
\hline
\end{tabular}

\begin{tabular}{|ll|}
\hline Variable dependiente & DEERADACION_ACUM \\
\hline N & 216 \\
\hline Multiple R & 1,000 \\
\hline Squared Multiple R & 1,000 \\
\hline
\end{tabular}

\begin{tabular}{|llllll|}
\hline Análisis de varianza & $\begin{array}{l}\text { Type III } \\
\text { SS }\end{array}$ & df & $\begin{array}{l}\text { Mean } \\
\text { Squares }\end{array}$ & F-ratio & p-value \\
\hline TIEMPO_ACUM & $\begin{array}{l}48.112,87 \\
5\end{array}$ & 8 & $6.014,109$ & $7.705 .186,233$ & 0,002 \\
\hline OXIDANTE_ACUM & $2.538,053$ & 3 & 846,018 & $1.083 .904,985$ & 0,005 \\
\hline PH_ACUM & 219,062 & 2 & 109,531 & $140.329,438$ & 0,009 \\
\hline $\begin{array}{l}\text { TIEMPO_ACUM*OXIDANTE_ACU } \\
\text { M }\end{array}$ & 800,866 & 24 & 33,369 & $42.752,409$ & 0,001 \\
\hline TIEMPO_ACUM*PH_ACUM & 142,470 & 16 & 8,904 & $11.408,131$ & 0,008 \\
\hline
\end{tabular}




\begin{tabular}{|llllll|}
\hline OXIDANTE_ACUM*PH_ACUM & 540,314 & 6 & 90,052 & $115.373,616$ & 0,009 \\
\hline $\begin{array}{l}\text { TIEMPO_ACUM*OXIDANTE_ACU } \\
\text { M*PH_ACUM }\end{array}$ & 861,475 & 48 & 17,947 & $22.993,945$ & 0,001 \\
\hline Error & 0,084 & 108 & 0,001 & & \\
\hline
\end{tabular}

9. ANOVA PARA EL RECUENTO DE UN CULTIVO DE $E$. coli TRATADO CON 0,1, 0,3, $0,7,1,5$ Y $5 \mathrm{mg} . \mathrm{L}^{-1}$ DE APA Y 0,5 Y $1 \mathrm{mg} . \mathrm{L}^{-1}$ EN SOLUCIÓN SALINA ISOTONICA 0,9\% A DIFERENTES TIEMPOS DE CONTACTO

\begin{tabular}{|llllll|}
\hline Variables & \multicolumn{5}{c|}{ Niveles } \\
\hline & 0,100 & 0,300 & 0,500 & 0,700 & 1,000 \\
\hline TIEMPO (6 Niveles) & 1,500 & 5,000 & & & \\
\hline & 0,000 & 1,000 & 2,000 & 3,000 & 4,000 \\
\hline & 5,000 & & & \\
\hline
\end{tabular}

\section{Variable dependiente RECUENTO}

\begin{tabular}{|ll|}
\hline N & 84 \\
\hline Multiple R & 1,000 \\
\hline Squared Multiple R & 1,000 \\
\hline
\end{tabular}

\begin{tabular}{|llllll|}
\hline Análisis de varianza & & & & & \\
\hline OXIDANTE & Type III SS & df & Mean Squares & F-ratio & p-value \\
\hline TIEMPO & $1,524 \mathrm{E}+010$ & 6 & $2,540 \mathrm{E}+009$ & $7.494,322$ & 0,000 \\
\hline OXIDANTE*TIEMPO & $9,526 \mathrm{E}+010$ & 5 & $1,905 \mathrm{E}+010$ & $56.202,843$ & 0,000 \\
\hline Error & $14.236 .847,498$ & 42 & $338.972,559$ & & \\
\hline
\end{tabular}

